October 2001 - NREL/SR-510-30813

\title{
Strategies for Enhancing Biomass Energy Utilization in the Philippines
}

R. Samson, T. Helwig, D. Stohl, A. De Maio, and

P. Duxbury

Resource Efficient Agricultural Production-Canada

T. Mendoza and A. Elepano

University of the Philippine at Los Banos

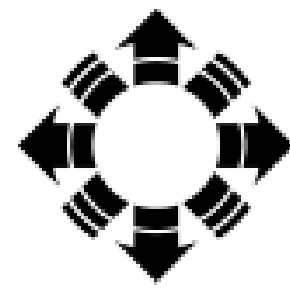

\section{NPE}

National Renewable Energy Laboratory

1617 Cole Boulevard

Golden, Colorado 80401-3393

NREL is a U.S. Department of Energy Laboratory

Operated by Midwest Research Institute $\bullet$ Battelle $\bullet$ Bechtel

Contract No. DE-AC36-99-G010337 


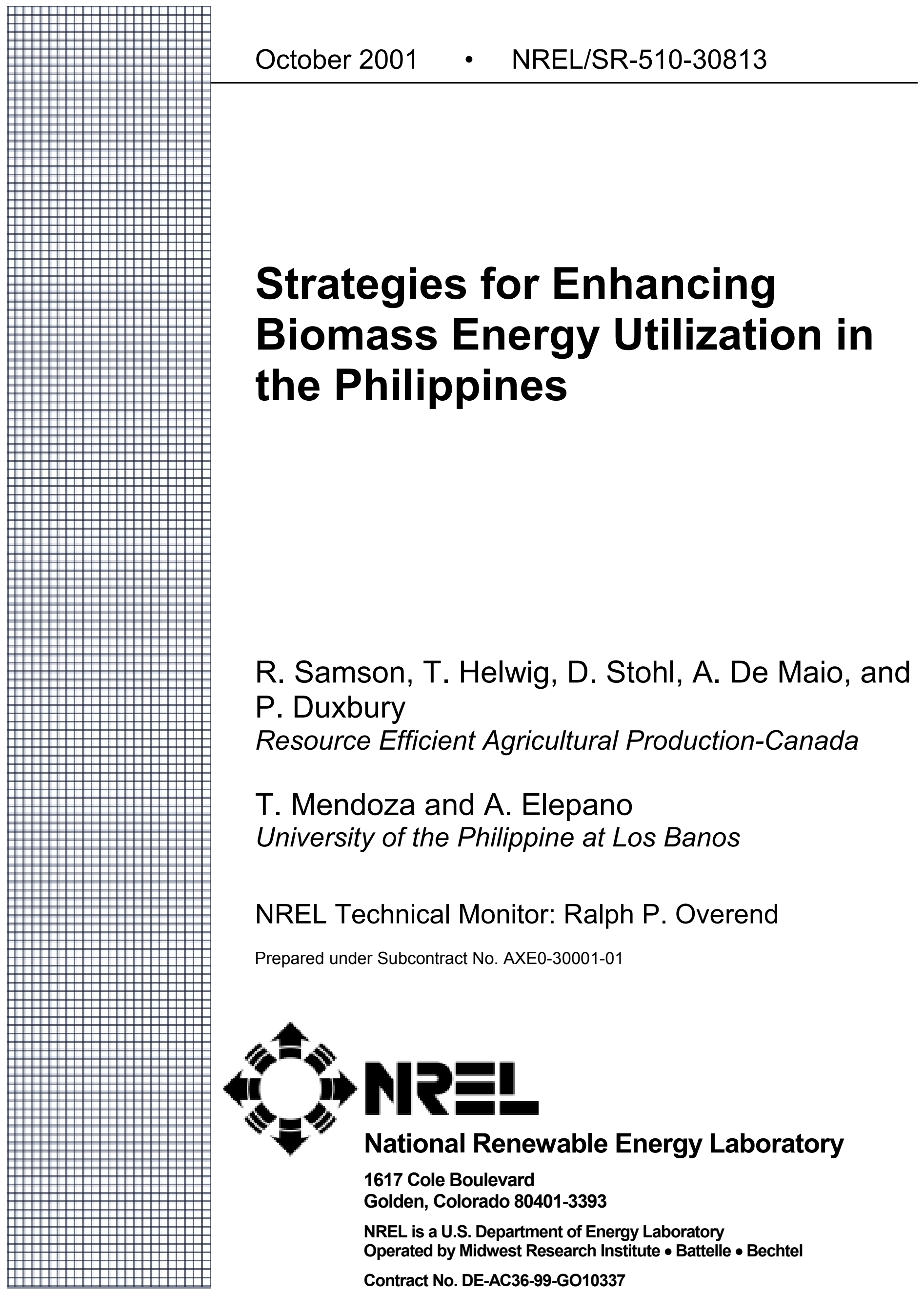




\section{NOTICE}

This report was prepared as an account of work sponsored by an agency of the United States government. Neither the United States government nor any agency thereof, nor any of their employees, makes any warranty, express or implied, or assumes any legal liability or responsibility for the accuracy, completeness, or usefulness of any information, apparatus, product, or process disclosed, or represents that its use would not infringe privately owned rights. Reference herein to any specific commercial product, process, or service by trade name, trademark, manufacturer, or otherwise does not necessarily constitute or imply its endorsement, recommendation, or favoring by the United States government or any agency thereof. The views and opinions of authors expressed herein do not necessarily state or reflect those of the United States government or any agency thereof.

Available electronically at http://www.doe.gov/bridge

Available for a processing fee to U.S. Department of Energy

and its contractors, in paper, from:

U.S. Department of Energy

Office of Scientific and Technical Information

P.O. Box 62

Oak Ridge, TN 37831-0062

phone: 865.576.8401

fax: 865.576.5728

email: reports@adonis.osti.gov

Available for sale to the public, in paper, from:

U.S. Department of Commerce

National Technical Information Service

5285 Port Royal Road

Springfield, VA 22161

phone: 800.553.6847

fax: 703.605.6900

email: orders@ntis.fedworld.gov

online ordering: http://www.ntis.gov/ordering.htm

Printed on paper containing at least $50 \%$ wastepaper, including $20 \%$ postconsumer waste 


\section{EXECUTIVE SUMMARY}

Land distribution, food security, and a sustainable and affordable energy source are among the most important development issues facing the Philippines in the $21^{\text {st }}$ century. Biofuel energy development can play a key role in eradicating rural poverty and creating self-reliant communities.

A rapidly expanding population and rising fossil fuel energy costs mean increased pressure on the use of biomass resources for energy generation. Substantial investments in research and development are required to expand the biomass supply and enhance energy conversion technology. This report analyzes opportunities for bioenergy utilization in the Philippines. It quantifies the potential biomass resource base, and identifies several uses for biofuel that would increase household energy security, promote self-reliant agricultural practices, and improve human and environmental health.

\section{Biomass Resources}

Several surplus crop residues could be recovered from primary agricultural production or after processing including:

- rice hulls (1.5 million Oven Dry Tonnes (ODT))

- sugar cane trash $(274,000$ ODT)

- bagasse $(322,000$ ODT)

- maize cobs (391,000 ODT)

- coconut (10.4 million tonnes are available, however utilization is limited by manual labour requirements and poor transportation infrastructure in remote locations)

The transition of rural land from tropical forests to agricultural farmland has shifted the biomass resource base. The majority of wood is now obtained from farmlands. Improving agro-forestry systems, increasing tree diversity, and extending tree rotations can help to bring about the appropriate use of woodfuel.

Dedicating land specifically to biomass production could increase the amount of biomass available for energy generation and other applications. Napier grass and other perennial warm-season grasses could be grown as energy crops on marginal farmland. The introduction of 100,000 ha of napier grass could generate 2 million ODT of biomass for energy applications.

\section{Bioenergy End-use Applications}

The use of bioenergy in households and in agricultural processing has been the focus of this study. An emphasis has been placed on heating because currently it consumes the most bioenergy and is best suited to the decentralized availability of resources (the economics of liquid fuel and power generation are not as favorable). Household cooking consumes approximately $75 \%$ of the total biomass used, and is of considerable importance as there are 13 million families in the Philippines. An economic analysis indicated that the LT-2000 multi-fuel stove for rural households and pellet stoves for urban households (using cane trash or grass pellets) provided the greatest opportunities 
for reducing cooking costs for those purchasing fuels. There are one million households that could potentially be using the LT-2000 multi-fuel stove in the Philippines. The domestic production of 1 million tonnes of fuel pellets (derived from napier grass, cane trash, or wood residues) could enable up to 2.5 million households make the switch to pellet fuel cooking. This could displace up to 2.5 million liquefied petroleum gas (LPG) cooking households, saving $\$ 145$ million US annually in LPG imports. Agricultural residues and pellet burning furnaces could also play an increasing role in crop drying applications and other heat related energy applications in the future.

With current crop residue production, biomass could supply approximately $160 \mathrm{MW}$ of power for national use (1\% of power by 2004). An assessment of year-round power generation found bagasse, followed by sugar cane trash, to be the most economical options. Fast growing tree plantations and napier grass were slightly higher in cost. The importation of 365,000 barrels of bunker oil for thermal processing by sugar mills could be displaced by about 161,000 tonnes of cane trash (at $26 \%$ moisture) which could save approximately $\$ 1$ million US in oil imports.

Cane trash farming is self-sustaining because improving soil fertility, nitrogen fixation, and water retention enhances crop yield, productivity, and longevity. Trash farming also results in a significant decrease in fertilizer use, which decreases energy input, overall production costs, and fossil energy use [and greenhouse gas (GHG) emissions]. Successfully implementing low input trash farming on the 350,000 ha of land currently producing cane could save up to 1.8 million GJ of energy inputs, which would generate 26.5 million GJ of energy (in the form of recoverable bagasse and cane trash) for bioenergy applications. Trash farming has the potential to transform the industry from a net energy importer into a domestic energy producer. 
Chapter 1 Overview of Biomass Resources in the Philippines ............................................... 1

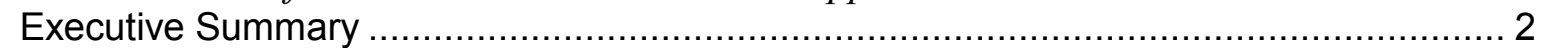

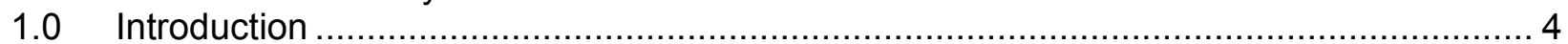

1.1 Major Farming Systems in the Philippines and Current Trends .................................. 4

1.2 Assessment of the Bioenergy Potential Of Major Agricultural Crops in the Philippines ..... 7

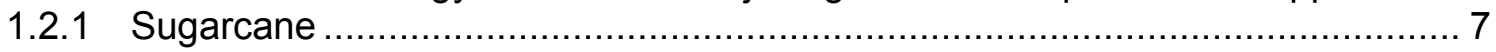

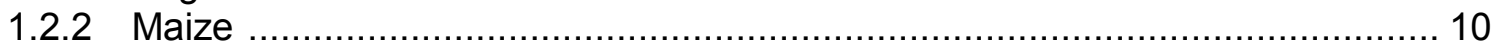

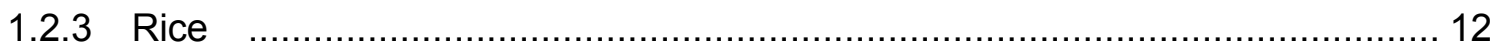

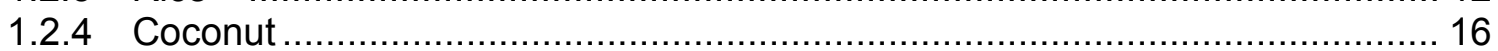

1.2.5 The Bioenergy Potential of High Yielding Perennial Grasses ......................... 21

1.2.6 Wood and Wood Based Residues ........................................................ 24

1.3 Suitability of Biomass Residues for Bioenergy Applications.................................... 27

1.4 Outlook for Biomass Resources in the Philippines ........................................... 29

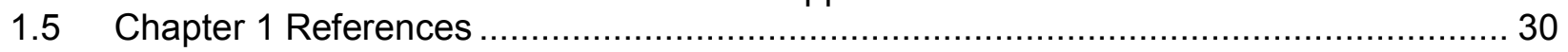

Chapter 2 Promoting Biomass Utilization in Agricultural Processing and in the Home........... 33

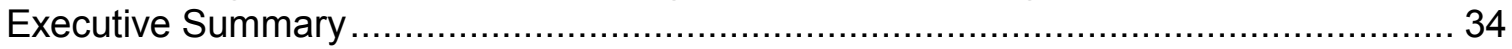

2.0 General Overview of Biomass Energy Utilization in the Philippines .......................... 35

2.1 Sectoral Opportunities for Biomass Power Generation ............................................ 39

2.2 Enhancing Biomass Energy Use in the Household............................................. 41

$2.3 \quad$ Main Fuels Used in the Philippines...................................................................... 44

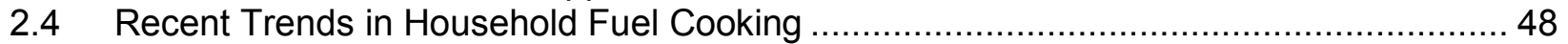

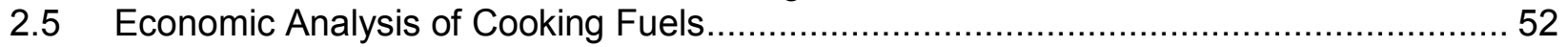

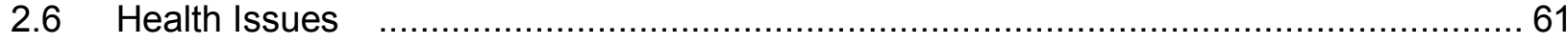

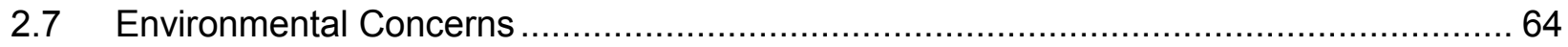

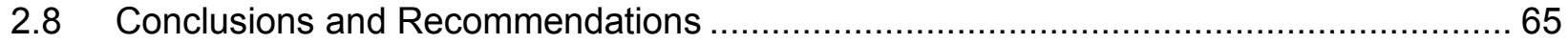

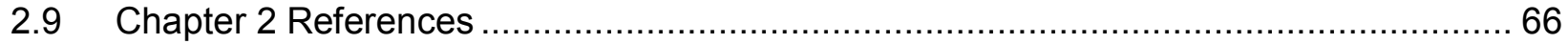

Chapter 3 Biomass Supply Options for Power Co-generation in Sugarcane Milling ................ 68

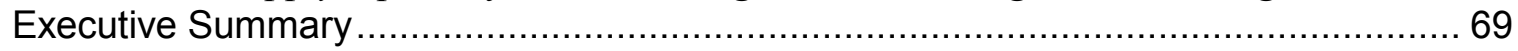

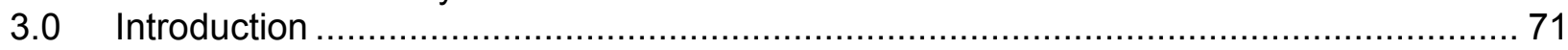

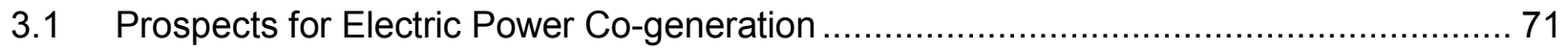

3.2 Fuel Supply Options for Year-round Power Production .......................................... 74

3.3 Renewable Biomass Supply Options for Power Co-generation in Sugarcane Milling...... 74

3.3.1 Negotiated Purchase of Excess Bagasse from Other Mills .................. 74

3.3.2 Removal of Cane Residue ....................................................... 75

A. Agronomic Effects of Trash Removal ............................... 75

B. Quantity of Sugar Cane Available for Removal ...................... 77

C. Use of Baled Sugarcane Trash ....................................... 77

D. The Collection of Cane Residues ..................................... 81

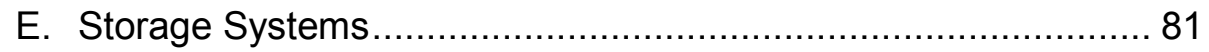

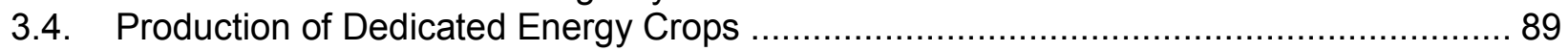

3.4.1. Production of High Yielding Perennial Grasses.............................. 89

3.4.2. Fast Growing Fuel Wood Tree Species ........................................ 93

3.5. Economic considerations for Biomass Usage in Sugarcane Mills .............................. 96

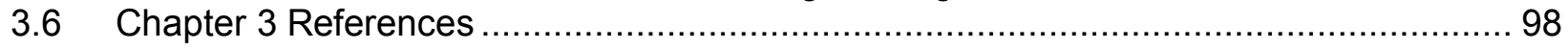

Chapter 4 Improving the Energy Efficiency and Economics of Sugarcane Production........... 100

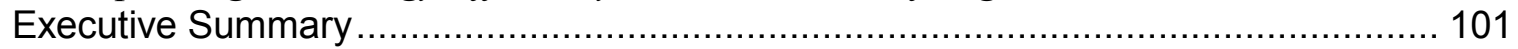

4.0 Introduction to Conventional Sugar Cane Cropping Systems................................. 103

4.1 Current Sugarcane Productivity and Trends in Cane Yields and Sugar Content ......... 103

4.2 Sugar Yield Trends and Major Factors Affecting the Decline in Yield........................ 105 
A. Increasing impact of Typhoons .............................................. 106

B. Economic Events in the 1970's and 1980's ............................. 106

4.3 Factors Affecting Cane Juice Quality ........................................................... 107

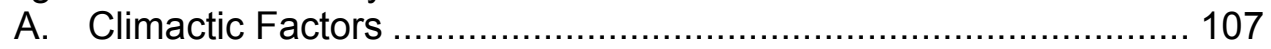

B. Cultural Management Factors …........................................... 107

C. Harvesting Practices ............................................................. 108

4.4 Sugar cane Production Practices and Their Relationship to Fossil Fuel Energy Use .. 108

4.4.1 The Survival of the Sugar Industry in the Philippines .......................... 108

4.4.2 Evaluating Fossil Fuel Energy Inputs in Sugar Cane Production........... 109

4.5 Trash Farming as a Strategy to Improve Sugar Cane Production Systems .................. 114

4.5.1 Impacts of Sugar Cane Trash Farming on Sugar Cane Yield.............. 114

4.5.2 Impacts of Sugar Cane Trash Farming on Tillage .............................. 116

4.5.3 Impacts of Sugar Cane Trash Farming on Cane Sugar Levels ............ 117

4.5.4 Impacts of Sugar Cane Trash Farming on Fertilizer Use and Other Impacts ..................................................................... 117

4.5.5 Impacts of Sugar Cane Trash Farming on Soil Properties ................... 118

4.5.6 Impacts of Sugar Cane Trash Farming on Human Health .................... 120

4.6 Promotion of Trash Farming in Sugar Cane ...................................................... 122

4.6.1 Reasons for Burning Trash .......................................................... 122

4.6.2 The Economics of Trash Farming Sugar Cane ................................. 123

4.6.3 Optimizing the Trash Farming System........................................... 125

4.7 The implications of Altering Agronomic Practices on Fossil Fuel and Residue Usage 126

4.7.1 Reducing Fossil Fuel Energy in Sugar Cane Production...................... 126

4.7.2 Implication of Trash Farming on the Utilization of Biofuels .................. 128

\section{Chapter 1}

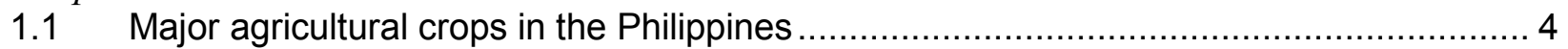

1.2 Oven dry yields of recoverable field crops in the Philippines .................................... 6

1.3 Estimates of recoverable sugarcane trash by region in the Philippines ......................... 8

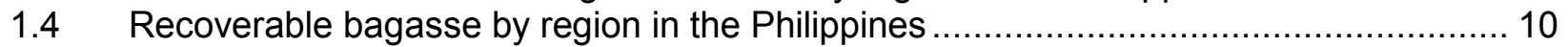

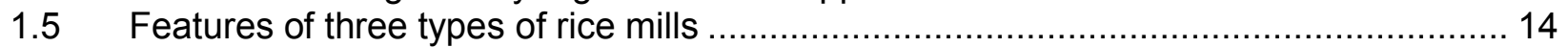

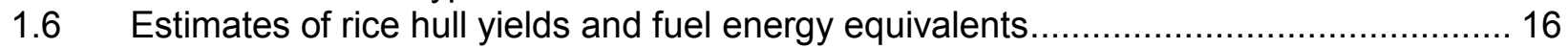

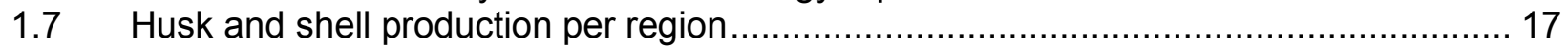

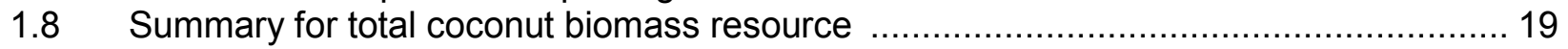

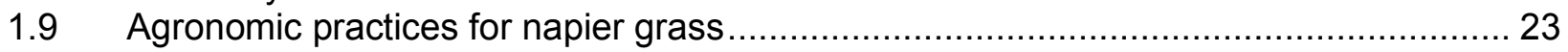

1.10 Suitability of biomass resources for bioenergy applications .................................... 28

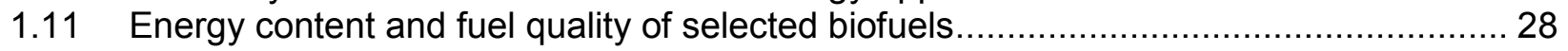

\section{Chapter 2}

2.1 Combustion of biomass by type of application in the Philippines ………................... 38

$2.2 \quad$ Number of households in the Philippines by income class ........................................ 45

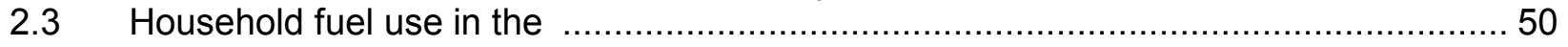

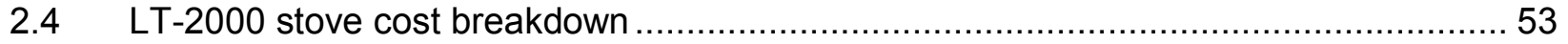

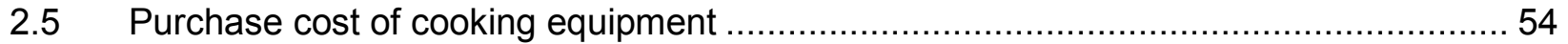

2.6 Energy content and cost per unit energy of various fuels ......................................5 56

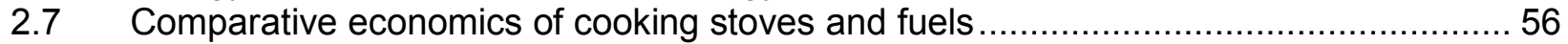

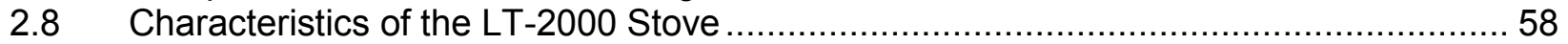

2.9 Respiratory disease/symptoms in women using different cooking fuels (age > 45) .......62

Chapter 3

3.1 Theoretical estimates of electrical power co-generation using bagasse during milling .. 71

3.2 Difficulties/options in exploiting power co-generation in the sugar industry .................... 73 
3.3 Prospects/Difficulties of using "excess" bagasse from other mills for power

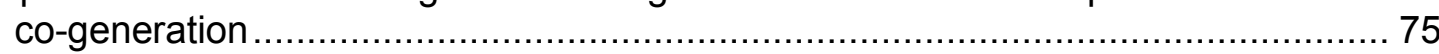

3.4 Collectible sugarcane residues on a dry weight basis for various worldwide locations .. 77

$3.5 \quad$ Nutrient value of sugarcane trash per tonne ....................................................... 78

3.6 Cost items of baled trash for biofuel in COGEN plant during off-milling season ........... 79

3.7 Trash baling : The Hacienda Luisita experience ................................................. 79

3.8 Difficulties encountered in trash baling and its utilization as fuel in the sugarcane mill.. 80

3.9 Benefits of using sugarcane trash for fuel .................................................... 81

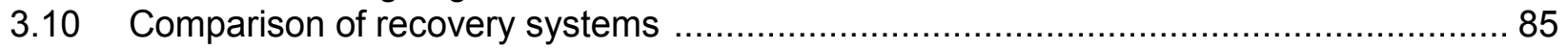

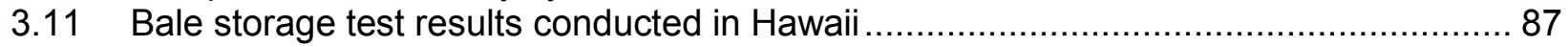

3.12 Dry matter loss data for round versus square bales after one-year storage ............... 87

3.13 Common features of high yielding C4 grasses as biomass crops ............................ 90

3.14 Estimated establishment costs for energy cane/napier ....................................... 90

3.15 Production budget for napier grass/energy cane ................................................. 91

3.16 SWOT analysis of using napier as a biofuel supply option for power COGEN ............ 93

3.17 Budgetary requirements for on-the-job training about NEM .................................. 95

3.18 Fuel value, cost of production and suggested purchase price of sugarcane bagasse,

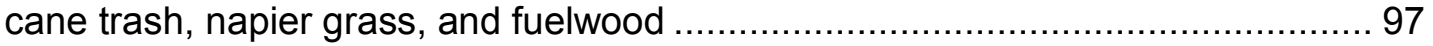

\section{Chapter 4}

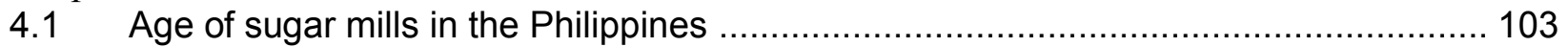

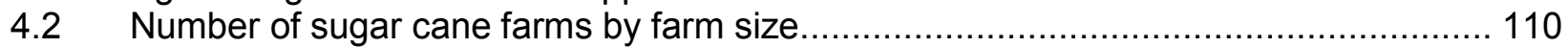

4.3 Summary of sugar cane yield response to trash farming .................................... 115

$4.4 \quad$ Impacts of trash farming on cane sugar levels ................................................ 117

4.5 Agro-ecological importance of humus .............................................................. 119

4.6 Parameters of soil fertility after mulching and not mulching ................................. 119

4.7 Reasons for pre- and post-harvest burning of sugar cane fields in the Philippines...... 122

4.8 15 steps for plant 1:3 ratoon cane cycles of sugar cane produced cum-trash farming 129

4.9 Potential for trash farming to increase biomass residue ...................................... 130

\section{List of Figures}

\section{Chapter 1}

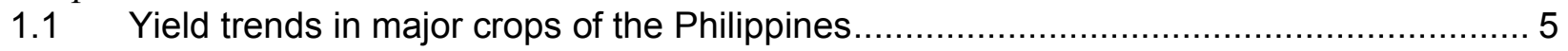

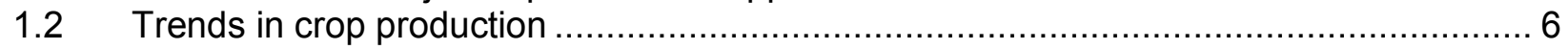

1.3 Annual production and estimated availability of selected agricultural residues .............. 7

1.4 Annual fuelwood use in the Philippines by mode of acquisition ............................... 25

1.5 Fuelwood and roundwood production in the Philippines, 1975-1997........................ 26

\section{Chapter 2}

2.1 Biomass share of the primary energy mix of the Philippines (1999) .......................... 36

2.2 Petroleum product demand in the Philippines (1999) .......................................... 37

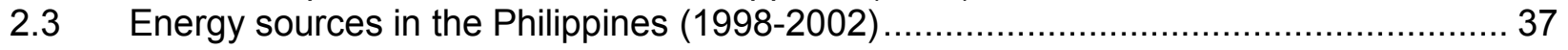

2.4 Percentage of rural households using fuels for cooking by monthly

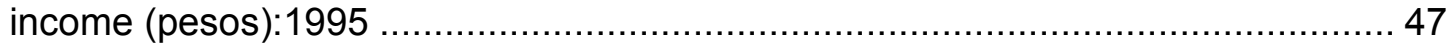

2.5 Percentage of urban households using fuels for cooking by monthly income: 1995 .... 48

$2.6 \quad$ Use of kerosene and LPG in urban and rural areas. ........................................ 51

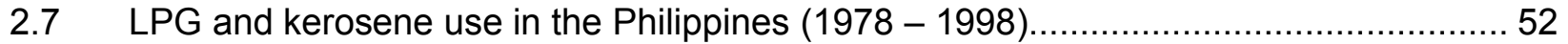

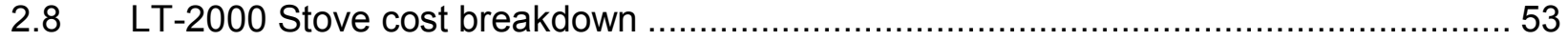

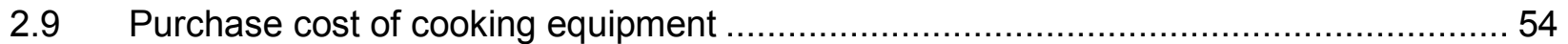

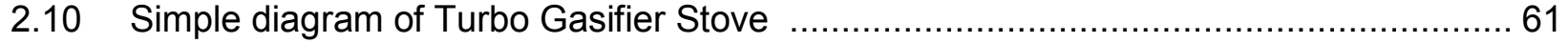

\section{Chapter 4}

4.1 Farm and hill operations involved in sugar manufacturing ...................................... 104

4.2 Average Energy use in conventional sugar cane plant and ratoon crops .................. 111 
4.3 Economic cost breakdown of conventional sugar cane plant and ratoon crops .......... 113

4.4 Sugar Cane intercropping scheme (cum-trash farming) .................................... 115

4.5 Effect of trash Mulching on sugar cane yields ............................................ 116

4.6 Summarized benefits of trash farming to the soil, farmer, society, and environment ... 121

$4.7 \quad$ Costs associated with sugar cane trash farming ................................................ 124

4.8 Energy use in trash farming cane production ............................................. 127

\section{List of Photos}

\section{Chapter 1}

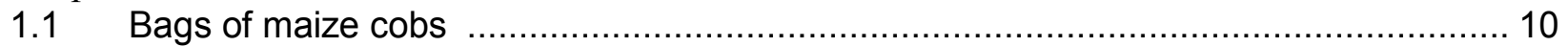

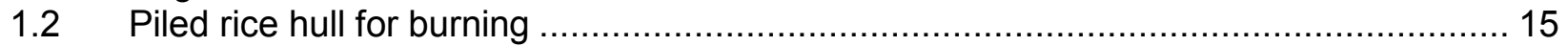

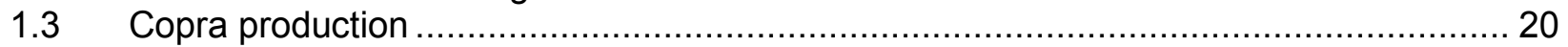

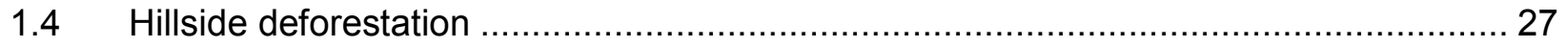

Chapter 2

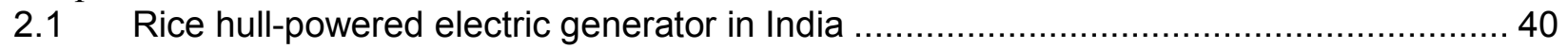

2.2 Rice hull-powered electric generator in India .................................................... 40

$2.3 \quad$ Native fuelwood for charcoal production ........................................................ 42

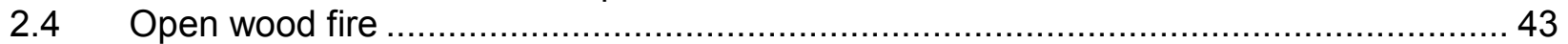

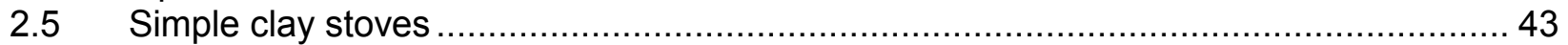

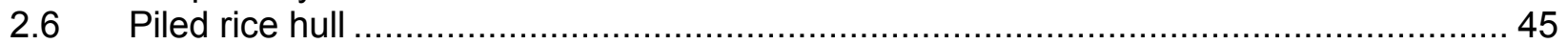

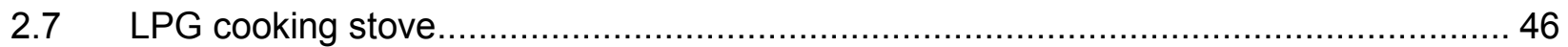

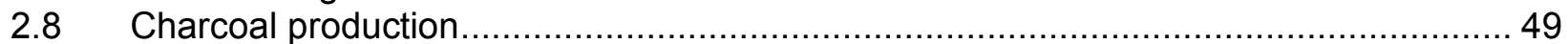

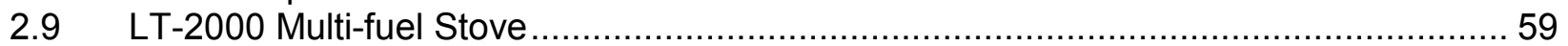

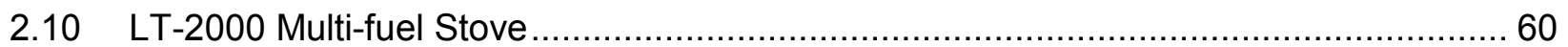

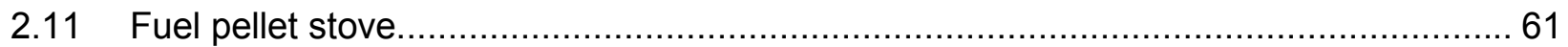

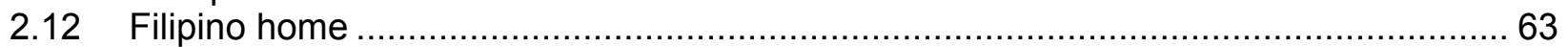

\section{Chapter 3}

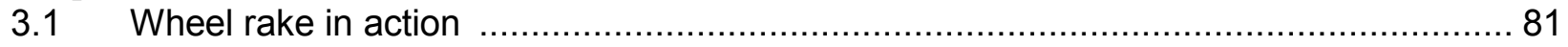

3.2 Small square baler with flatbed trailer in tow ................................................... 82

3.3 Bale elevator to ease the manual handling of square bales ................................ 83

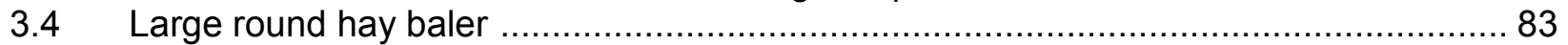

3.5 A big square baler produces rectangular ...................................................... 84

3.6 A self-propelled chaff cutter ....................................................................... 85

3.7 Stack of large square hay bales with tarpaulin for temporary storage ....................... 86

3.8 Single arch, woven fabric shelter can be used for bulk storage ............................. 88

S.9 Single arch, woven fabric shelter for storing bales ......................................... 88

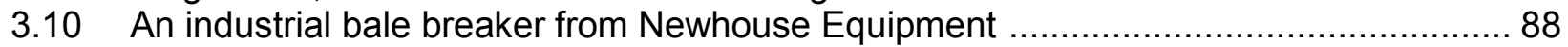

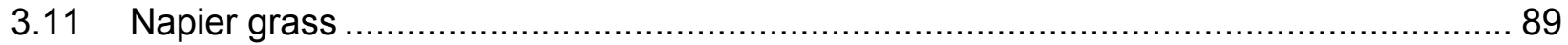

\section{Chapter 4}

4.1 Women in Negros Occidental manually preparing cane points .............................. 109

\section{Chapter 1}

\section{List of Appendices}

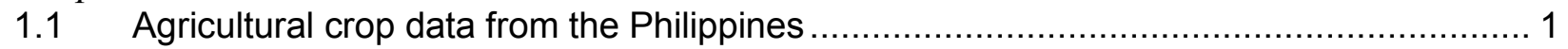

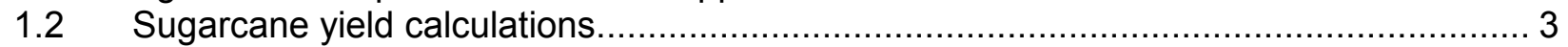

1.3 Estimates of maizecob production and recoverability in the Philippines ...................... 4

A. Estimates of total maizecob production and BFOE values by region ............ 4

B. Estimates of recoverable maizecob by region, BFOE and monetary value .... 5

1.4 Potential trash yield and recoverable trash yield as a percent of gross cane yield ......... 6

1.5 Estimates of excess bagasse by sugarcane producing regions in the Philippines......... 9 
1.6 The top 20 rice producing provinces of the Philippines ....................................... 10

1.7 Rice yields between 1995-1997 in the 14 regions of the Philippines ......................... 10

$1.8 \quad$ Available and recoverable rice hull yield estimates by region ............................... 11

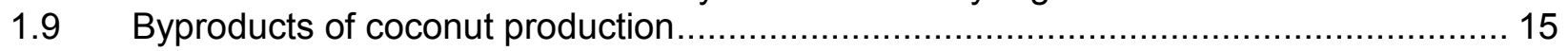

1.10 Estimates of total and recoverable coconut husks and coconut fronds ..................... 16

1.11 Estimates of number and weight of coconut frond/yr, and associated BFOE and \$US 17

1.12 Oven dry yields of various perennial grass species ......................................... 18

1.13 Trends of fuelwood acquisition and wood residue generation in the Philippines........... 19

A. Annual quantity of wood fuels in the Philippines by mode of acquisition ...... 19

B. Estimated amount of wood residues generated in the Philippines ............... 20

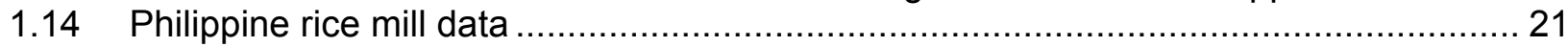

A. Rice mill capacity in the Philippines .................................................... 21

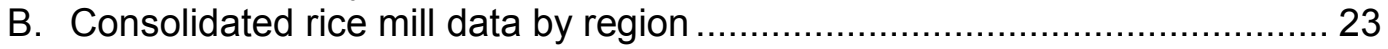

Chapter 2

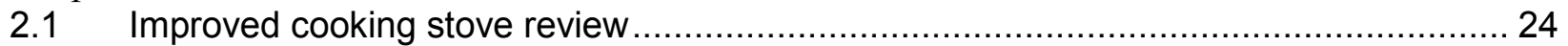

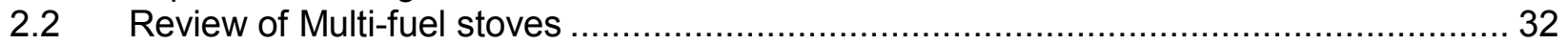

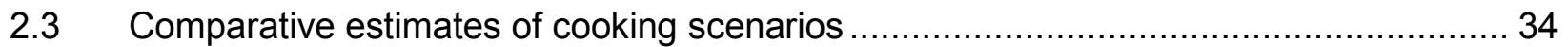

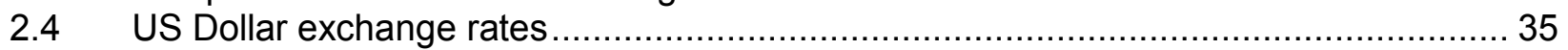

Chapter 3

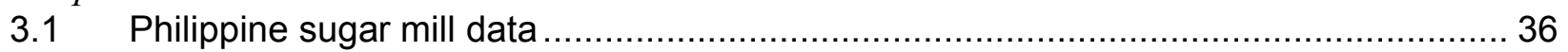

Table A. Sugar mills with excess bagasse (CY 1989-1990)..................... 36

Table B. Energy (by source) utilization in the Philippine sugar mills. ............. 37

Table C. Breakdown (\%) of fuel mix utilization by region in sugar mills........... 37

Table D. Figures of the different energy sources utilized in sugar mills .......... 37

Table E. Energy consumption of Philippine sugar mills. ............................ 38

Table F. Energy utilization in the Philippine sugar mills ............................. 39

Table G. Comparative energy utilization of some Sugar producing countries.. 39

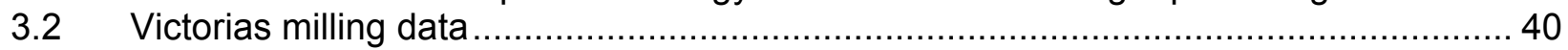

Table H: Victorias milling corporation: monthly data .............................. 42

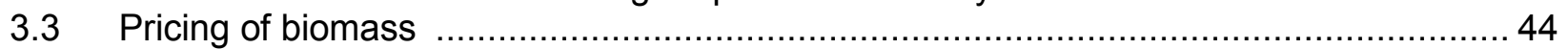

3.4 resources relative to their fossil fuel value ....................................................... 46

Table I. Fuel value, cost of production and suggested purchase price of biofuels .. 43

3.4 Data Sheet: economic analysis of sugarcane trash to supplement the use of bagasse. 44

Table J. Comparison of biofuel energy costs vs. bunker oil ........................... 45

3.5 Table K. Nutrient content $(\mathrm{N}, \mathrm{P}, \mathrm{K})$ at various trash yield levels ............................. 46

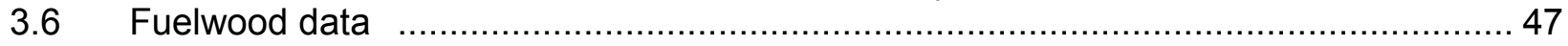

Table L. Some fuelwood tree species, their adaptability, quality, and yields .... 47

\section{Chapter 4}

4.1 Photo diary: A visual description of sugarcane trash farming .................................. 50

4.2 Overview of $\mathrm{N}_{2}$ fixation in sugarcane residues. D. Patriquin .................................. 53

4.3 Sugarcane mills, areas, yield components, and Philippine sugar export to the U.S. .... 58

4.4 Sugar yield trend for the last 60 years in the Philippines .......................................6 60

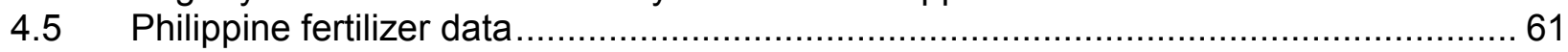

- Trends in sugar cane fertilizer use $(\mathrm{kg} / \mathrm{ha})$ in three regions of the Philippines

- $\quad$ NPK (\%) in energy equivalent (GJ/ha) of fertilizer applied crop

- Estimated fertilizer sales/use (1991-1996) in sugarcane

4.6 Number of typhoons and typhoons exceeding $100 \mathrm{kph}$ in the Philippines ....................63

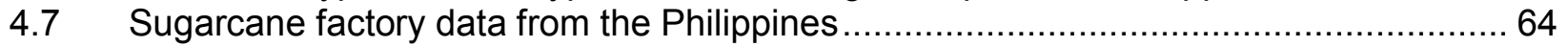

4.8 Fossil fuel energy consuming operations and prices of sugarcane production ............. 65

4.9 Sugarcane yield of two varieties as affected by trash application.............................6 66

4.10 Cost and return projection of conventional sugarcane production in Negros Occidental 67

4.11 Energy consumed/fossil energy consuming operation in sugarcane production ........... 70 


\title{
Chapter 1
}

\section{Overview of Biomass Resources in the Philippines}

\author{
T. C. Mendoza ${ }^{1}$, R. Samson ${ }^{2}$, A. Elepano , and P. Duxbury $^{2}$ \\ ${ }^{1}$ Department of Agronomy \\ U.P. Los Baños, College, Laguna, Philippines \\ Tel. (049) 536-2466, Fax (049) 536-2468 \\ tcm@mudspring.uplb.edu.ph \\ ${ }^{2}$ Resource Efficient Agricultural Production (REAP) Canada \\ Box 125, Ste. Anne de Bellevue, Quebec, Canada H9X3V9 \\ Tel. (514) 398-7743, Fax (514) 398-7972 \\ REAP@Interlink.net, www.reap.ca \\ ${ }^{3}$ College of Engineering and Agro-Industrial Technology \\ U.P. Los Baños, College, Laguna, Philippines \\ Tel (049) 936-3291 \\ are@mudspring.uplb.edu.ph
}




\section{EXECUTIVE SUMMARY}

The expanding population, increasing deforestation, and rise in fossil fuel prices have placed tremendous pressure on the biomass resources of the Philippines. It is essential to understand biomass residue production and factors influencing its recovery so it can contribute to a sound rural development strategy. This study quantifies existing biomass residue production for major sources including sugarcane bagasse and trash, rice hulls, coconut, and maize cobs. An overview of wood, wood-based residues, and high yielding perennial grasses as potential biomass fuels has also been completed.

It is estimated that 1.17 million tonnes ( $30 \%$ moisture) of sugarcane trash is recoverable as a biofeedstock in the Philippines. Optimal use of this resource appears to be as a trash residue left in the crop field as a means to increase cane productivity, increase soil organic matter, and reduce fertilizer requirements. Harvesting trash as a biofuel feedstock appears to be economical only in the final year of the ratoon crop, which reduces the recoverable trash residue to about 391,000 tonnes. Currently, 640,000 tonnes of surplus bagasse ( $50 \%$ moisture) is available from mills that produce raw sugar. Sugar mills with refineries or distillery operations have limited bagasse supplies, and consume the excess bagasse from surrounding mills. There is considerable potential for utilizing sugarcane residues as they are currently disposed of by burning in crop fields.

Maize is a potential source of biomass energy; however, concerns exist about harvesting maize residues from the land. Erosion, depletion of the nutrient pool, and loss of soil organic matter are known to occur when the above ground portion of the plant is harvested. As a result, the harvesting of maize stalks is not a sustainable practice for large-scale bioenergy development. However, the maize cob is a viable fraction that can be collected. It is widely utilized by small farmers in household cooking applications. An estimated 489,000 tonnes of cobs are recoverable per year.

One third of all agricultural land in the Philippines produces rice, and an accordingly large volume of rice straw and hulls are generated. Ninety percent of rice straw is disposed of by field burning. As a biofuel with high silica content, low energy potential, and high retrieval costs, rice straw is an unlikely candidate for major biofuel development. Rice straw is most effectively used by incorporating it in fields to maintain soil organic matter levels and to enhance $\mathrm{N}_{2}$ fixation during the decomposition process. An estimated 1.5 million tonnes of rice hulls are currently burned, but could be utilized as a biofuel. The main advantages of using rice hulls are their widespread availability and the lack of processing required for burning. They are well suited to low grade heating applications such as household cooking or crop drying because, like maize cobs, they are not a concentrated form of heat energy.

Approximately 300 million coconut trees in the Philippines produce tremendous amounts of biomass as husk ( 4.1 million tonnes), shell ( 1.8 million tonnes), and 
frond (4.5 million tonnes annually). However, the recovery of these residues is labor intensive, and the majority of materials are available in remote areas.

Napier grass and energy cane can produce up to 30 Oven Dried tones (ODT)/ha, which could be transformed into fuel pellets for household cooking or used directly for power generation during the sugar cane off-milling season. It would likely be most viable as an alternative crop to replace maize on marginal farmlands. Production of 100,000 ha of napier grass yielding 20 ODT/ha would provide an additional 2 million tonnes of biofuel for processing and replace only $4 \%$ of the maize acreage in the Philippines.

Wood fuel accounts for the largest share of biomass energy supply in the Philippines. It is generally collected from trees on agricultural land. There is significant room for upgrading current agro-forestry production systems to increase wood fuel production levels. The best approach would be to increase production of trees for higher value solid wood products. High volumes of these solid wood products eventually end up being recycled as a fuel source.

The use of crop residues as biofuels is increasing in the Philippines as fossil fuel prices continue to rise. Rice hull is perhaps the most important, underdeveloped biomass resource that could (like bagasse) be fully utilized in a relatively short time period if oil prices continue to climb and if a concerted effort is made. The development of cane trash recovery systems, improvement of agro-forestry systems, and development of napier grass as a biofuel, are important technologies that can play a major role in rural development in the Philippines. 


\subsection{Introduction}

Sugarcane produces two types of biomass: cane trash (field residue remaining after harvesting the cane stalk) and bagasse (milling byproduct remaining after extracting the sugar from the stalk). The potential value of these residues and byproducts created by the Philippine agricultural industry has traditionally been ignored. However, with rising fossil fuel prices and dwindling firewood supplies, this material is increasingly viewed as a valuable bioenergy resource. The main biomass energy applications include cooking and agricultural processing. Sugar mills have been using bagasse, the residual fibrous material left after sugarcane processing, to generate steam and electricity for internal plant requirements. The use of biomass for energy reduces dependence on imported petroleum and minimizes greenhouse gas emissions by closing the carbon loop. It also creates economic development opportunities for rural communities, and reduces the widespread deforestation that is a result of using timber for household activities.

An assessment of the Philippine resource base for biomass production was performed. Estimates of recoverable biomass material available for energy production were made for the major agricultural field crops of sugarcane, rice and maize. The potential use of high yield perennial grasses and wood for energy production was also examined as a means to diversify the supply of biomass resources and to estimate their economic value. Because the availability of agricultural residues was changing over the course of this analysis, it must be noted that estimates of recoverable biomass are generally higher than what is actually available for use. As well, during the course of this analysis a more precise and detailed local assessment of the biomass resources of the Philippines was undertaken (PBEL, 2001). The formulas used in this report for developing the potentially recoverable biomass can be used to get an updated assessment as crop production levels change and to assess potentially recoverable biomass resources in a region or near a biomass conversion plant.

\subsection{Major Farming Systems in the Philippines and Current Trends}

In the Philippines, major crop yields have plateaued in recent years. These crops, in order of descending total yield, are sugarcane, rice, coconut, and maize (Table 1.1). While sugarcane gives by far the greatest total yield $\left(2.8 \times 10^{7}\right.$ tonnes), the area of land under rice production is almost 10 times greater $(3.9 \mathrm{x}$ $10^{6}$ ha for rice vs. $3.5 \times 10^{5}$ ha of cane).

\begin{tabular}{|l|c|c|c|}
\hline \multicolumn{4}{|c|}{ Table 1.1: Major agricultural crops in the Philippines (FAO Statistics, 1999) } \\
\hline Type of crop & $\begin{array}{c}\text { Amount of land used } \\
\left(10^{6} \text { hectares }\right)\end{array}$ & Yield (tonnes/ha) & $\begin{array}{c}\text { Total yield ('000 } \\
\text { tonnes) }\end{array}$ \\
\hline Rice & 3.90 & 2.87 & 11,200 \\
Coconut & 3.05 & 3.61 & 11,000 \\
Maize & 2.61 & 1.61 & 4,200 \\
Sugarcane & 0.35 & 79.5 & 28,000 \\
\hline
\end{tabular}


Figures 1.1 and 1.2 illustrate the yield and production trends of sugarcane, rice, coconut and maize since 1960. The Philippine sugarcane industry has been in decline since the mid-1970s. Yields have remained relatively stagnant and the area of land under production has decreased since 1975. The challenges facing sugar production and suggested means to help revitalize the industry are discussed in Chapter 4.

Rice yields have increased steadily since the 1960's, and have been somewhat fixed since 1990. Production has also increased, while the area under production has remained constant for the past 25 years with only minor fluctuations.

Although production levels of coconut have more than doubled since 1961 to their present value of 11 million tonnes/year, yields have dropped. The 5-year average from 1961 to 1965 was 4.6 tonnes/ha, while from 1995 to 1999 the average yield was 3.7 tonnes/ha. The rise in production is explained by the increase in land area under coconut cultivation (1.2 million ha in 1961 vs. 3.1 million ha in 1999). Presently, the industry appears headed for a major decline due to reduced demand for coconut oil.

Maize yields have increased from 0.6 tonnes/ha in 1961 to 1.7 tonnes/ha in 1999, primarily due to increased applications of fertilizer and the use of hybrid seeds (Caccam, 2000). Although production has increased, current maize yields in the Philippines are low relative to other countries. The area under production has been reduced from a high of 3.8 million ha in 1990 to 2.7 million ha in 1999, returning amount of the land under maize production to 1970's levels. Appendix 1.1 lists in greater detail the agricultural data for the major Philippine crops (FAO statistics for yield, production, and area under cultivation).

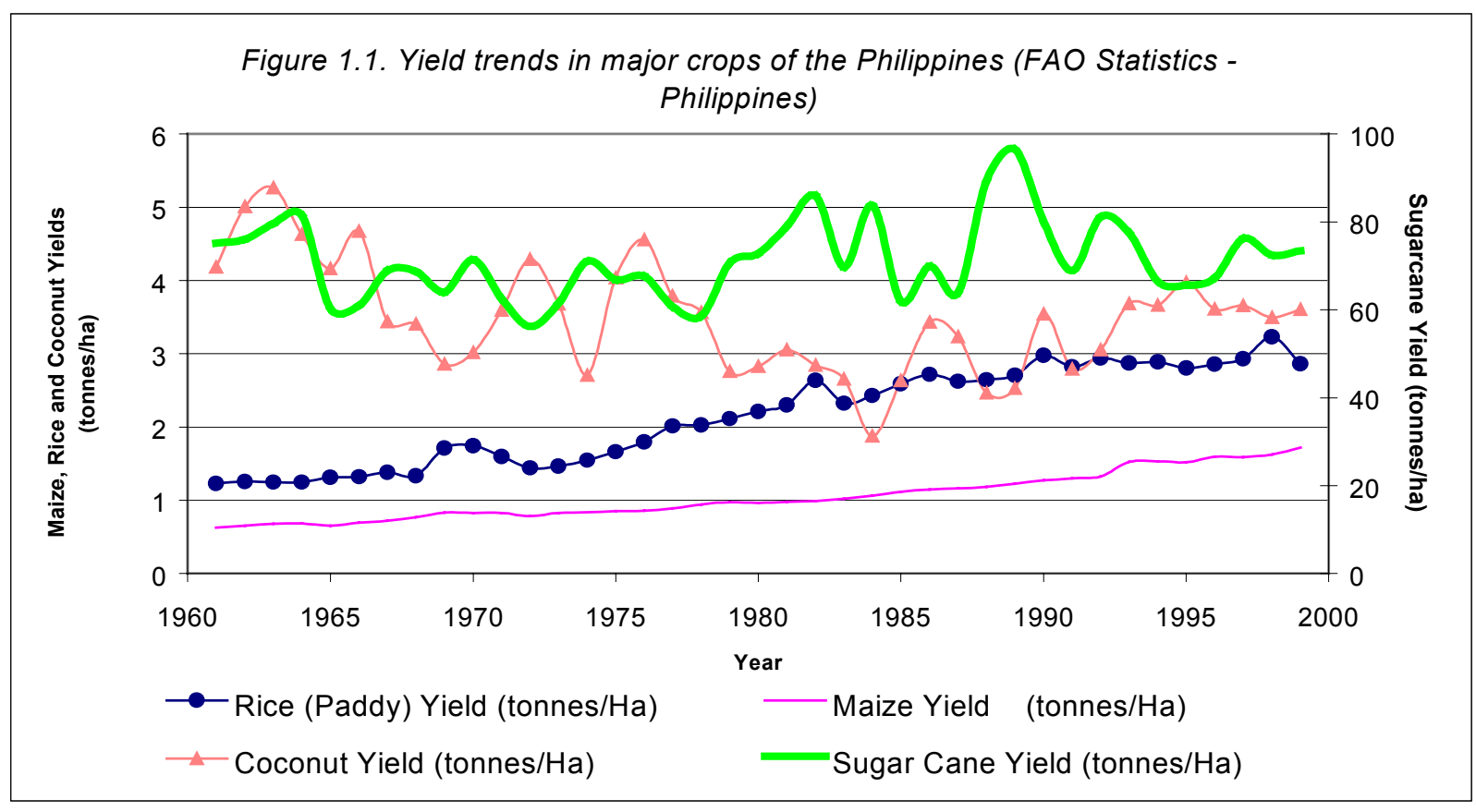




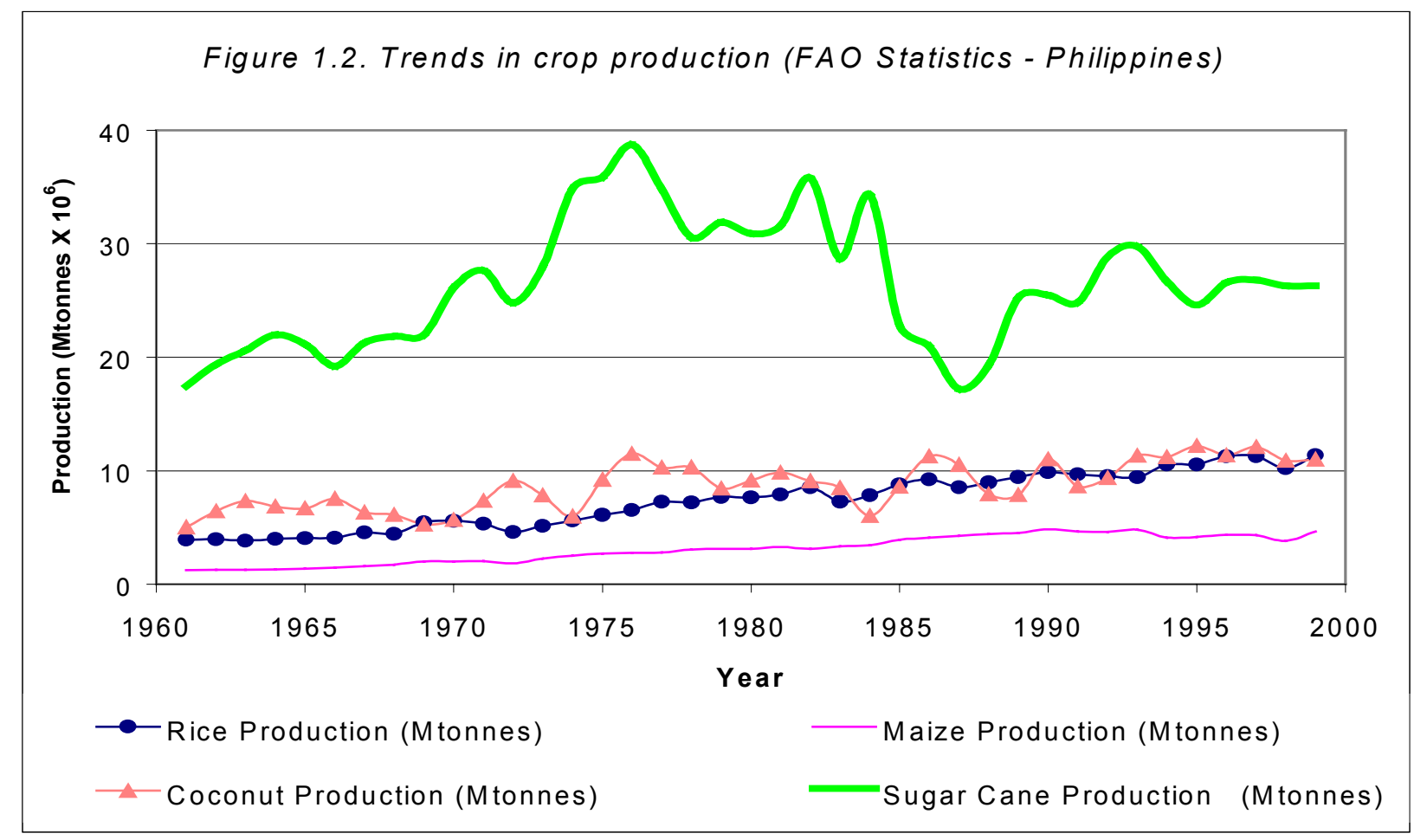

Annual estimates were calculated for the major agricultural crops that produce biomass and the yield of potentially recoverable residues on an as is basis (Figure 1.3). It should be noted that the yields in the analysis are on a wet basis. The energy values of sugarcane, maize, and rice residues (on an oven dry basis) are presented in Table 1.2. The estimates represent feasible values for annual recoverable biomass. In actuality, the current availability of this biomass may be much more limited. For example, in the case of bagasse, sugar refineries purchasing surplus material from raw sugar producers presently consume all the material.

Table 1.2. Oven dry yields of recoverable residues from selected field crops in the Philippines (annually)

\begin{tabular}{|l|c|c|c|}
\hline \multicolumn{1}{|c|}{ Biomass type } & $\begin{array}{c}\text { Recoverable yield } \\
\text { (tonnes) }\end{array}$ & $\begin{array}{c}\text { Moisture } \\
\text { Content (\%) }\end{array}$ & $\begin{array}{c}\text { Recoverable Yield } \\
\text { In oven dry tonnes }\end{array}$ \\
\hline${ }^{*}$ Sugarcane Trash & 391,486 & 30 & 274,040 \\
\hline Bagasse & 643,900 & 50 & 321,950 \\
\hline Maize Cobs & 489,000 & 20 & 391,200 \\
\hline Rice Hull & $1,500,000$ & 9 & $1,365,000$ \\
\hline
\end{tabular}




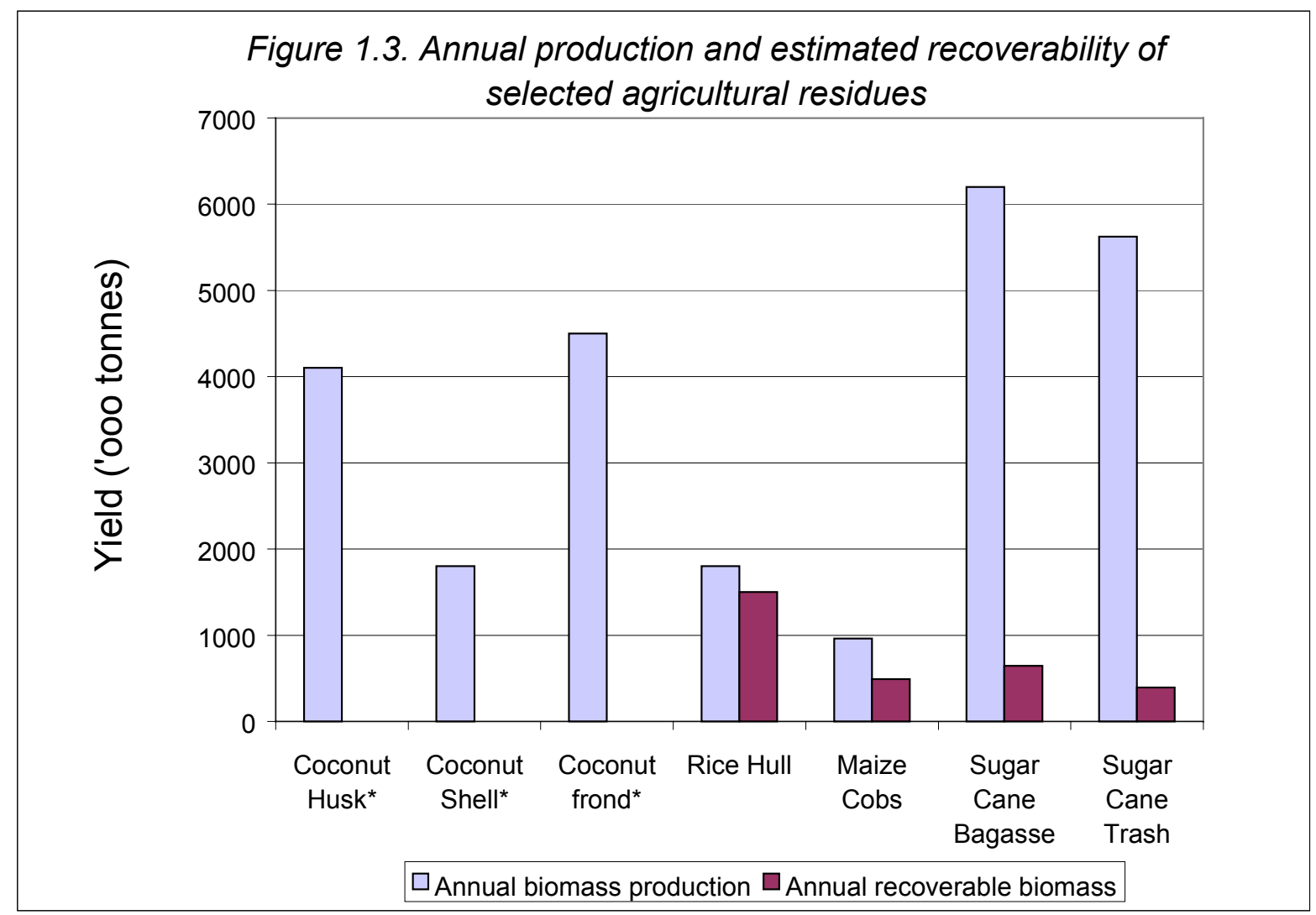

${ }^{*}$ Amount of recoverable coconut residues were not assessed.

\subsection{Assessment of the Bioenergy Potential of the Major Agricultural Crops in the Philippines}

\subsubsection{Sugarcane}

\section{A. Sugarcane trash and tops}

Sugarcane produces huge volumes (by weight) of tops and trash (residual leaves) at harvest time. Some researchers use the trash yield per hectare to estimate the total trash yield. Yield coefficients from literature vary in their estimates from 6.0 tonnes/ha (low), to 8 tonnes/ha (average), to 15 tonnes/ha (high). Other researchers use the summation of trash and tops as a percent of gross cane milled, using $10 \%, 15 \%$, and $20 \%$ for low, average, and high estimates, respectively. This particular study uses the percent trash yield, as it most accurately reflects the variations in sugarcane yields in the field.

For the purpose of using sugarcane trash and tops for biofuel, the recoverable trash yield was estimated using the following formula. For examples of cane yield calculations, see Appendix 1.2.

$\mathrm{RTY}=\mathrm{GCY} * \% \mathrm{TY}{ }^{*} \mathrm{MDF}{ }^{*} 0.65$

RTY is the Recoverable Trash Yield 
GCY is the Gross Cane Yield in a given mill district

MDF is the Mill District Factor

$\%$ TY is the percentage Trash Yield

0.65 is the amount of trash and tops that could be recovered out of

a possible yield of 1.0 .

Several studies in Southeast Asia have estimated the amount of recoverable trash in the field. Using present technologies for raking and baling, the recoverable yield appears to be in the $65 \%$ range (see section 3.2 of Chapter 3 ). This value could possibly be improved with better raking and baling technologies.

The mill district factor (MDF) was derived by considering the milling schedules of each sugarcane mill. The MDF varies by province due to different rainfall patterns per region. Luzon is relatively dry compared to Negros or Mindanao, allowing more trash to be collected earlier. Also, the rainy season in Negros or Mindanao begins earlier (last week of April), reducing the time available to recover trash.

The mill district trash recovery factor (RTY) is a percentage representing the ratio of the number of milling weeks (including the harvesting weeks) to the number of "dry" weeks in a region. Low, average, and high estimates of recoverable trash for low, average, and high estimates of trash yield are shown in Appendix 1.3 and summarized in Table 1.3.

Table 1.3: Estimates of recoverable sugarcane trash by region

\begin{tabular}{|l|c|c|c|}
\hline & Low & Average & High \\
\hline Total Trash Yield (tonnes) & $3,748,699$ & $5,623,048$ & $7,497,399$ \\
\hline Recoverable trash by region & & & \\
\hline Luzon & 199,961 & 299,942 & 399,923 \\
\hline Negros & 442,181 & 663,272 & 884,363 \\
\hline Panay & 61,486 & 92,229 & 122,972 \\
\hline East Visayas/ Mindanao & 79,344 & 119,016 & 158,688 \\
\hline Total recoverable trash (tonnes) & 782,972 & $1,174,459$ & $1,565,946$ \\
\hline $\begin{array}{l}\text { Recoverable trash of final ratoon/ } \\
\text { year* }\end{array}$ & 260,991 & 391,486 & 521,982 \\
\hline
\end{tabular}

${ }^{*}$ Trash is only removed in the final crop year of a 3-year production cycle

The above estimates of recoverable trash assume that green cane harvesting is implemented (canes are harvested without pre-harvest burning to facilitate the cutting the canes).

Millers in the Philippines are already discouraging the practice of cane burning. In general, no burning is done during the early milling schedule, as canes are difficult to ignite during the rains. During the middle to late harvesting period, however, the fields are dry and accidental and intentional fires sometimes occur. Although no precise measure of cane burning is currently available, it has been 
estimated that about 3.0 million tonnes of trash are being burned yearly, representing about $50 \%$ of all trash generated based on average estimates (Mendoza and Samson 2000). Post-harvest burning is mainly done to facilitate the re-growth of the ratoon crop or the establishment of new plant cane which requires land preparation.

Recovering residual material in bales could provide farmers with additional income if baling proves financially rewarding. An analysis in Chapter 4 highlights the benefits of conserving trash in the field during the sugarcane production cycle. This includes increased crop productivity and lower input requirements for Nitrogen $(\mathrm{N})$ fertilizer. The analysis indicates that the best utilization of the cane trash resource is to trash farm the residue in the field and to remove the trash only after the final ratoon harvest. Thus, as was indicated in Table 1.3, a 3-year cane planting sequence would reduce the available trash yield to only $1 / 3$ of the total recoverable trash.

\section{B. Bagasse}

Estimates for the amount of bagasse are more accurate than for the amounts of sugarcane trash and top residues because data is available from published statistics. In the Philippines, bagasse is about $28 \%-29 \%$ of the gross cane milled. For estimating excess bagasse available for for biofuel, we took the average for crop years 1995-96 (28\% bagasse), 1996-97 (28\%), and 1997-98 (29\%), from the Philippine Sugar Statistics.

To determine the amount of available bagasse for biofuel, we located mills that only process raw sugar. Mills with both a raw sugar factory and refinery produce no excess bagasse. When a distillery co-operates with a raw sugar factory/refinery operation, the mill is already bagasse-fuel deficient. A conservative estimate of excess bagasse in mills with only a raw sugar factory is about 30\%-35\%.

Table 1.4 and Appendix 1.4 show the estimates of excess bagasse in the different sugarcane-producing regions of the Philippines. The analyses include only mills that have a raw sugar factory; (i.e. sugar mills that have a refinery were not included). Excess bagasse was estimated at 643,900 tonnes. The total bagasse yield for the 38 mills in the country is about 6,199,562 tonnes ( 3 year average). The percent bagasse available is only $10.4 \%(643,900 \div 6,199,562 \mathrm{x}$ $100=10.4 \%$ ). Prior to the year 2000 , much of this bagasse was accessible. As this material is now utilized by the sugar mills with refineries or distilleries, no surplus bagasse exists. Most sugar mills purchasing bagasse are looking for additional sources to eliminate their bunker oil purchases. Only through expanding sugarcane productivity or installing more efficient boilers and energy conservation programs, will additional bagasse become available for bioenergy applications. 
Table 1.4. Recoverable bagasse by region in the Philippines

\begin{tabular}{|l|c|}
\hline Region & Amount of bagasse (tonnes) \\
\hline Luzon & 49,972 \\
\hline Negros & 366,632 \\
\hline Panay & 107,896 \\
\hline East Visayas/ Mindanao & 119,400 \\
\hline Total & 643,900 \\
\hline
\end{tabular}

\subsubsection{Maize Residue}

Maize is a major crop in the Philippines that generates large amounts of agricultural residues. RPR values (residue to product ratio) have been listed as 2 for the stalk, 0.3 for the cob and 0.2 for the husks. There are 4 million tonnes of grain maize and 0.96 tonnes of maize cobs produced yearly in the Philippines (Appendix 1.11, 1996-1999 values). Although the crop is a potential source of biomass energy, there are concerns about harvesting maize residue for energy applications. Maize cob burning is the main energy application of the crop, and is widely practiced by small farmers to supplement fuelwood for cooking. Maize stalks are also sometimes used for cooking but tend to be less convenient to store and less clean burning. Maize stalks could be mechanically harvested for collection in larger bioenergy applications, but there are a number of factors that may make this practice unsustainable in the tropics.

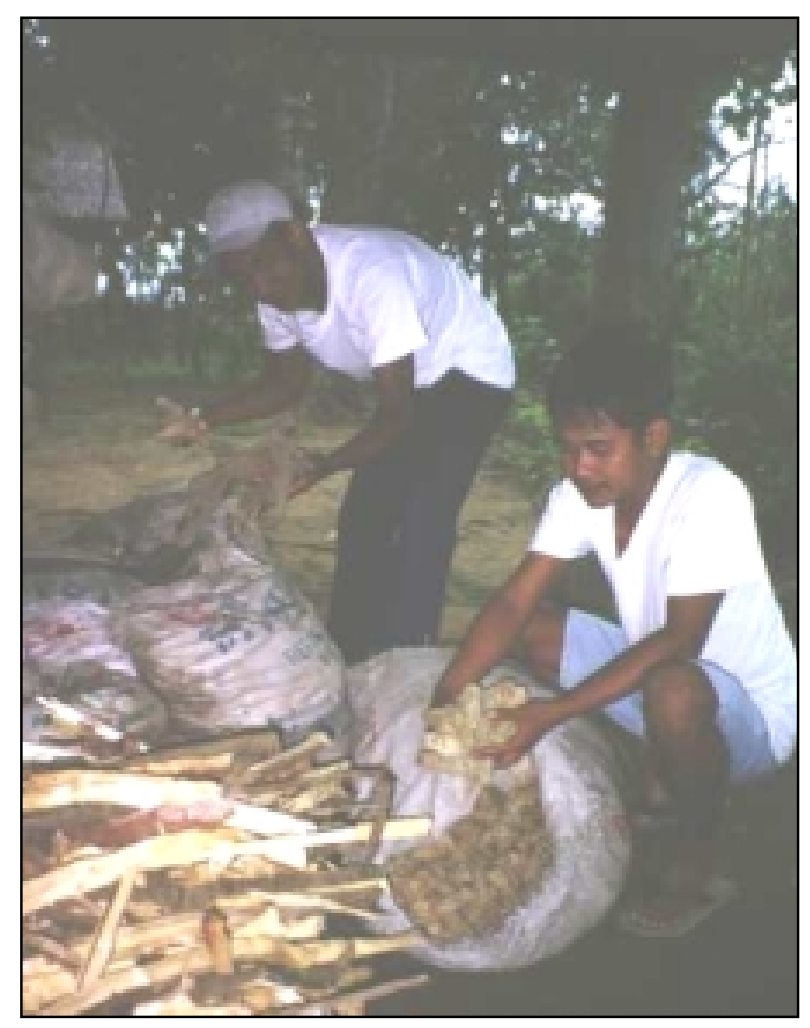

Photo 1.1. Although other residues from maize production do not have significant biofuel potential, many farmers use maize cobs as a cooking fuel. 


\section{Impacts of Harvesting Maize Residues}

\section{A. Depletion of the nutrient pool}

Maize residue contains appreciable amounts of nitrogen, phosphorous and potassium. The nitrogen component of surface deposited maize residue has little effect on soil fertility due to a slow mineralization rate and a tendency towards atmospheric loss when exposed to the air. However, potassium and phosphorous in the residues can contribute significantly to the soil nutrient pool. Over time, harvesting maize residue could result in decreased soil fertility as there is a net removal of nutrients off site.

\section{B. Depletion of soil organic matter}

Maize has the potential to maintain or increase organic matter content in soil due to its high residue production. When residue is left on the field, soil organic matter (SOM) levels may increase over time. This has been demonstrated in North America by comparison studies between no-till maize for grain and silage. After six years of no-tillage treatment, a significant difference was found between the SOM of grain maize (where $86 \%$ of soil surface was covered with residue) and the silage maize (53\% covered). (4.4\% and $3.2 \%$, respectively in the $0-15$ $\mathrm{cm}$ region of topsoil.) (Mehdi et al., 1999.)

When maize residues are not returned to the soil, the remaining soil organic matter can mineralize. This is particularly true for the Philippines where the humid, tropical climate provides excellent conditions for microorganisms to oxidize SOM. The degradation of organic matter can result in lower crop yields due to deteriorated soil structure and increased erosion potential.

\section{Erosion}

Crop residues protect the soil from erosion. This fact is of particular importance in the Philippines, where intense tropical rainfalls can result in devastating amounts of soil loss. Due to its wide spacing, maize can aggravate soil erosion during its early growth stage, making it important to maintain some residue cover to reduce the soil loss. Wide scale harvesting of maize residues could further contribute to an already significant environmental problem in the Philippines.

\section{Limited opportunities for biomass utilization from maize}

Given the concerns listed above, maize residues are not recommended as a bioenergy source. However, there is potential for the cob fraction of the crop. In the Philippines, maize is mainly harvested from the fields by hand and brought into the village to be shelled. This is commonly performed by hand or with simple hand powered shellers. Mobile maize shellers and permanent maize mills are also used. Current Philippine production is estimated at 962,000 tonnes/year. The cob represents about $23 \%$ of maize grain yield and has little economic value. Nonetheless, it is widely collected in the Philippines by small-scale farmers and 
used as a cooking fuel, with a fuel value of $16.1 \mathrm{GJ} /$ tonne. The yearly weight of recoverable cob is estimated to be 489,000 tonnes. Recovery of cobs planted during the dry season is currently estimated to be $50 \%-80 \%$, depending on the region, and $40 \%-60 \%$ during the wet season. Recovery is generally considered lowest in Mindanao and highest in Luzon. The recovery could be higher if persistent fuelwood shortages occur in some regions. Most cobs are simply gathered by hand, and commonly are stored under the Nipa palm roofed/bamboo huts in rural areas. Thus their collection is much more independent of the weather than machine harvested biomass sources such as sugarcane trash.

No estimate of the current utilization of maize cobs as a biofuel is presently available. In major maize growing areas, cobs are commonly burned in piles after shelling. Cobs are a relatively valuable agricultural residue that could be more fully utilized as a biofuel, especially since they burn effectively in most efficient wood stoves, or the central chamber of a LT 2000 Multi-fuel Stove (Chapter 2). They appear to be best suited for use in household cooking due to the lack of concentration of the resource.

\subsubsection{Rice}

\section{Rice Production}

The Philippines are situated in a humid, tropical zone and receive 1,800 to 3,000 $\mathrm{mm}$ of rainfall per year. This allows rice (Oriza sativa), a crop adapted to waterlogged conditions, to thrive in most Philippine landscapes where water can be stored for dry periods through ponding. Rice is the staple food to some 64 million Filipinos ( $80 \%$ of the nation's population of 80 million) and supplies about $90 \%$ of the caloric energy intake.

Rice is an integral part of Philippine socio-economic life. It is grown in all of the 74 provinces between the $4^{\text {th }}$ and $20^{\text {th }}$ latitudes (north of the equator). Almost one-third of all agricultural lands (approximately 11.3 million ha by Food and Agriculture Organization [FAO] 2000 statistics) are dedicated to rice, and nine out of ten Filipino farmers grow rice. The agricultural policy that governs research and development resource allocation is highly influenced by this crop. About $60 \%-70 \%$ of the research and development budget is spent on rice.

Approximately $58 \%$ of Philippine rice production (an average of 9.0 million tonnes between 1995-97) occurs during the wet season (July to December). More rice production could be achieved during the dry season with supplemental irrigation.

With plenty of sunshine and water, the Philippines could be self-sufficient in rice production. Some factors that presently constrain rice production include:

- Typhoons (the Philippines is situated in the Inter-Tropical Convergent Zone).

- Lack of irrigation facilities (only 1.2 million ha of the potentially irrigable 3.0 million ha are exploited). 
- The EI Niño/La Niña cycles in recent decades have made rice production difficult in some areas (about 40 towns in Central Luzon were flooded in July, 2000). The El Niño of 1998 decreased total rice yield by about $24 \%$. Of the 1.2 million ha usually irrigated in the dry season, only 0.4 million ha could be irrigated for rice production that summer.

- Pest outbreaks (golden snail, rice bug, and tungro) continue to reduce yields.

\section{Rice Straw}

The full utilization of the rice plant is another ongoing challenge. Rice straw is burned as the main method of disposal on 9 out of 10 farms. Rising fertilizer costs and declining soil fertility should increase awareness of the need to stop rice residue burning and the benefits of mulch farming. One hectare of rice producing 5 tonnes of unmilled grain yields about 5 tonnes of straw. Harvesting rice straw poses several problems. Its biomass quality is low due to its high silica content, it is difficult to chop and burn, and it has a low energy return. There are also logistical concerns about the ability to dry the relatively green material that is left in piles following threshing. As in the case of sugarcane, decomposing rice straw also fixes $\mathrm{N}$ during its decomposition. From the standpoint of a farmer, the best biomass use of this material may be to maintain SOM by spreading it back in rice paddies immediately after harvest for their next crop. Overall removal of rice straw poses many of the same concerns as removal of maize stalks (Section 1.2.2). Likely, small amounts of rice straw could be harvested in the dry season in productive rice growing areas and blended with other biomass fuels being fed into boilers.

\section{Rice Hulls}

Currently, the main opportunity associated with rice appears to be to more fully utilize the rice hull. On average, milling the grain yields about $20 \%$ rice hulls. This study attempts to present an estimate of rice hull yields in the Philippines. The average rice yields for the 1995-1997 crop years were used. The rice hull estimates are determined as follows:

\section{Total Rice Hull Yield.}

Rice hull yield is computed as follows:

$$
\begin{aligned}
& \mathrm{RHY} \quad=\quad \mathrm{TRY}{ }^{*} \mathrm{RHYcoeff} \\
& \text { RHY = rice hull yield in the area } \\
& \text { TRY = total rice yield in the area } \\
& \mathrm{RHYcoeff}=\text { rice hull yield coefficient }
\end{aligned}
$$

The RHYcoeff used were 0.18 for low, 0.20 for average, and 0.24 for high estimates. The Philippine total rice hull yield (RHY) was estimated by adding the individual RHY's. 


\section{Recoverable Rice Hull Yield.}

Estimates of recoverable rice hull yield were obtained by considering the following points:

- Rice produced in mountainous or hilly regions is not brought to rice mills in the lowland areas for milling. As no rice hulls are recoverable in these areas, separating the rice hull from the grain is done by manual pounding. The 20 provinces that produced less than 20,000 tonnes were excluded in the estimates as they provide less than $2 \%$ of the rice yield nationwide.

- Of the total rice produced in the area, $3 \%$ is used for seeds and another $6 \%$ is used for livestock feed and other purposes.

- Despite their low efficiency, a type of rice mill called a "kiskisan" is still being used. No rice hull is produced as it is mixed in the rice bran. About $10 \%$ of all rice is still milled by the kiskisan. Table 1.5 lists features of three rice mills in the Philippines.

Table 1.5. Features of three types of rice mills

\begin{tabular}{|l|c|c|c|}
\hline Mill type & Capacity (tonne/ha) & Usage (\%) & Milling recovery \\
\hline Kiskisan & $0.1-0.3$ & 10.5 & $55-63$ \\
\hline Cono & $0.5-2.0$ & 33.2 & 65 \\
\hline Rubber roll & $0.5-2.5$ & 56.1 & $65-70$ \\
\hline
\end{tabular}

Source: Vegara1998

The recoverable rice hull yield (RRHY) is computed as follows:

$$
\mathrm{RRHY}=\mathrm{RHYcorr}{ }^{*} 0.91 * 0.90
$$

$\mathrm{RHY}=$ rice hull yield in an area or province that produces 20,000 tonne of rice or more

$0.91=$ the correction factor for seeds and livestock feed $(0.03+0.06=0.09,1.00-0.09=0.091)$

$0.90=$ the correction factor for "kiskisan" $(1.0-0.10=0.90)$

The total recoverable rice yield is simply the sum of all the RRHY's. 


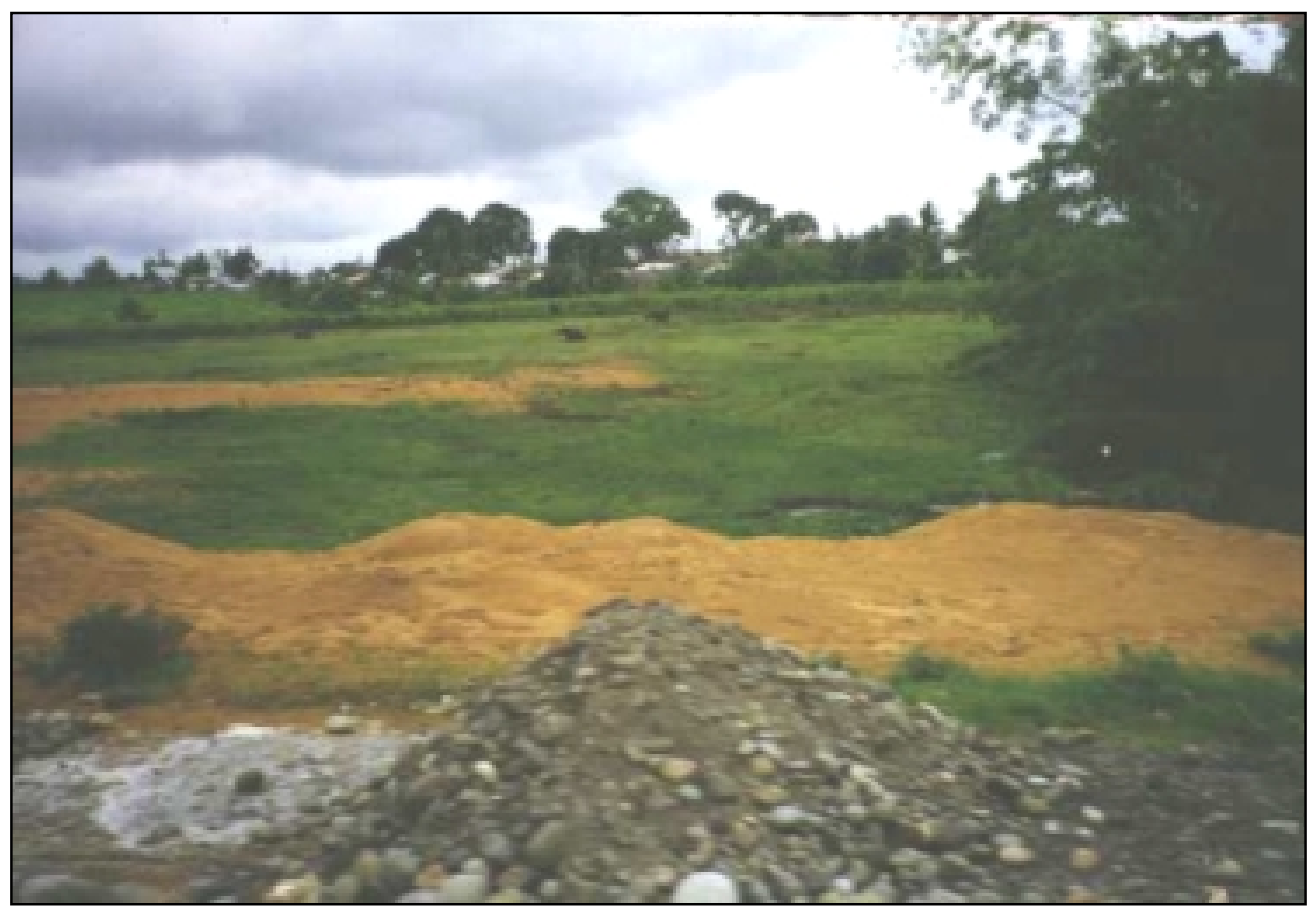

Photo 1.2. Rice hulls are commonly dumped in waste areas and burned for disposal. However, using the hull for bioenergy purposes is becoming more common.

\section{Total Rice (Grain) Yield And Total Rice Hull Yield Estimate}

Rice yield

The Philippines are composed of 3 main island regions, namely Luzon, the Visayas and Mindanao. In terms of rice yield distribution, Luzon accounts for $58.5 \%$, Mindanao, $28.7 \%$, and the Visayas, $12.8 \%$. This variation in yield can be attributed to the topography of the land. There is more flat land in Luzon (Central Luzon in particular) and also more irrigated areas than in the Visayas and Mindanao combined. Mindanao could increase its rice production, because more of its flat land is suitable for irrigation (pending the restoration of political stability to the region). Three regions in Luzon [Ilocos (11.4\%), Cagayan Valley $(17.8 \%)$, Central Luzon (21.6\%)] contribute more than half $(50.8 \%)$ of all rice produced nationwide.

The top 20 rice producing provinces (Appendix 1.5) contribute $71 \%$ of the 9.0 million tonnes of national rice produced. Rice yield data in the 14 regions of the Philippines were also calculated from 3 crop years (1995 to 1997) and summarized in appendix 1.6.

\section{Rice hull yield}

As the rice hull yield is a fraction of the grain yield upon milling, the trend in rice hull yield is identical to that of the grain yield. Recoverable rice hull yield is estimated to be approximately $20 \%$ less than the available rice hull yield in the 
Philippines. Table 1.6 outlines the low, average and high estimates of rice hull yields and the recoverable rice hull yields, and Appendix 1.7 lists regional values.

Table 1.6. Estimates of rice hull yields and fuel energy equivalents.

\begin{tabular}{|l|c|c|l|}
\hline & $\begin{array}{l}\text { Available rice hull yield } \\
\text { (million tonnes) }\end{array}$ & $\begin{array}{l}\text { Recoverable rice hull } \\
\text { yield (million tonnes) }\end{array}$ & $\begin{array}{c}\text { Fuel energy equivalent } \\
\text { of RRHY }\end{array}$ \\
\hline $\begin{array}{l}\text { Low } \\
\text { estimate }\end{array}$ & 1.6 & 1.3 & $\begin{array}{l}17.7 \times 10^{6} \mathrm{GJ} \\
\left(3.0 \times 10^{6} \mathrm{BFOE}\right)\end{array}$ \\
\hline $\begin{array}{l}\text { Average } \\
\text { estimate }\end{array}$ & 1.8 & 1.5 & $\begin{array}{l}20.4 \times 10^{6} \mathrm{GJ} \\
\left(3.5 \times 10^{6} \mathrm{BFOE}\right)\end{array}$ \\
\hline $\begin{array}{l}\text { High } \\
\text { estimate }\end{array}$ & 2.2 & 1.7 & $\begin{array}{l}23.12 \times 10^{6} \mathrm{GJ} \\
\left(3.9 \times 10^{6} \mathrm{BFOE}\right)\end{array}$ \\
\hline
\end{tabular}

\section{Other Factors Influencing Rice Hull Use}

Since rice hulls are generated by mills, their use as a biofuel also depends on the location and capacity of rice mills. Appendix 1.14 lists the capacity of rice mills by region/province. High rice producing provinces have the largest number of units and mill capacity.

The proximity of the rice mills to end-users is important, since:

- The cost of hauling increases with distance.

- Some mills, especially smaller ones, are only operational 6 to 7 months of the year (October to December and March to June), creating concerns about the seasonal availability of rice hulls. One solution to seasonal variation in milling is the storage of rice hulls by biofuel users during months of unavailability. In contrast to small mills, large rice mills operate throughout the whole year and are burdened by hull storage requirements. These mills frequently burn the residues from rice milling, reducing the amount of rice hull available for use as a biofuel.

In major rice growing provinces like Nueva Ecija, Tarlac, Pampanga and Ilo Ilo, farmers have requested that drivers of hauling trucks unload rice hulls directly into their fields. The rice hull is then spread through the fields and burned. A growing number of farmers are adopting this technique as they have observed improved growth and yields of vegetables, onion and garlic. However, this practice reduces the amount of rice hull available as a biofuel.

\subsubsection{Coconut}

In the Philippines, coconut is grown in 64 out of 78 provinces. About 3.0 million ha or $10 \%$ of the country's total land area is planted with this crop. At an average of 100 plants per ha, there are about 300 million coconut trees, managed by about 1.4 million coconut farmers. 


\section{Estimating the Quantity of Coconut Husks and Shells}

Due to the large number of coconut trees in the Philippines (300 million) and their perennial growth, they produce a substantial amount of biomass. In addition to the husk and coconut shell, coconut frond is also produced in abundant quantity. An estimate of the total yield of coconut husks and shells was made using the following procedure:

The average coconut production for three cropping years $(1996,1997,1998)$ was obtained by region. Coconut production was quantified on a mass basis by multiplying the number of coconuts by $1.2 \mathrm{~kg}$ (the average weight for 1000 coconuts) (Coconut Conversion Table, Philippine Recommendations for Coconut, 1989). The total weight of coconut husks and shells was then estimated using the following formula. The five regions listed in Table 1.7 produce about $70 \%$ of the coconut husks and shell in the Philippines.

Coconut husk (by region) $=$ Total weight of nut ${ }^{*} 0.3$

Coconut shell $($ by region $)=$ Total weight of nut ${ }^{*} 0.3$

Table 1.7: Husk and shell production (tonnes) per region

\begin{tabular}{|c|c|c|c|}
\hline Region & Provinces & $\begin{array}{c}\text { Husk } \\
\text { (tonnes } \times 10^{6} \text { ) }\end{array}$ & $\begin{array}{c}\text { Shells } \\
\text { (tonnes } \times 10^{6} \text { ) }\end{array}$ \\
\hline XI & $\begin{array}{l}\text { Davao City, Davao Sur, Davao Norte, Davao } \\
\text { Or., Sultan Kudarat }\end{array}$ & 1.10 & 0.50 \\
\hline IV-A & $\begin{array}{l}\text { Laguna, Batangas, Quezon, Marinduque, } \\
\text { Mindoro Or., Mindoro Occ., Quezon }\end{array}$ & 0.52 & 0.24 \\
\hline IX & $\begin{array}{l}\text { Zamboanga City, Zamboanga Sur, Zamboanga } \\
\text { Norte, Basilan }\end{array}$ & 0.49 & 0.22 \\
\hline XII & Lanao Norte, S. Cotabato, N. Cotabato & 0.40 & 0.18 \\
\hline VII & $\begin{array}{l}\text { Biliran, Leyte, S. Leyte, N. Samar, E, Samar, } \\
\text { W. Samar }\end{array}$ & 0.35 & 0.16 \\
\hline Total & & 2.87 & 1.29 \\
\hline
\end{tabular}

A more detailed breakdown of the products resulting from coconut production can be found in Appendix 1.8. Based on an average of 11.4 billion nuts produced nationwide (at $1.2 \mathrm{~kg}$ average weight per nut) crop biomass yield was estimated to be:

\section{Coconut husk $=4.1$ million tonnes \\ Coconut shells $=1.8$ million tonnes}

Of the 64 coconut growing provinces (out of 78 provinces), the top 28 provinces (Appendix 1.9) produced $83 \%$ (9.4 billion nuts) of the national crop (11.4 billion nuts). Davao, Zamboanga, and Quezon are the top 3 producing provinces. Of the major islands (Luzon, Visayas, Mindanao), $22.9 \%$ of coconut production is from Luzon, $9.8 \%$ from the Visayas, and the highest amount is from Mindanao $(64.7 \%)$. Mindanao has the highest portion of the 300 million Philippine coconut 
trees $(51.7 \%)$, followed by Luzon $(28.3 \%)$ and the Visayas $(20 \%)$. Furthermore, yields per tree were highest in Mindanao (48.5 nuts/tree), while nut yields were 29.1 nuts/tree in Luzon, and only 16.8 nuts/tree in the Visayas.

\section{Estimates of Coconut Frond Production}

The coconut frond creates large volumes of biomass. For example, a nut bearing coconut palm tree has 28-36 leaves, or an average of 32 leaves. The leaf duration (from full expansion) is about 18 months. Generally the tree forms 1 leaf per month, and correspondingly loses 1 mature leaf each month or 12 leaves each year. Leaf frond biomass varies with respect to tree quality. Healthy trees with bigger leaves produce more biomass and more nuts per tree. In approximating the weight of fronds, $1.2 \mathrm{~kg}, 1.5 \mathrm{~kg}, 1.8 \mathrm{~kg}$ were estimated for low, average, and high weights, respectively.

The following formula was used to estimate coconut frond biomass:

Weight of coconut frond $=$ \# of weight bearing tree fronds/year * \# of individual fronds

The results of frond biomass estimates are shown in Appendix 1.1. The average number of fronds produced per year was 2.7 billion, translating into 4.5 million tonnes of coconut frond. The 4.5 million tonnes of coconut frond represents a total energy equivalent of approximately 25 million GJ of energy (Table 1.8).

\section{Estimating the Fuel Value of the Coconut Biomass Resource}

A summary of the total coconut biomass resources (husk, shell, and frond) is shown in Table 1.8. Based on average estimates, coconut fronds (4.5 million tonnes) yielded the most biomass followed by coconut husk (4.1 million tonnes) and coconut shell (1.8 million tonnes). Coconut shell yielded the highest fuel value. The total Barrel of Fuel Oil Equivalent (BFOE) for coconut husk, shell, and frond was estimated at 23.3 million BFOE or 137.9 million GJ of energy. 
Table 1.8: Summary for total coconut biomass resource

\begin{tabular}{|c|c|c|c|}
\hline Coconut & Biomass produced & \multicolumn{2}{|c|}{ Fuel Value } \\
(million tonnes) & BFOE (million) & GJ (million) \\
\hline Coconut husk & 4.1 & 13.1 & 77.5 \\
\hline Coconut shell & 1.8 & 6.1 & 35.6 \\
\hline Coconut frond & & & \\
(Low) & 2.9 & 2.6 & 16.0 \\
(Average) & 4.5 & 4.1 & 24.8 \\
(High) $^{\text {Total* }}$ & 6.5 & 5.9 & 35.8 \\
\hline & 10.4 & 23.3 & 137.9 \\
\hline
\end{tabular}

*Using average value of coconut frond

\section{Estimating Recoverable Coconut Biomass Residue for Fuel Use}

No precise estimates can be made of the potential recoverability of coconut residues. A rough estimate gives $50 \%$ for coconut husks and $40 \%$ for coconut fronds (Appendix 1.10). Coconut shells (the most concentrated and highest quality coconut residue) are widely used for charcoal production or higher value applications. Unlike the other field crop residues, coconut residues are more widely dispersed and are frequently produced in marginal farming areas with limited transportation networks. Recovery is limited by gathering the residue manually, and the absence of a practical means to store the material and turn it into useful energy. Large-scale assembly or mechanized harvesting of the frond resource presently seems unlikely. However, if fuelwood production continues to decline, people will be more willing to use lower grade energy sources such as coconut fronds for simple applications such as household cooking. Recovering coconut biomass for fuel could provide substantial benefits by reducing fuelwood consumption for household cooking in rural areas. Additionally, the use of husks as a boiler fuel would improve the self-sufficiency of the coconut processing industry.

\section{Coconut shell}

Of the 3 coconut biomass resources, coconut shells have the highest biomass quality and are the most utilized as they are processed into charcoal and sold to traders for fuel. A small but growing percentage of coconut shell charcoal is also processed into activated carbon. In 1997, the Philippines exported about 28,335 tonnes of activated carbon, representing about $50 \%$ of world exports. In the same year, the country exported about 41,040 tonnes of charcoal, representing $58 \%$ of the world export of coconut shell charcoal. While not used specifically for fuel, it should be pointed out that much of the current supply of coconut shell is presently being utilized. At Bondoc Peninsula, Quezon, coconut shell is processed into charcoal in the field and hauled to other areas to be sold. With a 
fuel value of $28.3 \mathrm{GJ} /$ tonne, coconut shell charcoal commands a higher price than wood charcoal because it has a higher heating value per weight basis.

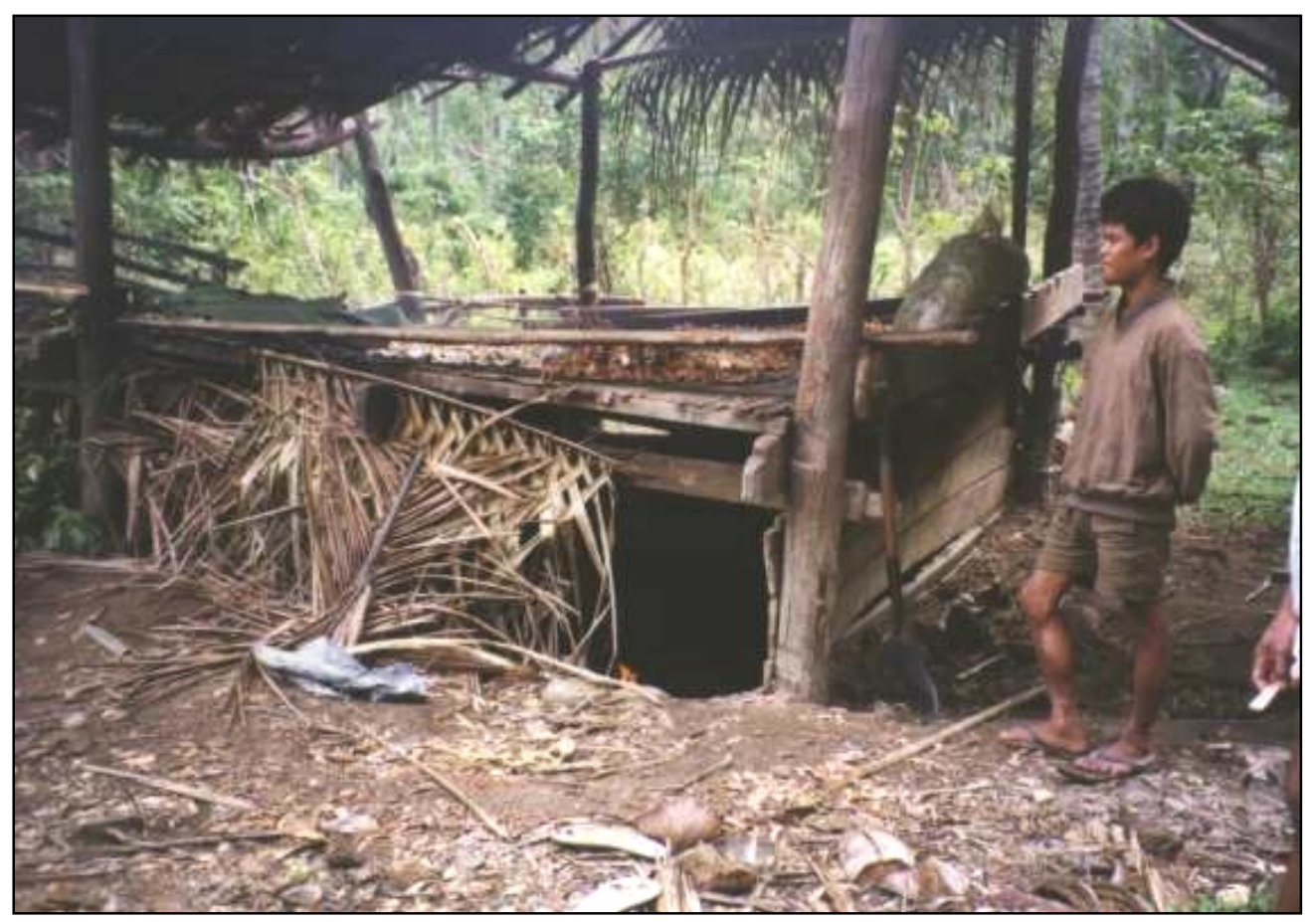

Photo 1.3. To make copra, coconut meat is frequently dried with coconut residues in simple drying apparatuses in remote areas. The material is then transported from these often hilly areas by carabao (water buffalo) or packed out on foot to the market. Much of the coconut biomass residue is not recoverable for energy applications because of difficulties in transporting the material out of these remote areas. Charcoal production eases the transport problem.

\section{Coconut husk}

Presently, farmers use up to $40 \%$ of the available coconut husks as fuel to produce copra (dried coconut meat). With large amounts of frond biomass available, a more efficient practice for farmers would be to use fronds for this purpose, freeing the husk resource for use in other potentially more valuable applications. However, gathering the frond is labor intensive. A significant added value for the husk would be required before this practice could become a practical means to expand utilization of the frond. The LT-2000 stove can burn sliced coconut husks in its central chamber, which could encourage its use in rural household cooking applications and alleviate concerns about seasonal rice hull availability. 


\subsubsection{The Bioenergy Potential of High Yielding Perennial Grasses}

Excess residues from sugarcane, rice, coconut, and maize production may not be sufficient to meet the energy requirements of the Philippines. Some residues, like bagasse, are already scarce, and others are likely to decline in availability. To generate more energy locally and encourage energy self-reliance, there will be an increasing need to plant dedicated energy crops.

Land availability constrains agricultural production in many parts of the tropics. High quality land is reserved for food production. Taking such land out of food production and replacing it with bioenergy crops is not a preferred option. Dedicated bioenergy crops would have to be established on marginal lands where food crops have difficulty growing, such as denuded hillsides, lands with thin, heavy or droughty soils, or lands exhausted from intensive maize cropping.

Attempting to grow energy crops under such unfavorable conditions leads to numerous difficulties. Several factors must be considered to identify suitable species capable of growing on marginal soils. They should be hardy, able to withstand large variations in climate (monsoon floods, droughts etc.), and achieve moderate to high productivity levels. Selected species must produce sufficient biomass and not allow excessive leaching of nutrients from the soil. The plants must have low fertility requirements, due to both the quality of available soil and the prohibitive cost of chemical and organic fertilizers for smallscale tropical farmers. Ideally, species that eliminate soil-erosion, improve soil fertility and structure, and provide a habitat for wildlife should be encouraged.

Perennial grasses seem to be likely candidates for bioenergy production in the tropics. In general, they are hardy with the ability to establish themselves on disturbed lands. Most of the tropical grass species suitable for bioenergy production have been domesticated as forage crops. Agronomic practices that encourage bioenergy production differ from the methods employed to provide livestock with quality fodder. The bulk of the literature available on tropical grasses is written from the perspective of the livestock producer. This information would have to be reassessed for the purpose of using perennial grasses as a bioenergy source.

\section{Biomass Productivity of Perennial Grasses}

Many tropical grasses have impressive biomass production rates (Appendix 1.12). In particular, napier grass (Pennisetum purpureum Schumach) is known for its high yields. In Puerto Rico, napier grass grown in a small plot system fertilized with $897 \mathrm{~kg} \mathrm{~N} / \mathrm{ha}$ reached a world record production of $84 \mathrm{ODT} / \mathrm{ha}$ (Vincete-Chandler et al., 1959). A four-year average yield of napier grass of 33.4 ODT/ha was achieved in sub-tropical Florida under a fertilization regime of 168$42-64 \mathrm{~kg} / \mathrm{ha} \mathrm{N}-\mathrm{P}_{2} \mathrm{O}_{5}-\mathrm{K}_{2} \mathrm{O}$ (Prine and Woodard 1994). This yield is slightly greater than that of sugarcane and energy cane (Saccharum spp.), which produced 30.8 
and 33.1 ODT/ha respectively. In another experiment where rates of 224-56-112 $\mathrm{kg} / \mathrm{ha} \mathrm{N}-\mathrm{P}_{2} \mathrm{O}_{5}-\mathrm{K}_{2} \mathrm{O}$ were used, napier grass yielded $47.8 \mathrm{ODT} / \mathrm{ha}$.

While napier grass appears to be the tropical forage species with the highest yield potential, other grasses have respectable yields and may be more easy to cultivate and harvest due to their thinner stems. Middleton and McCosker (1975) produced more than $60 \mathrm{ODT} / \mathrm{ha}$ of guinea grass (Panicum maximum Jacq.) at a fertilization rate of $300 \mathrm{~kg} / \mathrm{ha} \mathrm{N}$, in Queensland, Australia. Singh et al (1995) produced guinea grass yields of 18.9-26.9 ODT/ha with $120 \mathrm{~kg} / \mathrm{ha} \mathrm{N}$ in subtropical India. Gamba grass (Andropogon gayanus Kunth), another notable forage grass species, produced $40 \mathrm{ODT} / \mathrm{ha}$ with $50-44-30 \mathrm{~kg} / \mathrm{ha} \mathrm{N}-\mathrm{P}_{2} \mathrm{O}_{5}-\mathrm{K}_{2} \mathrm{O}$ in Tanzania (Hendy, 1975).

\section{Cutting Schedules for Biomass Production}

The grasses presented in this section are all forage varieties and much of the information concerning cutting schedules has been conducted in terms of improving nutritive characteristics. Frequent cutting promotes the growth of fresh, nutrient rich shoot material, which is highly digestible and ideal for livestock consumption. However, for the purpose of maximizing biomass for bioenergy crop production, longer cutting periods should be observed to increase biomass productivity and fiber content while minimizing nutrient extraction. Guinea grass (Panicum maximum), had greater biomass productivity, giving dry matter (DM) yields of 11.2 tonnes/ha, 16.7 tonnes/ha, and 23.3 tonnes/ha for cutting intervals of 20,30 , and 40 days respectively (Singh et al., 1995). While such increments in biomass productivity can be seen in short cutting intervals, there appears to be an interval length at which biomass productivity reaches a plateau. Napier grass (Pennisetum purpureum) grown for agro-industrial applications had no significant difference in yield between 3 month and 6 month cutting intervals (Ferraris and Stewart, 1979). There is a need to optimize the cultivar choice and cutting regime.

\section{Management Considerations for Napier Grass}

Napier grass (Pennisetum purpureum) is one of the few tropical grasses being examined for biomass production. Dr. Gordon Prine of the University of Florida, has developed a number of recommendations for napier grass in his examination of bioenergy production systems for the sub-tropical United States (Table 1.9). In addition to napier grass, Prine has grown energy cane and sugarcane as comparison bioenergy crops. He has found that napier grass forms a canopy faster than cane species after harvest, and also develops a full canopy within three weeks, while sugar and energy cane require 6-8 weeks. This fact is particularly important for potential biomass production on erosion-prone marginal soils. It is also believed that napier grass is more drought tolerant and better adapted to marginal soils than sugarcane. An advantage of energy cane over napier grass is that the finer stems of energy cane allow for more rapid drying (Prine 2000). 
Table 1.9. Agronomic practices for napier grass (Prine, 2000; FAO, 1997)

\begin{tabular}{|c|c|}
\hline Practice & Description \\
\hline Land preparation & $\begin{array}{l}\text { Full land preparation with plowing and subsequent disc- } \\
\text { harrowing and drilling }\end{array}$ \\
\hline Sowing time & Beginning of the wet season \\
\hline $\begin{array}{l}\text { Establishment } \\
\text { method }\end{array}$ & $\begin{array}{l}\text { The grass is planted in } 5 \mathrm{~cm}-7.5 \mathrm{~cm} \text { billets, or can be } \\
\text { established using root cuttings or stem pieces with } 3-4 \text { nodes. } \\
\text { When planting stem pieces, two nodes should be covered in soil, } \\
\text { leaving the third and fourth exposed. A sugarcane planter is } \\
\text { suitable for establishment where the planting material is planted } \\
\text { in furrows about } 15 \mathrm{~cm} \text { deep with a covering of } 7.5 \mathrm{~cm} \text { of soil. }\end{array}$ \\
\hline $\begin{array}{l}\text { Sowing rate and } \\
\text { spacing }\end{array}$ & $2000 \mathrm{~kg} / \mathrm{ha}$ of plant material at a rate of $90 \mathrm{~cm}$ \\
\hline Fertilization rates: & Topdress of $168 \mathrm{~N}: 42 \mathrm{P}_{2} \mathrm{O}_{5}: 84 \mathrm{~K}_{2} \mathrm{O} \mathrm{kg} / \mathrm{ha}$ \\
\hline Stand lifespan & $\begin{array}{l}4-6 \text { years is average; though some stands can survive up to } 15 \\
\text { years }\end{array}$ \\
\hline $\begin{array}{l}\text { Harvesting rate and } \\
\text { method }\end{array}$ & Napier grass is harvested with a flail harvester and then raked. \\
\hline Crop drying & $\begin{array}{l}\text { Air drying in windrows of mature crops of } 2-4 \mathrm{~cm} \text { stem diameters } \\
\text { requires } 7-10 \text { days without rainfall to reach moisture levels of } \\
15-20 \text { wt \% (Mislevy and Fluck, 1993). Due to its large stem } \\
\text { diameter, napier grass may have a longer drying period than } \\
\text { other tropical grasses. }\end{array}$ \\
\hline
\end{tabular}

\section{Biomass Quality Constraints for Tropical Grasses}

To employ tropical grasses as a fuel source in power generation, they must adhere to certain energy and ash content requirements. Tropical grasses, such as napier grass, contain relatively high levels of alkali metals and chlorine which can disrupt combustion systems. In general, napier grass has a similar chemical composition to sugarcane trash.

To reduce the fouling potential of the grasses, certain pre-treatments can be employed to minimize ash content. Jenkins et al., (1997) reduced the ash content of napier grass by pressing and rinsing the chopped grass. Without pre-treating, the ash content was $3.9 \%$ dry matter (DM). Pressing out residual moisture 
reduced ash content to $3.1 \%$, and pressing and rinsing resulted in an ash content of $2.7 \%$.

\section{Opportunities for Developing Napier Grass as a Biofuel in the Future}

Based on current cane production levels in the Philippines and international reports on napier grass production, it appears that productivity levels of 20 ODT/ha could be achievable for napier grass in the Philippines. If 100,000 hectares were planted (representing a land area of about $4 \%$ of the maize acreage), 2 million tonnes of biomass could be produced. This is about 7 times the available biomass that could be supplied from sugar cane trash if harvesting occurs only after the final ratoon crop.

Given the biomass quality concerns related to use in some boilers, it is plausible that napier grass and similar tropical grasses could first be introduced as a densified cooking fuel. Grasses could be densified into pellets or briquettes and then burned in simple household stoves. This strategy minimizes the problems of the high ash and silica content of grass biofuels because the combustion equipment has a simple design. This strategy is discussed in more detail in the household cooking section of Chapter 2.

\subsubsection{Wood and Wood Based Residues}

\section{Wood Fuel Supply}

Fuelwood and charcoal (woodfuels) in the Philippines account for as much as $30 \%$ of the country's total annual energy consumption (FAO, 1999). 1995 figures showed that some $38 \%$ of the Philippine population use wood as their main cooking fuel (Chapter 2). Fuelwood is currently the largest source of biomass energy in the Philippines, of which $86 \%$ originates on non-forested land. Fuelwood is obtained from trees that are commonly planted on agricultural land as perimeter trees, such as Gliricidia sp., Leucaena sp., Gmelina sp., and Eucalyptus sp. Pruned branches of fruit trees such as guava (Psidium guava), avocado (Persia americana), chico (Achras sapote), sereguelas (Spondias purpures), caimito (Chrysophyllum cainito), and duhat (Eugenia jambolana) provide significant volumes of wood. When these trees are pruned to improve fruit yields and to prevent the shading of underlying crops, the cut branches are used for fuel. Another source of fuelwood comes from pollarding; the trunk is cut at a specified distance from the base of the tree with the goal of multiplying the tree's branches. It will be essential to work with small farmers to introduce improved techniques and varieties of fast-growing trees if the supply of fuelwood is to be greatly expanded.

As shown in Figure 1.4, the majority of fuelwood (13 million tonnes) is selfcollected; only 1.7 million tonnes are purchased. (Appendix 1.13). In comparison, some 261,476 tonnes of charcoal are self produced, and 810,785 tonnes are 
purchased. The estimated value of consumed woodfuel is approximately 1.1 billion US dollars per year (FAO, 1999).

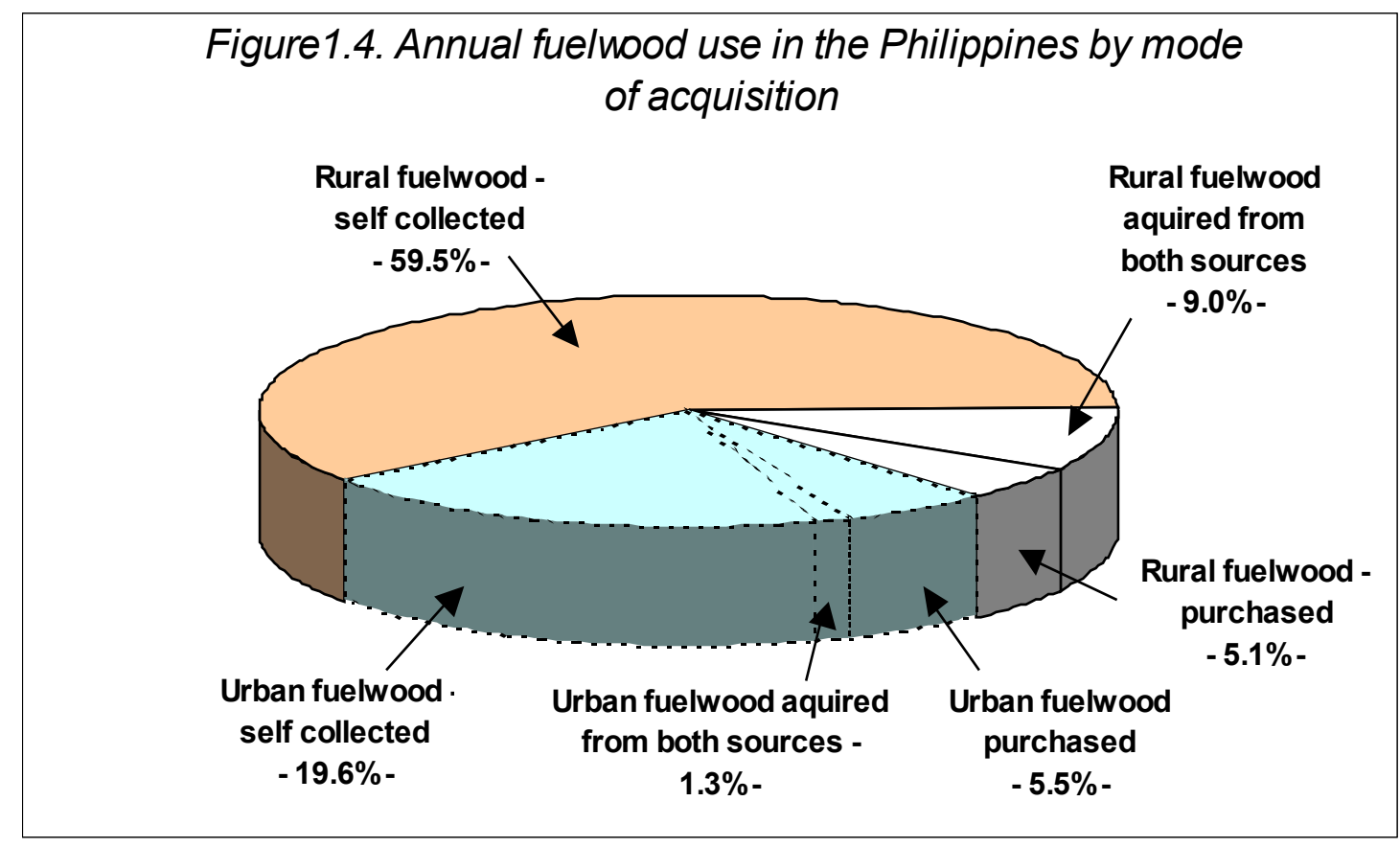

Information from the 1995 Household Energy Consumption Survey: Main Report and Annexes, Department of Energy, Republic of the Philippines

\section{Wood Based Residues}

FAO estimates (1997) suggest that roughly 1.95 million tonnes of wood residues are generated on a yearly basis in the Philippines. Approximately $73 \%$ of these residues are field-derived, mostly from logging operations. An estimated $40 \%$ of total waste wood products are logging residues left in the field. A significant amount of wood residues are in the form of kiln-dried wood $(20.4 \%)$, slabs $(20.4 \%)$, and bark $(7.2 \%)$.

\section{Fuelwood Versus Industrial Roundwood Production}

The ratio of industrial roundwood production to fuelwood and charcoal has been decreasing over the past 25 years (Figure 1.5). While industrial roundwood production has dropped from 1975 to 1997 (10.6 million $\mathrm{m}^{3}$ to 3.3 million $\mathrm{m}^{3}$ ), fuel and charcoal use has increased $\left(22.8\right.$ million $\mathrm{m}^{3}$ to 38.2 million $\left.\mathrm{m}^{3}\right)$. This trend is a result of the declining state of the forests in the Philippines and the expanded use of fuelwood from agricultural lands.

To maximize the return on forestry investments, forests need to be managed for their highest value usage. It is more viable to plant trees for roundwood production (as opposed to fuelwood) for the following reasons: 
(1) Fuelwood prices are generally much lower than roundwood prices

(2) There are wood residues produced from the processing of these materials that can be used for biomass energy.

(3) Eventually, almost all solid wood products are burned for fuel after their useful life is complete.

Figure 1.5: Fuelwood and roundwood production in the Philippines, 1975-1997

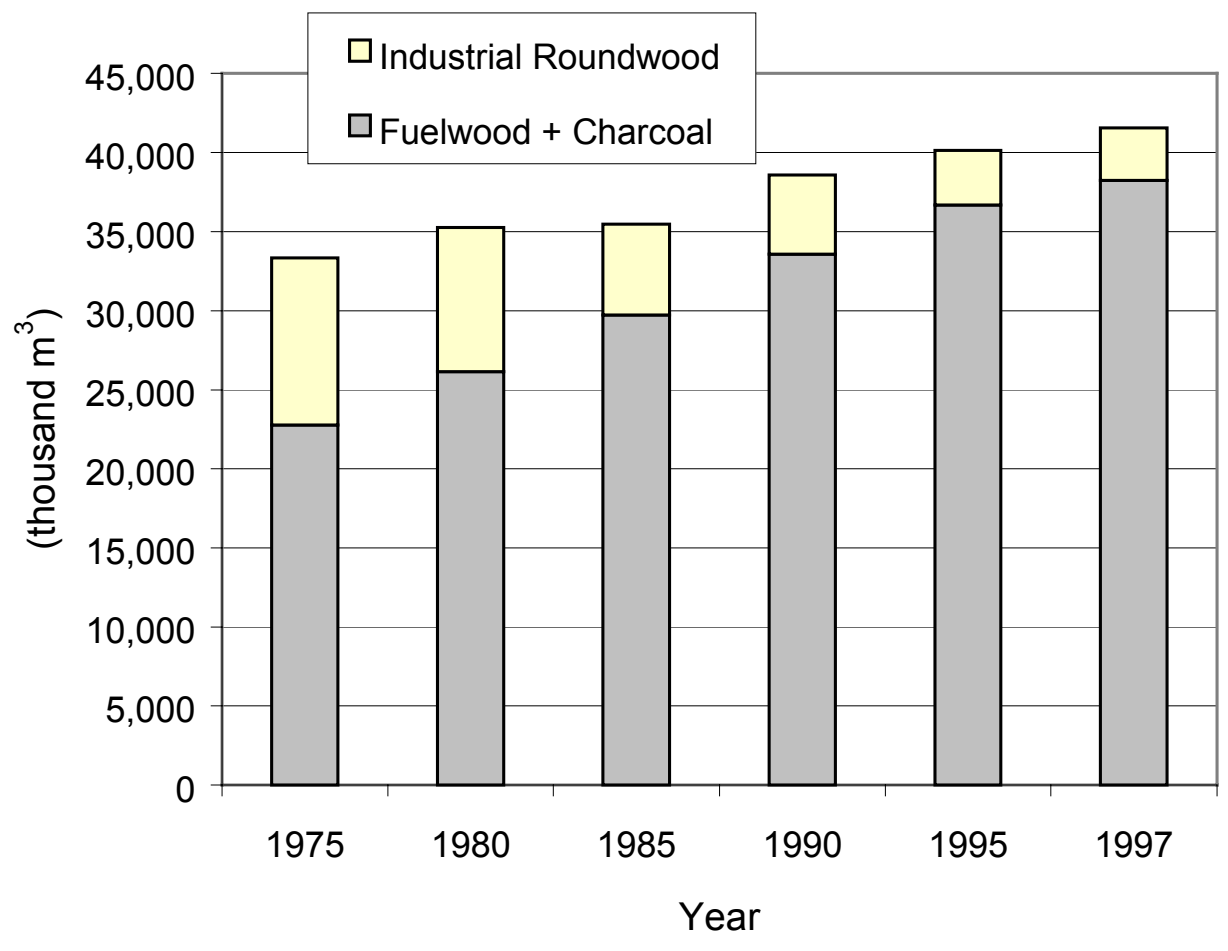

Besides maximizing profits, forestry management goals should include increasing biodiversity and reducing soil erosion losses. The far-reaching effects of deforestation need to be acknowledged. Landslides and soil erosion losses can be detrimental to both human life and farms/forests in sloping areas.

Improved forestry management practices should be adopted to reduce such losses. The appropriate species of trees should be planted on suitable soil types. Forest cover increases stability, slows runoff, and reduces erosion so the impact of floods can be minimized with decreasing landslides and on-farm soil losses. There is significant potential for widespread introduction of fast-growing trees such as Eucalyptus sp. in the Philippines. There is also significant need for tree improvement programs for existing species such as Gliricidia sp., Leucaena sp., and Gmelina sp. 


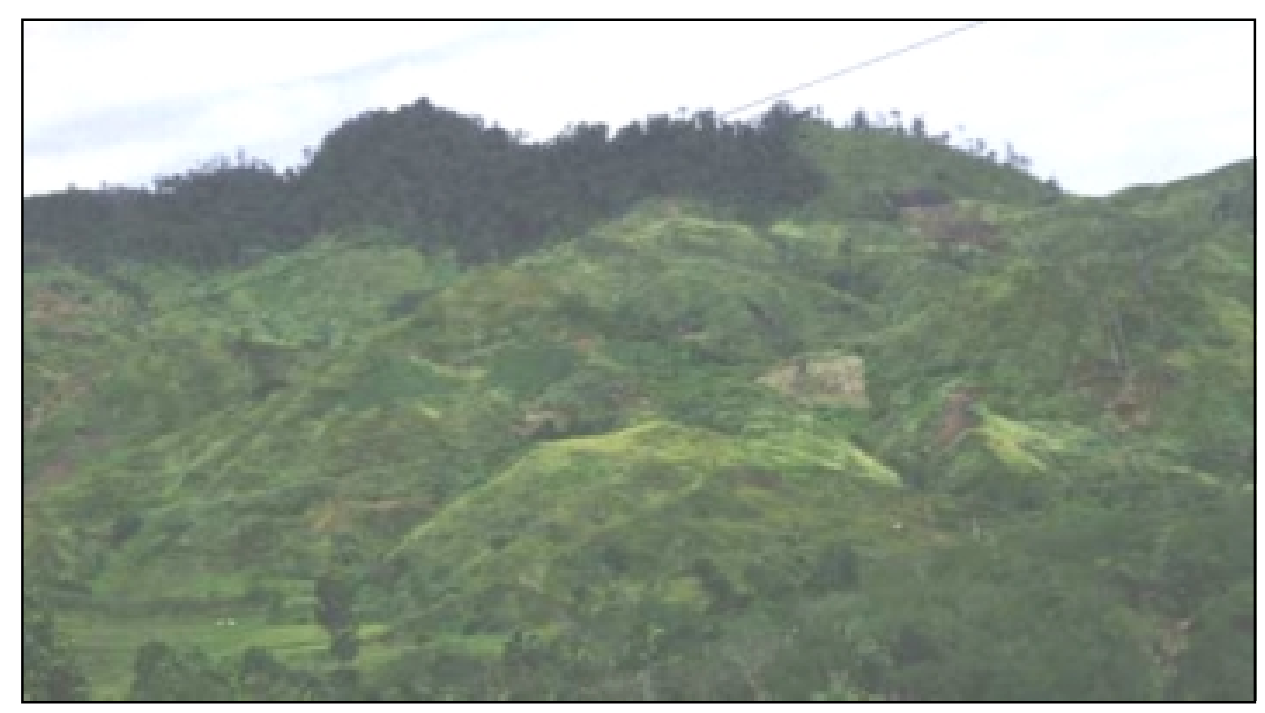

Photo 1.4. Deforestation of large areas of the uplands is common in the Philippines, causing serious environmental problems.

\subsection{Suitability of Biomass Residues for Bioenergy Applications}

In addition to the concentration of a biomass resource, biomass quality can have a major influence on its potential end use application (Table 1.10, Table 1.11). Important factors include physical properties such as size, moisture content, and bulk density, and chemical properties like ash content, energy content, and composition. In general, the lower the biomass quality of the feedstock, the simpler the end use application must be in order to utilize the resource to its greatest comparative advantage. Significant amounts of energy can be spent on gathering and transforming low quality biomass resources into concentrated high quality energy forms. However, the energy lost throughout this transformation process and the financial investment in doing so often leads to non-viable projects. 
Table 1.10. Suitability of biomass resources for bioenergy applications

\begin{tabular}{|c|l|l|}
\hline Resource Quality & \multicolumn{1}{|c|}{ Resource } & \multicolumn{1}{|c|}{ Limitations } \\
\hline \multirow{4}{*}{ High } & Wood & \\
\cline { 2 - 3 } & Bagasse & High water content \\
\cline { 2 - 3 } & Coconut shells & \\
\hline \hline \multirow{5}{*}{ Medium } & Rice hulls & High ash \\
\cline { 2 - 3 } & Sugarcane trash & $\begin{array}{l}\text { High potassium and chlorine, moderate } \\
\text { retrieval cost }\end{array}$ \\
\cline { 2 - 3 } & Coconut husks & High retrieval costs \\
\cline { 2 - 3 } & Napier grass & High potassium and chlorine \\
\cline { 2 - 3 } & Maize cobs & High retrieval cost \\
\hline \hline \multirow{2}{*}{ Low } & Coconut fronds & High retrieval cost \\
\cline { 2 - 3 } & Rice straw & High retrieval cost, high ash \\
\hline
\end{tabular}

In the Philippines, existing biomass supplies offer little opportunity to secure additional high quality resources for bioenergy production. Countrywide deforestation, the full utilization of sugarcane bagasse, and the widespread use of coconut shell resources for the production of charcoal have lead to a situation where there is no surplus of any high quality biomass resources for bioenergy applications. Introducing more efficient wood stoves, as well as improved sugar mill boilers and coconut charcoal making equipment could extend the utilization of these resources. Establishing efficient cultural practices and improved plant materials for the production of fast growing trees and sugarcane could also be another strategy to increase supplies of high quality biomass resources in the Philippines. Wood and sugarcane bagasse are the most valuable resources for power generation as they are the easiest to burn.

Medium grade biomass resources in the Philippines have significant bioenergy potential. These resources are best suited for low-grade heat applications using simple equipment for cooking and crop drying. Using these resources in complex power generation may lead to combustion problems.

\begin{tabular}{|c|c|c|c|c|c|c|c|c|c|c|}
\hline \multirow{2}{*}{$\begin{array}{l}\text { Ultimate } \\
\text { (wt \%) }\end{array}$} & \multicolumn{2}{|c|}{ Sugarcane } & \multicolumn{2}{|c|}{ Rice } & \multicolumn{2}{|c|}{ Maize } & \multirow{2}{*}{$\begin{array}{c}\text { Wood } \\
\text { Residues }\end{array}$} & \multirow{2}{*}{$\begin{array}{l}\text { Napier } \\
\text { Grass }\end{array}$} & \multicolumn{2}{|c|}{ Coconut } \\
\hline & Bagasse & Trash & Hulls & Straw & Stover & Cobs & & & Shells & |Husk \\
\hline $\begin{array}{l}\mathrm{HHV}=\text { heat } \\
\text { value or } \\
\text { energy } \\
\text { content } \\
\text { (GJ/tonne) }\end{array}$ & $\overline{17.9}$ & $\overline{18.1}$ & 16.1 & 16.3 & $\overline{17.7}$ & 17.0 & 20.0 & 18.2 & 18.1 & 18.6 \\
\hline $\begin{array}{l}\text { Moisture } \\
\text { Content (\%) }\end{array}$ & 50 & 15 & 9 & 14 & 15 & 10 & $15-50$ & 15 & 10 & 10 \\
\hline Nitrogen & 0.1 & 0.5 & 0.4 & 0.7 & 0.6 & 0.6 & 0.1 & 0.6 & & \\
\hline Ash & 5.8 & 5.0 & 17.9 & 13.4 & 5.6 & 6.8 & 0.3 & 3.9 & 1.0 & 6.0 \\
\hline
\end{tabular}

Adapted from Kinoshita et al., 1998; Beagle et al. 1978. 


\subsection{Outlook for Biomass Resources in the Philippines}

The Philippines have almost completed a country-wide energy transition from fuel derived from primary forests to fuel derived from agricultural lands. With rising oil prices, medium grade biomass resources such as rice hulls and sugar cane trash are the main biomass resources now available for utilization. In the future there will be a need for increased utilization of agro-forestry plantings and napier grass to ensure a dramatic increase in the biomass energy supply available to the nation. There is an impending need to invest in research for increasing productivity of these dedicated energy crops. With low prices for food commodities, increased use of the land for bioenergy production may be advantageous.

There is limited advantage for farmers to grow yellow grain maize to develop a feed grain-based livestock industry in the country. Much of current feed industry is based on low yielding mono-culture maize production on marginal soils with high erosion. These marginal lands could be used more productively if some of the landscape was converted to the production of perennial biomass energy crops. Production of one hundred thousand hectares of napier grass yielding 20 ODT/ha could produce the equivalent of approximately 6 million barrels of oil energy equivalent worth an estimated 180 million US dollars. Each hectare of land would save the nation $\$ 1800$ in oil imports if it could be used to directly displace oil in boiler fuel or crop drying applications. If the grass were pelleted, it could replace all the LPG used in the Philippines for household cooking (Chapter 2). The savings in LPG use would represent $\$ 58$ US/household or a total of $\$ 290$ million US per year (12.8 billion pesos per year) in LPG imports. Such a land use policy would enable each hectare to provide foreign exchange savings of $\$ 2900$. Under current land management, harvesting 1.7 tonnes of maize grain crops per year (the national average) would only produce a gross revenue of approximately $\$ 275 /$ ha (3.4 tonne at $\$ 80 /$ tonne) at current grain prices. It is evident that there is no comparative advantage in growing grain maize for feeding livestock in the Philippines and that bioenergy could be viable as an alternative land use policy. 


\subsection{References}

Adegbola, A. 1964. "Forage crop research and development in Nigeria." Nigerian Agric. J. , 59: 450-453, cited in "Tropical Grasses." (1990). FAO Plant Production and Protection Series \#23.

Barnard, C. 1969. "Herbage plant species." Aust. Herbage Plant Registration Authority; Canberra, CSIRO Aust., Divn of Plant Ind., cited in "Tropical Grasses." (1990). FAO Plant Production and Protection Series \#23.

BAS Cereal Statistics Section = Bureau of Agricultural Statistics, Department of Agriculture, Rep. of the Philipines 2001. Website http://www.da.gov.ph.

Beagle. E.C. 1978. Rice Husk: Conversion to energy. Agricultural Services Division, Food and Agriculture Organization of the United Nations. ISBN 92-5-100340-8, 174pp.

Caccam, M. 2000. The Maize Industry and GATT. Paper submitted to the Dept. of Agronomy, College of Agriculture, U.P. Los Baños, Laguna, Phil. $46 \mathrm{p}$.

Department of Energy, Republic of the Philippines. 1995. 1995 Household Energy Consumption Survey. Main Report and Annexes. p. 192.

FAO Statistics. 2000. http://apps.fao.org/

Ferraris, R. and G. Stewart. 1979. "Agronomic assessment of Pennisetum purpureum cultivars for agroindustrial application." Field Crops Research, 2: 45-54.

Grof, B.1981. "The performance of Andropogon gayanus-legume associations in Columbia." J. Agric. Sci. Camb, 96: 233-237.

Hanna, W., and W. Monson. 1986. "Dry matter yield and in vitro dry matter digestibility of winterhardy Panicum maximum Jacq. selections." Trop. Agric. (Trinidad), 63:101104.

Hendy, K. 1975 "Review of natural pastures and their management problems on the north coast of Tanzania." E. Afric. Agric. For. J., 41:52-57, cited in "Tropical Grasses." (1990). FAO Plant Production and Protection Series \#23.

Jenkins, B.M., R.R. Bakker, R.B. Williams, L.L. Baxter, S. Q. Turn, P. Thy, C. Lesher, G. Sclippa, and C. Kinoshita. 1997 "Measurements of the fouling and slagging characteristics of banagrass (Pennisetum purpureum) following aqueous extraction of inorganic constituents." Making a Business from Biomass. 1:705718.

Kinoshita, C., D. Ishimura, S. Turn, J. Zhou, J. Tantlinger, and M. Kaya. 1998. "Availability and Suitability of Bioresidues for Electric Power Generation in Asia." New and Renewable Energy Conference, June 25-26, Manila, Philippines, p. 3.

Mehdi B., C. Madramootoo, and G. Mehuys. 1999. "Yields and nitrogen content of maize under different tillage practices." Agron. J. 91:631-636. 
Mendoza, T.C. and R. Samson. 2000. Estimates of $\mathrm{CO}_{2}$ production from the burning of crop residues. Environmental Science and Management 3(1): 25-33.

Mendoza, T.C. and R. Samson. 1999. "Strategies to avoid crop residue burning in the Philippine context." Prepared for Frostbites and Sunburns: Canadian International Initiatives Toward Mitigating Global Climate Change, April 24-May2, 1999, San Salvador, El Salvador.

Middleton, C., and T. McCosker. 1975. T.H. "Makueni, a new Guinea grass for north Queensland." Queensland Agric. J. 101: 351-355.

Mislevy, P., and R.C. Fluck. 1993. In "Energy from Biomass and Wastes XVI." (D.L. Klass, ed.) p. 479. Institute of Gas Technology, Chicago.

Omaliko,C.P.E. 1980. "Influence of initial cutting date and cutting frequency on yield and quality of star, elephant and guinea grass." Grass and Forage Science, 35: 139145.

PBEL, 2001. Biomass Atlas of the Philippines, Philippine Biomass Energy Laboratory Final Report to the National Renewable Energy Laboratory and United States Agency for International Development.

Pennington, M., I. Lacrose, and A.D.C. Gonzales. 1996, Economic, Technological and Financial Issues related to Energy Generation in the Philippine Sugar Industry. Proc. $43^{\text {rd }}$ PHILSUTECH Annual Convention. August 6-8, Cebu city, Philipppines.

Philippine Recommendations for Coconut. 1989. Philippine Council for Agriculture and Resources Research and development Los Banos, Laguna, Philippines.

Philippine Sugar Statistics 1993-1998. Sugar Statistics and Monitoring Division, Planning and International Sugar Affairs Office, Sugar Regulatory Authority (SRA).

Prine, G.M. 2000. Personal communication.

Prine, G. M., and K.R. Woodard. 1994. "Herbaceous energy crops in humid lower South USA." First Biomass Conference of the Americas: Energy, Environment, Agriculture and Industry. 1: 278-283.

Roberts, O.T. 1970. "A review of pasture species in Fiji. I. Grasses." Trop. Grassl., 4: 129-137. cited in "Tropical Grasses." (1990). FAO Plant Production and Protection Series \#23.

Romney, D.H. 1961. "Productivity of pasture in British Honduras. II. Pangola pasture." Trop. Agric (Trinidad). 38: 39-47. cited in "Tropical Grasses." (1990). FAO Plant Production and Protection Series \#23.

Samson. E. 2000. Application of Total Quality Management in Sugarcane Production Systems. PhD Thesis in progress. Dept. of Agronomy, College of Agriculture, U.P Los Banos, Laguna, Phil. 
Singh, D., V. Singh, and P. Sale. 1995. "Effect of cutting management on yield and quality of different selections of Guinea grass [Panicum macimum (Jacq.) L.] in a humid subtropical environment." Trop. Agric. (Trinidad) 72:181-187.

Soerjani, M. 1970. "Alang-Alang. Pattern of growth as related to the problem of control." Bojor, Indonesia, SEAMEO Regional Center for Tropical Biology. Biotrop. Bull. No.1., cited in "Tropical Grasses." (1990). FAO Plant Production and Protection Series \#23.

Strickter, J.A., G.M. Prine, K. R. Woodard, D.L. Anderson, D. B. Shibles, and T. C. Riddle. 1993. Production of biomass/energy crops on phosphatic clay soils in central Florida. Proc. First Conference of the Americas: Energy, Environment, Agriculture and Industry. 1: 254-259.

Vergara, T. T. 1998. Categorization of Rice milling Capability in the Philippines: A Preliminary Survey. National Food Authority, Quezon City, Philippines.

Vincete-Chandler, J. S. Silva, and J. Figarella. 1959. "The effect of nitrogen fertilization and frequency of cutting on the yield and composition of three tropical grasses." Argon. J., 43: 291-296.

Williams, C. 1980. "Fertilizer response of napier grass under different soil conditions in Brunei." Expl. Agric, 16:415-423.

Woodard, K.R., and G. M. Prine, 1993. "Dry matter accumulation of elephantgrass, energycane and elephant millet in a subtropical climate." Crop. Sci., 33: 818824. 


\title{
Chapter 2
}

\section{Promoting Biomass Utilization in Agricultural Processing and in the Home}

\author{
R. Samson ${ }^{1}$, D. Stohl', A. Elepano ${ }^{1}$, and A. De Maio ${ }^{1}$ \\ ${ }^{1}$ Resource Efficient Agricultural Production (REAP) Canada \\ Box 125, Ste. Anne de Bellevue, Quebec, Canada H9X3V9 \\ Tel. (514) 398-7743, Fax (514) 398-7972 \\ REAP@Interlink.net, www.reap.ca \\ ${ }^{2}$ College of Engineering and Agro-Industrial Technology \\ U.P. Los Baños, College, Laguna, Philippines \\ Tel (049) 936-3291 \\ are@mudspring.uplb.edu.ph
}




\section{EXECUTIVE SUMMARY}

To optimize the potential of biomass resources in the Philippines, efficient technologies need to be developed for household cooking, crop drying, and power co-generation. An overview is presented to describe the role of biomass in creating a more sustainable energy economy.

Biomass could be used in household cooking and in power generation for agricultural processing. The potential to dedicate land specifically to biomass production is limited by the availability of surplus land. With current residue production levels, biomass could supply approximately $160 \mathrm{MW}$ to the nation (ESMAP 1993), representing $1 \%$ of the total supply by 2004 . However, the comparative advantage of using biomass in this market is restricted, as the material appears to have higher value for other markets such as fuelwood for cooking, activated charcoal, or building materials. In the household-cooking sector, wood use is on the decline because prices are rising and deforestation is severe. In the Philippines, households are using more convenient fuels such as LPG and kerosene, or they are switching to crop residues for cooking. There is a need to develop efficient, clean burning biofuel cooking-systems and dedicated biomass energy crops as fuel sources to prevent additional consumption of imported LPG and kerosene.

An improved rice hull cooker, the LT-2000 Multi-Fuel Stove, is able to utilize various agricultural residues (rice hulls, maize cobs, coconut husks). The introduction of one million stoves to the Philippines could replace the equivalent of 2 million tonnes of fuel wood per year. The stove has the lowest annualized cooking cost of all cooking systems using purchased fuel. The second opportunity identified was a pellet fuel stove for people residing in cities and towns near agricultural areas. Using sugar cane trash, napier grass, or wood residues as a biofuel, these stoves could have a projected annual fuel cost $30 \%$ below that of LPG while providing the same user convenience. Advances in pelleting technologies will enhance the potential for widespread introduction of pellet fuel cook stoves in the future. Pellet furnaces can also be used for crop drying and commercial applications such as baking and food processing.

Biomass energy could also aid in modernizing the agricultural economy. Sugarcane, coconut, and rice processing demand large amounts of energy and produce substantial amounts of energy rich by-products. Uutilized these residues could make processing industries largely energy self-reliant.

Biomass can play a major role in helping reduce oil imports if efficient biomass energy conversion technologies are developed. The most appropriate role for biomass appears to be as a low-grade heat source. Improved biomass cookers and new cooking fuels could have a dramatic impact. Health improvements, reduced ecological impact on the landscape and biosphere, and an effective response to the economic crisis within the country by creating employment and displacing imported goods and fuels, can be facilitated by the increased utilization of biofuels. 


\subsection{General Overview of Biomass Energy Utilization in the Philippines}

Biomass largely provided the energy requirements of the Philippines when tropical forests covered the islands and the population was modest. At the beginning of the $21^{\text {st }}$ century, biomass energy still plays a vital role in the nation's energy supply. Nearly $30 \%$ of the energy for the 80 million people living in the Philippines comes from biomass. Most is used for household cooking by the rural poor. More than half of Philippine households have an income level under 5000 pesos per month (Department of Energy 1995) and will probably have little choice but to continue using biomass fuels in the future. There is an urgent need to assess and develop new options for modernizing the role of biomass in the Philippine energy economy. With rising fossil fuel prices, demand for both forest and agricultural biomass resources will increase. To lessen the environmental impact from overexploitation of these resources sustainable utilization strategies need to be explored.

The Philippines is among the most vulnerable nations with regard to climatic instability and experiences some of the largest crop losses due to violent climatic events. As a result, the country has strong self-interest in advancing GHGfriendly technologies such as biofuels. The Philippines could become a model for other developing nations to follow, with a broad portfolio of renewable energy sources.

\section{Primary Energy Mix of the Philippines}

Biomass currently represents approximately $29 \%$ of primary energy consumption (Figure 2.1). Wood supplies an estimated $60 \%$ of this energy, with agricultural residues from sugarcane, rice, and coconut industries supplying the remainder. Biomass energy contributes approximately twice as much energy as other indigenous energy supplies in the Philippines, including coal, hydro, and geothermal energy.

Biomass energy plays an important role in reducing oil imports, particularly since oil prices have risen. Approximately $80 \%$ of the coal and $100 \%$ of the oil used in the Philippines is imported. Oil intensifies the detrimental impacts on the trade balance of the Philippines as 125 million barrels of fossil fuels are imported each year, representing more than 3.5 billion dollars. The use of imported coal for power generation is also increasing, and currently represents about $10 \%$ of imported oil energy. 
Figure 2.1. Biomass Share of the Primary Energy Mix of the Philippines (1998)

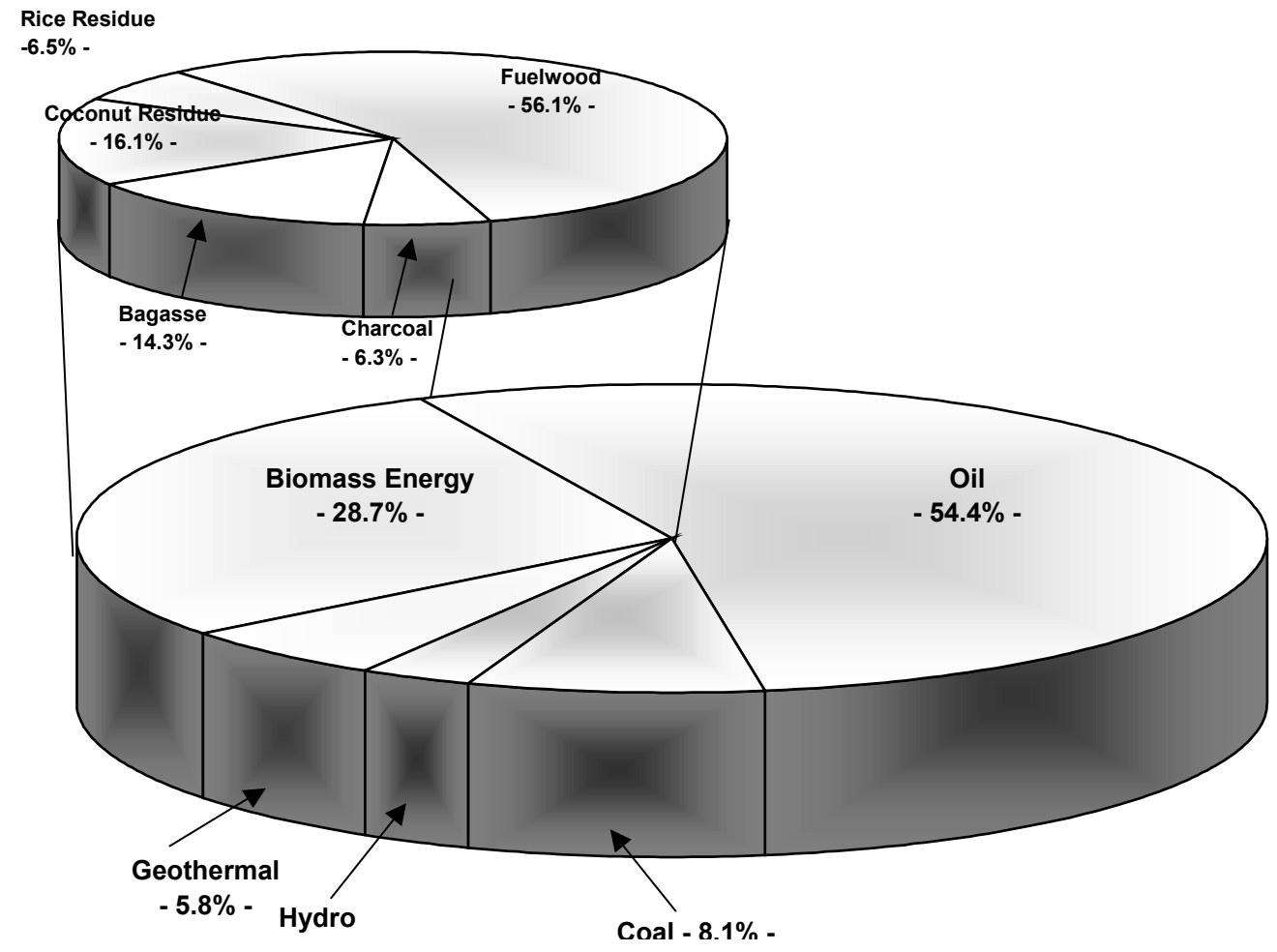

Source: Philippines Energy Plan 1999-2008.

In 1999 , diesel and fuel oil represented $34 \%$ and $28 \%$ of the major petroleum imports, respectively (Figure 2.2). Among petroleum products, demand for LPG is expected to increase the fastest, with $10 \%$ growth per annum expected until 2008 (Philippines Energy Plan 1999). Demand will be driven primarily by increased use of LPG for household cooking. Growth of kerosene use is expected to be slower, as it will be replaced by electricity in lighting applications and LPG in cooking. Large natural gas fields off the Island of Palawan are currently under development and will begin production by 2002; natural gas is expected to displace oil for power generation in the future.

Potential exists to develop a larger, renewable energy base for power generation in the future (Figure 2.3). In particular, hydro and geothermal energy sources show promise for future expansion. Hydropower production (including mini- and micro-production) has a target of 4025 MW for 2008 (Philippines Energy Plan 1999), with a total power production potential of approximately $5000 \mathrm{MW}$ for geothermal energy. An additional 70,000 MW could be supplied from wind energy (ASEAN 2000). Solar energy also holds potential, particularly for remote sites. 
Figure 2.2. Petroleum product demand in the Philippines (1999)

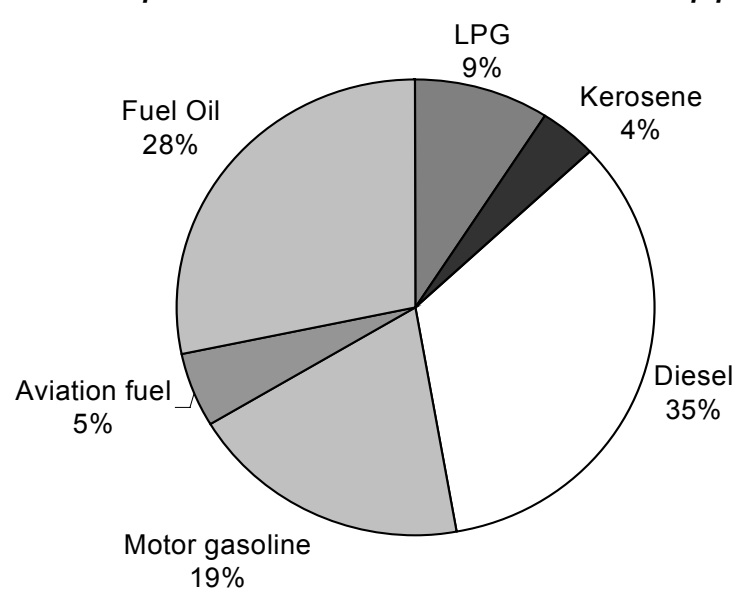

Source: Philippine Energy Plan 1999-2008.

Figure 2.3. Energy sources in the Philippines (1998 and 2002)

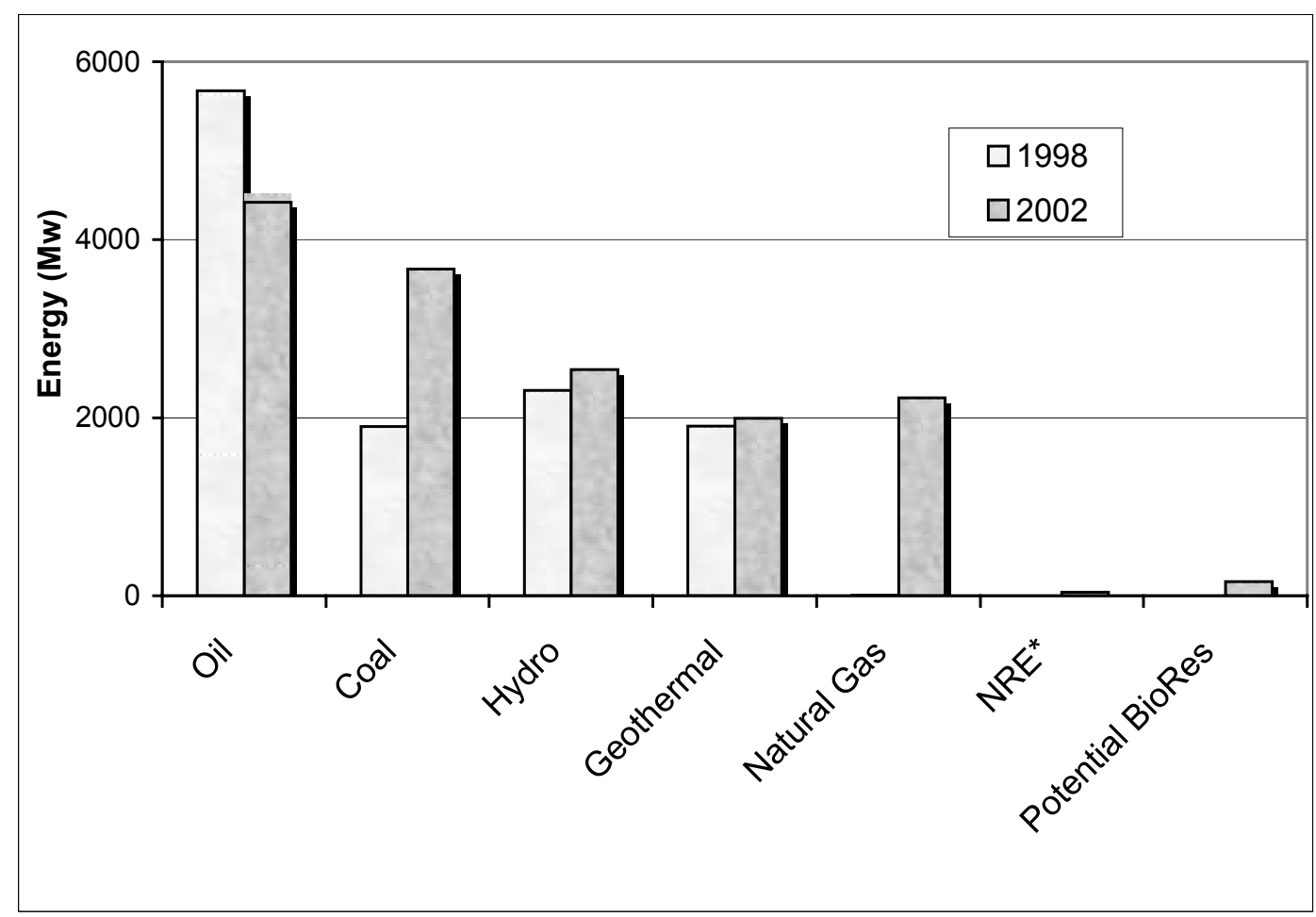

*New and renewable energy

Sources: ESMAP, 1993, Philippines Energy Plan 1999-2008 
Relative to hydro, geothermal, wind, and solar energy sources, the potential impact to the electrical power supply from biomass power production in the Philippines is limited. With current crop residue production levels, biomass could supply approximately 160 MW to the power grid (ESMAP, 1993), representing 1\% of the energy supply by 2004 . Furthermore, the advantage of using biomass in this market is restricted, as the material appears to have higher value for other markets such as firewood, activated charcoal, or building materials.

Approximately $3 / 4$ of the biomass energy currently used in the Philippines is employed in the household/residential sector, with the remaining $25 \%$ dedicated to the industrial sector (Table 2.1). Overall, biomass appears to have two main uses: (1) to provide lowgrade heat for household cooking and water heating, and (2) to provide process energy for agricultural industries that generate unused crop residues. For example, bagasse and cane trash can be used to generate internal electricity and steam for sugarcane processing.

\begin{tabular}{|l|r|r|r|r||}
\hline \multicolumn{5}{|c|}{ Table 2.1. Combustion of biomass by type of application in the Philippines (1990) } \\
\hline Application & tonnes/year & $\%$ & BFOE/year & $\%$ \\
\hline \multicolumn{1}{|c|}{ RESIDENTIAL SECTOR } & 22,712 & & 63,755 & \\
\hline Cooking and water heating & 22,712 & 100 & 63,755 & 100 \\
\hline COMMERCIAL/INDUSTRIAL SECTOR & 7,118 & & 11,572 & \\
\hline Electricity generation & 6,707 & 94.2 & 10,609 & 91.5 \\
\hline Paddy drying & 204 & 2.9 & 445 & 3.8 \\
\hline Baking & 63 & 0.9 & 164 & 1.4 \\
\hline Tobacco curing & 42 & 0.6 & 108 & 0.9 \\
\hline Multi-crop dryers & 20 & 0.3 & 58 & 0.5 \\
\hline Process steam & 18 & 0.2 & 59 & 0.5 \\
\hline Sugar milling & 17 & 0.2 & 25 & 0.2 \\
\hline Cooking (furnaces) & 8 & 0.1 & 18 & 0.2 \\
\hline Pottery & 7 & 0.1 & 19 & 0.2 \\
\hline Lime Factory & 7 & 0.1 & 19 & 0.2 \\
\hline Start-up furnaces & 7 & 0.1 & 19 & 0.2 \\
\hline Cooking (stoves) & 7 & 0.1 & 17 & 0.1 \\
\hline Copra drying & 3 & - & 7 & 0.1 \\
\hline Others & 9 & 0.1 & 24 & 0.2 \\
\hline Sours ARREC, & & & & \\
\hline
\end{tabular}

Source: ARREEC, 1996. 
The tremendous energy requirement for low-grade heat applications in rural areas where biomass is readily available is an ideal opportunity for biofuels. Biomass meets rural energy requirements in terms of energy quality and scale, and the use of biomass in household cooking and agricultural industries will likely continue. However, with the rising population of the Philippines outpacing the nation's rate of food production, there is not enough surplus land to develop dedicated biomass energy crops for power generation. An ongoing agrarian reform program is being implemented to redistribute large farmlands to impoverished peasants. The contribution of biomass to energy generation must be balanced with other development priorities. Strategies that optimize the biomass for energy without sacrificing food security or long-term productive capacity of the soil should be favored.

\subsection{Sectoral Opportunities for Biomass Power Generation}

There has long been interest in power generation from biomass in the Philippines. In the 1970's, a program to install Dendrothermal plants to be fired with wood was implemented. Initially, the government intended to supply the wood from captive plantations managed by cooperatives of small tree farmers (Durst 1986). However, these plantations were greatly affected by high financial costs and government cuts on funding and financial aid that were a result of the economic crisis of the mid-eighties (Durst 1986). The operation of the dendrothermal power plants thus suffered from both low wood production levels and political and economical instability. Since that time, much of the focus on power generation has involved developing co-generation opportunities within the rice, coconut, and sugar cane processing industries rather than stand alone plants which have no on site biomass supply. These COGEN plants have a demand for crop processing that can utilize low-grade waste heat produced during power generation.

A number of detailed reports were produced which overviewed the COGEN opportunity, most of which were performed within the rice and sugar cane industries (ESMAP, 1993). The analyses indicated that the best opportunities lie with internal power generation requirements within the industry with some surplus. In the case of the sugar cane industry, the main opportunity is the need for a sustainable biomass fuel supply during the off-milling season to justify the investment in power co-generation at the facility (Chapter 3 ).

\section{Power Generation from Rice Hulls}

A number of studies have been performed to assess the utilization of rice hulls for power generation in the Philippines. The potential aggregate rice-hull fired capacity is estimated to be no more than 40MW (ESMAP, 1993). Compared to bagasse burning, the corrosive nature of rice hulls increases the risk associated with their use as a boiler fuel. There is need for skilled labor to operate the systems. The technology is being successfully implemented in countries such as India. (Photo 2.1, Photo 2.2). 

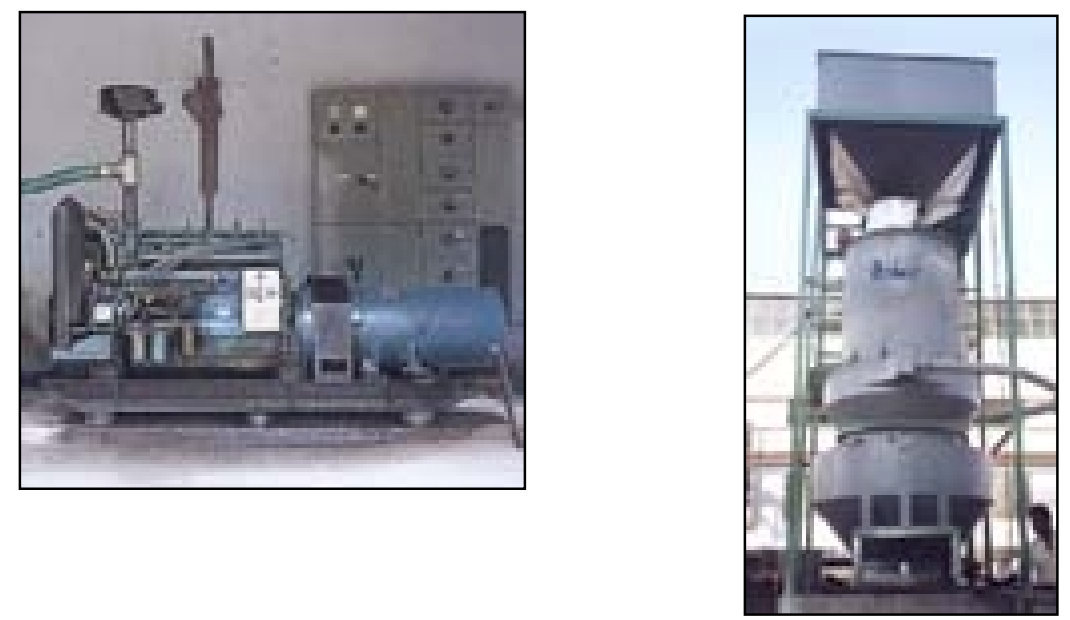

Photos 2.1 and 2.2: This $100 \mathrm{~kW}$ electric system in India is powered by rice hulls.

According to the ESMAP study (1993), the sale of rice hull ash would increase the financial return of rice hull power generation, improving the internal rate of return by $11 \%-24 \%$. To be financially viable, projects need to install a minimum of $350 \mathrm{KW}$. Presently, only systems above $500 \mathrm{KW}$ are assumed to generate sufficient power to produce surplus electricity for the grid. Most of the power from the smaller units could be used to displace diesel-generated electricity for internal plant use. The ESMAP study (1993) also indicated that because mills are normally in areas with low power demand, a sufficient load factor $(85 \%)$ could be difficult to attain.

A large $40 \mathrm{MW}$ power plant is proposed for Bulacan in 2001 (ASEAN 2000). However, a sufficient supply of rice hulls or other biomass for a plant of this size could be problematic. First, the over-loaded Philippine road network creates major logistical problems for transporting long distances. There could also be increasing demand for biomass resources such as rice hulls for cooking. If fossil fuel prices continue to climb, biomass costs could rise as a result of higher transport costs and competition from other users of the material. The increasing availability of cooking stoves and crop dryers capable of using rice hulls could make this resource disappear quickly. The disappearance of surplus bagasse in Negros (as a replacement for bunker fuel) indicates that biomass power generation could rapidly run into supply problems. Additional challenges include the seasonal availability of rice hull, creating storage problems, and increasing climatic instability. The water demanding rice crop is particularly vulnerable to droughts, and the rice hull supply could be severely restricted during these periods. The past failure of Dendrothermal plants indicates that supply problems rather than technological difficulties may be the greatest challenge for power generation from biomass.

Based on current understanding of power generation opportunities from rice hulls, one promising approach is the communal rice hull power plant (1-3 MW capacity) where rice hulls are provided by nearby plants. Waste heat produced could be used for crop drying and residual ash could be sold. A comparative evaluation study done in 1993 indicated that Cabanatuan, Isabela, had the highest rating for communal rice power production (PNOC-ERDC, 1993). 
The advantage stemmed from:

- in-plant rice hull availability

- ratio of communal power generation capacity vs. communal peak power load

- distance of participating rice mills from the pilot plant site

- access to other paddy supply

- manageability of rice mill owners

When surveyed, rice mill owners in Isabela were receptive to the idea of accessing a more reliable and cheaper source of power. Frequent power outages in the Philippines creates power shortages, which have forced some rice mills to stop operations because of the prohibitive cost of running backup diesel engines.

\section{Future outlook}

Overall the experience with biomass power generation has been one of limited success, with the exception of internal use within the sugarcane industry. Future developments are likely to be restricted to increasing bio-power use in agricultural processing facilities to reduce their dependency on the power grid. Chapter 3 examines further opportunities for bioenergy production in the sugarcane milling industry.

\subsection{Enhancing Biomass Energy Use in the Household}

\section{The Role of Biomass in Cooking at the Household Level}

To optimize biomass fuels for household cooking, it is essential that the social and economic aspects are understood. The types of foods being cooked, where cooking occurs (rural and urban areas), family economics, and health risks all play a significant role in fuel use. It is also important to consider available fuels, how these fuels are procured, recent trends in fuel use, factors people consider when choosing cooking fuels, and the availability of biofuel sources and cooking systems that can provide more economical and environmentally friendly energy for household cooking. 


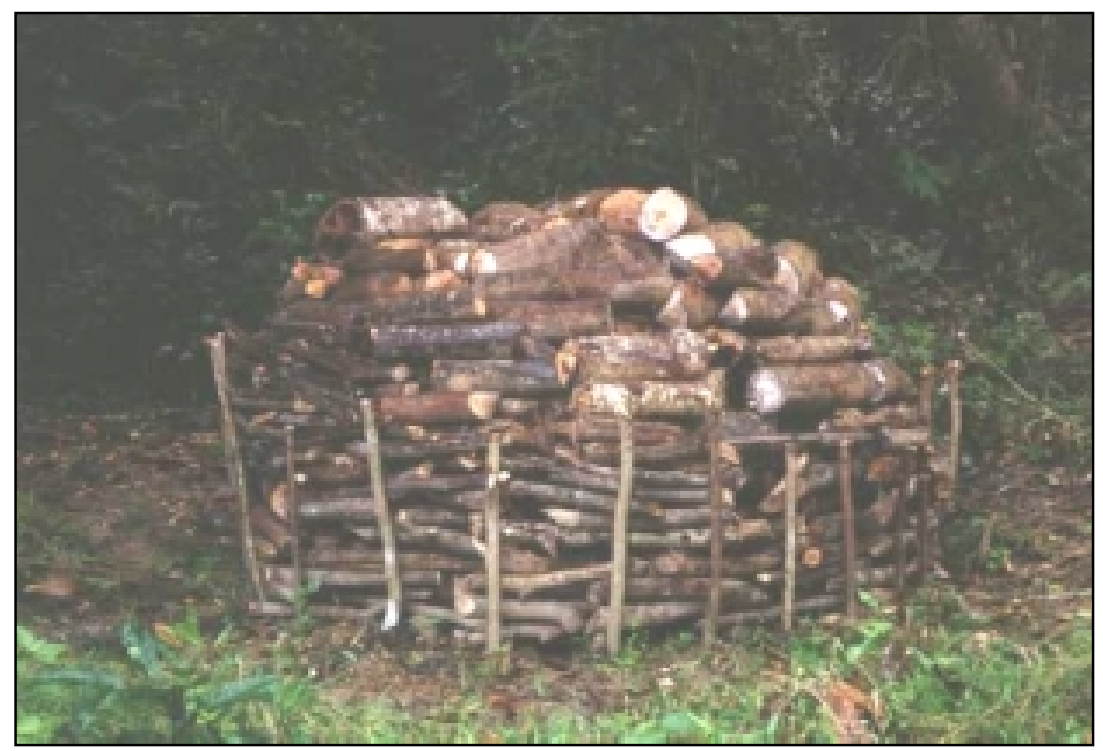

Photo 2.3. Native forests have been depleted by using wood for household cooking and by its conversion to charcoal (as shown in the above photo). Inefficient production systems and inefficient charcoal stoves mean that only about $5 \%$ of the wood energy is recovered as useful heat for cooking. There is a large, illegal charcoal trade that persists in the Philippines. Modernizing the charcoal industry and developing new cooking systems would reduce this trade.

\section{Cooking Habits in the Philippines}

The traditional Philippine diet revolves around rice, fish, and vegetables. The preferredstaple food is rice, but maize is also widely eaten in the upland regions. This is particularly true for the Central Visayas and Mindanao. Meals are generally prepared in a large aluminum pot over a biomass stove. Rice or maize is cooked first followed by vegetables which cook more quickly. Fish and meat are commonly cooked in the same pot as vegetables. Dried and fresh fish are pan-fried in oil, and fresh fish and chicken are also grilled over charcoal. Roasting maize over biomass stoves is also popular. Baking is uncommon at the household level, though Filipinos enjoy purchased baked snacks. Coffee is also very popular, and water is boiled several times per day or stored in thermoses to make instant coffee. Filipinos in urban areas and towns often purchase their noon meal at a Carenderia. These small cafeteria style restaurants usually are found in urban areas where people gather or work and can also found at rest points on rural transportation routes.

School starts early in the Philippines (often about 7:20 am) and time is valuable in the morning, particularly in rural areas where transportation time is lengthy. The weather also has an important influence on cooking because gathering dry fuewood is difficult in the rainy season. Families often supplement wood cooking with charcoal and/or use more kerosene as fire starter. Open wood fires are generally made underneath pots which are supported by steel rails (photo 2.4). Relatively simple firewood and charcoal clay stoves are also common (photo 2.5). Exposure to smoke from fuelwood stoves is high for women and children. Chimney systems are often absent or of very poor design. 


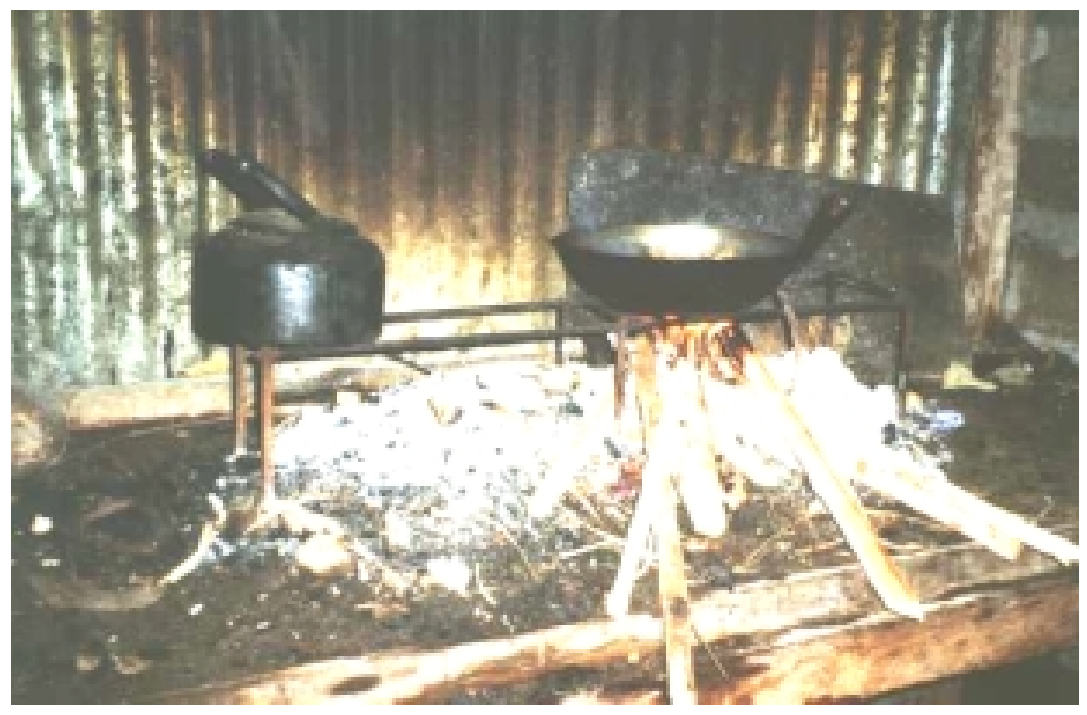

Photo 2.4. Open wood fires commonly used for household cooking have approximately $10 \%$ conversion efficiency, and are wasteful of energy during periods when low heat is required since there is no control of the oxygen supply. More efficient wood stoves are uncommon in rural households. Wood use per household is approximately 2 tonnes/year. Cooking with firewood has a tremendous impact on the landscape ecology of the nation.

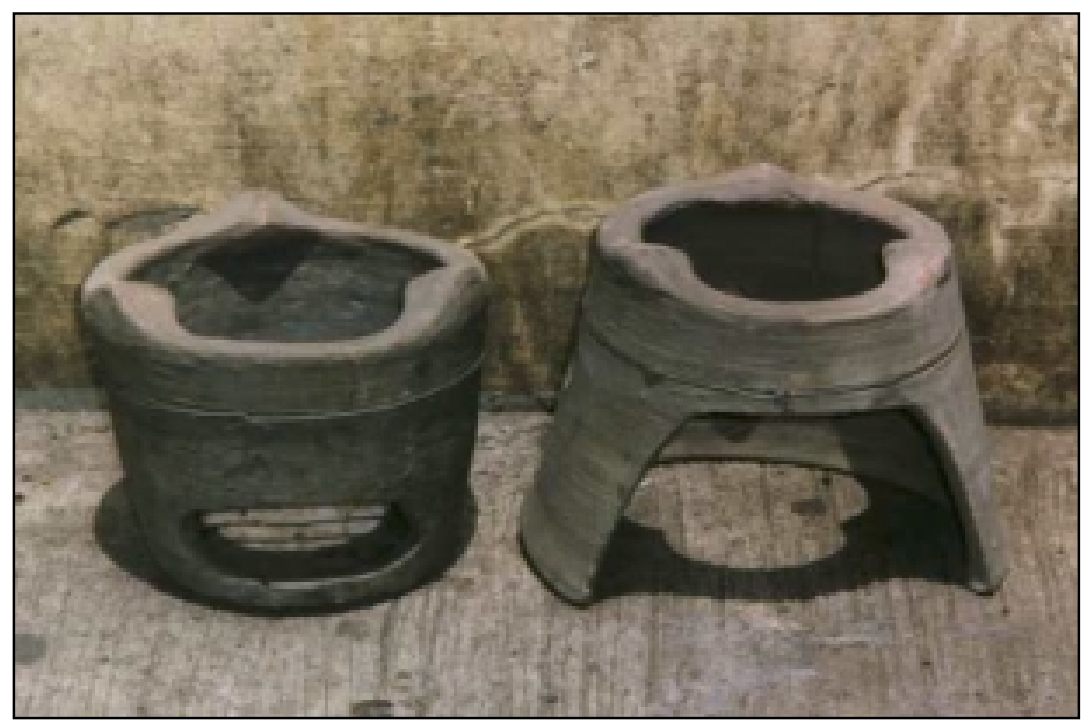

Photo 2.5. Simple clay stoves for charcoal and firewood are available in markets in the Visayas 


\subsection{Main Fuels Used in the Philippines}

The main cooking fuels used in the Philippines include agricultural residues, fuelwood, charcoal, LPG, and kerosene.

Agricultural residues are defined as any agricultural byproducts such as coconut husks and shells, rice hulls, or maize cobs and stalks. These materials are often dumped into waste areas, left to rot or burned in the fields. Increasingly, these residues are being used for cooking fuels as wood supplies tighten and fossil fuel prices increase.

Fuelwood refers to any wood product directly burned. Wood is the backbone of the rural energy economy and is still used in urban areas in surprisingly large quantities. The main source of fuelwood was once tropical forests, but this land is now used for agriculture. Frequently trees such as leucaena and gliricidia are grown on farms for fuelwood purposes and branches and prunings of gmelina trees and fruit trees are also widely used. In 1998, fuelwood comprised $16.1 \%$ of the total fuel used in the Philippines, which equates to 38.3 million BFOE.

Charcoal is a wood or plant product burnt into a porous carbon mass. In the Philippines, it is now mainly produced from leucaena in upland sloping areas. Charcoal is more easily transported than wood from remote hill areas. It is widely used for grilling certain foods and is preferred in urban areas as it emits less smoke than wood.

Liquid petroleum gas (LPG) or propane is becoming a more popular fuel choice, especially in countries with large urban areas and rising income levels. It is popular with middle and upper income families because it is a clean burning and quick cooking compressed gas with an adjustable heat output.

Kerosene is commonly used as a cooking fuel by the urban poor. It is also widely used in rural areas for lighting and fire starting. As a cooking fuel it has a relatively flexible heat output and is fast cooking, but is less user friendly because it gives off more noxious fumes than LPG. 


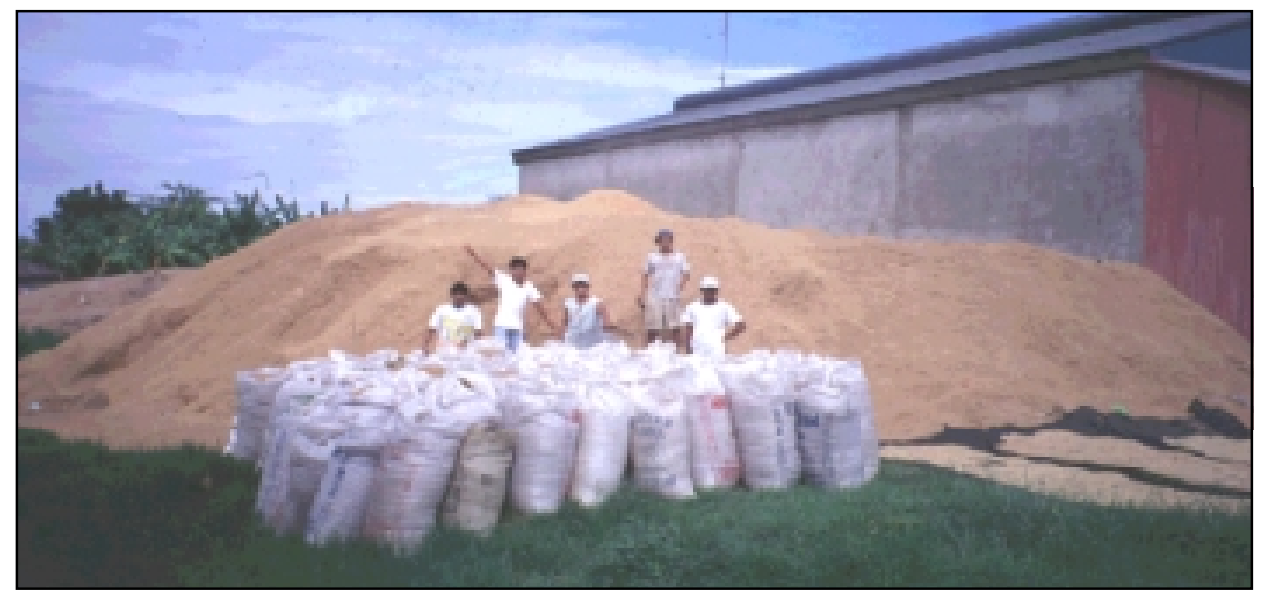

Photo 2.6. Rice hulls are an unused residue at most rice mills that can be recycled for household cooking. About 1.5 million tonnes of rice hulls are available in the Philippines.

\section{Present Use of Cooking Fuels at the Household Level}

The Philippines is typical of many developing countries where the majority of the population has a low income and the middle class is small. In 1995 there were $12,821,000$ households in the Philippines, with $57 \%$ in the lowest income bracket (less than 5000 pesos/month) (Table 2.2). Unfortunately, the 1995 Philippine household survey combined $57 \%$ of the population into one income category, limiting a more detailed understanding of fuel choice relative to income level. Nonetheless, the household survey provides some valuable insights into the fuel choices made by the general populace.

\begin{tabular}{|l|c|c|}
\hline \multicolumn{3}{|l|}{$\begin{array}{l}\text { Table 2.2. Number of households in the Philippines by income } \\
\text { class (1995)(Philippine Energy Plan: 1999-2008) }\end{array}$} \\
\hline $\begin{array}{l}\text { Monthly Income Class } \\
\text { (pesos/month) }\end{array}$ & $\begin{array}{c}\text { Total Number of } \\
\text { Households ('000) }\end{array}$ & $\begin{array}{c}\text { Percentage of Total } \\
\text { Population }\end{array}$ \\
\hline Total population & 12,821 & 100 \\
\hline Less than 5,000 & 7,263 & 57 \\
\hline $5,000-9,999$ & 3,238 & 25 \\
\hline $10,000-14,999$ & 1,173 & 9 \\
\hline $15,000-24,999$ & 666 & 5 \\
\hline More than 25,000 & 466 & 4 \\
\hline
\end{tabular}

\section{Rural Household Cooking}

In the rural sector, the greatest use of fuelwood is among households with incomes lower than 5000 Philippine pesos (Figure 2.4). Considering that the number of members in the average rural household exceeds the national average, the low cost of fuelwood makes it the most viable energy source. Fuelwood is also extremely popular among the 
higher income rural households, which can be attributed to its availability and higher quality of food taste.

The use of other fuels varies greatly among the differing income brackets. As they are readily available and inexpensive, agricultural wastes are popular for households earning less than 5000 pesos. The majority of these low-income households have little income for purchasing fuel and rely heavily on gathering firewood and biomass residues. Currently, the fuel requirement of $55 \%$ of the rural poor is supplied by firewood, with another $25 \%$ of the requirement met through biomass residues. As the Philippine landscape is becoming increasingly agricultural in nature (deforestation and land conversion have become more widespread), the rural poor will likely be driven to rely more heavily on agricultural residues for their fuel supply instead of firewood and charcoal. Biomass residues seem to be quite popular across all income brackets in rural areas due to their availability.

In terms of more modern cooking fuels, LPG seems to be predominant in those households earning more than 10,000 pesos per month with about $20 \%-25 \%$ of households using the fuel. Charcoal is not used as a principle fuel, and like kerosene, is considered a 'dirty' fuel. However it is widely used for grilling. The rural poor use the least amount of charcoal because it is expensive and they rarely have the opportunity to enjoy fresh fish and chicken. Rural charcoal consumption is about half that of urban areas.

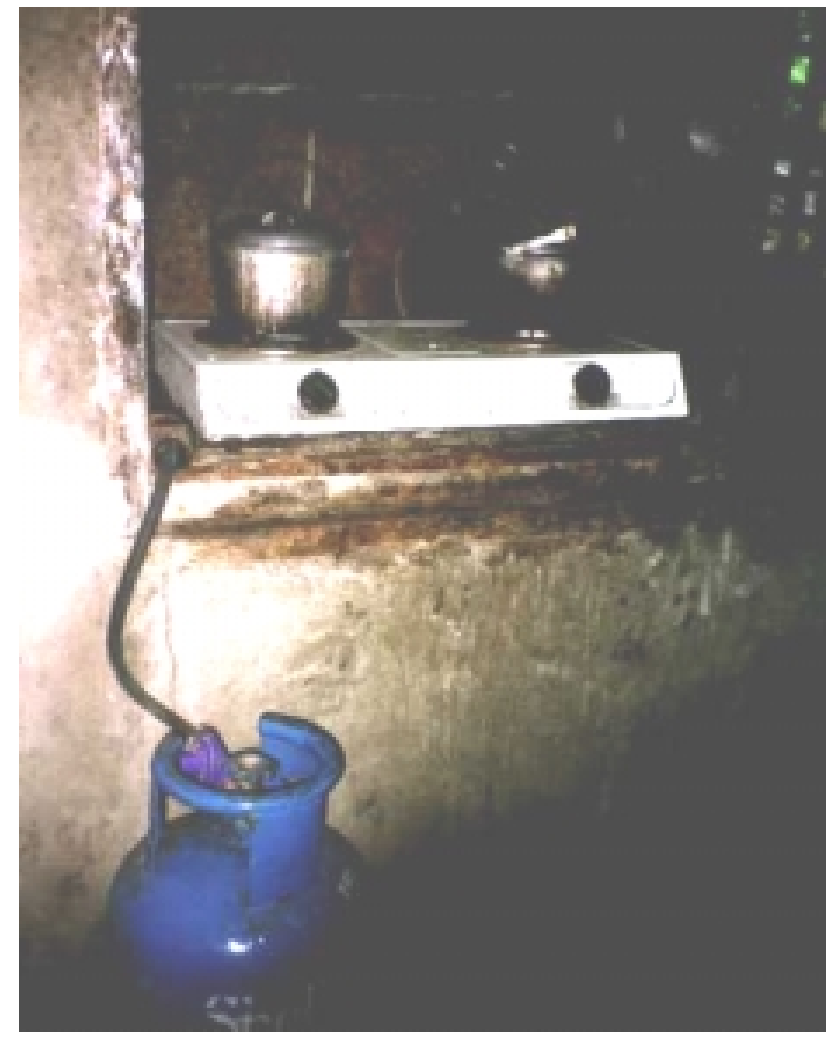

Photo 2.7. A typical LPG cooking stove with bottled gas, a system used in more than 4 million households in the Philippines. 


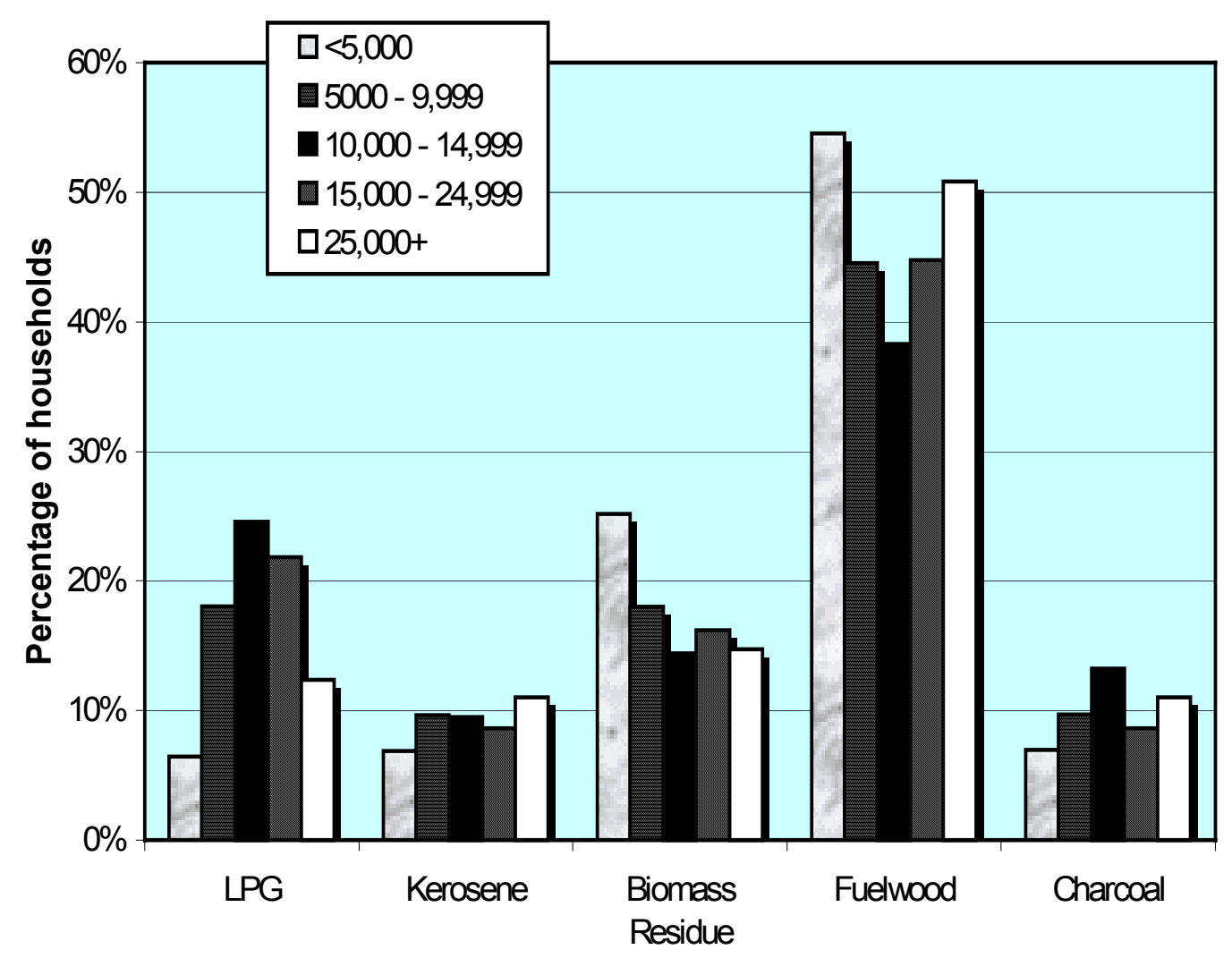

Type of fuel

Figure 2.4. Percentage of rural households using fuels for cooking by monthly income (pesos): 1995 (Philippine Energy Plan 1999-2008)

\section{Urban Household Cooking}

Cooking fuel use in the urban sector differs greatly from that of rural areas for several reasons (Figure 2.5). The primary reason is the lack of biomass available. For example, fuelwood is not as readily available in the urban market and is more expensive. However, low-income urban households rely on fuelwood and biomass residues for over $50 \%$ of their cooking fuel. A surprising $74 \%$ of these urban fuelwood users collect all of their own fuelwood. This involves scrounging for wood at construction sites, obtaining old crates at markets, and collecting any other available wood scraps. Low income households supplement their fuelwood and biomass residue use with kerosene and charcoal. All other incomes use LPG as their main cooking fuel source with over $40 \%$ of urban households earning 10,000 pesos or more per month using the fuel. Charcoal and fuelwood remain a popular secondary fuel source for all income brackets, which can be attributed to the preference for grilled foods. 


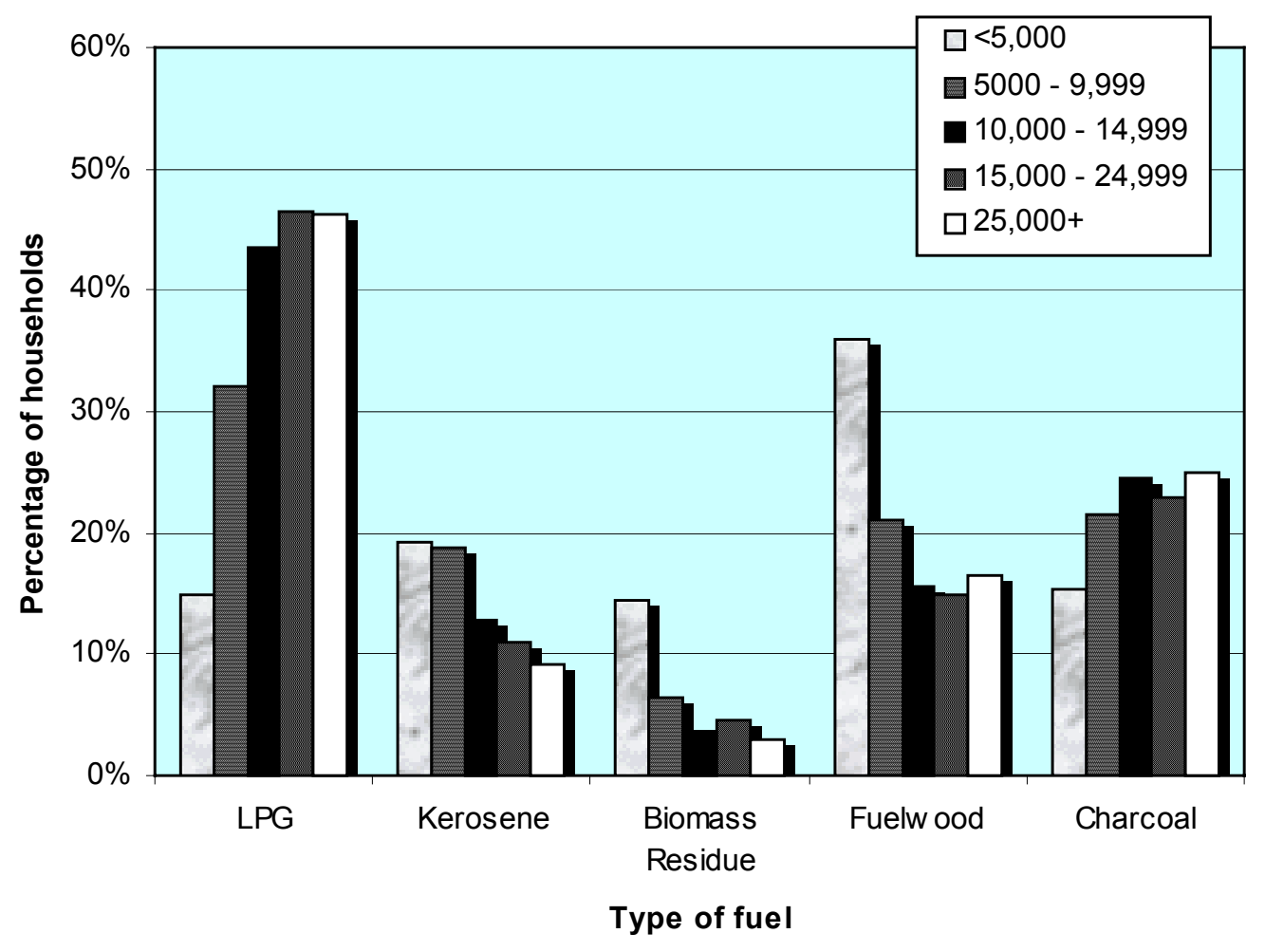

Figure 2.5. Percentage of urban households using fuels for cooking by monthly income: 1995 (Philippine Energy Plan 1999-2008)

\subsection{Recent Trends in Household Fuel Cooking}

\section{Overall Trends}

Household surveys were conducted in the Philippines to explore fuel choice in 1989 and in 1995 (Table 2.5). The surveys suggest that an increasing agricultural land base, ongoing deforestation of the uplands, and population urbanization have an important influence on household fuel use patterns. The surveys indicate an increasing trend toward LPG users and LPG consumption, and an overall decline in biomass use. Kerosene consumption also rose between the two surveys, although the number of users remained somewhat constant, and the use of kerosene for direct cooking applications comprised only about $1 / 3$ of its total use. In the biomass sector, fuelwood use declined by $20 \%$ between 1989 and 1995, charcoal fuel consumption declined by $51 \%$, and biomass residue use increased by $43 \%$. Overall biomass use decreased by $15 \%$ on a tonnage basis over the 6 years. The more widespread availability of electricity in the Philippines appears to have had minimal impact on cooking fuel choice to date.

The main reason people switched their primary cooking fuel was that new fuels were more convenient $(70 \%)$ and more widely available (56\%). Urban users also reported 
that changes in income $(47 \%)$, and higher prices of fuels $(44.9 \%)$ were also important factors. Technology for biofuels must be modernized if biomass is to remain a primary cooking fuel in the future.

\section{Specific Fuel Use Trends:}

\section{Firewood}

Firewood consumption declined from 18.3 million tonnes in 1989 to 14.6 million tonnes in 1995 (Table 2.3), while the number of users increased from 7.5 million households to 8.1 million. Average household consumption of fuelwood for cooking showed a decline in per capita consumption from $342.7 \mathrm{~kg}$ in 1989 to $327.6 \mathrm{~kg}$ in 1995 . Fuelwood was used almost exclusively for cooking in the home. Based on the 1995 household survey, dedicated rural firewood users were consuming 2.0 tonnes/household per year. This translates into an average $10 \%$ conversion efficiency if $3.17 \mathrm{GJ}$ of delivered heat were required for cooking per household (Table 2.3).

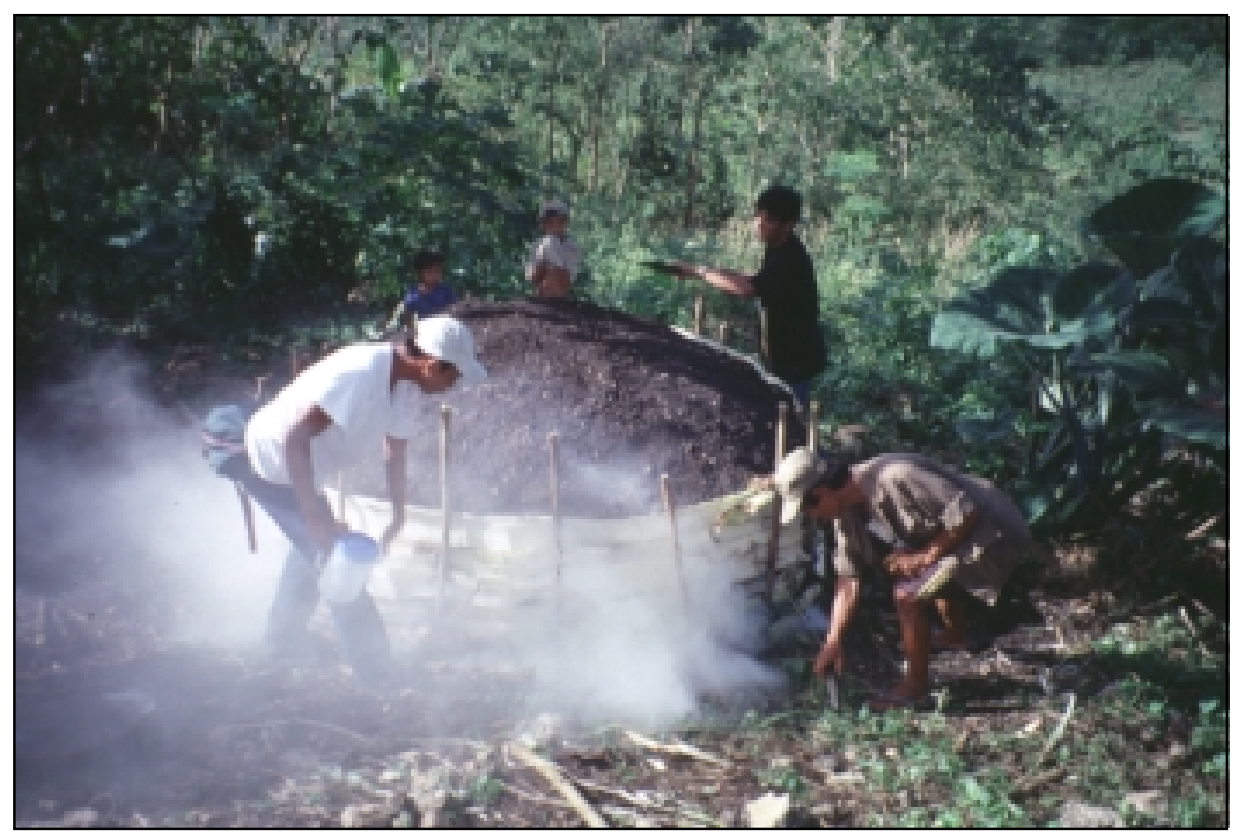

Photo 2.8. Charcoal is made by poor, small-scale upland farmers by carbonizing leucaena wood. Generally, the wood is gathered, dried and split, and placed in a shallow pit. The woodpile is wrapped with banana leaves and covered with soil or sand prior to ignition. 


\section{Charcoal}

During the 6 year period between 1989 and 1995, charcoal consumption dropped dramatically $(51 \%)$. During the same period, however, the total number of users increased by $41 \%$. Overall household consumption, therefore, dropped from an average of $445 \mathrm{~kg} / \mathrm{year}$ to $156 \mathrm{~kg} / \mathrm{yr}$. Clearly charcoal use is becoming less common as a primary cooking fuel. However, more people use charcoal as a secondary fuel, mainly for grilling. Overall, charcoal is not a fuel for the poor, but a product produced by poor upland farmers for moderate to upper income families mainly in urban areas. Only $60.8 \%$ of the charcoal used in 1995 was for cooking. Other uses were ironing and, to a lesser extent, water heating.

\section{Biomass residues}

According to the surveys, approximately $90.6 \%$ of biomass residues used for fuel are self-collected or gathered. The annual consumption of biomass residues per capita rose from $46.4 \mathrm{~kg}(1989)$ to $53.9 \mathrm{~kg}(1995)$.

Table 2.3. Household fuel use in the Philippines

\begin{tabular}{|l|c|c|c|c|c|c|}
\hline \multirow{2}{*}{ Type of fuel } & \multicolumn{4}{|c|}{1989} & \multicolumn{3}{|c|}{1995} \\
\cline { 2 - 6 } & $\begin{array}{c}\text { Number of } \\
\text { households } \\
\text { ('000) }\end{array}$ & $\begin{array}{c}\text { percentage } \\
\text { of } \\
\text { households } \\
\text { (\%) }\end{array}$ & $\begin{array}{c}\text { Bulk } \\
\text { Weight } \\
\text { ('000 } \\
\text { tonnes) }\end{array}$ & $\begin{array}{c}\text { Number of } \\
\text { households } \\
\text { ('000) }\end{array}$ & $\begin{array}{c}\text { percentage } \\
\text { of } \\
\text { households } \\
\text { (\%) }\end{array}$ & $\begin{array}{c}\text { Bulk } \\
\text { Weight } \\
\text { ('000 } \\
\text { tonnes) }\end{array}$ \\
\hline $\begin{array}{l}\text { Electricity } \\
\text { (GWh) }\end{array}$ & 7,236 & 64.7 & 6,845 & 10,760 & 83.9 & 8,134 \\
\hline $\begin{array}{l}\text { LPG } \\
\text { ('000 MT) }\end{array}$ & 2,449 & 21.9 & 321 & 4,236 & 33.0 & 503 \\
\hline $\begin{array}{l}\text { Kerosene } \\
\text { ('000 m }{ }^{3} \text { ) }\end{array}$ & 8,332 & 74.5 & 496 & 10,245 & 79.9 & 776 \\
\hline $\begin{array}{l}\text { Fuelwood } \\
\text { ('000 MT) }\end{array}$ & 7,504 & 67.1 & 18,317 & 8,142 & 63.5 & 14,557 \\
\hline $\begin{array}{l}\text { Charcoal } \\
\text { ('000 MT) }\end{array}$ & 3,509 & 32.1 & 1,565 & 4,941 & 38.5 & 770 \\
\hline $\begin{array}{l}\text { Biomass } \\
\text { residues } \\
\text { ('000 MT) }\end{array}$ & 5,189 & 46.4 & 2,570 & 3,744 & 29.2 & 3,668 \\
\hline
\end{tabular}

Source: Department of Energy, Republic of the Philippines 1995.

\section{Fossil Fuel Use Trends for Cooking}

Electricity, LPG, and kerosene are becoming more popular fuel sources in the Philippines. Between 1989 and 1995 the household utilization and the amount consumed of each of these fuels rose significantly (Table 2.3). On a household scale, the use of both LPG and kerosene increased 26\% per year between 1989 and 1995. 


\section{$L P G$}

In 1995, 491.3 million $\mathrm{kg}$ of LPG were consumed almost entirely for cooking. About $74 \%$ of the total LPG was used by urban dwellers. These same households used LPG as their primary cooking fuel source and, to a lesser extent, as a fuel for water heating. LPG has become something of a household status symbol, and its increasing popularity is largely due to the characteristics of the fuel. People view it as very convenient and clean burning relative to biomass fuels. The unpopularity of LPG in rural communities is accounted for by the lower average income and its limited availability compared to other fuel sources (i.e. fuelwood, agriwastes, charcoal). Another drawback is that initial equipment costs are quite high.

\section{Kerosene}

In 1995, total consumption of kerosene on a household scale exceeded 750 million litres. Some 4.2 million households, or about half of all firewood users, reported an average use of 58 litres per year. Two thirds of the total kerosene consumed was for heating related purposes (i.e. bath water heating, cooking, and fire starting).

The use of kerosene differs between urban and rural populations (Figure 2.6). Lighting (lamps) in rural areas accounts for $49 \%$ of the kerosene due to the lack of electricity in these communities. Fire starting accounts for $40 \%$ of the kerosene used as a result of the long rainy seasons. Rural areas generally use fuelwood, not kerosene, as their main cooking fuel. Urban use of kerosene is strongly biased towards cooking applications. Of the 400 million litres of kerosene used by the urban sector, $53 \%$ was for cooking. Lighting and fire starting accounted for $23 \%$ and $24 \%$ of use, respectively. Overall, households reported kerosene to be a somewhat unsafe, dirty fuel, but convenient to use as it accelerates fuelwood cooking.

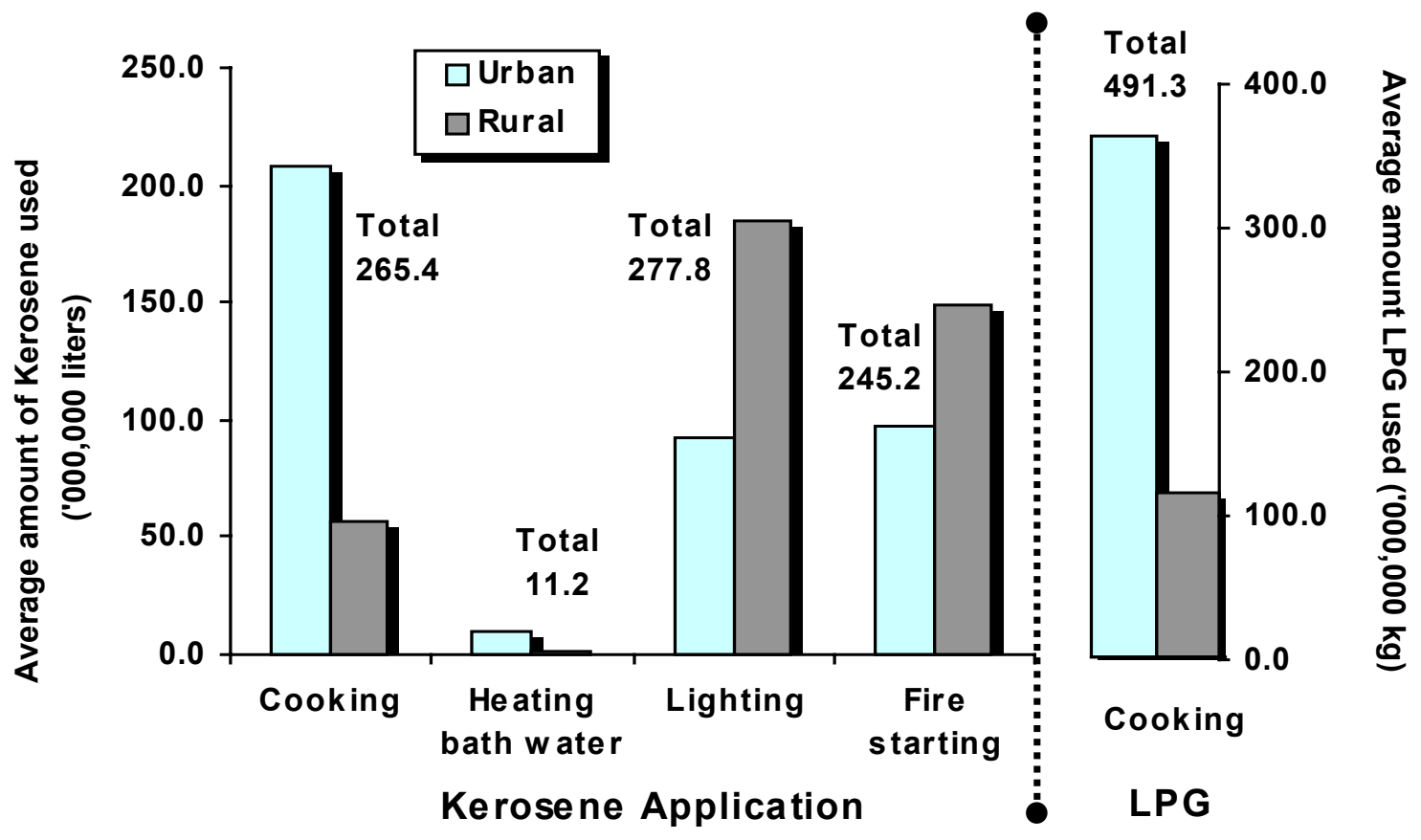

Figure 2.6. Use of kerosene and LPG in urban and rural areas. 


\section{Overall Outlook for Kerosene and LPG}

In 1986, LPG and kerosene consumption in the Philippines was 2.46 million barrels of fuel oil equivalent (MBFOE) and 2.27 MBFOE respectively. By 1998, kerosene use had increased $220 \%$ (approximately $18 \%$ per year). The $445 \%$ rise in LPG use (approximately 37\% per year) by 1998 is even more remarkable. Based on 1995 calculations, virtually all of the kerosene consumed in the Philippines is used at the household level. Similar calculations for LPG show that approximately $50 \%$ is used in households. LPG use in the Philippines has been steadily rising for approximately 12 years (Figure 2.7). Electricity should reduce the use of kerosene for lighting applications in the future, but the continuing trend towards urbanization will likely increase the demand for convenient fuels. Biomass could play a larger in household cooking and displace fossil-based fuels like LPG and kerosene if more convenient systems were available.

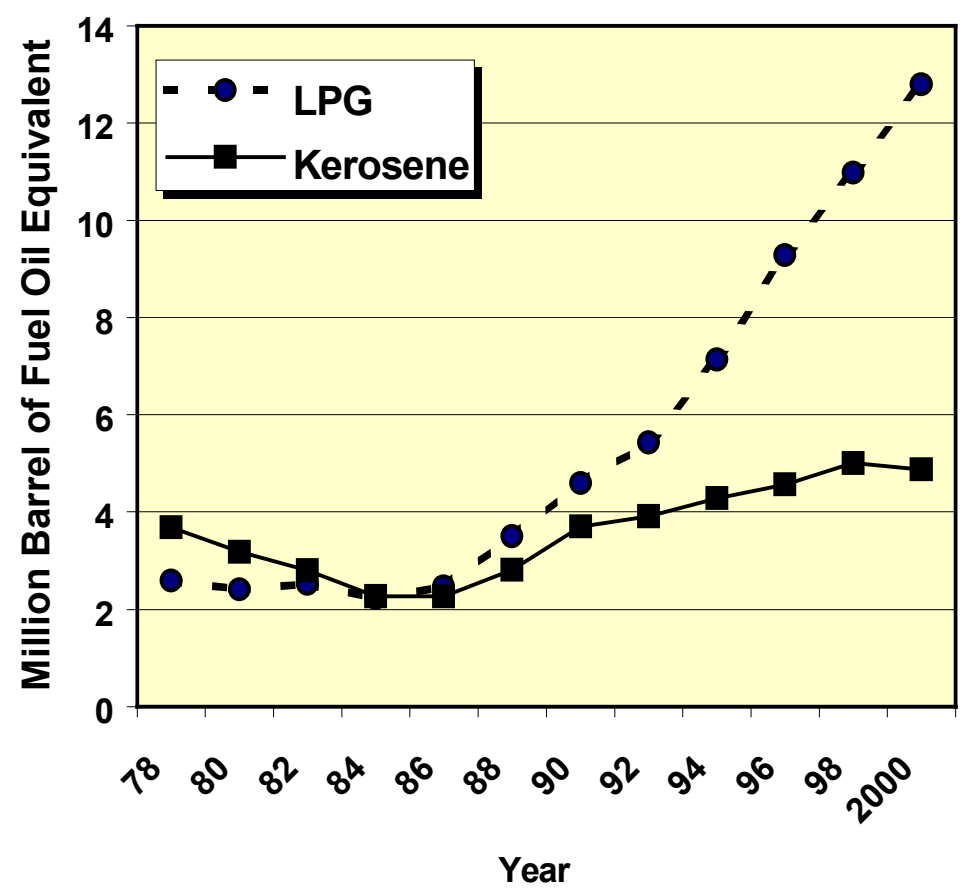

Figure 2.7. LPG and kerosene use in the Philippines (1978-2000) Source: Inquirer Philippine Daily 2000, Philippine Energy Plan 1999-2008.

\section{$\underline{2.5 \text { Economic Analysis of Cooking Fuels }}$}

\section{Financial Analysis}

Two main factors affect the cost of household cooking. First is the purchase cost of cooking equipment (Dutt and Ravindranath 1993), which usually represents a lump sum payment that acts as an obstacle for low-income households. The second factor is the annual cost of operating the fuel stove (Dutt and Ravindranath 1993). This is composed 
of the annual consumption of fuel plus the annualized cost of the cooking equipment. From a financial point of view, the annual cost of operating a fuel stove is a better parameter than the purchasing cost of the cooking equipment when comparing across different fuel stove alternatives.

\section{Purchasing Cost}

The purchasing cost of cooking stoves was determined as the market price of the stove. The market price of LPG, fuelwood, kerosene, and charcoal stoves was obtained through marketing research in the Island of Negros, Philippines. The market price of the LT-2000 Multi-Fuel stove was calculated as the cost of producing, selling, and distributing the stove plus a commercial margin (Table 2.4, Figure 2.8).

\begin{tabular}{|lc|}
\hline Table $2.4 L T-2000$ Multi-Fuel Stove Cost Breakdown \\
\hline \multicolumn{1}{|l|}{ Philippine pesos } \\
\hline Labour & $\mathrm{P} 115$ \\
Materials & $\mathrm{P} 163$ \\
Fixed & $\mathrm{P} 20$ \\
Contingency & $\mathrm{P} 35$ \\
Marketing \& margin & $\mathrm{P} 67$ \\
Total & $\mathrm{P} 400$ \\
\hline
\end{tabular}

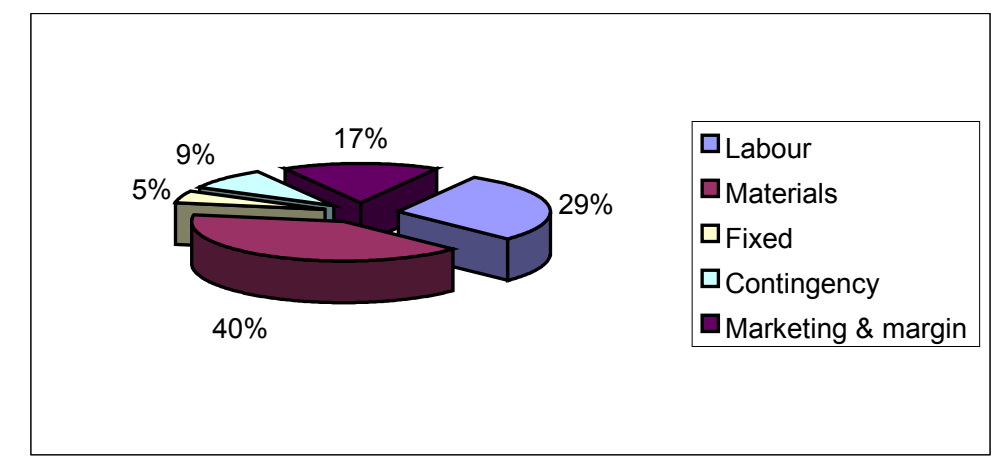

Figure 2.8: LT-2000 Multi-Fuel Stove cost breakdown

Table 2.5 and Figure 2.9 show that the LT-2000 Multi-Fuel stove is cheaper than most alternatives. $\mathrm{LPG}^{1}$ and kerosene stoves are three to seven times more expensive than rice hull stoves. Low efficiency stoves that use fuelwood and charcoal, however, are significantly cheaper (20-75\%) than the rice hull stove. Low-income households usually cannot afford to buy (or cannot access) the most efficient biomass stoves, so they use low-efficiency ones. Rice hull stoves are available at a modest cost and allow lowincome households to access a more efficient cooking system that does not require a large initial investment in equipment.

\footnotetext{
${ }^{1}$ The cost of a LPG stove includes the cost of buying one gas bottle.
} 
Table 2.5 Purchase cost of cooking equipment

\begin{tabular}{|l|c|c|c|c|c|c|c|c|c|c|}
\hline Fuel & LPG & Kerosene & Fuelwood & E-FW & H-E-FW & Charcoal & E-Charcoal & $\begin{array}{c}\text { HE- } \\
\text { Charcoal }\end{array}$ & $\begin{array}{c}\text { Rice } \\
\text { Hull }\end{array}$ & Pellet \\
\hline $\begin{array}{l}\text { Cost } \\
\text { (Pesos) }\end{array}$ & 2800 & 1200 & 115 & 315 & 800 & 115 & 315 & 800 & 400 & 1000 \\
\hline
\end{tabular}

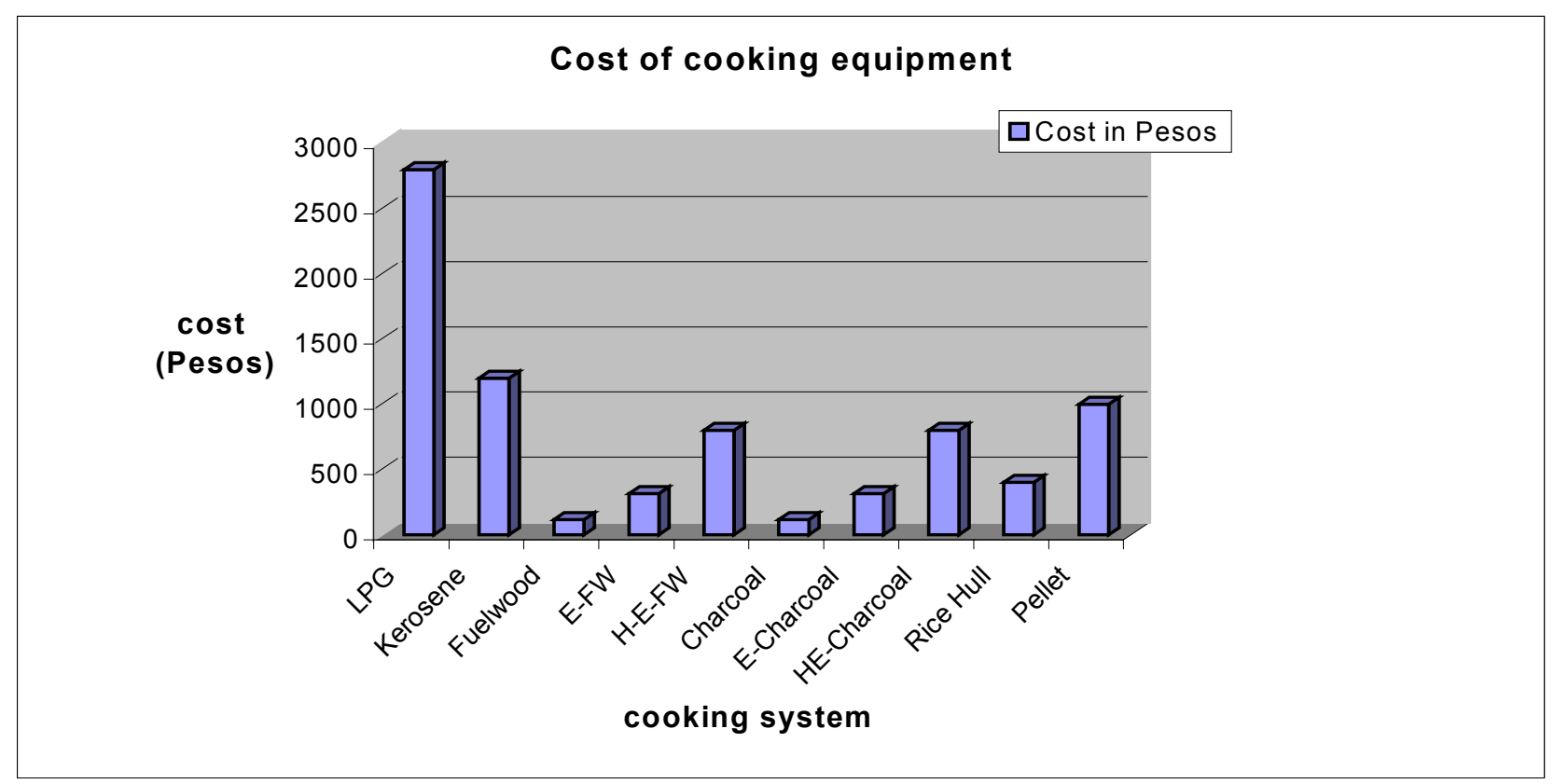

Figure 2.9 Purchase cost of cooking equipment

\section{Annual Cost of Operating Cooking Stoves}

The annual cost of operating a cooking stove has two components. The first is the cost of the fuel consumed during one year of regular use. The second component is the annualized cost of the initial investment required to purchase the cooking equipment (Appendix 2.3). The cost of fuel is determined by multiplying the quantity of fuel consumed by the price of the fuel to the consumer. Fuel consumption per year by a household was only available for LPG and fuelwood (Dept. of Energy, Republic of the Philippines 1995). 
Kerosene, charcoal, and rice hull consumption was determined analytically, using data on energy used by a household per year, energy content and thermal efficiency of the corresponding fuel, and the following equation ${ }^{2}$ :

Fuel consumption $=$ Energy used per year

Thermal efficiency $x$ Energy content

The price to the consumer of the different fuels was obtained from statistical reports (Dept. of Energy, Republic of the Philippines 1995) and from marketing research in the Island of Negros.

The type of stove and energy content of the fuel directly affect the amount of fuel consumed by a cooking system (Table 2.6). The type of stove determines the heat efficiency range and the flexibility of heat output control. Higher heat efficiency or broader capacity to control the heat output of the stove is associated with lower fuel consumption. In the Philippines, rice is simmered after boiling, and the lack of heat control makes fuelwood-cooking systems energy inefficient. LPG, kerosene, and charcoal stoves allow better control of heat output, thereby improving efficiency. Programs to improve cooking stoves (Appendix 2.1) have been widely implemented outside of the Philippines and have in many cases successfully increased the heat efficiency of cooking systems, thus decreasing the amount of fuel consumed in cooking.

The cost of an energy source per unit of energy delivered takes into account the efficiency of the cooking system as well as the fuel's energy content (Table 2.7). Fuels that have high energy content and are generally used in efficient cooking systems (LPG and kerosene) are usually more expensive than fuels with a lower energy content used in less efficient stoves (fuelwood and agricultural residues). Electricity presents a high cost per unit delivered energy because the savings due to increased efficiency and energy content are offset by higher prices. Rice hulls are a cheap alternative per unit of delivered energy because of the low cost of acquisition. Charcoal represents the most expensive fuel choice because it has a low efficiency and a high price (Table 2.7).

\footnotetext{
${ }^{2}$ It is assumed that an equal amount of delivered heat energy (3.17 GJ/year) is required to cook a typical meal for a typical household using different fuels and stoves.
} 
Table 2.6 Energy Content, fuel cost and cost / unit energy of various cooking fuels

\begin{tabular}{||c|c|c|c|c|c|c||}
\hline & Electricity & LPG & Kerosene & Charcoal & Fuelwood & Rice Hull \\
\hline $\begin{array}{c}\text { Energy Content } \\
\text { (MJ/unit) }\end{array}$ & $\begin{array}{c}3.6 \\
\mathrm{MJ} / \mathrm{kWh}\end{array}$ & $\begin{array}{c}45.5 \\
\mathrm{MJ} / \mathrm{kg}\end{array}$ & $35 \mathrm{MJ} / \mathrm{L}$ & $\begin{array}{c}28 \\
\text { GJ/tonne }\end{array}$ & $\begin{array}{c}16 \\
\text { GJ/tonne }\end{array}$ & $\begin{array}{c}14.7 \\
\text { GJ/tonne }\end{array}$ \\
\hline $\begin{array}{c}\text { Cost (Philippine pesos } \\
\text { /unit) }\end{array}$ & $3.1 \mathrm{p} / \mathrm{kWh}$ & $25 \mathrm{p} / \mathrm{kg}$ & $15 \mathrm{p} / \mathrm{L}$ & $\begin{array}{c}7380 \\
\text { p/tonne }\end{array}$ & $\begin{array}{c}2290 \\
\text { p/tonne }\end{array}$ & $\begin{array}{c}500 \\
\text { p/tonne }\end{array}$ \\
\hline $\begin{array}{c}\text { Cost per unit energy } \\
\text { (pesos/GJ) }\end{array}$ & $850 \mathrm{P} / \mathrm{GJ}$ & $549 \mathrm{P} / \mathrm{GJ}$ & $400 \mathrm{P} / \mathrm{GJ}$ & $264 \mathrm{P} / \mathrm{GJ}$ & $143 \mathrm{P} / \mathrm{GJ}$ & $34 \mathrm{P} / \mathrm{GJ}$ \\
\hline $\begin{array}{c}\text { Heat efficiency range } \\
(\%)\end{array}$ & $55-75 \%$ & $\begin{array}{c}55- \\
65 \%\end{array}$ & $\begin{array}{c}45- \\
55 \%\end{array}$ & $15-35 \%$ & $10-25 \%$ & $10-25 \%$ \\
\hline $\begin{array}{c}\text { Cost per unit } \\
\text { delivered energy - } \\
\text { (pesos/GJ) }\end{array}$ & $1545 \mathrm{P} / \mathrm{GJ}$ & $\begin{array}{c}845-998 \\
\mathrm{P} / \mathrm{GJ}\end{array}$ & $\begin{array}{c}727-889 \\
\mathrm{P} / \mathrm{GJ}\end{array}$ & $\begin{array}{c}754-1760 \\
\mathrm{P} / \mathrm{GJ}\end{array}$ & $\begin{array}{c}572-1430 \\
\mathrm{P} / \mathrm{GJ}\end{array}$ & $\begin{array}{c}136-340 \\
\mathrm{P} / \mathrm{GJ}\end{array}$ \\
\hline
\end{tabular}

Source: Department of Energy, Republic of the Philippines 1995, Inquirer Philippine Daily 2000 (see Appendix 2.3).

The annual cost of equipment was estimated using the function PMT in an Excel spreadsheet. The function PMT in Excel can be applied to calculate an annuity, given a present value, an interest rate, and a period of time for the investment. In this case, the present value is the purchasing cost of the cooking equipment and the period of time is the life span of the cooking equipment. The interest rate used is an average of the lending interest rates published by the Central Bank of the Philippines over the period $1996-2000(14.4 \%)$.

Table 2.7: Comparative Economics of cooking stoves and fuels

\begin{tabular}{|c|c|c|c|c|c|c|c|c|c|c|}
\hline & $\begin{array}{c}\text { LPG } \\
a \\
\end{array}$ & $\begin{array}{c}\text { Kerosene } \\
\text { b } \\
\end{array}$ & $\begin{array}{c}\text { Fuelwood } \\
\text { c } \\
\end{array}$ & $\begin{array}{c}\text { E-FW } \\
\text { d }\end{array}$ & $\begin{array}{c}\text { HE-FW } \\
\text { e } \\
\end{array}$ & $\begin{array}{c}\text { Charcoal } \\
\mathrm{g} \\
\end{array}$ & \begin{tabular}{|c} 
E-Charcoal \\
h \\
\end{tabular} & $\begin{array}{c}\text { HE- } \\
\text { Charcoal } \\
\text { I }\end{array}$ & $\begin{array}{c}\text { Rice } \\
\text { Hull } \\
f\end{array}$ & $\begin{array}{c}\text { Pellet } \\
\text { j }\end{array}$ \\
\hline $\begin{array}{c}\text { Annual } \\
\text { equipment } \\
\text { cost }\end{array}$ & 728 & 520 & 115 & 192 & 347 & 115 & 192 & 347 & 173 & 434 \\
\hline $\begin{array}{c}\text { Cost of fuel } \\
\text { per year }\end{array}$ & 2900 & 2534 & 4431 & 2592 & 1816 & 5572 & 3343 & 2384 & 720 & 2095 \\
\hline $\begin{array}{l}\text { Total Cost } \\
\text { in Pesos }\end{array}$ & 3628 & 3054 & 4546 & 2785 & 2163 & 5687 & 3535 & 2731 & 893 & 2529 \\
\hline
\end{tabular}

Considering the annual cost of operating a cooking stove using purchased fuels, the LT2000 stove is the cheapest alternative available (Table 2.5, Figure 2.7). Operating the stove costs about $33 \%-42 \%$ as much as operating the cheapest fuelwood and charcoal stoves, and $25 \%$ as much as operating an LPG stove. The main reasons for such a large difference are that the LT-2000 stove is cheaper than most alternatives, and that rice hulls are largely available for free. The only cost to households is the cost of transportation from the mill to the house. 


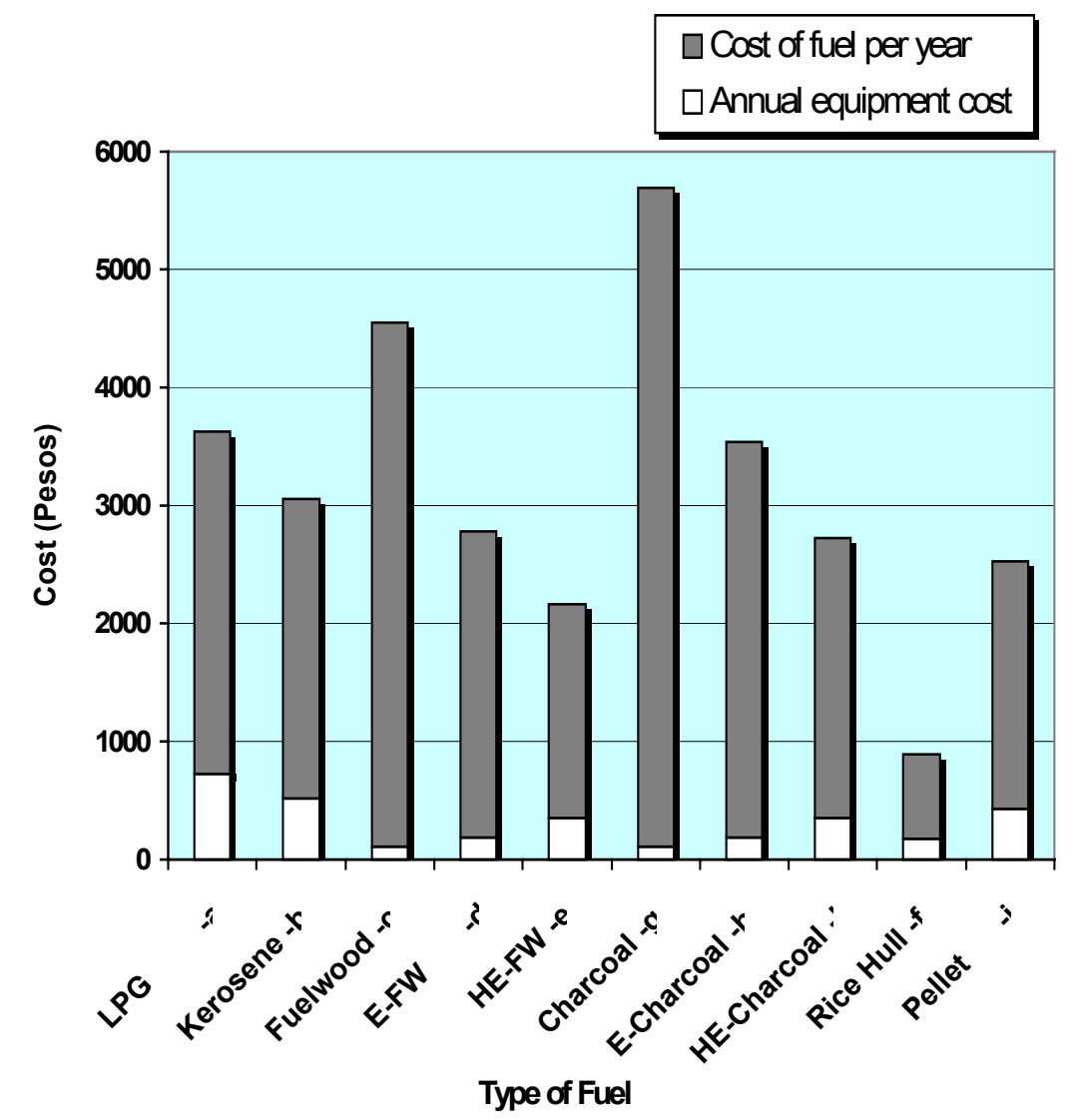

Figure 2.7: Annualized cost of cooking equipment

\section{Other economic components}

Financial aspects do not constitute the only factors considered by households when making a decision on which cooking system to adopt. Other important characteristics include convenience, aesthetics, time requirements, smoke emissions, and health risks.

Convenience refers to availability/accessibility of fuel supply, the adaptability of the cooking stove to local food preferences and cooking habits, and installation and maintenance requirements. Time requirements refer to the time spent acquiring or gathering fuel and time spent cooking. Smoke emissions are important when using biomass fuels as they generate considerable dirt and respiratory problems. Health risks are associated with the chemicals released in the combustion process and present in the fuels and their ashes. Aesthetics may also play an important role, as cooking systems can be seen as a symbol of status.

Characteristics of the LT-2000 Multi-fuel stove identified during a pilot field-testing program on the island of Negros in 2001 by REAP-Canada are summarized in Table 2.8. These and other characteristics have an influence on the economic value of the stove. Thus, considerable effort has to be devoted to quantifying the stove's economic value and how this affects households acceptance of the cooking system. Previous experience with stove programs has shown that inconvenience, poor aesthetics, and smoke or health problems can offset the financial advantages provided by a new cooking system (Leach and Mearns 1988). 
Barnes et al (1994) suggested that efforts be directed at:

1. Marketing research and surveys to assess market potential

2. Alleviating smoke and health problems

3. Adapting stove design to consumer tastes, preferences, and cooking habits

4. Engaging local artisans in the design and production processes

5. Creating local institutions and developing local expertise

6. Setting up mechanisms for obtaining credit

Table 2.8 Characteristics of the LT-2000 Multi-Fuel Stove

\begin{tabular}{|l|l}
\hline - Advantages & Disadvantages \\
\hline
\end{tabular}

- Rapid cooking speed

- High heat output

- Modest emission of pollutants compared to fuelwood stoves

- Safe use in the house compared to fuelwood

- Reduce labour requirement for wood collecting

- Capable of burning other fuels (coconut husks, maize cobs, pieces of wood), which allows the user to buy other stoves and resolves concerns about rice hull availability

\section{Opportunities for Using the LT-2000 Multifuel Stoves}

In the Philippines there are approximately 1.5 million tonnes of rice hulls produced that are recoverable on an annual basis (Chapter 1 ). This source of biomass energy could be effectively harnessed by using the LT-2000 in rural areas and agricultural towns where rice is processed (Appendix 2.2). This stove could have a significant impact on cooking systems and bioenergy utilization if large quantities of stoves were available. Burning rice hulls in this stove represents a high value application: for example, as a substitute for LPG, 1.44 tonnes of rice hulls saves \$58 US in LPG fuel purchases. This end use application provides a much higher value than other bioenergy uses including crop drying and power generation. In addition to rice hulls, the stoves are capable of burning large volumes of maize cobs, chopped coconut fronds, and coconut husks identified in Chapter 1. These fuels improve the convenience of the LT-2000 as they reduce the amount of care needed to maintain the heat output relative to rice hulls. Additionally, the use of multiple fuels eases seasonal supply concerns of rice hull availability. Advantages of the LT-2000 include its rapid cooking speed (the stove boils water in 5-7 minutes, comparable to LPG), its high heat output, its reduced emission of pollutants compared to fuelwood stoves, and its relatively safe use in the home. It also enables rice hull ash to be recycled efficiently back into farming systems or gardens. More complicated rice hull combustion systems are available and can be used successfully. Overall, the LT-2000 appears to be a promising means to utilize rice hulls and other agricultural residues. 
More research is needed on stove design, cost and production. In particular, efforts should be directed towards reducing emissions, improving user convenience, and reducing stove production costs. Marketing studies should be conducted to assess the potential of the stove as well as to determine the need for credit mechanisms that can alleviate the financial burden on potential buyers, especially low-income households.

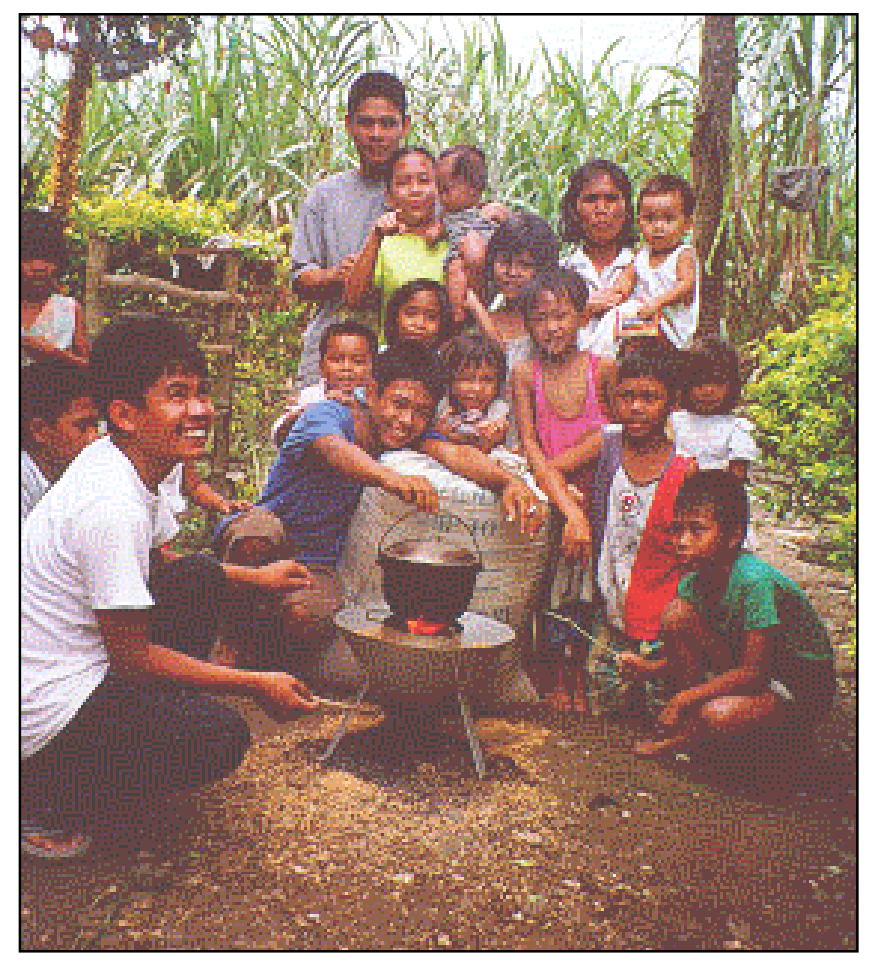

Photo 2.9. Communities in the Philippines are extremely interested in the LT-2000 stove. Fueled by residual hulls from rice production, this low-cost stove produces modest levels of smoke, is simple to start, and has a high heat output. Rice hull has the lowest annualized cost of the purchased fuel systems in the Philippines (Figure 2.7.) 


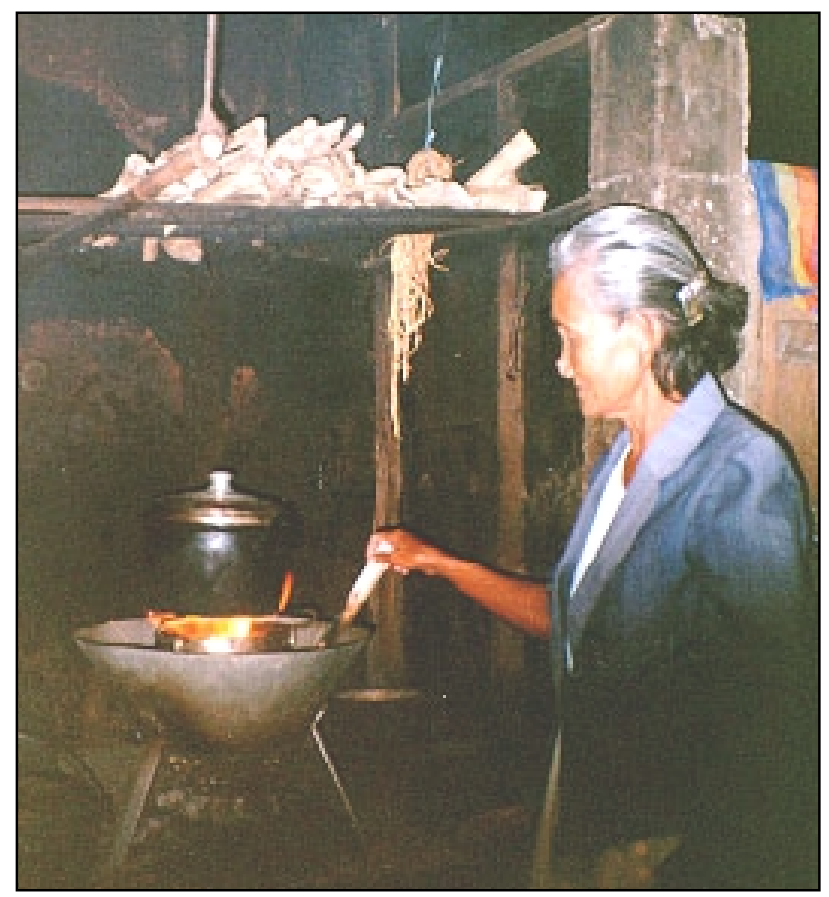

Photo 2.10. High efficiency stoves completely burn the fuel being used and effectively transfer the heat to the pot, thus reducing the amount of fuel needed for cooking. An important fuel saving feature is an adjustable heat output, for boiling then simmering rice. Sufficient energy is needed to replace heat losses during the latter part of the cooking cycle. Greater control of heat output would improve user acceptance of improved biomass cooking stoves.

\section{Opportunities for Using the Pellet Fuel Stoves}

Pellet fuel stoves are one of the most promising approaches to modernizing biomasscooking systems, especially as a substitute for fossil fuel and charcoal cooking in urban areas. The rising price of fossil fuels could encourage the success of pellet stoves in many developing countries where wood resources are increasingly limited and fossil fuels are prohibitively expensive. Pellet fuel cooking has already begun to be more widely used in some developing countries such as Ethiopia. Napier grass (Chapter 1), sugarcane trash, and wood wastes could be used as potential feedstocks to fuel these stoves.

Pelletized biomass enables more efficient combustion relative to other biomass forms and makes fuel convenient to transport and store for consumers. Significant improvement in pelleting technologies (Samson et al., 2000) and small cook stoves suitable for burning these fuels are under development (Reed and Larson, 1996, Drisdelle, 2000). Advances in pelleting technologies will significantly enhance the potential for the widespread introduction of pellet fuel stoves, as well as larger stoves and furnaces. Pelleting studies and commercial experience indicate that herbaceous biomass sources such as grasses have higher throughput rates and are less expensive to pellet than wood fuels, because they have a more pliable fiber. Unlike other biomass processing systems, the production of fuel pellets is not energy intensive. An energy analysis of grass production, pelleting, and delivery indicated a 14.5:1 energy output to input ratio for fuel pellets made of perennial grasses (Samson et al., 2000). The stove has the potential to greatly reduce the exposure of women and children to air-borne pollutants, reducing respiratory illnesses. A stove with an efficiency of $45 \%$ to $50 \%$ and a cost of 1000 pesos appears to be an achievable target with the current understanding of pellet stove manufacturing and pellet combustion. 


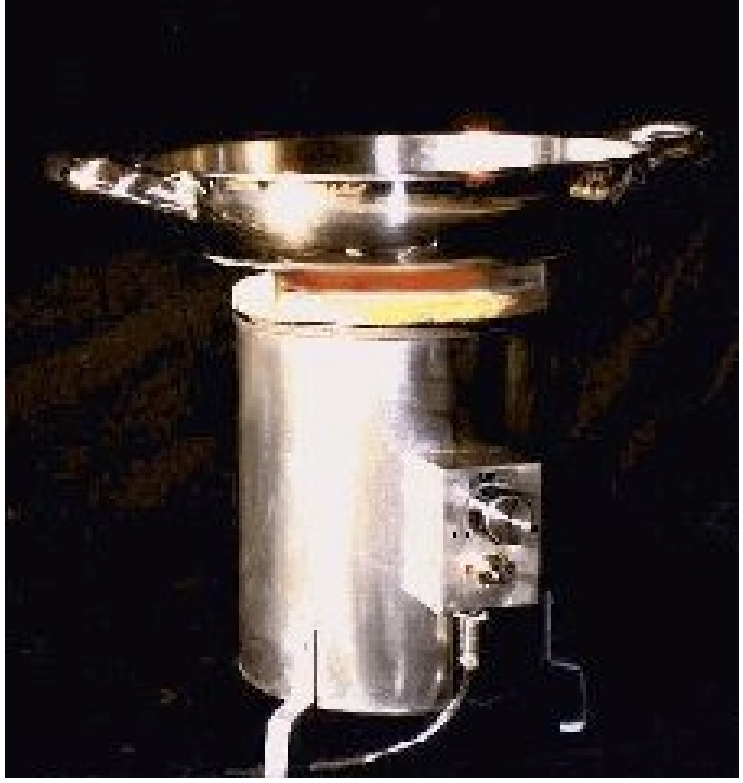

Photo 2.11: Prototype CPC Turbo (WoodGas) Stove suitable for burning pellets (Reed and Larson, 1996)

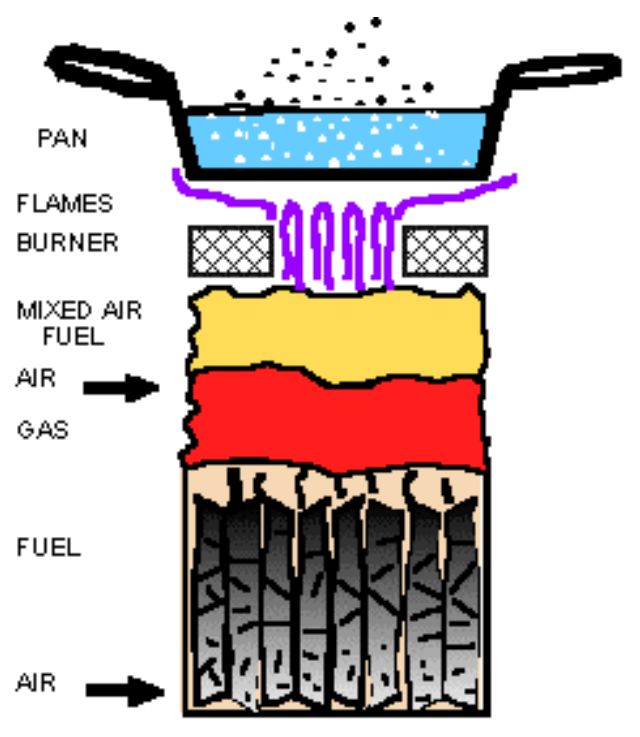

Simple Diagram of Turbo (Gasifier) Stove

Figure 2.10: Simple Diagram of Turbo (Gasifier) Stove

\subsection{Health Issues}

Petroleum products produce far less smoke and suspended particulate matter within the home than biomass fuels. The combustion of biomass can produce carbon monoxide (CO), sulphur dioxide $\left(\mathrm{SO}_{2}\right)$, nitrogen oxides $\left(\mathrm{NO}_{\mathrm{x}}\right)$, fluorine, suspended particulate matter, and other products of incomplete combustion. Within the home, these compounds are often many times more concentrated than health standards recommend, and can exceed pollution levels of the most polluted industrial cities. Inhaling these products can lead to serious respiratory problems, including silicosisrelated diseases, and birth defects. In densely populated areas it is essential that efficient combustion stoves be introduced to avoid air pollution problems.

\section{Respiratory Diseases}

Respiratory diseases such as chronic bronchitis and lung/throat cancer are a common health problem in cultures that rely heavily on biomass as a fuel source. In many developing nations, young children are especially vulnerable to lower respiratory tract infections (RTI). A 1980 study in Indonesia showed that respiratory illness caused $28.8 \%$ of the deaths in children aged $1-4$, second only to diarrhea $(36.9 \%)$ (Achmadi, 1992). Investigators in Nepal found a strong relationship between the incidence of acute respiratory infections in children and the number of hours spent by the fire (Pandy, 1992). A study in Gambia involving 500 children under the age of 5 showed that in confined huts, young girls carried on their mother's backs were 6 times more likely than other children to suffer from acute respiratory illnesses (Smith, 1987). 
Adults are also susceptible to respiratory illnesses. Because women are largely responsible for meal preparation in developing countries, they are exposed to particularly high quantities of indoor air pollution. For example, the quantity of benzoalpha-pyrene (BAP) to which the average rural woman is exposed in a day is equivalent to smoking 450 non-filter cigarettes (Sims and Kjellstrom, 1992). Exposure to carcinogenic poly-aromatic hydrocarbons (PAHs) contained in smoke significantly increases the risk of lung cancer. Studies in China have shown that for women over 45 years of age, the incidence of various respiratory problems is higher for those who cook with coal instead of gas(Hong, 1991) (Table 2.9).

\section{Silica and its Health Risks}

Silica $\left(\mathrm{SiO}_{2}\right)$ is a constituent of the ash produced by the combustion process. Different types of biomass fuels contain different quantities of silica. The International Agency for Research on Cancer has classified silica as a human carcinogen. Long term inhalation of airborne silica particulates can cause lung cancer or other related health problems. As rice hull ash contains high levels of silica $(\sim 15 \%)$, its use as a biomass fuel presumably increases the risk of developing silicosis-related illnesses, and care should be used in handling the ash.

Table 2.9. Respiratory diseases/symptoms in women using different cooking fuels (age $\geq 45$ )

\begin{tabular}{|l|c|c|}
\hline Disease/symptoms & Coal users (\%) & Gas users (\%) \\
\hline Cough & 40.1 & 17.7 \\
\hline Productive cough & 25.6 & 12.9 \\
\hline Shortness of breath & 25.6 & 9.7 \\
\hline Chronic Bronchitis & 24.6 & 11.8 \\
\hline Emphysema & 10.1 & 2.2 \\
\hline Bronchodilatation & 6.2 & 1.6 \\
\hline Asthma & 7.3 & 3.3 \\
\hline
\end{tabular}




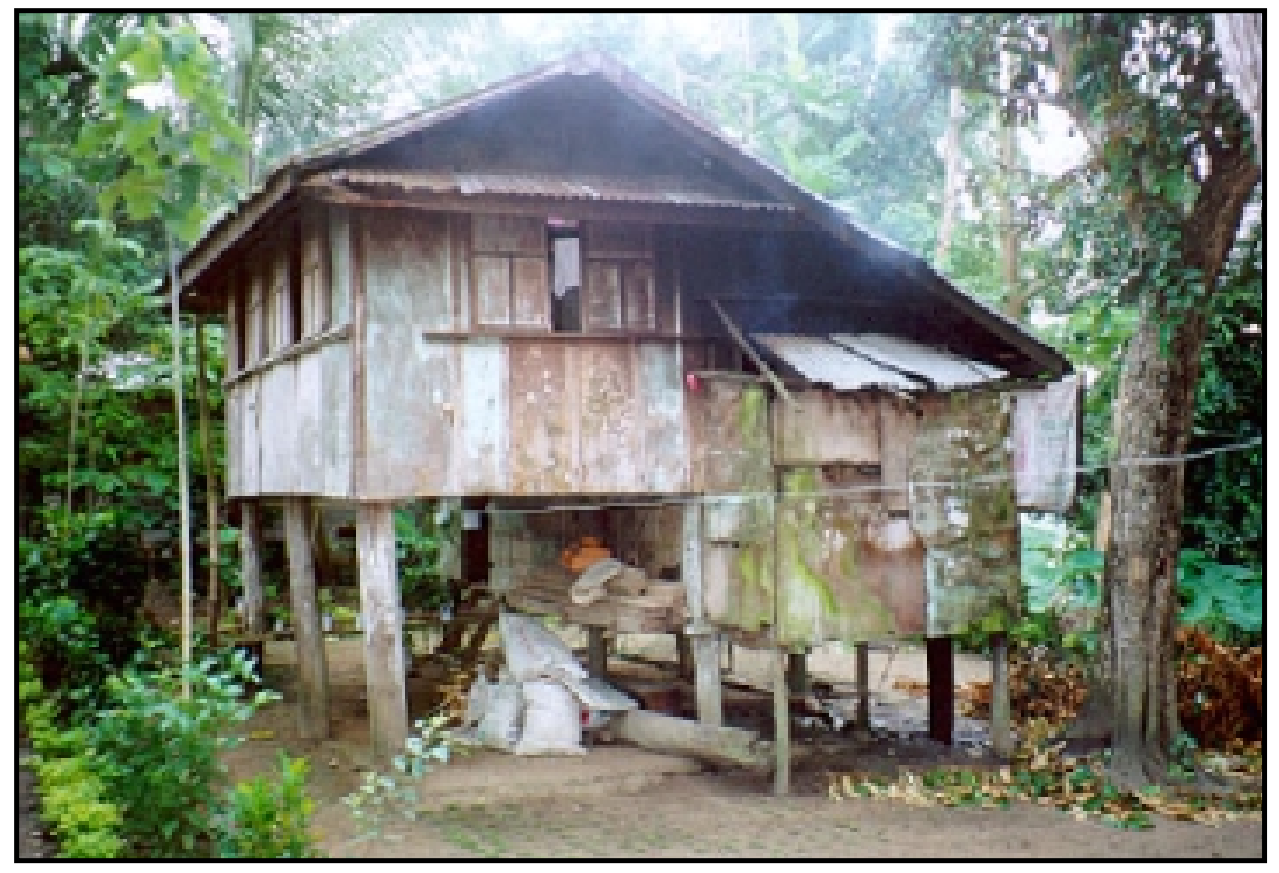

Photo 2.12: In the Philippines, many women are frequently exposed to indoor air pollution from inefficient firewood cooking and poorly designed chimneys, resulting in chronic respiratorv problems that can lead to earlv mortalitv.

\section{Birth Defects}

More recent studies in China have shown that children born into homes that use coal for cooking or space heating have higher rates of birth defects. Furthermore, there is a strong correlation between the time of conception and the rate of birth defects. Children conceived in coal-heated homes during the winter months (when indoor air pollution is highest) have increased rates of birth defects. Unborn children are also at a greater risk of suffering birth defects if their mothers spend long periods indoors (Hong, 1991).

\section{Other Possible Health Effects}

Studies in India have suggested that indoor smoke could increase the risk of ailments such as tuberculosis, blindness, and perinatal effects (stillbirth, low birth weight, and death during the first two weeks following birth). Strong evidence points to the danger of acute respiratory infections in children under 5 years of age, chronic lung disease in women, and lung cancer in women who cook with coal (Smith, 1998).

\section{Improving the Safety of Biomass Stoves}

Improvements in cooking stove design can reduce the health implications associated with biomass fuels. Stoves that burn fuelwood and agricultural residues efficiently require less fuel and emit fewer pollutants. Additionally, stoves that are equipped with a chimney system and an ash trap or holder can reduce pollutants in the home. It is not possible to completely eliminate all pollutants, but the combination of an efficient 
burning stove and a proper chimney system can significantly decrease indoor air pollutants and reduce health risks in the home.

\subsection{Environmental Issues}

Recently, improved cooking stove programs have been viewed as a possible means to reduce greenhouse gas emissions (GHG). Approximately $75 \%$ of biomass fuel used in the Philippines is consumed by households for cooking purposes (ARREEC 1996). A substantial portion of the total GHGs emitted is from biomass fuels. Thus, there is great potential for reducing emissions through improved cooking stoves.

Multi-fuel stoves represent an alternative to the burning of biomass fuels and can reduce emissions of GHGs. The LT-2000 Multi-fuel stove is designed primarily for rice hulls as a fuel, but is also capable of burning other crop residues such as coconut husks, maize cobs, sawdust, etc. In the Philippines, rice mills produce approximately 1.5 million tonnes of rice hulls per year that could be recovered for biomass applications (Chapter 1). Rice hulls are usually treated as an unusable residue and commonly disposed of by burning in fields (Chapter 1), and as a consequence, greenhouse gases are released into the atmosphere. Using this residue as a fuel for cooking stoves would capture the energy that would otherwise be lost to the atmosphere, while at the same time replacing other fuels such as fuelwood, charcoal, kerosene, and LPG. Thus, the use of rice hulls as a cooking fuel would not increase the emission of GHGs, and the replacement of other fuels decreases net GHG emissions.

One of the potential benefits of developing the LT-2000 is the reduction in land use required per household for cooking. With the introduction of the LT-2000, 1.4 tonnes of rice hull replace almost two tonnes of gathered fuelwood. The current production of leucaena firewood is approximately 10 tonne/ha/year, thus 7 tonnes of rice or 1 ha of napier grass converted into fuel pellets, could provide cooking fuel for 50 families. This is because of the high yield (20 ODT/ha) and a high end-use conversion efficiency (45\% in the pellet cooker) so only $400 \mathrm{~kg}$ of fuel are required per family. Approximately 100,000 ha of napier grass converted into pellets could replace $50 \%$ of all LPG imports for fuel cooking and one third of all fuel wood requirements (5 million tonnes) in the Philippines. 


\subsection{Conclusions and Recommendations}

Although the use of petroleum based cooking products such as LPG and kerosene is increasing in the Philippines, biomass fuels will always remain popular. The annualized fuel costs of LPG and kerosene systems are well above the economic means of the majority of the populace, and rising costs are making them more inaccessible. Cheaper alternatives such as fuelwood and biomass residues still remain viable solutions for households with lower incomes. Although these fuels are not as clean burning as LPG, improvements in fuelwood stoves and innovations in residue stoves could provide efficient alternatives. The promotion of such technologies would help alleviate the burden of purchasing expensive imported fuel products and reduce the impact of fuelwood demand.

Improvements in biomass cooking must:

- Decrease cooking time

- Reduce smoke and suspended particulates in the atmosphere, providing a healthier environment within the home.

- Be designed with traditional cooking methods in mind

- Be cost effective over their life span.

- Minimize fuel consumption, and hence reduce fuel purchases

- Be aesthetically pleasing to the user and not offend others in the community

This analysis indicated that the LT-2000 and a high efficiency pellet stove are promising options for providing economical, convenient, and environmentally responsible cooking. A significant research and development effort is required for these systems to facilitate rural development, poverty alleviation, community health, and climate change mitigation. 


\subsection{References}

Achmadi, U. F., 1992. "Health Aspects of Biomass Fuel Use in Households: The Indonesian experience." Working paper from Indoor Air Pollution from Biomass Fuel, World Health Organization.

ASEAN Centre for Energy. 2000. http://www.ace.or.id/pressea/philippines/wind/wind fr.htm.

ARREEC (Asian Regional Research in Energy, Environment and Climate). 1996. "Status of Biomass Energy Technologies: Philippines." p.15.

Barnes, Douglas, Keith Openshaw, Kirk Smith, and Robert van der Plas. 1994. What makes people cook with improved biomass stoves? World Bank Technical Paper Number 242, Energy Series.

Department of Energy, Republic of the Philippines. 1995. 1995 Household Energy Consumption Survey. Main Report and Annexes. p. 192.

Drisdelle, M. (2000). Personal communication. Also refer to www.pelletstove.com.

Dutt, Gautam S. and N.H. Ravindranath, 1993. Bioenergy: direct applications in cooking. In Renewable Energy: sources for fuels and electricity, Ed. Thomas.

ESMAP (Energy Sector Management Assistance Program). 1993, September. Philippines: Commercial Potential for Power Production from Agricultural Residues. The World Bank department of industry and energy, UNDP, and the Philippines Department of Energy.

Hong, C.J. 1991. "Health aspects of Domestic Use of Biomass Fuels and Coal in China." Working paper from Indoor Air Pollution from Biomass Fuel, World Health Organization, 1992.

Inquirer Philippine Daily, 2000. http://www.inquirer.net/issues/nov2000/nov11/news/news $15 . h t m$, visited on November 11, 2000.

Leach, Gerald and Robin Mearns, 1988. Beyond the woodfuel crisis: people, land and trees in Africa. London, UK: Earthscan Publications Ltd.

Pandy, M. 1992. Health aspects of biomass use in Nepal and interventions implemented or under consideration. Working paper from Indoor Air Pollution from Biomass Fuel, World Health Organization.

PNOC-ERDC (Energy Research and Development Center). 1993. Detailed Feasibility study for the pilot demonstration of a communal rice-hull power plant in the Philippines utilizing the Vyncke Technology at Cabanatuan, Isabela. Task force on communal rice-hull power plant project. Diliman, Quezon City.

Philippine Energy Plan. 1999-2008. Republic of the Philippines: Department of Energy. http://www.doc.gov.ph/PEP-Demand.htm 
Reed, T. and R. Larson. (1996). "A wood-gas stove for developing countries." http://www.ikweb.com/enuff/public html/TI.htm

Samson, R., P. Duxbury, M. Drisdelle, and C. Lapointe. 2000. "Assessment of Pelletized Biofuels." PERD Program, Natural Resources Canada, Contract 23348-8-3145/001/SQ.

Sims and Kjellström, 1992. "Biomass Fuel and Indoor Air Pollution: Underlying Issues from a Social Perspective." Working paper from Indoor Air Pollution from Biomass Fuel, World Health Organization.

Smith, K.R. 1987. "Biofuels, Air Pollution and Health: A Global Review." Plenum Press.

Smith, K.R. 1998. "Overview of the Indian National Burden of Disease from Indoor Air Pollution." Prepared for Conference on Health and Environment, July 7-9, 1998.

Vergara, T. T. 1998. Categorization of Rice milling Capability in the Philippines: A Preliminary Survey. National Food Authority, Quezon City, Philippines. 


\title{
Chapter 3
}

\section{Biomass Supply Options for Power Co-generation in Sugarcane Milling}

\author{
T. C. Mendoza ${ }^{1}$, R. Samson, ${ }^{2}$ and T. Helwig ${ }^{2}$ \\ ${ }^{1}$ Department of Agronomy \\ U.P. Los Baños, College, Laguna, Philippines \\ Tel. (049) 536-2466, Fax (049) 536-2468 \\ tcm@mudspring.uplb.edu.ph \\ ${ }^{2}$ Resource Efficient Agricultural Production (REAP) Canada \\ Box 125, Ste. Anne de Bellevue, Quebec, Canada H9X3V9 \\ Tel. (514) 398-7743,Fax (514) 398-7972 \\ REAP@Interlink.net, www.reap.ca
}




\section{EXECUTIVE SUMMARY}

The existing sugarcane industry can make a substantial contribution to the bioenergy supply of the Philippines. This study examines the potential for utilizing renewable biomass fuel as an alternative for power generation. Biomass such as sugar cane residues and perennial grasses could be used as an off-season fuel for year-round power generation at sugar mills. There is also a high demand for biomass as a boiler fuel during the sugar-milling season. Approximately $5.9 \%$ of energy used for boilers in sugar processing is provided by 365,000 barrels of imported bunker oil. At $\$ 30$ US per barrel of oil, this represents a cash outflow of 438 million pesos.

Four biomass supply alternatives have been investigated:

(1) The negotiated-purchase of excess bagasse from sugar mills

(2) The use of baled sugarcane trash

(3) High yielding perennial grass (i.e. napier grass)

(4) Fast growing tree species

Excess bagasse from raw sugar producers is generally the lowest cost fuel. The surplus bagasse that was once available is now completely consumed as a boiler fuel in sugar refineries and distilleries.

Cane trash has been used effectively as a boiler fuel for sugar processing for more than 10 years at Hacienda Luisita in Tarlac. To displace all the bunker oil currently imported for sugar processing, it would require approximately 161,000 tonnes (at $26 \%$ moisture) of cane trash. This volume represents $41 \%$ of the 391,000 tonnes of recoverable trash available, and that could be harvested following the final ratoon crop in a three year cane planting system (Chapter 1). A cane trash price of P1650/tonne would provide sufficient incentive for farmers to develop this opportunity and provide an alternative to boiler fuel at the cost of oil at $\$ 20 \mathrm{US} /$ barrel. Several baling and storage systems are available that are suitable for retrieving material from both large and small farms.

The production of fast growing grasses such as napier grass and energy cane, and fast growing trees such as leucaena and eucalyptus, would be required if year round power generation is to be undertaken. The cost of producing napier grass was projected to be $7 \%$ higher than the cost of cane trash harvesting, mainly due to land lease costs for the crop. A purchase price equal to that of sugar cane trash (P1650/tonne) would likely encourage farmers to plant the crop. The main concern with fast growing trees is the long period farmers would have to wait prior to receiving an economic return. In the case of firewood crops such as leucaena, they can be harvested every two to three years, and command a high retail price of approximately $\mathrm{P} 2560 /$ tonne. To provide a biofuel to mills at a cost equivalent to oil ( $\$ 20$ US per barrel), wood could be bulk purchased at P2000/tonne. The major concern with promoting wood biofuel use is the further contribution to deforestation problems in the Philippines. Sugar refineries have been cited as a major source of deforestation in the past. 
Overall, the economic, environmental, and social implications of utilizing cane trash in the final ratoon crop year as a substitute for bunker oil appears promising. It represents an opportunity for developing bioenergy use within the sugarcane industry. Positive socio-economic impacts include the provision of large-scale rural employment and the minimization of oil imports. It can also develop the expertise necessary to create a reliable biomass supply for year-round power generation. Investment in the research and development of these technologies is essential to create an effective biomass utilization system for the future. 


\subsection{Introduction}

The sugarcane industry is the largest biomass processing industry in the Philippines. In other developing countries such as Brazil, biomass has become a major rural energy development strategy. In this study, two mills were visited in Negros Occidental, the First Farmers Mill and Victorias Mill, to assess opportunities for bioenergy development and potential feedstock supply systems that would enable year-round power generation for mills (COGEN). During the course of the study, bunker oil prices rose dramatically and it became evident that mills with sugar refineries were also looking to biomass as a means to displace bunker oil. The supply systems described for year-round power generation could be implemented immediately, which would encourage the development of a reliable biomass supply.

\section{Energy Demands of the Sugar Industry}

Sugar processing is an energy intensive process. About $30 \mathrm{KWh}$ (including $10 \mathrm{KWh}$ parasitic load) of electricity is used per tonne of cane milled. Most electricity is used by machinery for heating processes including the evaporation of water from cane juice (Pennington, et al., 1996). During production, a large amount of by-product, called bagasse is produced ( $28 \%$ of total cane tonnage). The mills can use bagasse as a supplementary source of fuel. After internal requirements, raw sugar mills still produce excess bagasse. Sugar mills that have factories (refineries or distilleries) have an inadequate supply of bagasse and traditionally rely on bunker oil.

The present average thermal efficiency of most mill boilers is about $62.5 \%$. This poor efficiency is the result of a number of factors:

(1) The design and construction of low-pressure boilers (40 years ago) occurred when the cost of fossil fuel oil-based energy was low.

(2) Boilers operating at low pressure discourage the accumulation of bagasse, which decreases bagasse disposal. To illustrate; in a low-pressure boiler $9 \mathrm{~kg}$ of bagasse is used to produce $1 \mathrm{kWh}$ of electricity, while efficient, high-pressure boilers ( $80 \mathrm{bar}$, $570^{\circ} \mathrm{C}$ ) can use $2 \mathrm{~kg}$ of bagasse to produce the same amount of electricity (Pennington et al., 1996).

(3) The technology for high pressure/temperature boilers was not available when most of the existing boilers were constructed.

(4) Environmental concerns about global warming and climate change were limited at the time of construction, so high efficiency mill boilers (an efficient, renewable energy, with low GHG emissions) were not fully appreciated. The advent of efficient, high-pressure boiler systems have not only altered the energy balance in the mill, but can also provide additional income (Tangon, 1995).

\subsection{Prospects for Electric Power Co-generation}

The sugar industry has the potential to generate electricity for the Philippines. Estimates of potential electric power co-generation are as high as 540MW nationwide $(1,889$ GWh) (Table 3.1). At least 60-90 MW of bagasse co-generated power is available as an energy source (ESMAP 1993). Energy audits of 15 (out of 17) mills belonging to the 
Philippine Sugar Millers Association Inc. (PSMAI) showed that they were buying 18 GWh of electricity every season, which is equivalent to about $10 \%$ of their total power requirement (EDUFI, 1994). The installation of high efficiency boilers for electrical cogeneration would directly benefit many sugar mills (Department of Energy 1996).

While the advantages of improving the thermal efficiency of boilers are clear, the adoption of such systems remains to be realized. Table 3.2 presents the difficulties of adopting thermally efficient bagasse boilers.

The absence of a sustained year-round supply of biomass remains an important issue. Bagasse is only available during the sugarcane-milling season (about 5-7 months in duration). A mill modernized for efficient year-round power co-generation (a COGEN plant) would be bagasse deficient half the time (assuming that all the bagasse during the milling season is consumed).

Table 3.1. Theoretical estimates of electrical power co-generation using bagasse during milling.

A. Technical Assumptions (based on information from Pennington, et al., 1996)

- $3 \mathrm{~kg}$ bagasse generates $1 \mathrm{KWh}$

- $20 \mathrm{KWh}$ is used per tonne cane milled

- $10 \mathrm{KWh}$ is the parasitic load

B. Other Assumptions

- Bagasse $/$ cane ratio $=28 \%$

- Bagasse utilization $=80 \%$

- 37.5 million tonne cane milled (Ave. for 3 years)

C. Computations : Power Co-generation

- Per tonne cane milled

$=1000 \mathrm{~kg} \times 0.28=93 \mathrm{KWh}, 3 \mathrm{~kg} / \mathrm{KWh}$

$=93 \mathrm{KWh}-[20 \mathrm{KWh}+10 \mathrm{KWh}]$

$=63 \mathrm{KWh}$

- Total Power Co-generation

$=63 \mathrm{KWh} \times 37.5$ Million tonne $\times 0.80$

$=1,889 \mathrm{GWh}(540 \mathrm{MW})$ 


\section{Table 3.2. Difficulties/options in exploiting power co-generation in the sugar industry}

\section{Difficulties}

Old age of equipment: 15 out of 17 PSMAI mills that produced $60 \%$ bagasse ( $3.8 \mathrm{M}$ tonne) are 40 years old.
- boiler retubing and rehabilitation

- boiler replacement or addition using low-tomedium pressure boilers

- boiler replacement or addition using high pressure boilers

Planter-miller cane sharing system

Fixed ratio : 60-70:30-40

Poor maintenance of mill facilities/conservative operating practices of most mills

Large financial outlay for installing cogeneration facilities:

P $342.9 \mathrm{M}$ for $10.7 \mathrm{MW}$

P 1,350.8M for $43.0 \mathrm{MW}$ the Philippine Sugar Industry (Corpuz F. APS Study Committee Report, 1996)

Adopt comprehensive technology transfer plant operation and specific knowledge of the bagasse-fired energy plant. and Thompson, 1998):

- Internally generate funds by issuing new
Adopt the alternative cane purchase system for i.e. Comprehensive training program for power Adopt any of the following financing mechanisms (as proposed by Pennington, et al., 1996; Doon equity shares

- Debt financing (i.e. borrow money from the bank )

- Leasing

- Joint ventures

- Build-operate-transfer (BOT) scheme and its variants

Fear of the unknown, inadequate knowledge, and large capital outlay needed for power cogeneration predispose millers to take a waitand-see attitude
The government and donor agencies should put up putup/guarantee matching funds for ventures in power co-generation. 


\subsection{Fuel Supply Options for Year-round Power Production}

Existing sugarcane mills in the Philippines employ a secondary fuel source (coal) for power production during off-milling season. In addition to the pollution and health hazards associated with burning coal for power generation, coal is a non-renewable resource. Furthermore, the Philippines does not have substantial coal deposits and must import it.

Power co-generation can use renewable biomass energy during the off-milling season if individual mills have access to sufficient biomass in their district or region. Soil type and rainfall/climate regimes across the country could affect biomass production, and must be taken into consideration.

$\mathrm{CO}_{2}$ released during combustion of biomass in a boiler is recycled back through crop photosynthesis into the standing biomass in the agricultural landscape. Thus, when renewable biomass replaces fossil fuel derived power, it has the net effect of reducing GHG emissions. "Green power" production initiatives are being encouraged in developed countries with various incentives; In Australia, it is about $1.2 \phi \mathrm{US} / \mathrm{KWh}$. This has effectively spurred a number of new sugar mill-based co-generation projects (Doon and Thompson, 1998).

\subsection{Renewable Biomass Supply Options for Power Co-generation in Sugarcane Off-milling}

Assessing the biomass supply options during the off-milling season is necessary for year-round power co-generation. The following options are under consideration:

- A negotiated purchase of "excess" bagasse

- Use of baled sugarcane trash

- High yielding perennial grass, i.e. Napier Grass (Pennisetum purpureum)

- Fast growing tree species (FGTS) for biofuel

\subsubsection{Negotiated Purchase of Excess Bagasse from Other Mills}

Bagasse could be available from smaller mills where power co-generation is not financially viable. The prospects and/or difficulties of using excess bagasse from other mills are outlined in Table 3.3. Excess bagasse from raw sugar producers is generally the lowest cost fuel. Transport costs represent more than $3 / 4$ of the delivered cost (approximately P340-760/tonne for trucking in Negros). 
Table 3.3. Advantages /Difficulties of using "excess" bagasse from other mills for power co-generation.

\section{Advantages}

- Provides additional income to the mill. Encourages the mill to improve present bagasse usage for power to generate more excess supply.

- Eliminates the cost of disposing of the excess bagasse among bagasse-surplus mills.

- Saves dollars from bunker fuel oil importation

- As a biofuel, bagasse is $\mathrm{CO}_{2}$ neutral and will reduce greenhouse gas emissions associated with using bunker oil.

\section{Difficulties}

- Planter-miller sharing scheme does not give the miller full ownership of bagasse.

- Hauling bagasse to other mills is bulky and somewhat expensive.

- Converting to bagasse-briquette or compacting is an added cost (Apolinario, et al., 1998)

- Sustained supply is risky due to the other uses of bagasse that can provide higher revenue among bagasse-surplus mills.

- Stored bagasse is prone to fire and fire protection is an added cost.

Several factors must be considered before excess bagasse can be purchased from other mills for power co-generation:

- The distance between the bagasse source and the COGEN plant affects transportation costs.

- All excess bagasse is currently being utilized as a boiler fuel in Negros (Chapter 1) as a result of rising bunker fuel costs. The purchase price of bagasse could theoretically increase if oil prices continue to increase.

- Although an additional expense, sheltered storage for bagasse at the mill site minimizes exposure to rain, improving its burning quality.

- The additional cost of purchasing hauling trucks and mechanical loaders is favorable. Renting the trucks will reduce capital costs but will restrict availability.

- There is a fixed planter-miller share (under R.A. 809) whereby the planter owns the majority of the bagasse $(60-70 \%)$.

\subsubsection{Removal of Cane Residue}

\section{A. Agronomic Effects of Trash Removal:}

Residue removal in between ratoon cycles may have detrimental effects on cane growth. Santo (1991) listed the following seven factors to be considered when removing sugarcane trash.

(1) Damage to ratoons by the collection equipment. Residue collection equipment can cause damage by wheel slippage, compaction, or wheel penetration into moist soil.

(2) Soil compaction and tillage requirements with increased infield traffic. 
(3) Influence on soil water retention, evaporation, infiltration, and drainage properties.

(4) Susceptibility of the unprotected soil surface to wind or water erosion. Mulch from cane trash protects the soil surface from splash, runoff, and wind erosion and reduces evapotranspiration. With the presence of mulch, the infiltration rate of the soil is greater, minimizing runoff.

(5) Application of organic or inorganic fertilizers to replace plant nutrients removed with the residue. Santo (1991) described the respective concentrations of N, P, and K in the cane residue as about $0.3,0.05$, and $0.50 \%$ dry weight basis (i.e. for a 15 tonne/ha yield, the losses are $45,7.5$, and $75 \mathrm{~kg} / \mathrm{ha}$ of $\mathrm{N}, \mathrm{P}$ and $\mathrm{K}$, respectively). However the average nitrogen gain from trash farming can be approximated as 125 $\mathrm{kg} \mathrm{N} / \mathrm{ha}$. Patriquin (2000) estimated that cane trash farming increases nitrogen content of the soil by 50 to $200 \mathrm{~kg} / \mathrm{ha}$ through asymbiotic nitrogen-fixation. Thus the nitrogen content of the decomposing trash is only a small fraction of this value.

(6) Control of weeds, diseases, insects, and other pests. Preharvest burning ordinarily kills off borer insects (Rhabdosceius obscurus) and reduces the rat population. Without burning, pest populations could increase.

(7) Deterioration of physical and chemical soil properties with less carbon being returned to the soil.

Residue removal is predicted to have no significant agronomic effect when compared with preharvest or postharvest burning provided the ash is returned to the field (Jakeway, 1993). However, there may be reduced yields due to ratoon damage, and the fertility benefits associated with trash-mulch farming would be lost. In some areas such as Northern Australia, trash farming has been identified as one of the best management practices to improve cane productivity. Analysis in Chapter 4 indicates it is not economical for growers to remove the cane material until the final ratoon crop. The best residue recovery option was to collect the trash only after the last ratoon crop of a three or four year cycle. Harvesting after the final ratoon crop has minimal impact on soil fertility if trash farming is practiced in the proceeding crops. Trash remaining in the field following the final ratoon crop prior to land conversion presents a problem for farmers where burning is the most common means of disposal. Harvesting at this time would be very compatible with farming operations and compensation to farmers for its removal could be realized at a cost reflecting the value of the nutrients in the cane. It would also minimize the potential for conflict with the cane producer, as there would be no concerns if ratoons were damaged during the harvest or if harvesting was delayed because of wet weather. Partial removal of residue has been suggested as an alternative management practice, but the same problems associated with complete trash removal will be encountered under this system. 


\section{B. Quantity of Sugarcane Available for Removal}

Several experiments quantified the tonnage of sugarcane trash available for retrieval (Table 3.4). Typically, $70 \%$ of available material can be collected; at Hacienda Luisita, 8.6 tonnes/ha (representing $68.8 \%$ recovery) were harvested.

\begin{tabular}{|c|c|c|}
\hline Location & Reference & $\begin{array}{c}\text { Residue } \\
\text { (tonnes/ha) }\end{array}$ \\
\hline Australia & $\begin{array}{l}\text { King et al., } 1965 \\
\text { Stewart and Kingston, } 1979\end{array}$ & $\begin{array}{c}19 \\
8-16\end{array}$ \\
\hline Dominican Republic & $\begin{array}{l}\text { Lopez, } 1986 \\
\text { ABA International, } 1983\end{array}$ & $\begin{array}{l}10 \\
22\end{array}$ \\
\hline Hawaii & $\begin{array}{l}\text { Stewart and Verret, } 1929 \\
\text { Anders, } 1988 \\
\text { M. Nakahata, unpublished data, } 1989 \\
\text { Jakeway and Santo, } 1991\end{array}$ & $\begin{array}{l}25 \\
25 \\
13 \\
12\end{array}$ \\
\hline India & Rasal et al., 1987 & 10 \\
\hline Jamaica & Jakeway and Santo, 1991 & 12 \\
\hline Philippines & L.A. Jakeway, unpublished data, 1991 & 10 \\
\hline Puerto Rico & Bonnet et al., 1950 & 12 \\
\hline South Africa & $\begin{array}{l}\text { Thomson, } 1966 \\
\text { Barnes, } 1974\end{array}$ & $\begin{array}{c}16-23 \\
14\end{array}$ \\
\hline Thailand & Jakeway and Santo, 1991 & 11 \\
\hline
\end{tabular}

\section{Use of Baled Sugarcane Trash}

The trash yield to tonnage ratio can reach $20 \%$ for excessively leafy canes, with an average estimate of $15 \%$. At Hacienda Luisita, Tarlac, Philippines, the estimated cane trash yield was about 12.5 tonnes/ha. The sugarcane tonnage yield in the Philippines has fluctuated between 70 and 80 tonnes cane/ha in recent years. In Chapter 1 the recoverable trash yield was identified as approximately 1.17 million tonnes per year. However, responsible management practice is to only harvest the residues after the final ratoon crop. Assuming harvesting occurs one year in three, the tonnage produced would reach 390,000 tonnes of cane residues/year.

Burning the trash in the field is the most common disposal practice on sugarcane farms, but some farmers mulch their cane trash for the ratoon crops. At Hacienda Luisita, (Tarlac, Philippines) the farmers, who have ownership and control of the hacienda, use green harvest practices to bale sugarcane trash and use it as biofuel for boilers. Experiences at Hacienda Luisita have shown that baled trash can be economically used as a biofuel.

Because trash baling generates employment, the community accepts the system. Since community members own the farm, they do not need to negotiate or make arrangements, and trash baling can be synchronized with harvesting. The hauling 
distance is negligible because the mill is in the middle of the hacienda (the hauling truck can transport 4 loads/day). Additionally, people involved in hauling trash work more efficiently as they are paid based on the tonnage of baled trash.

The following issues were raised by independently operated COGEN power plants:

1. A reliable source of baled trash is needed (since the COGEN power plant owners do not own the farms).

2. The price of the material is undetermined.

3. The cost of labour for collecting, baling and loading/unloading the baled trash is also undetermined.

From the nitrogen, phosphorus, and potassium ratio of sugarcane trash, a value of about P143/tonne of trash can be estimated using the current price of commercial fertilizer as a reference point (Table 3.5). This is the estimated purchase price. By selling the trash harvest, farmers would save the costs associated with burning (removing trash from edges and fireguards).

Table 3.5. Nutrient value of sugarcane trash per tonne

\begin{tabular}{|c|c|c|c|}
\hline Nutrient & $\begin{array}{c}\text { Amount of Nutrient } \\
(\mathrm{kg} / \text { tonne) }\end{array}$ & $\begin{array}{c}\text { Unit Price / tonne trash } \\
(\mathrm{P} / \mathrm{kg})\end{array}$ & $\begin{array}{c}\text { Price of nutrient } \\
(\mathrm{P})\end{array}$ \\
\hline $\mathrm{N}$ & 2.87 & 17.7 & 51 \\
$\mathrm{P}$ & 0.5 & 26.6 & 13.3 \\
$\mathrm{~K}$ & 4.58 & 10 & 45.8 \\
TOTAL & \multicolumn{3}{|l|}{} \\
\hline \multicolumn{3}{|l}{} \\
TOTAL NUTRIENT PRICE: $P$ 110.10/tonne $\times 1.3=P 143.13$ \\
(All other nutrients cost 30\% of total NPK price)
\end{tabular}

* Based on April 2000 retail price of commercial NPK fertilizer sources, Laguna, Philippines. International price of N, P, K is about $\$ 0.73, \$ 2.19$, and $\$ 0.64$ per $\mathrm{kg}$, respectively.

Considering the purchase price of baled trash and the additional baling/hauling expenses, the viability of baled sugarcane trash for COGEN remains an issue. The cost items that should be considered in using baled-trash during the non-bagasse yielding off-milling months are listed in Table 3.6. There are 3 major cost items:

- $\quad$ trash purchase

- collection/baling/hauling

- $\quad$ temporary storage

After adding these cost items for year round power generation, 1 tonne of trash costs approximately P1248 (It should be emphasized that these are initial estimates, which need to be verified in the field). As a fuel supply option during the off-milling season, the cost of baled trash can be competitive to bunker oil or coal. (The fuel value of trash is approximately $\$ 55.70 \mathrm{US} /$ tonne $=1.855 \mathrm{BFOE} /$ tonne $\times \$ 30 \mathrm{US} / \mathrm{barrel}$.) 


\begin{tabular}{|c|c||}
\hline ITEM & Estimated Cost/tonne (P) \\
\hline 1. Trash purchase (Table 3.5) & 143 \\
\hline 2. Hacienda Luisita collection (Table 3.7) & 905 \\
\hline 3. Trash storage & 200 \\
\hline TOTAL COST & 1,248 (on a wet basis) \\
\end{tabular}

1 - Trash purchase price is based on value of NPK nutrient plus $30 \%$ to account for other nutrients.

2 - Trash storage cost is incurred because baled trash shall be used during off-milling.

\begin{tabular}{|c|c|c|c|}
\hline ITEM & Cost/ODT & Per $7 \mathrm{~kg}$ bale $(P)$ & P/tonne \\
\hline A. Direct Costs of Collection & & & $(26 \% \mathrm{MC})$ \\
\hline 1. Manual Windrowing & 67.6 & 0.35 & 50 \\
\hline 2. Cost of baling & & & \\
\hline Tractor rental (P 0.75/bale) & & & \\
\hline Fuel and oil (P 0.20/bale) & & & \\
\hline Twine (P 0.57/bale) & & & \\
\hline Total cost of baling & 293.2 & 1.52 & 217 \\
\hline 3. Labor Costs (Checking, etc.) & 48.8 & 0.25 & 36 \\
\hline 4. Transport & 202.8 & 1.05 & 150 \\
\hline Sub-Total & 612.4 & 3.17 & 453 \\
\hline B. Indirect Costs & & & \\
\hline Depreciation, repair maintenance & 610.8 & 3.17 & 452 \\
\hline administration: $0.4528 / \mathrm{kg}$ & & & \\
\hline $\begin{array}{l}\text { Total (for } 7 \mathrm{~kg} \text {-bale) } \\
\text { Cost = P 905/tonne @ 26\% MC }\end{array}$ & 1223.2 & 6.34 & 905 \\
\hline
\end{tabular}

Source: Buan 2000.

Due to the difficulties associated with collecting, baling, hauling, and preparing trash as a biofuel (Table 3.8), incentives to COGEN power plant owners should be provided. This is successfully being done in Australia (Doon and Thompson, 1998). The use of sugarcane trash as a biofuel for power COGEN can provide financial benefits to the plant owners and investors. Moreover, the positive features can be appreciated in both the rural and national economy. Table 3.8 shows the benefits of using sugarcane trash for fuel. It could employ 4142 (low trash yield), 6214 (average), and 8285 (high) rural workers for a 5 month period (Table 3.9). For the Philippine trade balance, significant savings could be achieved by reducing the importation of bunker oil. Estimated savings ranged from $\$ 14.5$ million US (low trash yield), to $\$ 21.8$ (average), and $\$ 29$ million (high yield). 
Table 3.8. Difficulties encountered in trash baling and its utilization as fuel in the sugarcane mill*.

Collection at the farm

- Rainfall will suspend manual windrowing operations, causing hardship for the workers who are paid by the quantity of work done. Much of this field work could be mechanized using wheel rakes.

Loading/unloading is still manual

- The use of lightweight small square bales (e.g. $7 \mathrm{~kg}$ at Hacienda Lusita) for ease of handling is not optimizing storage or transport costs. Using wagons attached to the baler (Photo 3.2) and bale elevators (Photo 3.3) for loading could eliminate the use of lightweight bales and reduce overall costs.

- Weight of baled trash increases after heavy rains

Loading/piling of baled trash in the millyard consumes space.

- Bagasse needs to be pushed in the yard by mechanical loaders (added machine, fuel, repair/maintenance for loader). Bagasse needs a cover, which is an added cost. Without a cover, the fuel value decreases over time due to rains/moisture.

- Baled trash should be conveyed directly to the shredding machine and subsequently fed to the boiler to avoid large piles of baled trash.

Shredding baled trash

- Trash is quite pliable when baled at high moisture contents. The power requirement of effective shredding equipment is high.

- Stock piling of baled trash requires much space

- Efficient shredding machinery is not yet installed in the Philippines.

The need to mix bagasse and shredded trash when used as fuel in the suspension-fired boiler

- Bagasse has a high moisture content (48-52\%) while trash is drier (26\% m.c. average). This leads to mixing difficulties.

*Source: Buan 2000. 
Table 3.9 Benefits of using sugarcane trash for fuel

Rural employment generation

Low Yield: 260,991 tonne x P 285.7/tonne $\div$ P 150/day per person

$=497,100.9$ days $\div 24$ working day $(\mathrm{wd}) / \mathrm{mo}$

$=20,712.5$ months of work or employment for $4,142.5$ workers for 5 months

Ave. yield: 391,486 tonne $\times \mathrm{P} 285.7 /$ tonne $\div \mathrm{P} 150 /$ day per person

$=745,650.3$ days $\div 24 \mathrm{wd} / \mathrm{mo}$

$=31,069$ months of work or employment for 6,214 workers for 5 months

High Yield: 521,982 tonne x P 285.7/tonne $\div$ P 150/day per person

$=994,201.7$ days $\div 24 \mathrm{wd} / \mathrm{mo}$

$=41,425$ months of work or employment for 8,285 workers for 5 months

Barrel Fuel Oil Equivalent (BFOE) of sugarcane trash

Low yield: $260,991 \times 1.8551$ bfoe/tonne trash

$=484,164.4 \mathrm{bfoe} \times 30 \mathrm{USD} / \mathrm{barrel}=14.5$ million USD

Ave yield: 391,486 tonnes $\times 1.855$ bfoe/tonne trash

$=726,206.5 \mathrm{bfoe} \times 30$ USD $/$ barrel $=21.8$ million USD

High Yield: 521,982 tonnes $\times 1.855$ bfoe/tonne trash

$=968,277.6$ bfoe $\times 30 \mathrm{USD} / \mathrm{barrel}=29.0$ million USD

*Source: Buan 2000.

- $\quad$ P 285.7/tonne is the labor cost per tonne in trash baling at Hacd. Luisita, Tarlac, Phil.

- $\quad P 150 /$ day is the average wage rate at the time of the study

- 24 working day ( $\mathrm{wd}) / \mathrm{mo}$ is the average working days of workers

- 5 months (Nov.-April) is the duration of trash baling

\section{The Collection of Cane Residues: Baling Versus the Bulk Retrieval and Handling of Sugarcane Residues:}

A brief overview is made of some cane trash handling options, which may provide alternative systems to those currently being used at Hacienda Luisita. The optimal choice will likely vary depending on whether the supply system is for immediate use as a bunker fuel substitute during milling or if it is stored as a biofuel for power cogeneration during the off-milling season. Conventional hay harvesting equipment (Photos 3.1-3.2) can be used for sugarcane residue retrieval. Jakeway (1993) found machinery productivity was generally lower for sugarcane than for hay.

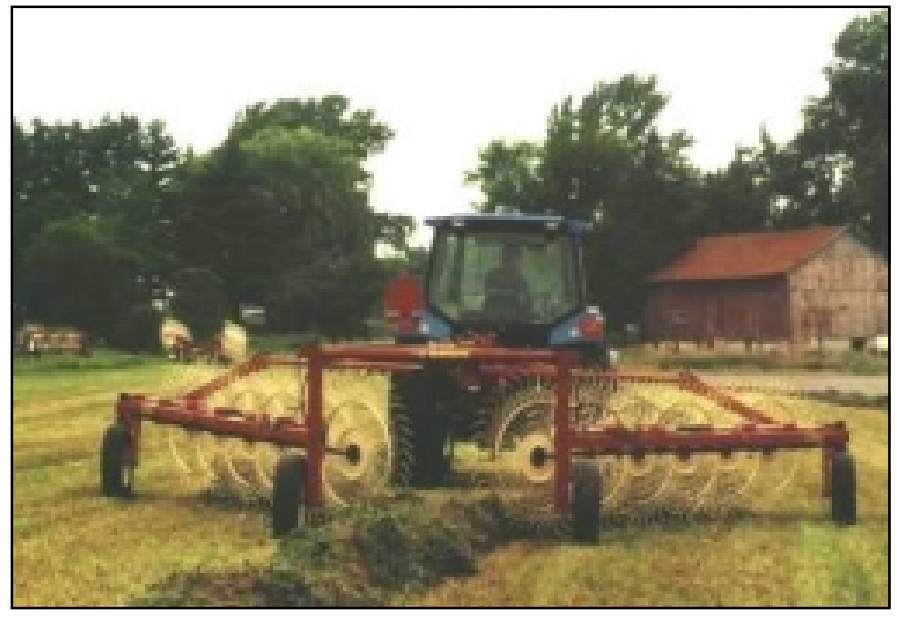

Photo 3.1. Wheel rake in action (hay windrows) 
Three methods of residue retrieval and handling are described below as possible handling systems:

1. Small square balers.

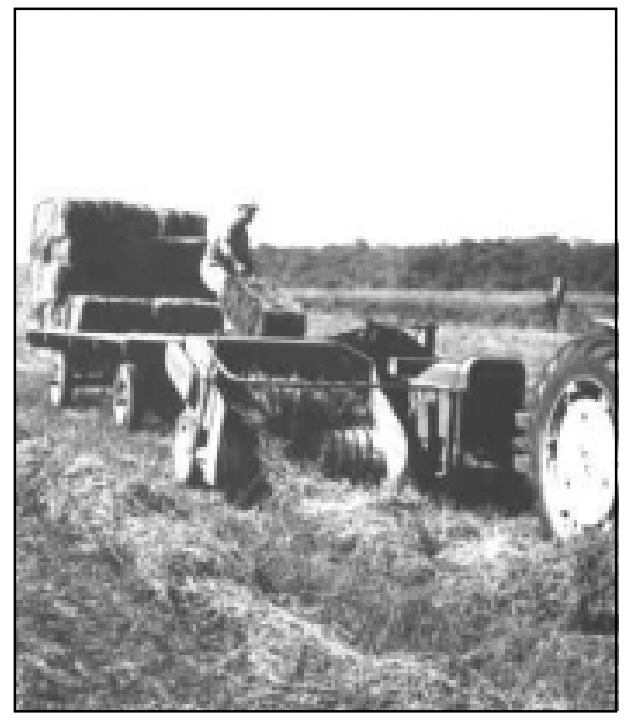

Photo 3.2. Small square baler with flatbed trailer in tow (hay bales)

The small baler (Photo 3.2) creates bales $46 \times 36 \times 80 \mathrm{~cm}$. Small bales are currently used at Hacienda Luisita. The harvest capacity of small bales is approximately 5 tonnes/hour. However, the capacity can be lower in field situations with hand loading (Jakeway et al., 1993). It was estimated as 2.6 tonnes/ha in Thailand where cane residue was square baled and hand-loaded onto a flat bed trailer at a residue recovery rate of $69.3 \%$. The average cost of baling for the small square bales was $\$ 21.66 /$ tonne in 1989 US dollars. The fuel requirement to operate the rakes and balers was 0.036 GJ/tonne (0.92 I fuel/tonne).

At Hacienda Luisita in the Philippines, the effective production rate was reported as 2.1 tonnes/hour. Lightweight bales $(7 \mathrm{~kg})$ were produced to ease manual loading. In comparison, average weights of straw bales are $12 \mathrm{~kg}$ with a bale density of 90 to $100 \mathrm{~kg} / \mathrm{m}^{3}$ (Centre for Biomass Technology, 1998). The retrieval system at Hacienda Luisita consisted of manually raking the windrows and using six Ford New Holland Model 311 engine driven balers and two CLAAS PTO-driven balers. Total costs (harvest, transport, and harvesting) amounted to $\$ 34.55$ in 1989 US dollars/tonne. Most of the cost was for the baling, which included the added cost of repairs and maintenance. A more recent cost analysis was performed by Teodoro Mendoza in February 2000 (Table 3.7) and amounted to 905 pesos/tonne at $26 \%$ moisture (P1,248/tonne including storage and trash purchase, see tables 3.6-3.7). In the former study, one tonne of $\mathrm{CR}$ at $22 \%$ moisture was equivalent to $250 \mathrm{~L}$ of bunker oil. The factory consumed 27,000 tonnes of cane residue, collected from 3,151 ha (Jakeway, 1993). 


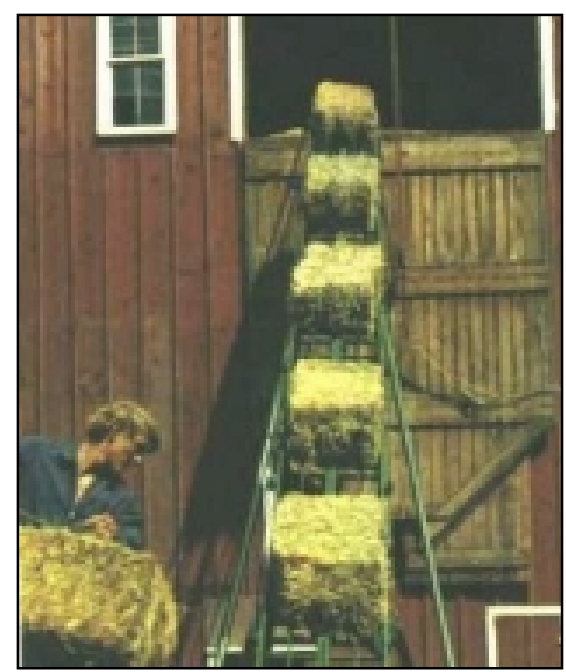

Photo 3.3. Bale elevator to ease the manual handling of square bales

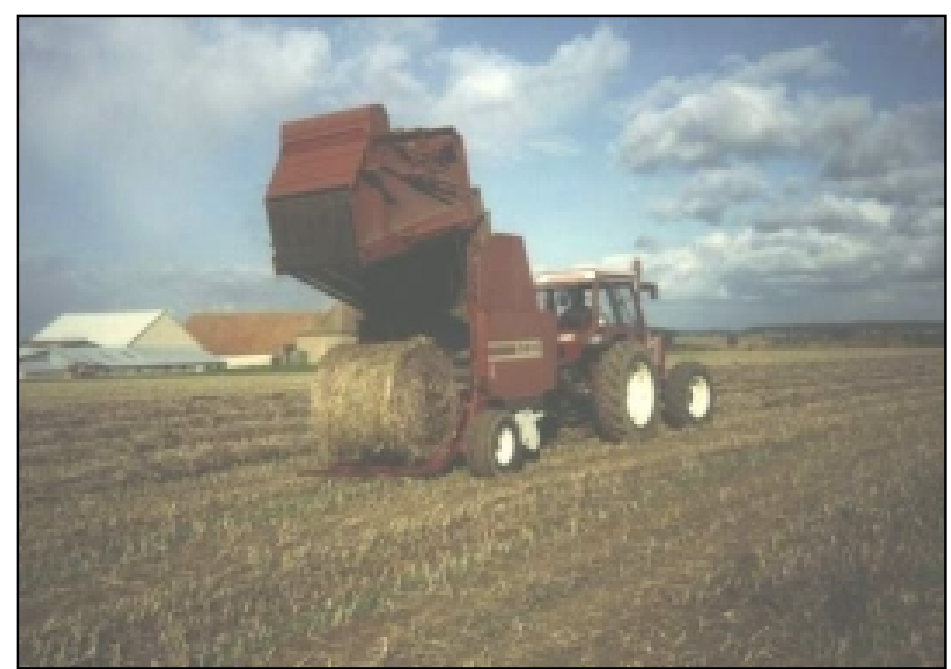

Photo 3.4. Large round hay baler (straw bale, Eastern Canada)

\section{Large round or square bales}

The most common type of round baler (Photo 3.4) creates bales $120-\mathrm{cm}$ in width by $150-\mathrm{cm}\left(4^{\prime} \times 5^{\prime}\right)$ in diameter. The average bale weight for straw is $244 \mathrm{~kg}$ with a bale density of $110 \mathrm{~kg} / \mathrm{m}^{3}$ (Centre for Biomass Technology, 1998). A popular large square bale size in North America is the 3'x4'x8' large square bale, which provides optimal efficiencies for transport.

In the Dominican Republic, cane residue was collected in large round bales at a cost of $\$ 27.75 /$ tonne (in 1983 US dollars). This price included storage and preparation costs (Jakeway, 1993).

In Thailand, big round balers processed 5.0 tonnes $/ \mathrm{hr}$ at $71 \%$ recovery. The large round bales weighed on average $375 \mathrm{~kg}$ (at $72 \%$ residue recovery) and required handling equipment to remove the bales from the fields and load them onto trucks for transport (Jakeway, 1993). The delivered cost of the bales was $\$ 21.84$ (in 1989 US dollars), and the fuel requirement was $1.04 \mathrm{~L} /$ tonne $(0.04 \mathrm{GJ} /$ tonne $)$. No studies could be identified which examined cane residue harvest with large square bales, but it would be expected that harvesting costs would be comparable or slightly higher than round bales. The main reason for the increasing popularity of square bales for biomass processing facilities is efficiency of storage and transport. However, they do tend to spoil more quickly than round bales and require covered storage in most climates. 


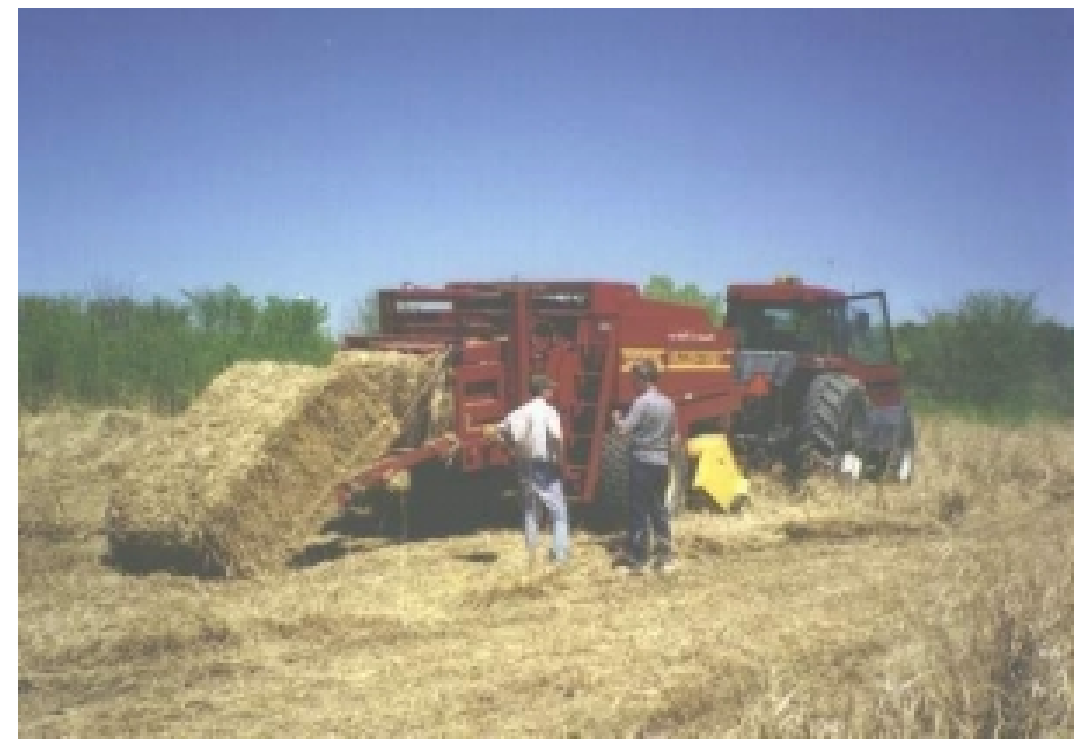

Photo 3.5. A big square baler produces rectangular bales $3^{\prime} \times 4^{\prime} \times 8^{\prime}$ in dimension which have a density of $150-175 \mathrm{~kg} / \mathrm{m}^{3}$.

\section{Bulk Handling.}

As an alternative to baling material, cane trash could be harvested in bulk, for example, by a chaff cutter/blower-system (Photo 3.6). This would be most practical where cane residues are used immediately as a biofuel. The density of bulk material ranges from 40 to $45 \mathrm{~kg} / \mathrm{m}^{3}$ for straw, although storage by loader tractor or straw blower with adjuster fan can increase the density to $70-80 \mathrm{~kg} / \mathrm{m}^{3}$ (Centre for Biomass Technology, 1998).

Forage choppers for mechanically harvesting cane residue have already been used in the Dominican Republic (Phillips, 1987; Lopez, 1986). The effective production rate of the forage harvesters was 5.7 tonnes/ha at $68 \%$ field efficiency and $28 \%$ moisture. Conventional hay rakes were used for windrowing, while forage harvesters were used for collecting and processing. The average bulk density of the finely chopped cane was reported as $120 \mathrm{~kg} / \mathrm{m}^{3}$, which appears high compared to other data. Operating costs were given as $\$ 8.18 /$ tonne (in 1985 U.S. dollars), $37 \%$ of which were attributed to the forage chopper. In the US, field chopping has proven to be a viable grass biofuel handling system (Bransby 1999).

The cost of rural labour (between 75 to 100 pesos/day per person) is approximately thirty times less on Negros Island, Philippines, than in North America. Consequently, the influence that labour has on the overall cost of handling is small in the Philippines compared to industrialized nations. Handling the material in bulk reduces the processing steps required for the material, and does not require a bale breaker for pre-processing prior to being fed into the boiler. Table 3.10 below summarizes the advantages and disadvantages associated with the three methods of sugarcane trash retrieval. 


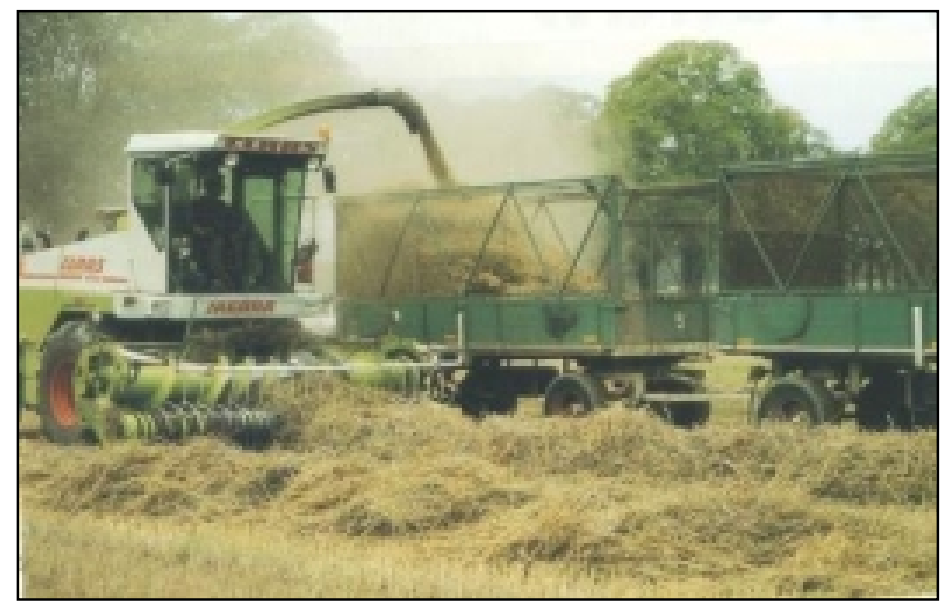

Photo 3.6: A self-propelled chaff cutter can blow straw into wagons or open transport trucks that can take the materials directly to the processing plant (Centre for Biomass Technology, 1998).

Table 3.10: Comparison of recovery systems

Advantages

Disadvantages

Small square bales

- Low capital investment for baler and tractor.

- Low density $\left(75-110 \mathrm{~kg} / \mathrm{m}^{3}\right)$.

- Labour intensive and slow loading

- Proven performance.

- Lightweight equipment reduces compaction in the rainy season. (2-2.5 tonnes/hr for hand loading of a flatbed trailer).

- Requires covered storage

- Well suited to small farms.

- Creates much employment

\section{Large Round or Square Bales}

- High Density $\left(150-175 \mathrm{~kg} / \mathrm{m}^{3}\right)$.

- High capital costs.

- High harvest capacity (5 tonnes/hr).

- Fast loading and good transport capacity for the square bales.

- Heavy equipment may cause compaction, may not be suitable for humid tropical areas during the rainy season.

- Larger machinery required (a front end loader is needed for transport).

- Somewhat more difficult to process

\section{Bulk Retrieval}

- Lowest harvest cost as baling costs and bale breaking eliminated.

- Can be fully mechanized.

- Generally lowest energy costs.

- Harvest capacity varies, depending on type of retrieval system.

- Well suited for immediate use
- Higher transport and storage costs due to the low density $\left(50-75 \mathrm{~kg} / \mathrm{m}^{3}\right)$

- Potential for large field losses if dry material / windy conditions

- Higher risk of fire.

- Low employment potential 
The following observations were made with respect to the harvesting/handling of sugarcane residues:

- In the case of Hacienda Luisita trash collection system, the use of higher density bales $(12-15 \mathrm{~kg}$ vs. $7 \mathrm{~kg}$ ) could reduce collection costs. Collecting material in fields directly from the baler with bale wagons would minimize the manual handling of heavy bales.

- Other systems of trash handling may ultimately prove more effective, especially for large mills. For direct use as a bunker oil substitute, bulk harvesting could be the most economical system if sufficient trash could be located near the sugar refinery. Small bales would be more appropriate for situations where small fields exist or where wetter soil conditions are present.

- The storage of sugar cane trash allows for the option of generating electricity during the off-milling season. Large square bales would be the most suitable as the highdensity product reduces transport and storage costs. For year-round power generation, biomass will have to be collected at a greater distance from the mill than for bunker oil substitution. The system can be fully mechanized and efficient; chopping devices are now available to break down large bales to feed into boilers. Small square balers could be used to supplement this system. The feasibility of using bulk handling for stored systems needs further examination.

The best way to expand the utilization of cane trash would be to improve the Hacienda Luisita system. This could be achieved by using higher density bales and collecting material in fields with bale wagons to minimize the weight problem of increasing bale density. Bale elevators could also be used for stacking bales in piles.

\section{E. Storage Systems}

\section{Exposed Bales:}

The effect of storage under exposed conditions on both dry matter and energy content were evaluated for cane bales (small square bales vs. large round bales) (Jakeway 1993). It was found that during the wet season small bales required storage cover for protection if not used immediately. After one year only $9.8 \%$ of the round bale dry matter was lost, vs. $57.6 \%$ for the square bales. Degradation in fuel value was also noted for the small square bales.

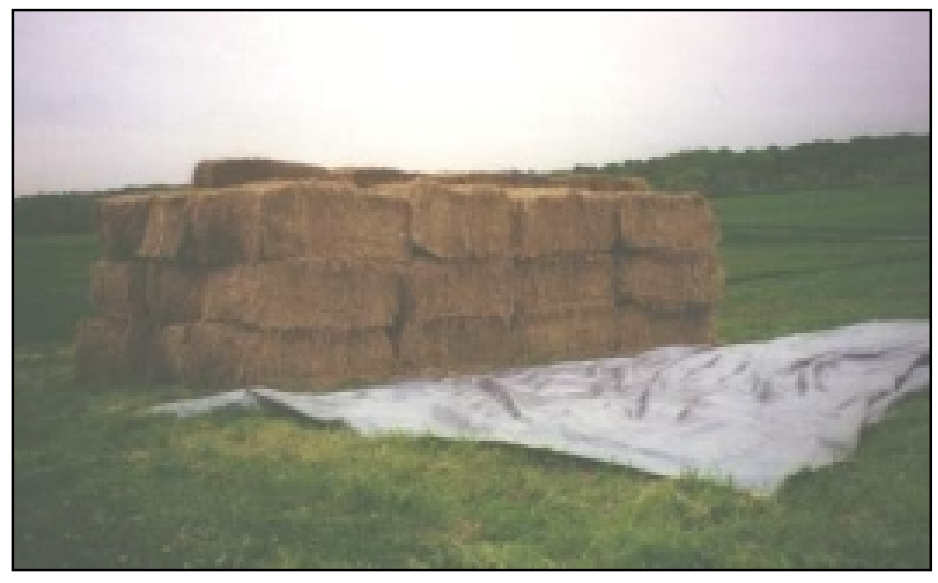

Photo 3.7: Stack of large square hay bales with tarpaulin for short-term storage 
Table 3.11: Bale storage test results conducted in Hawaii

\begin{tabular}{|l|c|c|c|c|c||}
\hline & \multicolumn{5}{|c|}{ Storage Period (Months) } \\
\hline & 0 & 3 & 6 & 9 & 12 \\
Round Bales & 18.3 & 14.6 & 28.1 & 26.5 & 14.2 \\
Moisture, \% & 12.2 & 10.6 & 13.5 & 15.0 & 13.3 \\
Ash (dry basis, \%) & 12561 & 13494 & 10570 & 10639 & 13132 \\
NCV* (as received) KJ/kg & & & & & \\
Square Bales & & & & & \\
Moisture, \% & 25.4 & 23.6 & 72.2 & 66.5 & 49.4 \\
Ash (dry basis) \% & 10.5 & 11.8 & 16.0 & 20.5 & 27.4 \\
NCV (as received) KJ/kg & 11493 & 11634 & 2477 & 3150 & 5336 \\
& & & & & \\
\hline Precipitation (mm) & 0 & 50 & 440 & 650 & 60 \\
\hline
\end{tabular}

Source: Jakeway, 1993.

${ }^{*} \mathrm{NCV}=$ net caloric value expressed in GJ per kg

Table 3.12: Dry matter loss data for round versus square bales after one-year storage.

\begin{tabular}{|l|c|c|}
\hline & Round & Square \\
\hline Initial average bale weight $(\mathrm{kg})$ & 339.0 & 21.2 \\
Initial Moisture (\%) & 26.6 & 25.4 \\
Dry Matter Weight (kg) & 248.8 & 15.8 \\
Final average bale weight (kg) & 251.8 & 11.5 \\
Final Moisture (\%) & 10.9 & 58.3 \\
Dry Matter Weight (kg) & 224.4 & 6.7 \\
\% Difference in dry matter from initial & 9.8 & 57.6 \\
\hline
\end{tabular}

Source: Jakeway, 1993.

Covered storage of the sugarcane trash, whether in bulk or baled form, keeps the material dry, prevents rotting, and preserves the energy content of the bales. Several relatively inexpensive storage alternatives could be used, as shown in Photos 3.7-3.9. There are essentially three main storage options: short-term storage with tarpaulins (Photo 3.7), steel buildings (commonly used for bagasse storage), or a truss arched tarp building (Photo 3.8). The arch, a woven-fabric type of structure, is increasingly used in North America to store hay bales on individual farms (Photo 3.9). The material has a 1015 year life span and could be replaced if lost in a severe typhoon. Tarpaulin covers could also be used for short-term protection as a low-cost (but less reliable) storage system (Photo 3.7). A recent economic analysis (Huisman et al. 2000) found that steel buildings might prove to be the most economical option for large-scale biomass storage. This is particularly true for large square bale storage. Costs were similar for the steel and tarp covered systems at \$4-6 US/tonne while costs for the fabric covered truss systems were approximately double. Storage costs of high density square bales (174 $\mathrm{kg} / \mathrm{m}^{3}$ ) were approximately $40 \%$ below that of the lower density $\left(110 \mathrm{~kg} / \mathrm{m}^{3}\right)$ small 
square bales. The combined use of high-density square bales and increasing the storage height of the piled bales appears a successful strategy to minimize storage costs.

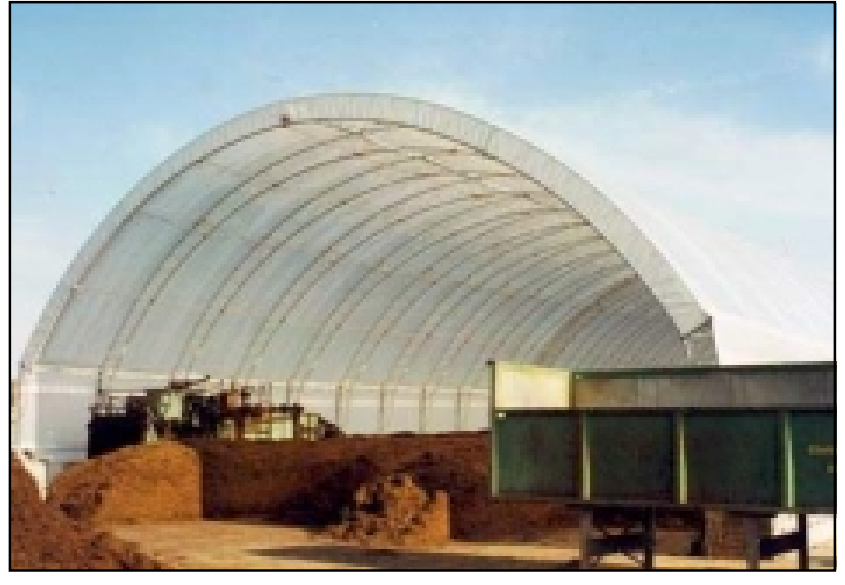

Photo 3.8 Single arch, woven fabric shelter can be used for bulk storage

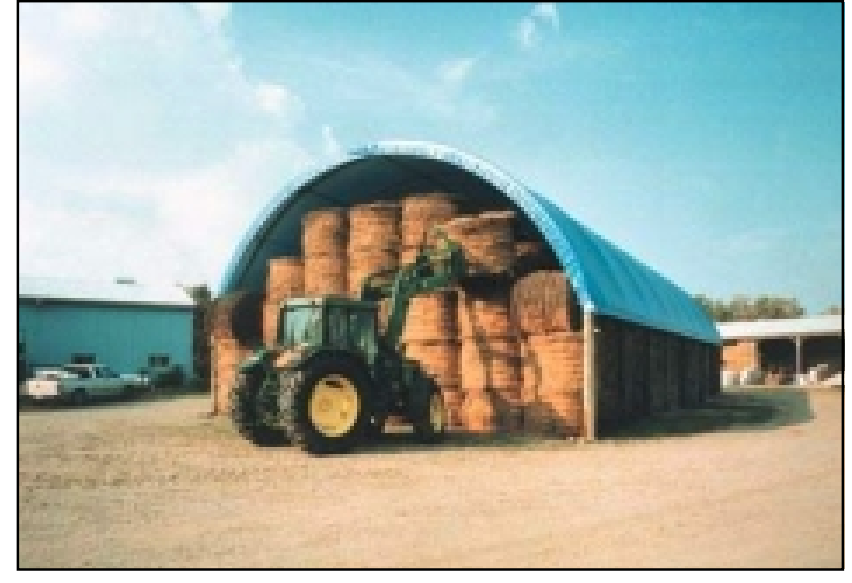

Photo 3.9. Single arch, woven fabric shelter for storing bales

\section{Bale Breakers}

For the large square bale system to be practical, bales will have to be broken down into a size suitable for the boiler. New bale breaking equipment has been designed with relatively low power requirements (Photo 3.10). These machines have much higher capacities and lower energy requirements than tub grinders. Further experience with large volumes of biomass should greatly improve the ability to use large bales for cane boiler fuel.

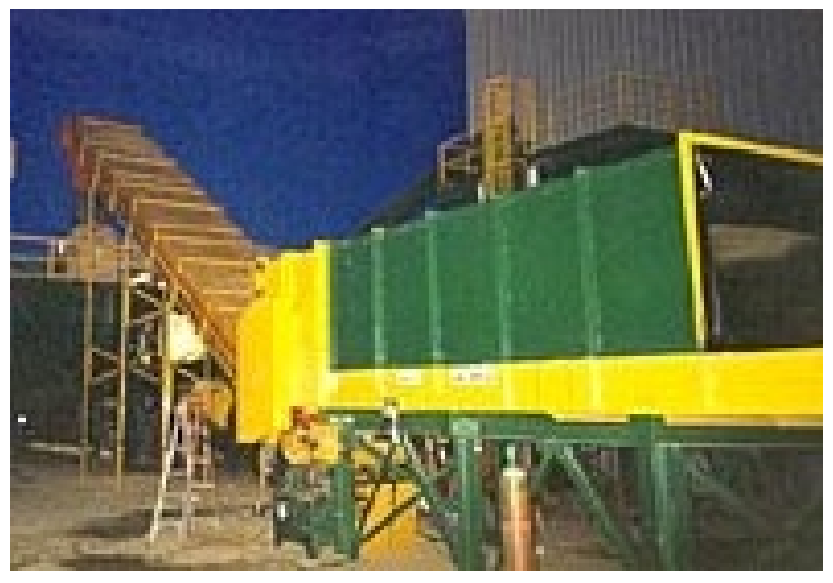

Photo 3.10. An industrial bale breaker from Newhouse Manufacturing in Oregon produces an output of 10 tonnes/hour for large square bales, has an 80 horsepower motor, and produces a chop of 1.5 to 6 inches in length. The cost of the device is approximately $\$ 50,000$ US. 


\subsection{Production of Dedicated Energy Crops}

3.4.1. Production of High Yielding Perennial Grasses [i.e. Napier grass, (Pennisetum purpureum)l

Napier grass (Pennisetum purpureum) is a very tall grass (Photo 3.11) similar to sugar cane and energy cane and well suited to tropical environments. Grown in fertile soils or regularly fertilized with chemical fertilizer and manure, this and other high yielding perennial grasses produce a large amount of biomass and are easily planted from stem cuttings. Like sugarcane, they can be ratooned after harvesting the matured stem/leaf. Adapted cultivars can be maintained for 5-10 year production cycles. Table 3.13 summarizes the outstanding features of perennial high yielding warm season grasses as biomass crops. Napier grass (Photo 3.11) is not new to the Philippines. It is mainly grown as animal forage. In fact, the two varieties available in the Philippines- Mott ( $\underline{P}$. purpereum $\mathrm{Cv}$. Mott) and King ( $\underline{P}$. purpereum X $\underline{P}$. glaucum hybrid) were specifically selected and bred for animal forage. In other countries, selections and/or cultivars for biomass fuel are becoming available.

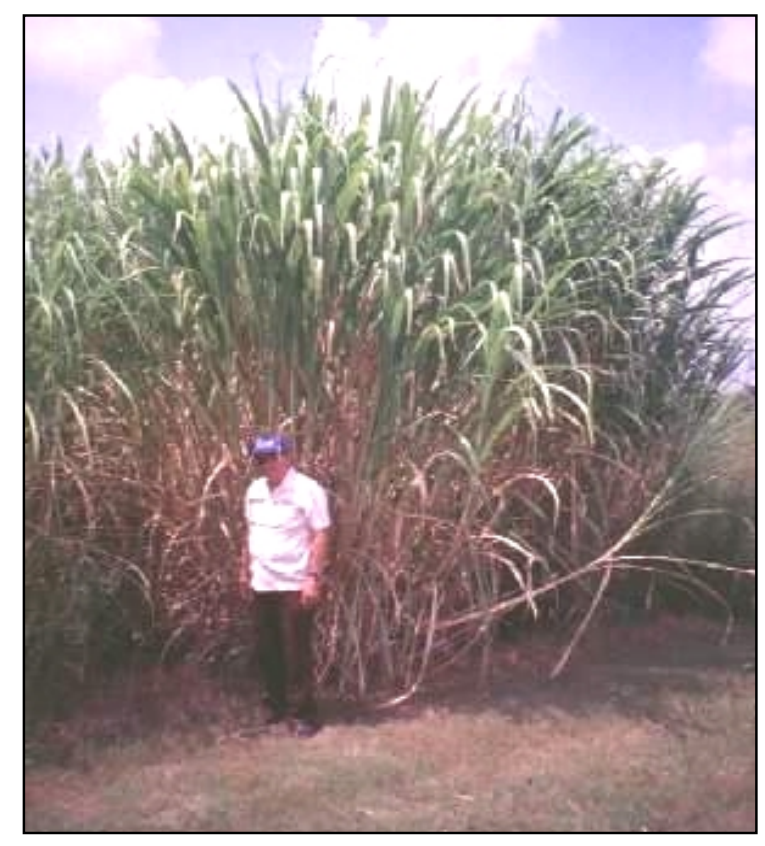

Photo 3.11. Dr. Gordon Prine with napier Grass in Florida. It is a tall, high yielding, perennial species that develops a canopy faster than sugarcane, reducing soil erosion losses in sloping areas. 


\section{Table 3.13. Common features of high yielding C4 Grasses as biomass crops (as}

summarized by Samson et al., 1993)

High productivity. When appropriate cultivars are chosen, yields can be up to 30 tonnes/ha.

Water use efficient. Uses water 2 times more efficiently than C3 crops. Root systems can extend up to $3.3 \mathrm{~m}$ with greater root weight at deeper soil depths than cool season grasses.

Low $\mathrm{P}$ requirements. Use of mychorrhizal symbiosis for $\mathrm{P}$ nutrient uptake provides advantages on soils with low levels of available $P$.

Low $\mathrm{K}$ requirements. Has lower critical K level.

Stand longevity. Exhibits longer persistence (perennial trait), minimal disease, and fewer insect problems.

Acid tolerance. Tolerates low pH (less than 5.0).

Environmentally friendly. They can provide nesting and food sources (seeds) for birds. As application of chemical fertilizer it is lower than most field crops, nitrate and P loading into water sources is minimized.

Research and development on the adaptability and selection of napier cultivars for biofuel is necessary for sustaining biomass supply in COGEN power plant projects. An economic analysis of napier production for biofuel revealed that the total cost as it reaches the mill yard is approximately P1339/tonne (Table 3.14).

\begin{tabular}{|c|c|c|}
\hline ITEM & Unit Cost $(P)$ & Cost Per ha $(\mathrm{P})$ \\
\hline \multicolumn{3}{|l|}{ Establishment Cost } \\
\hline \multicolumn{3}{|l|}{ 1. Land Preparation } \\
\hline \multirow{3}{*}{$\begin{array}{l}\text { Plowing } \\
\text { Harrowing } \\
\text { Furrowing }\end{array}$} & \multirow{3}{*}{$\begin{array}{l}\text { Mold Board (P2,500) } \\
\text { Secondary plowing (P1,000) } \\
\text { P } 900 \times 2 \\
\text { P } 900 \times 1\end{array}$} & 3,500 \\
\hline & & 1,800 \\
\hline & & 900 \\
\hline \multicolumn{3}{|l|}{ 2. Preparation of planting materials } \\
\hline \multicolumn{2}{|l|}{45,000 cuttings } & 2,400 \\
\hline \multicolumn{2}{|l|}{ 3. Hauling/distribution of cuttings } & 1,800 \\
\hline \multicolumn{2}{|l|}{ 4. Planting of cuttings } & 3,000 \\
\hline
\end{tabular}

\begin{tabular}{|l|l|c|}
\hline 5. Cultivation/Weeding & $\begin{array}{l}\text { Chisel plow/ripper }=(\mathrm{P} 450) \\
\text { Cultivator }(2 \times 300 / \mathrm{ha}) \\
\text { Hand weeding (P500) }\end{array}$ & 1,550 \\
\hline TOTAL & & $\begin{array}{c}14,950 \\
\text { (P2,990 when amortized over 5 years })\end{array}$ \\
\hline
\end{tabular}


Research suggests that it costs almost the same to grow and harvest napier as to collect, bale, haul, and store sugarcane trash as a biomass supply during the off-milling season. The largest additional cost is the land, as napier is a dedicated crop unlike sugarcane. Unfortunately, the Philippines has limited land available, as most of the agriculturally favorable areas have been cleared and are entirely used for crop production. The areas with the most potential for napier based biofuel production are hilly areas with marginal, eroded/degraded soils. Due to the remoteness of such sites, (50-100 km from the nearest mill or COGEN power plant) hauling and transport costs may be somewhat higher.

\begin{tabular}{||c|c|c|}
\hline \multicolumn{3}{|c|}{ Table 3.15. Production budget for napier/energy cane } \\
\hline \multicolumn{1}{|c|}{ Item } & $\mathrm{P} / \mathrm{ha}$ & $\begin{array}{c}\text { P/tonne } \\
(26 \% \text { moisture content.) }\end{array}$ \\
\hline $\begin{array}{l}\text { Establishment (amortized over 5 years, } \\
\text { from Table 3.14: 14,950/5 = 2990) }\end{array}$ & 2990 & 100 \\
\hline Fertilizer & & \\
\hline$\bullet \quad 168 \mathrm{~kg} \mathrm{~N} \mathrm{@} \mathrm{17.7} \mathrm{P/kg}$ & 2974 & 99 \\
\hline$\bullet \quad 84 \mathrm{~kg} \mathrm{~K} \mathrm{@} \mathrm{26.6} \mathrm{P/kg}$ & 1117 & 37 \\
\hline Fertilizer Application (P66/bag) & 840 & 28 \\
\hline Harvest and Transport (P 645/tonne) & 900 & 30 \\
\hline Subtotal & 19350 & 645 \\
\hline Land Lease and Management & 25181 & 939 \\
\hline Storage & 6000 & 200 \\
\hline Total Cost & 6000 & 200 \\
\hline Total Revenue & 40170 & 1339 \\
\hline Net Return & 49500 & 1650 \\
\hline
\end{tabular}

The pricing of napier grass and the actual costs of production remain to be determined. Our analysis indicates that napier hauled at $26 \%$ moisture could be produced at about P73.6/GJ (P1339/tonne) with 1 to 2 weeks sun drying after cutting. Napier grass at $26 \%$ moisture has $28 \%$ of the energy value of bunker oil. If bunker oil is priced at $\$ 220.50$ US/tonne (\$30/barrel) the equivalent oil energy value of napier is $\$ 62.50 \mathrm{US} /$ tonne. Napier grass and sugarcane trash have roughly the same heating value, and could be priced at the same level. Assuming that napier grass and sugarcane trash were priced at one third below the price of bunker oil (approximatley P1650/tonne) it would be economically attractive for use by sugar mills as a bunker oil substitute. This would provide growers with a reasonable rate of return. Assuming a price of napier grass of $\mathrm{P} 1650 /$ tonne, at 30 tonnes/ha, the farmer would be earning $P$ 49,500/ ha.

Using napier as a biofuel option for power co-generation is positive for the environment since it is a renewable form of energy. The SWOT (strength/weaknesses/ opportunities/threats) analysis of using napier during the sugarcane off-milling season is shown in Table 3.16. The use of napier is comparatively better than rice, maize, and 
root crops, and if land is accessible, growing napier as a biofuel could be attractive. The main advantage of napier grass production is its potential to dramatically increase biofuel availability during the off-milling season. Planting 50,000 ha of napier grass could provide one million ODT; 3.5 times more biomass than the amount of available sugarcane trash. The development of napier grass would follow the utilization of sugarcane trash as a substitute for bunker fuel (presumably the first step towards an offseason power generation industry). One outstanding question is the suitability of the napier grass as a feedstock for long term boiler operation, and concerns about clinker formation and fouling.

To promote napier cultivation to ensure a biofuel supply for power co-generation during off-milling, two possibilities are being suggested:

1) Forming contracts with small to medium sized farmers. An assured buy-back at an agreed price of P1650/tonne will encourage them to grow napier. COGEN plant owners should provide technical advice on the proper establishment and care of napier. High yielding and well-adapted cultivars should be provided to farmers. Whenever possible, an advance purchase of the appropriate amount (i.e. $30 \%$ ) of harvestable napier should be made.

2) The COGEN plant owners may also look for landowners that are willing to lease their land for napier cultivation. Current lease rentals may range from P5000$8000 / \mathrm{ha} / \mathrm{yr}$.

Adding lease rental and storage to the establishment, maintenance, harvesting, and hauling costs increased the price to about by P400/tonne. When the additional costs of administration, depreciation, and interest are taken into account, the cost of napier cultivation totals P 73.6/GJ (1,339/tonne or more). An advantage of leasing lands is the assurance of a better/higher supply by placing napier management under control of the COGEN plant owners. 
Table 3.16. SWOT analysis of using napier as biofuel supply option for power COGEN STRENGTHS

- Renewable supply

- No net $\mathrm{CO}_{2}$-GHG contribution

- Generates rural employment

- Saves dollar via reduced bunker oil imports

- Alternative crop for small hold farmers

- Causes less soil erosion/degradation than maize or root crops

- Easier to grow than vegetables, root crops, upland rice, or maize

- Perennial (less labor required)

- Presently no major pest or disease problems

OPPORTUNITIES

- Crop option for diversification.

- Less labor intensive, suiting the utilization /diversification pattern in rural areas. WEAKNESSES

- Revenue can only be obtained after 1 year

- May compete with land devoted to staple crops

- Requires high fertilizer input to achieve high yield

- Cultivar types for biofuel are yet to be selected/identified

- Requires a period of promotion as farmers in general have a "wait-and- see" attitude.

- Logistics of drying and storage more difficult than wood.

\subsubsection{Fast Growing Fuel Wood Tree Species}

Despite the wood deficit in the Philippines, tree planting has not gained acceptance among farmers. Possible explanations include the long growing period of wood tree species and the lack of a ready market for wood in communities where trees are to be planted. There also appears to be a lack of support services for tree improvement.

Adopting power co-generation in sugarcane milling would provide an additional market for fuelwood. Thus, planting or integrating fuelwood tree species into the existing agricultural landscape would offer the potential for increasing farmers' income. Tree cultivation is also compatible with environmental enhancement, protection and conservation measures in the rural areas (Lasco, 1999; Espiritu, 1999).

Farm-level promotion of fuelwood tree species cultivation would require research in the following areas:

- Appropriate wood tree planting schemes

- Identification/selection of fast growing fuelwood tree species

- Provision of seeds/seedlings and initial tree-establishment techniques and subsequent care and maintenance

- Optimization of the logistics of fuelwood supply systems. 


\section{Fuel wood tree planting schemes}

There are at least 2 schemes of planting and/or integrating wood tree species in the agricultural landscape. These are as follows:

Perimeter or boundary planting of wood tree species. Instead of using barbed wire or hog wire to border an area, trees can be planted at dense spacing. These trees would serve as barriers, property-line markers, wind-breaks, and a fuelwood source for 6-8 years after planting. 2 to 3 rows along the farm perimeter may be planted to increase wood tree yield per farm.

Planting trees on marginal agricultural areas. Planting marginal areas with 3 to 4 species of fuelwood diversifies the landscape and readily promotes a solution to the current problem of soil erosion. It also addresses the need to manage micro-watersheds in the farm or community. Assessing $\mathrm{CO}_{2-}$ sequestering agricultural practices (Mendoza and Delos Santos, 1999) showed that integrating wood tree species in the agricultural landscape yielded the highest $\mathrm{CO}_{2}$ sequestration impact.

\section{Identification/selection of fast growing fuelwood tree species.}

To encourage farmers to plant trees for biofuel, information must be provided about species of trees adapted to their specific farm situation and location. Appropriate species mixtures for perimeters/boundaries should be specified. Farmers dedicating areas entirely to fuelwood also require information about appropriate tree species.

Appendix 3.6 provides the fuelwood tree options for a given planting scheme and farm situation. The inclusion of multipurpose tree legume species appears advantageous and practical and eliminates the need for $\mathrm{N}$-fertilizer application to boost tree growth. Leaflitter serves as a nutrient supply to the shallow rooted crops grown by the farmers.

\section{Provision of seeds/seedlings}

Agricultural landscapes are generally planted with only a few annual crop species. In Negros, sugarcane is planted on about $90 \%$ of agricultural lands while the remaining land is planted with rice (waterlogged areas) and maize/vegetables (upland areas).

Fuelwood seeds and seedlings must be readily available, as currently it is difficult for interested farmers to obtain seeds for fuelwood species. Part of an investment package in power COGEN project would be to allocate funds for nursery establishment in selected farms and communities.

On-the-job training (OJT) about nursery establishment and management (NEM) will be necessary. Cost estimates of OJT are shown in Table 3.17 (Mendoza, 1999). 
Table 3.17. Budgetary requirements* for on-the-job training (OJT) about nursery establishment and management (NEM).

\begin{tabular}{|l|c|}
\hline \multicolumn{1}{|c|}{ Training Inputs } & Cost per 5 Nurseries (P) \\
\hline $\begin{array}{l}\text { 1. Orientation on the principles/practices of NEM (Meals, } \\
\text { transport, training facilitation) }\end{array}$ & 270,000 \\
\hline $\begin{array}{l}\text { 2. Nursery materials: seeds, nursery contributions, etc. } \\
\text { 3. Seedling care and management: meals, materials, other } \\
\text { expenses }\end{array}$ & $1,435,000$ \\
\hline $\begin{array}{l}\text { 4. Activity supervision/monitoring: salaries, transportation, } \\
\text { allowances, technical supervision (1 year) }\end{array}$ & 280,000 \\
\hline $\begin{array}{l}\text { 5. Nursery cost indicators } \\
\text { Ave. Cost/nursery }\end{array}$ & 539,000 \\
\hline Target seedling output per nursery (minimum) & $2,524,000$ \\
\hline Cost per seedling ready for outplanting & 150,000 \\
\hline
\end{tabular}

* Source: Mendoza 1999.

\section{Purchasing Fuelwood}

There are two concerns associated with the purchasing of firewood:

(1) The management of the tree-cutter labor-force (e.g. location of collection points of the harvested wood).

(2) The purchasing price by weight or volume of fuelwood. In Mindanao, where planting wood trees for pulp and paper has gained acceptance by progressive farmers, it is the farmers themselves who decide the appropriate length and diameter to cut the trees. The wood is then hauled (by carabao) to pick-up points accessible by hauling trucks. If the farm is accessible, the hauling truck may go directly to pick up the harvested trees.

The pricing of biomass may be determined by different methods. A simplified method is to compare the energetic value (e.g. BFOE or GJ/tonne) associated with the biomass to that of oil.

For illustrative purposes, let us consider an average BFOE of fuelwood of 2.56 BFOE/tonne of wood: Different tree species have varying BFOE's. These shall be specified later.

$\begin{array}{lll}1 \text { tonne wood } & = & 2.56 \mathrm{BFOE} \text { per dry tonne } \\ 1 \text { barrel oil } & = & \$ 30 \mathrm{US} \\ 1 \text { tonne wood } & = & \$ 30 \times 2.56 \mathrm{BFOE} \text { per tonne } \\ & = & \$ 76.80 / \text { tonne }\end{array}$

The price of fuelwood in the Philippines is rising with the continued deforestation of the nation. The average retail price for firewood was identified in the 1995 household survey to be P 2,480/tonne (in the rural areas of the Western Visayas). Purchase of wood in shelterbelts or plantations will have to compete with firewood prices. For the very high volumes of fuelwood required to develop an off-season sugar milling industry, the 
delivered cost will be higher than the relatively low cost materials the mill can currently procure for the initial firing of the boilers. Production of large volumes of wood will ultimately compete with firewood prices. Hence, a purchase price for fuelwood of $80 \%$ of the 1995 household survey price was assumed. At P2000/tonne, fuelwood can produce steam at 2/3 the cost of bunker oil at $\$ 30$ per barrel.

\subsection{Economic Considerations of Biomass Usage in Sugarcane Mills}

Currently bagasse accounts for $87 \%$ of the fuel requirements of Philippine sugarcane mills. Thus, an energy deficit of $13 \%$ of overall fuel usage is replaced by other means (see Appendix 3.1,Table B). Nationwide, 5.9\% of this deficit is covered by bunker fuel oil. An economic analysis (Appendix 3.4) was completed to examine using sugarcane trash to supplement bagasse and maximize the replacement of bunker oil. The energy deficit that is usually filled by bunker oil represents approximately 364,570 barrels of oil. At a current oil price of $\$ 30 \mathrm{US} / \mathrm{barrel}$, this represents a cost of $\$ 11$ million US. Hence, the sugar industry stands to gain considerably from adopting economic energy alternatives such as sugarcane trash and napier grass biofuels.

Appendix 3.4 compares the cost of steam production by oil and by biomass fuel sources (bagasse, sugarcane trash, and napier grass). Cost savings associated with utilizing of sugarcane trash were estimated as $\$ 6.3$ million US if the cane was purchased at the cost of production (P1048/tonne). This estimate assumed that the harvested trash was used as a feedstock and did not require storage. If storage were required, the overall cost would increase by roughly $20 \%$, but would still be the most economic alternative to bunker oil. Harvesting the trash one year in three for a 1plant:2ratoon cycle easily satisfies energy requirements. Annually, 161,000 tonnes of trash are needed, while approximately 391,486 tonnes are available if trash is only harvested in the final ratoon year (Appendix 3.1). As well, an estimated 2,500 jobs could be created for 5 months for the harvest of the cane trash. Napier grass also was also determined to be an economically viable alternative to bunker oil.

The price of napier grass and sugar cane trash will most likely be higher than their costs of production. Estimates for the purchase price of cane trash and napier grass were made (Table 3.18). Napier grass and cane trash have similar heating values, and would be priced at the same level. If mills were to purchase napier and cane trash at a price of P1650/wet tonne, the savings would still be an estimated at $\$ 3.7$ million US.

The pricing of wood remains an issue, as the purchase of wood for mill use from tree plantations would be in competition with firewood. The purchase price of fuelwood was thus assumed to be higher than the price of napier and cane trash, at P 2,000/tonne due to its higher steam production potential. It was priced the same as napier grass and sugarcane trash on a per pound of steam basis $(21 \phi / \mathrm{lb})$ or the equivalent of $\$ 20 \mathrm{US}$ per barrel of oil.

The Philippine sugar industry has lagged behind other nations in modernizing management practices and equipment used in its mills (see Appendix 3.1,Table G). Bunker oil supplementation is about double that used per tonne in Australia, and Thailand's sugar mills meet nearly $100 \%$ of their energy needs with bagasse through the use of high efficiency boilers. Clearly there is an opportunity for the Philippine sugar 
industry to reduce fossil fuel imports. This can be done by installing more efficient boilers, which would use the bagasse resource more efficiently. Alternatively, with a very small investment in field machinery, sugar cane mills could procure trash to eliminate expensive fuel imports. The potential also exists for sugar cane trash, napier grass, and fuelwood to create a year round power generation industry (concurrently with modernization of sugar mills). This analysis indicated that all three fuels could be used as potential substitutes for power generation from oil. Further study is required on the suitability and biomass quality of sugarcane trash and napier grass for sustained firing in boilers currently being utilized by the industry.

Table 3.18. Fuel value, cost of production, and suggested purchase price of sugarcane bagasse, cane trash, napier grass, and fuelwood.

\begin{tabular}{|c|c|c|c|c|c||}
\hline Biomass & $\begin{array}{c}\text { Fuel value per tonne (wet) } \\
\text { based on bunker oil energy } \\
\text { equivalent, Pesos }\end{array}$ & $\begin{array}{c}\text { Cost } \\
\text { of Production }\end{array}$ & $\begin{array}{c}\text { Suggested } \\
\text { Purchase price } \\
\text { per delivered } \\
\text { tonne (P) }\end{array}$ & $\begin{array}{c}\text { HHV } \\
\text { GJ/tonne }\end{array}$ & $\begin{array}{c}\text { Moisture } \\
\text { Content \% }\end{array}$ \\
\hline $\begin{array}{c}\text { Sugarcane } \\
\text { bagasse }\end{array}$ & $\mathrm{P} 1,658$ & 0 & 1,050 & 18 & $48-52$ \\
\hline $\begin{array}{c}\text { Sugarcane } \\
\text { trash }\end{array}$ & $\mathrm{P} 2,489$ & $\mathrm{P} 1,048$ & 1,650 & 18 & 26 \\
\hline Napier & $\mathrm{P} 2,489$ & $\mathrm{P} 1,339$ & 1,650 & 18 & 26 \\
\hline Fuelwood & $\mathrm{P} 3,100$ & Varies & 2,000 & 20 & 35 \\
\hline
\end{tabular}

${ }^{*}$ The suggested purchase price for biofuels is $2 / 3$ of the energy cost of oil or $\$ 20$ USD per barrel 


\section{$\underline{3.6 \text { References }}$}

Apolinario, M. A., D. V. Gatanela, L. T. Escarilla, N. D. Gaston. 1998. Study on the Production of Briquettes from Bagasse. Proc. $45^{\text {th }}$ Annual National Convention. Aug. 11-14, 1998. Cebu City, Phil.

Bransby, David E. Field chopping as an alternative to baling for harvesting and handling switchgrass. Proceedings of the $4^{\text {th }}$ Biomass Conference of the Americas. Oakland, California, 1999. p. 325.

Buan, Raul S. Feb. 2000. Trash and Sugarcane By-Products Optn. Group Manager, Finance and Administration, Hacienda Luisita Inc.

Centre for Biomass Technology, 1998. Straw for Energy Production - Environment -Economy. Danish Energy Agency.

Corpuz, F. H. and P. S. Aguilar. 1992. Specific Energy Consumption of Philippine Sugar Mills.Energy Consumption of Philippine Sugar Mills. Proc. $39^{\text {th }}$ Annual Convention. Bacolod. City. pp. 410-421.

Corpuz, F. and APS Study Committee. 1996. The Evolution of an Alternative Payment System for the Philippine Sugar Industry. Proc. $43^{\text {rd }}$ PHILSUTECH Annual Convention. Aug. 69, 1996. Cebu City, Phil. p. 41-56.

Department of Energy. 1996. Department of Energy, Non-Conventional Energy Division. Energy Utilization Management Bureau, Status of Biomass Energy Technologies: Philippines. Asian Regional Research Program in Energy, Environment, and Climate : In cooperation with AIT, Bangkok, Thailand. $84 \mathrm{p}$.

Doon, R. and J. Thompson. 1998. Powering the Philippine sugar industry into the next millennium. Proc. $45^{\text {th }}$ PHILSUTECH Annual National Convention. Cebu City, Phil. P. 243-252.

EDUFI. (Energy Development and Utilization Foundation Inc.) 1994. Biomass Co-generation Potential in the Philippines Sugar Milling Industry. A Joint report of EDUFI, Office of Energy Affairs, Sugar Regulatory Administration and the Philippine Sugar Milling Assoc., Inc. (PSMAI), Mla., April, 1994.

ESMAP. 1993. Philippines: Commercial Potential for Power Production from Agricultural Residues. Joint study of Energy Sector Management Assistance Program (ESMAP, UNDP) and the Philippines Department of Energy.

Espiritu, N. O. 1999. Economy-Energy Nexus: Impacts and Implications for Change. Paper presented, National Consultation on Woodfuel Production, Trade and Education in the Philippines, Nov. 17-19. Training Center for Tropical Resources and Ecosystems Sustainability, UPLB, College of Forestry and Natural Resources, College, Laguna.

Hensleigh, T. E. and B. K. Holaway. 1988. Agroforestry Species for the Philippines. AJA Printers. No. 39 Prelayo Street, Tugatog, Malabon, Metro Manila, Philippines.

Huisman, W., B.M. Jenkins and M.D. Summers. 2000. Comparison of bale storage systems for biomass. Joint European and Americas Biomass Conference, Sevilla, Spain (in press). 
Jakeway, L.A., P. Kradangnga, A. Therdwongworakul. 1990. Evaluation of Sugarcane Residue Recovery Operations in Thailand. Conference Proceedings, ASAE Annual Convention. Chicago, Illinois. Paper \# 90-1534.

Jakeway, L.A. 1993. Cane Residue Recovery. Conference Proceedings. International Conference on Energy from Sugarcane. Hilo, Hawaii. Paper \#780.

Mendoza, T. C. and W. L. Delos Santos. 1999. Mitigating $\mathrm{CO}_{2}$ - Greenhouse Gas Emitting Agricultural Practices in the Philippines Context. Paper presented $4^{\text {th }}$ IFOAM-Asia conference, DAP, Tagaytay City, Phil. Nov. 18-21, 1999.

Mendoza, T.C. 1999. People's Organization (PO) Managed Nurseries. On-Site Nursery Establishment and Management at Bondoc Peninsula, Quezon, Phil. PEACE-BDP Project.

Lasco, R. 1999. Wood Energy Development in the Philippines : Environmental Impacts. Paper presented, National Consultation on Woodfuel Production, Trade and Education in the Philippines, Nov. 17-19. Training Center for Tropical Resources and Ecosystems Sustainability.

Lopez, P. A. 1986. The utilization of cane trash as a source of energy and furfural production at Central Romana. Inter-American Sugarcane Seminars, energy and by-products from sugarcane. September 24-26, 1986, Miami, Florida.

Pennington, M., I. Lacrose, A.D.C. Gonzales. 1996. Economic, Technological, and Financial Issues Related to Energy Generation in the Phil. Sugar Industry. Proc. 43 ${ }^{\text {rd }}$ PHILSUTECH. Annual Convention. Aug. 6-8, Cebu City, Phil. p. 332-345.

Phillips, A. L. 1987. Biomass Fuel from sugarcane crop residue. ASAE, St. Joseph, Michigan. Paper no. 876026.

Samson, R., P. Giroard, J. Omielan, and J. Henning. 1993. Integrated Production of warm season grasses and agroforestry for low cost biomass production. Proc. First Biomass Conference of the Americas: Energy, Environment, Agriculture, and Industry. Aug. 30Sept. 2, 1993, Burlington, Golden, Co., p. 235-247.

Santo, L. T. (1991). Agronomic Issues in Sugarcane Residue Collection. In Agronomic, social and environmental Issues. HSPA Expt. Station. Conference Proceedings. International Conference on Energy from Sugarcane. Hilo, Hawaii. Paper \#778.

Tangon, I. 1995. Electric Co-generation: Power systems analysis and protection - the BUSCO Experience. Proc. 42 ${ }^{\text {nd }}$ PHILSUTECH Annual Convention. Aug. 16-18, 1995. Cebu Plaza Hotel, Cebut City. p. 280-299.

Victoria’s Mill. April 2000. Victoria’s Milling Corporation, Philippines. 


\title{
Chapter 4
}

\section{Improving the Energy Efficiency and Economics of Sugarcane Production}

T. C. Mendoza ${ }^{1}$, R. Samson, ${ }^{2}$ and T. Helwig ${ }^{2}$

\author{
${ }^{1}$ Department of Agronomy \\ U.P. Los Baños, College, Laguna, Philippines \\ Tel. (049) 536-2466, Fax (049) 536-2468 \\ tcm@mudspring.uplb.edu.ph \\ ${ }^{2}$ Resource Efficient Agricultural Production (REAP) Canada \\ Box 125, Ste. Anne de Bellevue, Quebec, Canada H9X3V9 \\ Tel. (514) 398-7743,Fax (514) 398-7972 \\ REAP@Interlink.net, www.reap.ca
}




\section{EXECUTIVE SUMMARY}

Increasing the productivity of sugarcane in the Philippines is an important strategy for biomass energy production. It would further the stabilization of the sugar industry by improving mill capacity and reducing cane costs. Unfortunately, sugarcane production is declining as a result of extreme weather conditions including typhoons, floods, drought cycles (such as El Niño/La Niña), and difficult socio-economic conditions. Some of these factors can be mitigated by on-farm measures such as improving soil fertility and reducing the use of fossil fuel energy. This report analyzes the potential of resource efficient farming practices to reduce the cost of cane production and decrease the overall energy input in sugar production.

Sugarcane production is a mixture of manual and mechanized operations. The highest proportion of energy consumed in conventional practices is in the form of fertilizer $(50 \%$ of the total energy for the plant cane and $67 \%$ for the ratoon crop). Approximately $90 \%$ of the total fossil fuel energy consumed is as nitrogen fertilizer. Transporting cane to the mill consumes approximately $25 \%-30 \%$ of the total energy, and field preparation consumes $13 \%$ of the plant crop energy. Consequently, minimizing fertilizer inputs would result in the greatest decrease in fossil energy use and associated greenhouse gas emissions.

This study demonstrates that sugarcane trash farming could increase productivity and crop longevity, while reducing fertilizer inputs. Up to a $50 \%$ reduction in tillage could be realized by extended ratooning/trash farming under a plant crop 1:3 ratoon crop cycle compared to current practices (normally 1:1 or 1:2). One of the primary benefits of trash farming is the reduction of $\mathrm{N}$ fertilizer that is required to maintain high crop yields because of asymbiotic $\mathrm{N}$ fixation from decomposing trash litter. Research studies indicate that $50-200 \mathrm{~kg} \mathrm{~N} / \mathrm{ha}$ can be fixed/year during the ratooning cycle. Phosphorus fertilization can also likely be reduced, as crops under a surface mulch support more surface rooting and undergo less competition from weeds. Other benefits of mulching include a $50 \%$ reduction in inter-row cultivation, improved soil fertility, increased water retention, and minimized lodging of crops. A summary of sugarcane trash studies in Southeast Asia indicated that trash-farming increases yields by $5.8 \%$ in the plant crop and $20.1 \%$ and $30 \%$ in the $1^{\text {st }}$ and $2^{\text {nd }}$ ratoon crops, respectively.

Trash farming significantly increases the economic return of cane production when compared with conventional farming methods. Although net revenue decreases by $4 \%$ in the plant crop ( $\mathrm{P}$ 1184/ha), in the ratoon crop the net revenue increases by $28 \%(\mathrm{P}$ 8924/ha) when compared to conventional farming. The net result is an increase in net revenues for trash farming relative to conventional farming. This was primarily due to increased yields and reduced $\mathrm{N}$ fertilizer inputs. Further increases in profitability would be expected in subsequent ratoon crops.

Trash farming decreases the overall energy input required per tonne of cane produced. Conventional cane was projected to consume 0.44 and $0.40 \mathrm{GJ}$ of energy per tonne in the plant and ratoon crops respectively. Trash farming of the cane ratoon reduced the 
GJ/tonne demand to $0.24 \mathrm{GJ} /$ tonne. The $40 \%$ improvement in energy use was the result of a $20 \%$ increase in cane ratoon yield under trash farming and a $110 \mathrm{~kg} / \mathrm{ha}$ reduction in nitrogen input per year. An important strategy for success is the selection of cane with superior ratooning characteristics and adaptation to low nitrogen inputs. A $25 \%$ savings in energy per tonne of cane produced would provide 1.8 million GJ in overall savings. Another advantage of increasing trash farming is the potential bioenergy supply of cane residues. The combination of increasing cane yields and harvesting cane trash one year in three could increase the bioenergy supply by 26.5 million GJ/yr in the Philippines.

Despite these benefits, there are some difficulties associated with trash farming. The biggest challenge is management of the immense amounts of trash produced at harvest time. Three options are suggested to handle this problem:

(1) Modify the row spacing to accommodate the trash with minimal handling

(2) Pre-harvest detrash to eliminate the need for pre-harvest burn

(3) Increase planting and further develop self-detrashing varieties

A management system to optimize the utilization of cane residue to meet both the needs of farmers and cane millers would include in-situ trash mulching from the plant crop to the second or third ratoon, and trash baling in the final ratoon crop. This would increase the efficiency of cane production for the farmers, and provide millers with more cane of higher quality than they are currently receiving. It would also provide a sustainable biofuel supply that could be used to offset the bunker oil used in cane processing and expand opportunities for power generation during the non-milling season.

Cane trash farming is a self sustaining production system, as improving soil fertility enhances crop productivity, leading to further improvements in soil fertility, cane productivity, and energy self reliance for the industry. Trash farming has the potential to increase the international competitiveness of the Philippine sugar industry and to transform the industry from a net energy importer into a domestic energy producer. A sustainable production system could considerably revitalize the sugar cane industry and encourage bioenergy utilization in the Philippines and other developing nations. 


\subsection{Introduction to Conventional Sugarcane Cropping Systems}

Sugarcane is the most efficient major crop in the world at converting solar radiation into plant biomass. In Brazil, sugarcane is a primary agricultural export crop and the feedstock for a large biofuel ethanol industry. Unfortunately, the Philippine sugar industry currently does not produce enough sugar to meet the nation's need, or enough biofuel to make the sugar processing industry energy self-reliant. The industry is in a long-term state of decline and requires modernization.

As discussed in Chapter 1, major crop yields in the Philippines have plateaued, and in some cases decreased in recent years. Sugar is the commodity that has observed the most drastic decline in production. From a high of 2.6-2.8 million tonnes of refined sugar in the mid-1970s, production has dropped to about 1.6-1.8 million tonnes by the 1990s (Appendix 4.3). This decline in production can be attributed to many factors including typhoons, floods, drought, pests, low application of inputs, reduced production landbase, and most importantly, deteriorating soil fertility. Soil organic matter, an important indicator of soil fertility, was $2.3 \%$ in the 1970 s in the Victorias Mill district of Negros, Philippines. It dropped to $1.7 \%$ by 1988 , representing an approximate decline of $26 \%$ in organic matter (Alaban et al., 1990).

Implementation of more resource efficient farming practices, such as mulch farming crop residues and avoiding field burning, could promote bio-energy opportunities and decrease the overall energy input in crop production. The subsequent improvement in soil fertility would lead to a reduction in fossil fuel based energy inputs for crop production, increased productivity, and enhanced profits.

This chapter examines the implementation of resource efficient practices as a strategy to resolve current cane supply problems of sugar mills, and expand the bioenergy potential of the sugar industry. It overviews the current state of the sugarcane industry in the Philippines, describes factors leading to recent declines in crop yield and quality, and relates production practices to fossil fuel demand. It also explores the effect of trash farming on sugarcane production and economics, describes strategies to promote trash farming, and assesses the impact of increasing cane productivity on bioenergy production potential.

\subsection{Current Sugarcane Productivity and Trends in Cane Yields and Sugar Content}

The Philippine sugar industry has been in a decline for the past 20 years (Ledesma, 1997). The country was the world's fourth largest exporter of sugar as recently as the early 1980s, but now must import sugar. In 1995-96, the Philippines imported 816,668 metric tonnes of raw and refined sugar, whereas in 1977-78, the Philippines supplied $10 \%$ of the world's sugar requirements. Sugar exports contributed to about $20 \%$ of the country's export earnings at that time. The industry currently provides about 500,000 jobs directly and an additional 5.0 million indirect jobs (Zabaleta, 1999). Figure 4.1 outlines the farm and mill processes associated with sugarcane processing. 
Figure 4.1. Farm and mill operations involved in sugar manufacturing

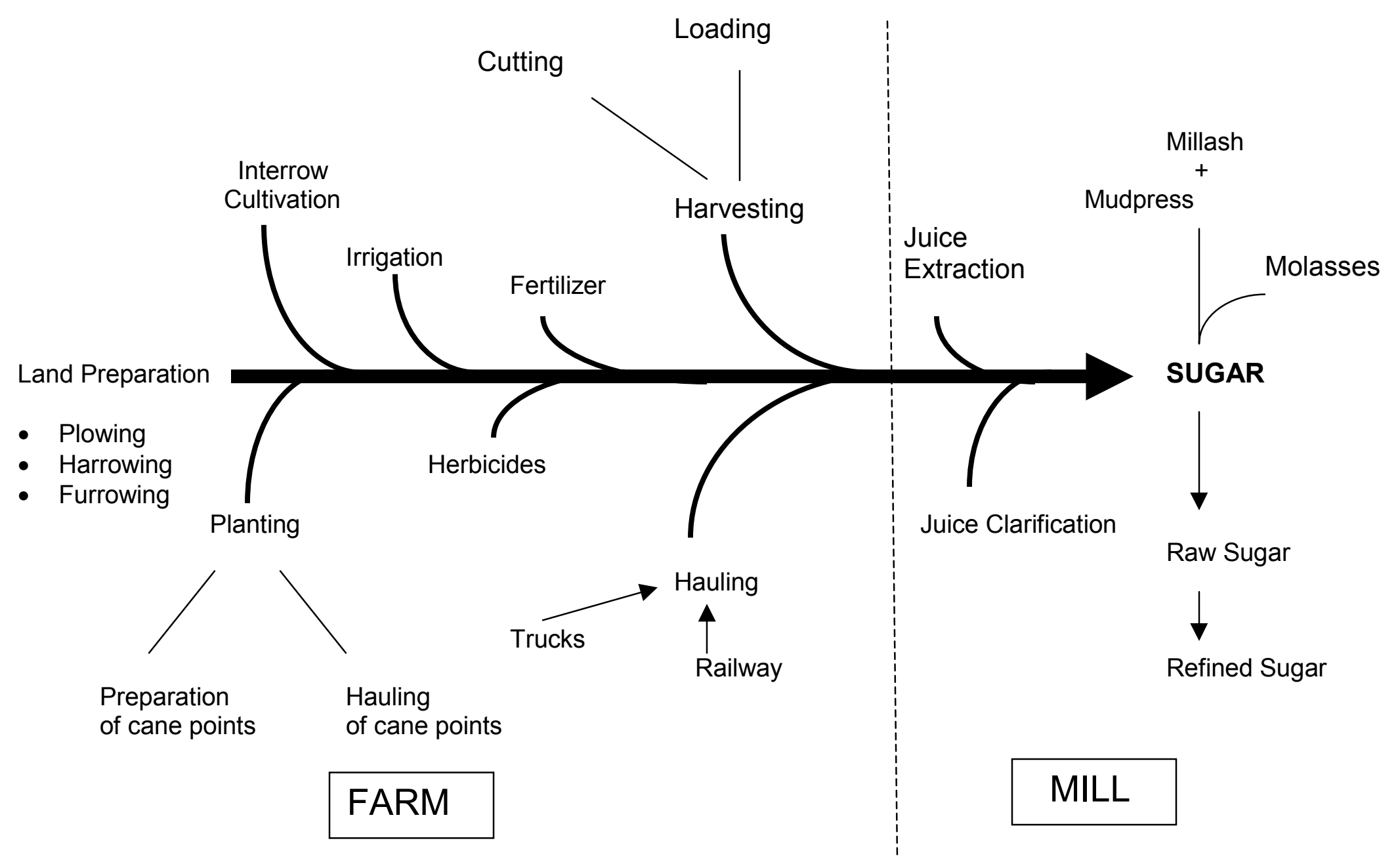




\subsection{Sugar Yield Trends and Major Factors Affecting the Decline in Yield}

A number of researchers and industry leaders have examined the declining trends in sugar yields and output in the Philippines (Covar, 1989; Alaban, et. al., 1990; Rosario, 1992; Mendoza, 1993; Cerbo et al., 1996; Ledesma, 1997). The principal cause of the $30 \%$ reduction in sugar output (from 2.6-2.8 million metric tonnes in the 1990s) was the significant decrease in area under cane production (Appendix 4.3). Sugarcane production occupied about 530,000 ha in the mid-1970s, but decreased to about 370,000 ha in the mid 1990s onward. Ledesma (1997) attributes this shift to the conversion of sugar producing land to residential and industrial usage. About 160,000 ha have been phased out of sugar cultivation since the peak period of cane production in the 1970s.

The other significant downward trend in sugar production is the decline in the sugar content in harvested cane. Sugar concentration has dropped from about $11.20 \%$ in the $1934-1954$ period to $10.5 \%$ in $1954-74,9.73 \%$ in $1975-86$, and $8.93 \%$ in $1986-1988$ (Appendix 4.4). This issue will be discussed at greater length later in the report.

Several factors affect crop yield, which are characterized in the equation:

$$
\begin{aligned}
\mathbf{Y}=\mathbf{f}\left\{(\mathbf{G} * \mathbf{E}){ }^{*} \mathbf{M}\right\} \text {, where : } \\
\mathbf{Y}=\text { Yield } \\
\mathbf{G}=\text { Genotype (variety) } \\
\mathrm{E}=\text { Environment (climate, soil factor) } \\
\mathrm{M}=\text { Management (inputs applied, cultural practices i.e. land } \\
\text { preparation, planting, mulching, fertilizer application practices, } \\
\text { irrigation, harvesting/milling practices). }
\end{aligned}
$$

The parentheses around $G{ }^{*} E$ indicate that both are influenced by management. The environment $(E)$ can be optimized for sugarcane by optimizing tillage, timing of planting/harvesting, etc. Genotype (G) can be exploited fully by planting location, adapted cultivars, and programming varietal traits in relation to their maturity/milling schedules (i.e., early, medium, late milling schedules).

Sugarcane production is not only influenced by technical considerations such as biophysical, cultural management practices or technology, but also by marketing and pricing. The formerly high sugar output was mainly a result of the preferential US quota extended to Philippine sugar producers during the pre-war and post-war years (19341978) (Appendix 4.3). The removal of the quota upon termination of Laurel-Langely Agreement in 1974 sent a signal to planters to reduce the area devoted to sugarcane.

Analyses of historical yields (Appendix 4.3) suggest that significant decline in production levels are attributed to a combination of events including:

- Increasing impact of typhoons on major sugarcane growing areas

- Economic events in the 1970s and 1980s 


\section{A. Increasing Impact of Typhoons}

Crop damage from typhoons is not uncommon as the Philippines are situated in the inter-tropical convergent zone above the equator. Strong typhoons $(100 \mathrm{~km} / \mathrm{hr}$ and above) force canes to lodge. Lodging leads to the production of tillers that divert sugar from matured stalks to shoots and roots growing on stem joints. Additionally, flooding associated with typhoons results in muddy, dirty canes at harvest time, complicating sugar processing in the mill (Appendix 4.6 ).

Two additional factors explain the increasing damage caused by typhoons; deforestation, which destroys the natural protection by trees against strong winds; and the development of hard pan soils on cane lands which reduce water infiltration and root penetration. As a result, sugar cane grow short roots that do not have sufficient anchorage to withstand typhoons.

\section{B. Economic Events in the 1970s and 1980s:}

The oil crisis

Rising oil prices in the 1970s and 1980s increased the cost of tillage, fertilizer, transport, and cane milling. The increase in commodity prices led to wage hikes, consequently increasing the labor costs.

Sugar surplus

Despite increased production costs, sugar prices plummeted to an all time low in 1976 ( $7 \not \mathrm{US} / \mathrm{lb}$ ). The world price of sugar at the time was $11 \phi \mathrm{US} / \mathrm{lb}$. With the termination of Laurel-Langely Agreement in 1974, the country's preferential access to the highly protected US sugar market was lost. This dampened the enthusiasm of planters to improve sugarcane production practices.

\section{Currency devaluation}

To make commodities competitive in the export market (not only sugar) and to increase foreign investment, the Philippine peso was devaluated. The labor sector again demanded a wage hike due to the drastic decline in the purchasing power of the peso, which increased overall production costs.

The establishment of alternatives in the sweetener market

The establishment of alternative sweeteners, particularly HFCS (high fructose corn syrup) reduced US sugar demand, and the resulting surplus in world sugar supplies further depressed sugar prices.

\section{Lack of modernization}

Sugar production (farm to mill) is a machine-dependent process. Tractors, hauling trucks, mill equipment (crusher, boiler equipment, and electrical power instrumentation) and spare parts are all imported. The majority of mills in the Philippines (24) are now 70 years old or more (Table 4.1). The high cost of importation (due to currency devaluation) and the dwindling profit margin are disincentives for planters to buy bigger tractors and for the millers to improve, upgrade, or modernize old sugar factories. 
Uncertain and/or dwindling cane supply has made many factories run below their rated capacity. The current mill capacity utilization of the 36 mills operating in the Philippines is only $62 \%$ (Appendix 4.7).

\begin{tabular}{|l|c|c|c|}
\hline \multicolumn{4}{|l|}{ Table 4.1. Age of sugar mills in the Philippines } \\
\hline $\begin{array}{l}\text { Date } \\
\text { established }\end{array}$ & Number of Mills & Ave. Age of Mills & $\begin{array}{c}\text { \% of Established } \\
\text { Sugar Mills }\end{array}$ \\
\hline$<1920$ & 10 & 81 & 24.4 \\
\hline $1921-1940$ & 14 & 70 & 34.1 \\
\hline $1941-1960$ & 1 & 45 & 2.4 \\
\hline $1961>$ & 16 & 30 & 39.0 \\
\hline TOTAL/MEAN & 41 (Total) & 56.5 (mean) & \\
\hline
\end{tabular}

Source of basic data: Sugar Regulatory Administration

\subsection{Factors Affecting Cane Juice Quality}

The decline in cane and juice quality has been an area of research since the late 1980s. Harvesting practices, climate changes, and cultural management factors may have an effect on cane juice quality. Several investigations have explored this subject, as summarized below.

\section{A. Climatic Factors}

- Typhoons or general wet weather damages sugarcane areas during the ripening/harvesting period (Rosario et al., 1992, Covar, 1989).

- Prolonged dry weather and/or shorter flood/drought cycles create poor growing conditions (Covar, 1989)

\section{B. Cultural Management Factors}

- Sugarcane areas in some mill districts have developed hard pan soils, which reduce water infiltration and root penetration. This has led to water logging during heavy rainfall months and moisture stress for cane during dry months. The result is short rooted plants that are poorly anchored and more susceptible to lodging during the typhoon months (Rosario et al., 1992, Covar, 1989).

- Variety deterioration or the continued and widespread use of the variety PHIL 56226, which is susceptible to smut, leaf scorch, and downy mildew. Leaf scorch and downy mildew are more invasive during rainy periods, and are aggravated due to poor soil drainage (Rosario et al., 1992).

- Application rates of fertilizer have been low and unbalanced, with excessive application of nitrogen (Appendix 4.5). Based on crop nutrient uptake, a tonne of cane absorbs 1.5-2.0 kg Nitrogen; 0.5-0.7 kg Phosphorus, and 1.5-2.5 kg Potasium, or a ratio of about 3:1:3 1/2. In comparison, fertilizer ratios as applied by sugarcane farmers have been 3:1:1 (Rosario et al., 1992, Covar, 1989). 


\section{Harvesting Practices}

- Canes are topped to get seed pieces or for use as animal feed (Covar, 1989)

- Delayed milling after cutting leads to cane drying and sucrose deterioration due to poor transportation networks to mills, cane pole jaulting, inadequate cane supply at the beginning and end of milling operations, and an excessive supply of cane during peak milling (Rosario et al., 1992, Covar, 1989).

- Trashy, muddy, immature stalks are sometimes delivered to mills, leading to low overall mill recovery (Rosario et al., 1992, Covar, 1989).

\subsection{Sugarcane Production Practices and their Relationship to Fossil Energy Use}

\subsubsection{The Survival of the Sugar Industry in the Philippines}

Despite the problems and constraints to attaining profitable sugar yields, the Philippine sugar industry continues to survive. This can be attributed to several reasons:

\section{Agronomic}

- Sugarcane is a high yielding, perennial, $\mathrm{C}_{4}$ crop species and no other major agricultural crop surpasses its biomass productivity. Sugarcane remains the cheapest available source of caloric energy food.

- Being perennial and asexually propagated, sugarcane is easy to grow. After canopy closure (3-5 months after establishment), little care is required until the crop reaches maturity.

\section{Economic}

- The industry continues to employ some 500,000 people and provide indirect employment to another 5 million people.

- At P14,000 per tonne (domestic sugar price, April 2000) and a sugar output of 1.6 to 1.8 million metric tonnes, sugar has a monetary value of about P22.4 to P25.2 billion (\$0.56-0.63 billion US). If sugar needs had to be met by imports, it would present a staggering cost to the country.

Nonetheless, challenges to sustaining the sugar industry in the Philippines remain. If the industry is to survive, the following issues must be addressed:

- The need to improve efficiency in the use of fossil energy. Sugar production is an energy intensive process, consuming $30 \mathrm{kWh}$ to process a tonne of cane (Pennington 1996). The recent oil price hike has provided a clear challenge to reducing dependency on fossil fuel based inputs for sugarcane production and processing.

- To increase sugarcane yields as a means of decreasing the unit cost of production, and to increase the utilization capacity and efficiencies of sugar mills. 
Since sugar manufacturing starts in the field, reducing fossil energy inputs also begins in the field. Areas and practices that are energy intensive must be identified and examined for potential energy reductions.

\subsubsection{Evaluating the Fossil Energy Inputs in Sugarcane Production}

There are more than 34,000 sugarcane farms in the Philippines (Table 4.2). Small farms are more prevalent, but big farms produce more sugar (and require higher inputs) as they are generally mechanized. Most sugarcane producers in the Philippines employ both manual and mechanical operations. At Hacienda Luisita (Tarlac, Philippines) some fields are almost fully mechanized from planting to harvesting, with some manual harvesting done early in the season.

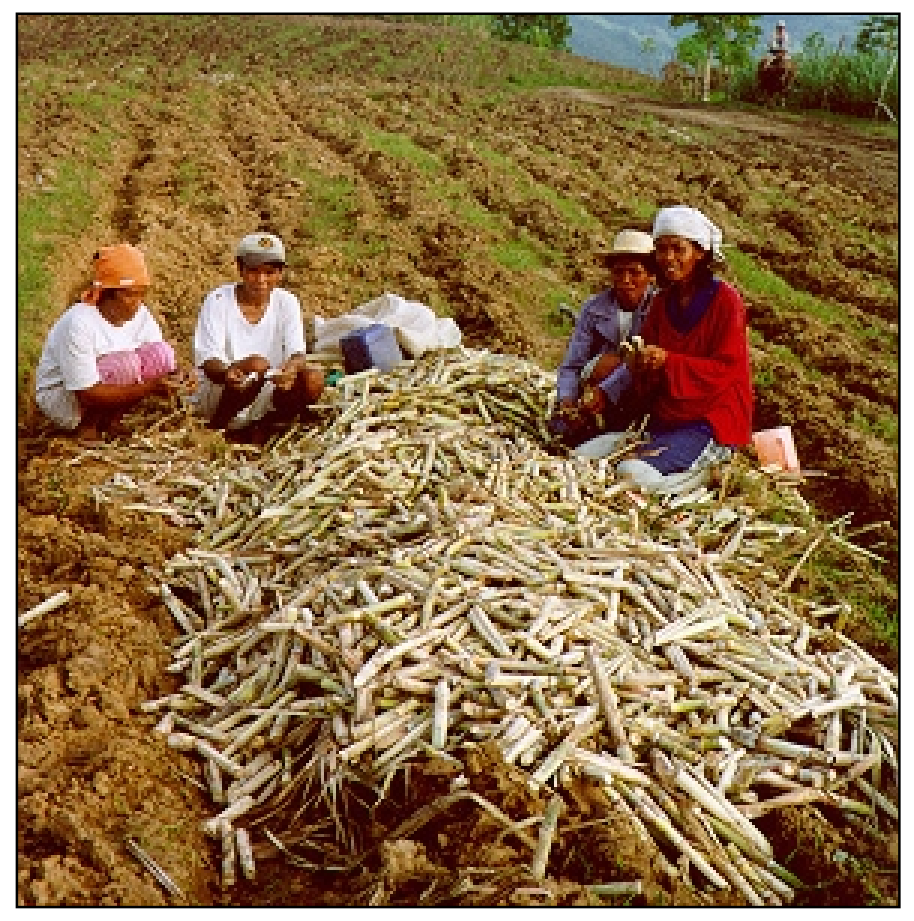

Photo 4.1. Women in Negros Occidental manually preparing cane points before planting the new cane crop.

Many operations in sugarcane production are still done manually for the following reasons:

- Procedures like cane point cutting and weeding within the rows of sugarcane are still performed more efficiently manually than by machinery (Photo 4.1 ).

- Inter-row cultivation can be done quickly after rainfalls with the use of animal drawn plows or harrows. Machines skid and compact the soil.

- Sugarcane-stool directed applications of fertilizer can only be done manually. This saves fertilizer from being applied in idle furrows and reduces weed pressure.

- Alternative employment for displaced workers is difficult to provide if all operations are mechanized.

- Small sugarcane planters cannot afford to buy expensive machinery. 
Table 4.2. Number of sugarcane farms by farm size (ha).

\begin{tabular}{||c|c|c|c|c|c|c|c||}
\hline Year & $0.01-5$ ha & $5.01-10$ ha & $0.1-25$ ha & $25.1-50$ ha & $50-100$ ha & $100+$ above & TOTAL \\
\hline $1989-93$ & 22,373 & 4,699 & 3,600 & 1,750 & 1,026 & 629 & 34,077 \\
\hline $1976-80$ & 19,605 & 5,729 & 5,055 & 2,331 & 1,275 & 721 & 34,716 \\
\hline $\begin{array}{l}\text { Change in } \\
\text { number of } \\
\text { farms }\end{array}$ & $+2,768$ & $-1,030$ & -1455 & -581 & -249 & -92 & -639 \\
\hline \% change & +14.12 & -17.97 & -28.78 & -24.92 & -19.52 & -12.76 & -1.84 \\
\hline
\end{tabular}

SOURCE: Philippine Sugar Statistics, 1973-1993

An assessment of fossil fuel energy consumption was completed and yield levels were projected to be 80 tonnes/ha in the plant crop and 65 tonnes/ha in the ratoon crop. These yields are typical of crops in the region. Yields from the plant crop decline on average by about 20\% in the first ratoon (Mendoza 1989; Mui et al. 1997b, Wood 1991). These estimates provide a basis for defining management practices for developing an improved cane production system. Ideally a cane system can be developed with reduced energy inputs and improved financial and yield performance to help rejuvenate the industry. The results of the partial energy audit (machine depreciation and manufacturing were not included) in Appendix 4.11 provides base values for Figure 4.2. The major assumptions are:

- Field operation energy inputs (tillage, inter-row cultivation) are based on the two studied farms in Appendix 4.11

- A projected yield of 80 tonne per ha is used for the plant crop and 65 tonne per ha for the ratoon crop

- An energy cost per tonne of cane harvested/hauled of $0.115 \mathrm{GJ} /$ tonne is assigned which is derived from the study in Appendix 4.11

- Average fertilization levels are estimated to be $209 \mathrm{~kg} \mathrm{~N}, 55 \mathrm{~kg} \mathrm{P}$, and $74 \mathrm{~kg} \mathrm{~K}$ (Appendix 4.5.3) which requires a fossil energy input of $17.7 \mathrm{GJ} / \mathrm{ha}$.

In the ratoon crop, an energy savings of $6.5 \mathrm{GJ} /$ ha occurs as the energy associated with land preparation and planting is avoided. However, the net effect on energy use in $\mathrm{GJ} /$ tonne of cane in the ratoon crop only improves by $10 \%$ as ratoon crops yield less than the plant crop. Fertilizer is the single largest operational energy input in conventional sugarcane production comprising 50\% (plant) and $67 \%$ (ratoon) of the total energy input. Of the three main nutrients applied in fertilizer, nitrogen is by far the most energy intensive accounting for about $90 \%$ of overall energy inputs associated with fertilization (Appendix 4.5). Strategies to improve the energy efficiency from their current level of approximately 0.4-0.44 GJ/tonne of cane produced using low input trash farming and extended ratooning are discussed in greater detail in section 4.5. 
Figure 4.2. Average Energy Use (\%) in Conventional Sugarcane Plant and Ratoon Crops (GJ/ha) (adapted from Appendix 4.11)

Plant Crop

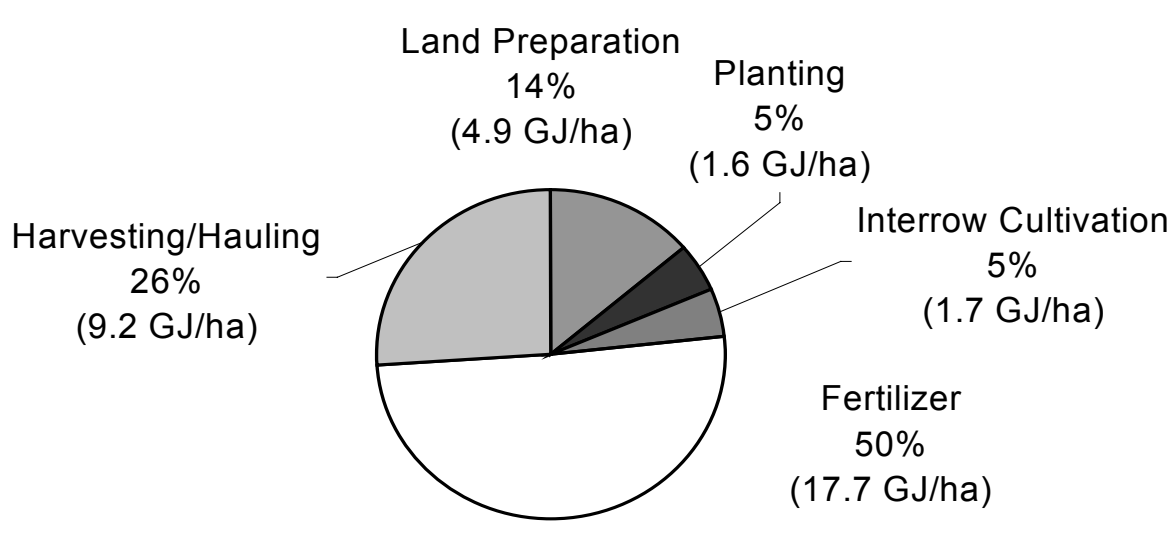

Total Energy Expenditure $=35.1 \mathrm{GJ} / \mathrm{ha}$

based on a yield of 80 tonnes/ha (or $0.44 \mathrm{GJ} /$ tonne)

Ratoon Crop

Interrow

Cultivation

$4 \%$

Harvesting/

(1.1 GJ/ha)

Hauling

$29 \%$

(7.5 GJ/ha)

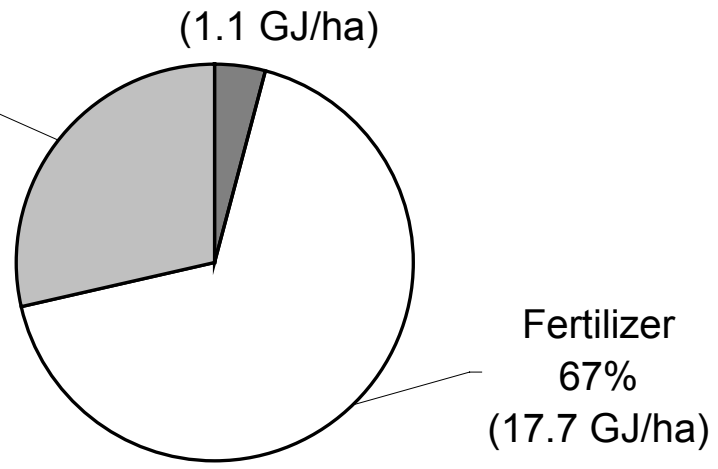

Total Energy Expenditure $=26.3 \mathrm{GJ} / \mathrm{ha}$

based on a yield of 65 tonnes/ha (or $0.4 \mathrm{GJ} /$ tonne) 


\subsubsection{Economics of Conventional Cane Production}

A cost analysis of growing sugar cane under conventional farm management practices is listed in Appendix 4.10. For a summary of the costs associated with the plant and ratoon crops, see Figure 4.3.

The financial return on the first ratoon crop is $14 \%$ higher (at 31,694 pesos/ha) for an assumed yield of 65 tonnes/ha relative to the plant crop (at 27,874 pesos/ha) at an assumed yield of 80 tonnes/ha. The main difference is the high cost associated with establishing the plant crop, including land preparation, cane point procurement, and planting. These activities collectively contribute to $30 \%$ of the total cost of cane production in the establishment year, or 13,400 pesos. In the ratoon crop, the major costs are fertilization, at $26 \%$ of the production cost and harvesting (cutting/ hauling and transport) at $61 \%$.

To reduce overall production costs, productivity increases, and extended ratooning cycles, reductions in input costs need to be brought about. As illustrated in the following section, trash farming holds considerable promise to increase ratoon yields and ultimately cane production levels. However, this requires the introduction of cultural management strategies including the use of trash farming and selection of cane cultivars with good ratooning characteristics. Extending the ratooning cycle is necessary to significantly reduce overall production costs, along with the reduction of fertilizer use and costs associated with harvesting.

Figure 4.3 summarizes the cost items associated with the plant and ratoon crops. Cane establishment includes the costs of land preparation, cane point preparation, and planting the cane points. Maintenance includes weeding and cleaning the drainage canal, trash clearing, stubble shaving, and replanting gaps in the ratoon crop (see Appendix 4.10). 
Figure 4.3: Breakdown of variable costs for conventional sugarcane plant and ratoon crops

\section{Plant Crop}

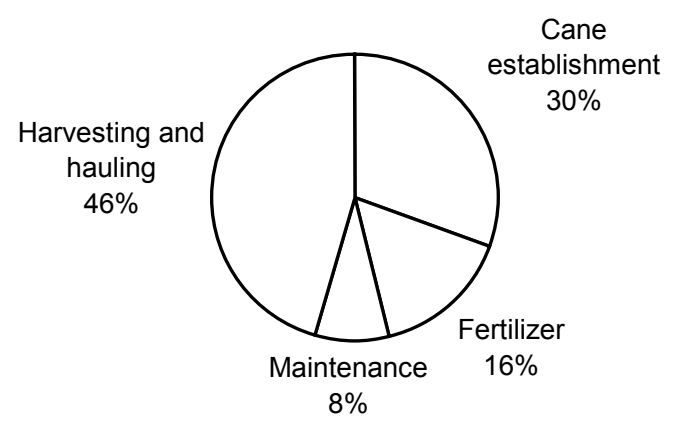

Variable cost $=P 43.966$ based on a yield of 80 tonnes $/ \mathrm{h}$ c

Variable cost $=P 43.966$ based on a yield of 80 tonnes/ha

Net return to variable cost $=\mathrm{P} 27.874 /$ ha

\section{Ratoon Crop}

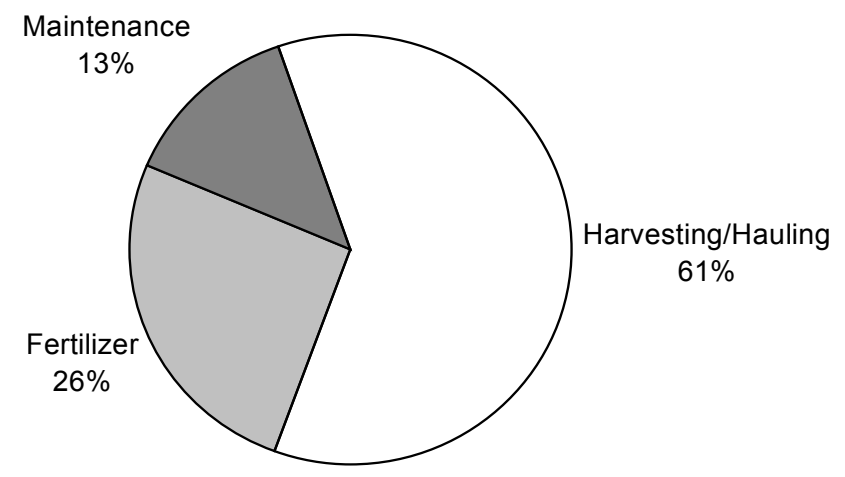

Total Variable Cost $=P 26,676 /$ ha based on a yield of 65 tonnes/ha Net Return to Variable Cost $=$ P $31,694 /$ ha 


\subsection{Trash Farming as a Strategy to Improve Sugarcane Production Systems}

In the Philippines and other areas of the world, conserving the large volumes of residues produced during cane production restores soil fertility, extends the number of ratoon crops, increases yields and reduces production inputs. This section analyzes the benefits of cultural management strategies involved in recycling harvest residues, and the subsequent influences on production practices, economics, and energy balance. The potential of trash farming to contribute to the bioenergy industry in the Philippines by increasing bagasse production and enabling harvest of cane trash after final ratooning is also examined.

\subsubsection{Impacts of Sugar Cane Trash Farming on Sugarcane Yield}

It was noted as early as the 1950 s that trash mulching improves the yield of sugarcane (Pinda, 1956). While the results of this experiment were presented in the annual convention of the Philippine Sugar Technologist in 1956, they were not sufficiently appreciated by sugarcane planters. Three important reasons can be cited:

(1) Pre- and post-burning was the standard practice to facilitate harvesting and the subsequent ratoon cane establishment

(2) The price of fertilizer at that time was low

(3) Soils were relatively fertile and the need for annual carbon contributions to the soil was not considered as necessary to maintain soil fertility

In the late 1970s, increasing oil prices resulted in augmented production costs. Fertilizer was particularly affected, emphasizing the need to recycle nutrients back into the farm. Organic fertilizer from sugarcane trash serves as a soil amendment, increasing sugar yield (percent polarization) both in tonnage and sugar quality (Abrigo 1981). High sugar yields are desirable as they increase mill efficiency and returns to the farmer. Moreover, higher quality canes delivered to the mill reduce the cost per $\mathrm{kg}$ of sugar manufactured.

The benefits of trash mulching in sugarcane are well recognized. However, the practice of row-to-row mulching is difficult to implement on a large scale because of high volumes of trash. It is also labor intensive, as trash is most often moved to provide space for regenerating tillers from the stubble and the subsequent interrow cultivation in the ratoon. Studies on spatial arrangement were conducted to accommodate trashmulching in ways that would not require so much handling of the trash (Mendoza 1985; Mendoza 1979). A double row spaced at 0.5-0.75 m and a wider interval space of $2.0 \mathrm{~m}$ was found to be suitable for intercropping cum trash farming (Figure 4.4). 
Figure 4.4. Sugarcane intercropping scheme-cum trash farming (Mendoza, 1989)

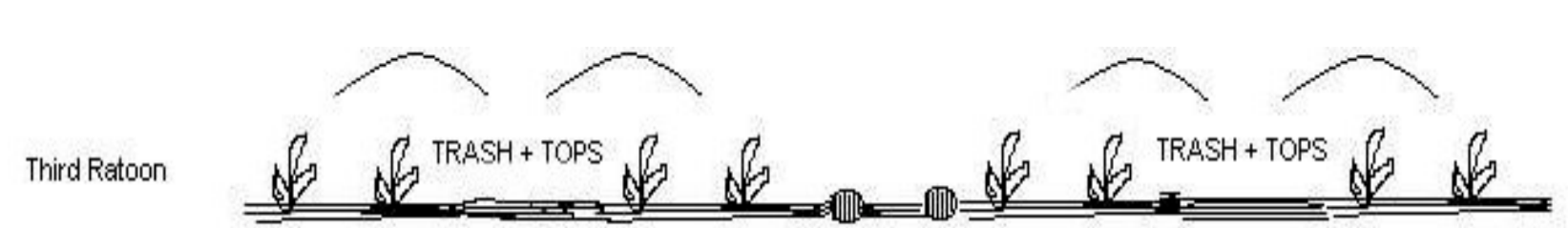

Plant Crop: Set furrows at $0.75 \mathrm{~m}$ interval, plant 2 rows of sugarcane and skip two rows for the intercrop. Low tiller population can be overcome by destroying primary shoots to flush tillers. This can be done by simple harrowing and nitrogen fertilizer application

Ratoon: Trashes and tops shall be placed between double rows (as shown above) and the other interval row for cane stalk piling. After hauling stalks, usual ratooning practice shall be performed. The trash-free row can still be used for intercropping. Piling of trash in alternate rows shall be done in subsequent ratoons.

Mendoza et al., (1987) showed that yields in the ratoon were up to $33 \%$ higher in the trashed field than the non-trashed fields $(128.6 \mathrm{PS} / \mathrm{Ha}$ vs. $96.5 \mathrm{PS} / \mathrm{Ha}$, especially with good ratooning varieties for both tonnage and sugar quality (Appendix 4.9).

\section{Trash Farming and Extended Ratooning Cycles}

A summary of research studies in Southeast Asia on mulch farming systems (Table 4.3 ), indicates that sugarcane yields increase on average by $7 \%$ in the plant crop and $20.1 \%$ and $30.0 \%$ in the first and second ratoon crop. These findings have major implications for increasing the profitability of sugar cane production by extending ratooning cycles.

Table 4.3. Summary of sugarcane yield response to trash farming (percent yield increase in cane tonnage)

\begin{tabular}{|l|c|c|c|c|c|}
\hline $\begin{array}{c}\text { Name of } \\
\text { Researchers }\end{array}$ & Location & $\begin{array}{c}\text { Plant } \\
\text { Crop }\end{array}$ & $\begin{array}{c}1^{\text {st }} \\
\text { Ratoon }\end{array}$ & $\begin{array}{c}2^{\text {nd }} \\
\text { Ratoon }\end{array}$ & Comments \\
\hline $\begin{array}{l}\text { Mendoza, T.C. } \\
(1989)\end{array}$ & Philippines & $-2 \%$ & $+18.7 \%$ & - & Average of 2 varieties \\
\hline Mui et al., (1996) & Vietnam & $+6.3 \%$ & $+20 \%$ & $+30 \%$ & $\begin{array}{c}\text { Average of } 3 \text { row } \\
\text { spacings }\end{array}$ \\
\hline Mui et al., (1997a) & Vietnam & $+10.6 \%$ & - & - & $\begin{array}{c}\text { Average results of } 10 \\
\text { farms }\end{array}$ \\
\hline Mui et al., (1997b) & Vietnam & $+4.2 \%$ & $+21.6 \%$ & - & Average of 4 varieties \\
\hline Average & - & $+7 \%$ & $+20.1 \%$ & $+30 \%$ & \\
\hline
\end{tabular}

Mulch farming reduces the yield decline associated with the ratooning practice (Fig.4.5). It enables sugarcane to be cropped an additional 1 to 2 ratoon crops before yields become economically non-viable. Ratoon cropping is most easily extended on soils with 
high soil fertility and high moisture holding capacity. On well drained alluvial soils in the humid tropical zone of northern Australia, trash farming sustained yields above 65 tonnes/ha for 5 consecutive ratoon crops, while yields fell below 65 tonnes/ha in the second ratoon in a burnt cane field (Figure 4.5).

Improving soil fertility through trash farming will gradually create a positive feedback system with longer ratoon cycles. Improving cultural practices along with widespread screening of cane trash varieties for ratooning will enable extended cycles of 4 years or more to be achieved in the Philippines, as is commonplace in Australia and Brazil (Boddey et al., 1995).

Figure 4.5 Effect of trash mulching on sugarcane yields

(average of 5 sites in Northern Australia)

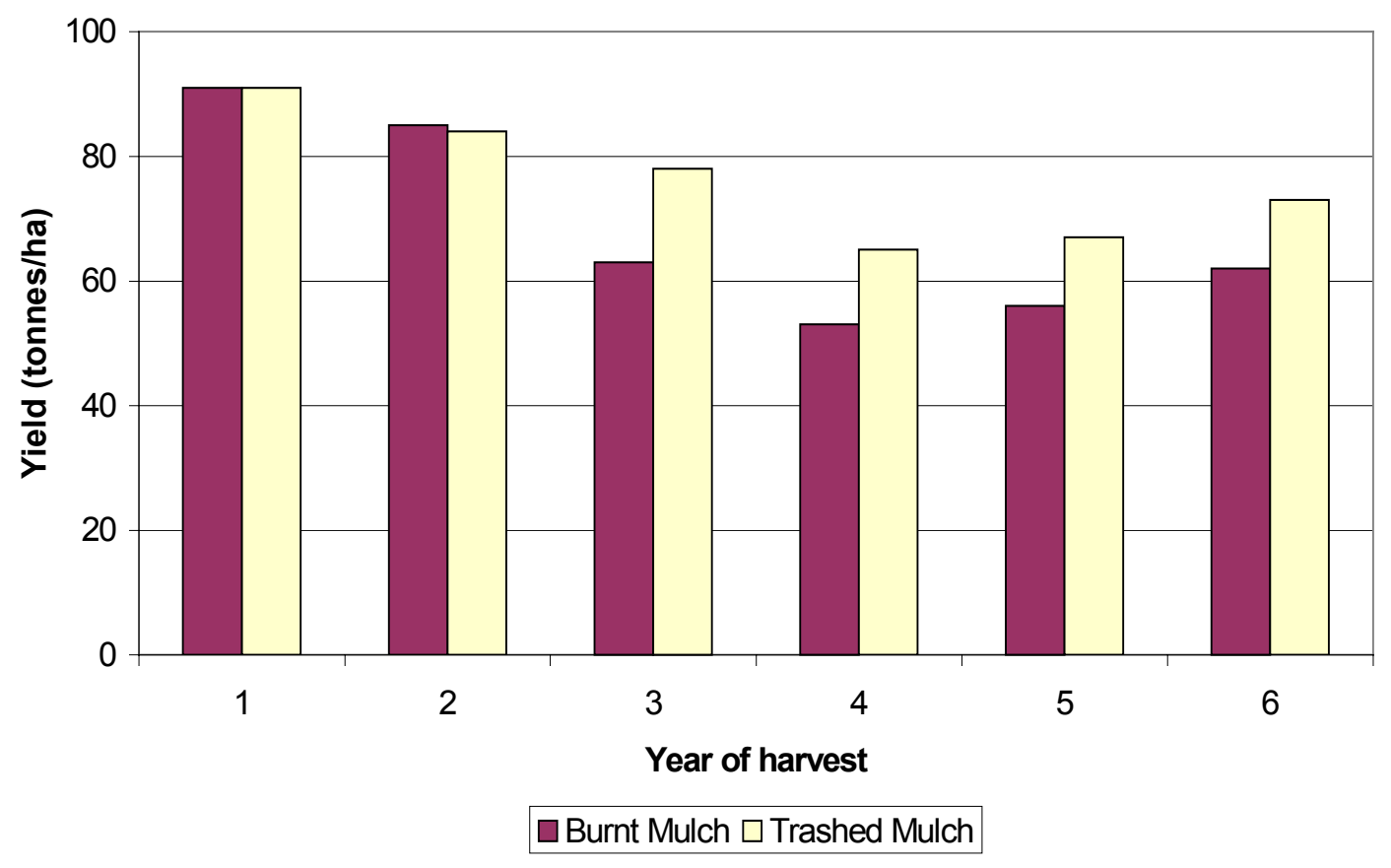

Source: Wood, 1991.

\subsubsection{Impacts of Sugarcane Trash Farming on Tillage}

Sugarcane trash farming reduces fossil fuel-intensive inputs associated with tillage in two principal ways:

1) It increases the number of ratoons, thereby decreasing the frequency of land preparation associated with new plant cane establishment. The most energy intensive component is primary tillage or deep plowing $(40-50 \mathrm{~cm})$ as sugarcane is deep rooted. Extending the number of ratoon cycles from the conventional system of one plant crop $(P)$ : 1 ratoon crop $(R)$ to $1 \mathrm{P}: 3 \mathrm{R}$ or $1 \mathrm{P}: 4 \mathrm{R}$ results in considerable 
reduction of energy inputs due to land preparation. Under a trash farming scheme of 1 plant crop and 3 ratoon crops, a $50 \%$ reduction in tillage requirements is obtained, while a $60 \%$ reduction occurs for 1 plant crop: 4 ratoon cycles. This is a considerable energy and cost savings due to reduced demand for diesel and lubricants, and fewer repairs and maintenance. Likewise, farmers can reduce their capital outlay for equipment or carabao (water buffalo), as well as widening the service area of farm tractors and implements. From $2 \mathrm{Hp}$ of farm power, which would normally farm only one ha, 2-3 ha can be worked. The use of tractors for farming is energy intensive, and their manufacture also uses considerable amounts of energy.

2) Under trash farming, trash-mulched interrows need no cultivation. As per the trash farming scheme (Mendoza, 1979, Mendoza, 1985) presented in Figure 4.4, the ratio of non-trash and trash mulched rows is $50: 50$. This represents a $50 \%$ reduction in interrow cultivation.

\subsubsection{Impacts of Sugar Cane Trash Farming on Cane Sugar Levels}

Studies indicate that mulch farming can increase sugar content (Mendoza et al., 1989, Tan, 1995, Table 4.4). In 2 of the 4 studies, mulching was shown to significantly improve the sugar level of ratoon crops, but not plant crops. Trash farming would likely enhance the sugar concentration of crops growing on degraded soils with low fertility. Long term fertility improvement of degraded soils through trash farming could overall increase sugar levels and boost economic returns.

Table 4.4 Impacts of Trash Farming on Cane Sugar Levels

\begin{tabular}{|c|c|c|}
\hline Study & Plant Crop & 1st Ratoon \\
\hline Mendoza (1987) & - & $+11.6 \%$ \\
\hline Mui et al., (1997a) & - & 0 \\
\hline Mui et al. (1997b) & - & 0 \\
\hline $\begin{array}{c}\text { Tan (1995) } \\
\text { Note : The average of 3 trials } \\
\text { (tops and base of stalks at 3 N levels) }\end{array}$ & - & 3.0 \\
\hline Average & - & $+3.7 \%$ \\
\hline
\end{tabular}

\subsubsection{Impacts of Sugar Cane Trash Farming on Fertilizer Use and Other Inputs}

Fertilizer use (cost + application) accounts for about $20 \%$ of sugarcane production costs. Trash farming conserves significant amounts of nitrogen in the soil (approximately $30-35 \mathrm{~kg} \mathrm{~N} / \mathrm{ha}$ ). When trash is burned, the nitrogen is lost as nitrous oxide $\left(\mathrm{NO}_{\mathrm{x}}\right)$. Some of the $\mathrm{P}$ and $\mathrm{K}$ can also be lost through burning (Cook 1994). In trash farming systems, $\mathrm{P}$ uptake appears more efficient as the mulch protects the soil from desiccation and permits root proliferation in the soil surface where $P$ levels are high. Mulching permits a greater recycling of $P$ from residues than burning, and BallCoellno et al. (1993) suggest that lower P fertilization rates could be used to maintain 
productivity on sites where burning is practiced. Trash farming not only helps conserve organic matter in the soil during the decomposition process but encourages nitrogen fixation in sugarcane litter. Hill and Patriquin (1990) described a highly active system, involving a microaerophylic $\mathrm{N}_{2}$ fixing Azosprillium brasilense and adematiaceous fungus Helicomyces roseus. In Brazilian cane varieties, high yields without $\mathrm{N}$ fertilizer are associated with greater biological $\mathrm{N}_{2}$ fixation and include Acetobacter diazotrophicus (Boddey, 1995). The $\mathrm{N}_{2}$ fixation process is overviewed in Appendix 4.2.

In Brazil, gains in soil nitrogen equivalent to $54 \mathrm{~kg} \mathrm{~N} / \mathrm{ha} / \mathrm{yr}$ over 9 years were reported for unburned cane (Boddey et al., 1995). Burned cane lost soil $\mathrm{N}$ at an average of $44 \mathrm{~kg}$ $\mathrm{N} / \mathrm{ha} / \mathrm{yr}$. N fixation levels of 50-200 $\mathrm{kg} \mathrm{N} / \mathrm{ha}$ occur in trash farmed sugarcane fields, with the higher range associated with higher trash levels (Appendix 4.2). A mean value of $125 \mathrm{~kg} \mathrm{~N} / \mathrm{ha}$ could be expected where trash farming is established as a practice (Patriquin 2001). In Brazil, where trash farming is frequently practiced, only $60 \mathrm{~kg} \mathrm{~N} / \mathrm{ha}$ on average is applied to the crop, while $150-300 \mathrm{~kg} \mathrm{~N} / \mathrm{ha}$ are used in most cane producing countries such as Cuba, Peru, India, and the United States (Boddey, 1995). A summary of 135 field experiments in Brazil found that only $19 \%$ of plant crop trials significantly responded to fertilizer (Azeredo et al., 1986). The $\mathrm{N}$ response of the ratoon crop is rarely more than half the amount that the crop accumulates, possibly because the sugarcane cultivars in Brazil were bred under low N conditions. Boddey (1995) found that breeding low $\mathrm{N}$ requiring plants generated major energy savings in terms of $\mathrm{N}$ use for the Brazilian biofuel industry.

Trash mulching sugarcane fields helps protect the soil. It minimizes and/or prevents soil erosion which is the principal factor leading to massive land resource base degradation, even on relatively flat to gently sloping lands (Rosario et al., 1992). Without soil conservation, an annual loss of 20 to 200 tonnes/ha of fertile topsoil can occur depending on soil type, slope, and rainfall intensity. This rate far exceeds the tolerable rate of soil loss of 10 tonnes per ha. Soil organic matter is also lost through erosion. Between 0.4 to 4.0 tonnes of organic matter are lost per ha in a soil with $2 \%$ organic matter. A 200-tonne/ha soil loss corresponds to a $2.0 \mathrm{~cm}$ loss of topsoil, a resource that takes about 100 years to form. Such a reduction can occur over a one-year period if soil conservation measures such as trash mulching, contour tillage, and use of biophysical barriers like buffer strips or hedgerows for steeper slopes are not employed (Rosario et al., 1992).

\subsubsection{Impacts of Trash Farming on Soil Properties}

Upon decomposition, sugarcane trash (as organic matter) is transformed into a stable product called humus, which is of significant agro-ecological importance (Table 4.5). Also, Hodge (1998) pointed to the importance of organic matter for long-term sustainability of agriculture. Conserved as mulch, sugarcane trash decomposes into humus, improving soil tilth, and decreasing tillage required. By increasing water infiltration into the soil, water retention is improved, thereby decreasing the need for irrigation. Trash-mulched canes can tolerate the normal dry season and EI Nino events better than ratoon crops in burned cane fields, which have no trash mulch cover. 
This effect is even more evident in long term trash-mulched fields with higher soil organic matter levels and a permanent surface mulch cover.

\section{Table 4.5. Agro-ecological importance of humus}

- Humus gives the top soil a dark or brownish color, indicative of a fertile soil

- Humus serves as stock of nutrients for higher plants

- Humus provides several active agents, plant hormones and antibiotics

- Humus supports nitrogen fixing organisms that supply additional nitrogen to the crop

- Humus enhances the physical and chemical properties of soil by:

a) enhancing soil cation exchange capacity

b) improving the soil water holding capacity ( 4 to 5 times more than clay, humus absorbs water $80 \%-90 \%$ of its weight)

c) acting like glue to link mineral soil particles to so-called clay-humus complexes, thus improving soil particle aggregation

- Humus reacts with many substances to form complexes. For example, humus:

a) Reacts with oxides of iron and aluminum to form a stable aggregate, thus reducing toxic metal concentrations

b) Reacts with herbicides applied in the soil

c) Serves as a buffer system for the $\mathrm{pH}$ value in the soil

The effects of mulching on soil fertility have been studied in research station and onfarm field trials in Vietnam (Mui et al., 1997a, Mui et al., 1996). During a three year experiment, it was consistently shown that mulched fields had higher percentages of carbon, phosphorus, potassium, nitrogen, and lower bacteria, actinomycetes and fungi than unmulched fields (Table 4.6). The higher \% carbon denotes the unique contribution of mulching in terms of carbon sequestration into the soil, which is important in reducing greenhouse gas emissions.

Table 4.6. Parameters of soil fertility after mulching and not mulching before planting and at the end of 1993, 1994, and 1995.

\begin{tabular}{|l|c|c|c|c|c|c|c||}
\hline \hline & Prior & \multicolumn{2}{|c|}{1993} & \multicolumn{2}{c|}{1994} & \multicolumn{2}{c||}{1995} \\
\hline Mulching & & Mulch & No Mulch & Mulch & No Mulch & Mulch & No Mulch \\
\hline $\mathrm{pH}(\mathrm{KCl})$ & 5.5 & 5.7 & 5.4 & 5.6 & 5.5 & 5.6 & 5.5 \\
\hline $\mathrm{C}, \%$ & 0.79 & 1.73 & 1.57 & 1.48 & 1.33 & 1.44 & 1.2 \\
\hline $\mathrm{P} 2 \mathrm{O} 5, \%$ & 0.09 & 0.126 & 0.1 & 0.103 & 0.09 & 0.08 & 0.07 \\
\hline $\mathrm{K} 2 \mathrm{O}, \%$ & 0.06 & 0.43 & 0.33 & 0.55 & 0.46 & 0.42 & 0.33 \\
\hline $\mathrm{N}, \%$ & 0.14 & 0.14 & 0.1 & 0.084 & 0.08 & 0.15 & 0.14 \\
\hline Bacteria (105) & & & & 3.2 & 3 & 90 & 49 \\
\hline Actinomycetes (103) & & & & 5.5 & 4 & $\mathrm{~N} / \mathrm{A}$ & $\mathrm{N} / \mathrm{A}$ \\
\hline Fungi (103) & & & & 15 & 1.5 & 82 & 7.7 \\
\hline
\end{tabular}

Source : Mui et al., 1996 


\subsubsection{Impacts of Trash Farming on Human Health}

Sugarcane workers have been observed to have high mortality rates due to illnesses originating from agricultural operations. A case-control study in the U.S. suggests that people engaged in sugarcane farm related occupations have significantly higher rates of lung cancer (Mulvey and Rothschild, 1983). According to the U.S. Occupational Health Department (1999) sugarcane workers have an increased risk of lung cancer which may be related to the practice of burning foliage at the time of cane cutting. The burning of the sugar fields releases fly soot to the atmosphere which contain PAH's with mutagenic and carcinogenic properties (Zamperlini et al., 1997). A recent cancer study involving agricultural workers in India (Amre et al., 1999) also found an increased risk of lung cancer for workers employed on a sugarcane farm. Work involving burning after harvesting and exposure to fibers of biogenic amorphous silica (BAS) during fieldwork may account for the increased risks of lung cancer and possibly mesothelioma among sugarcane farmers (Poolchund, 1991). By eliminating the field burning of residues, trash farming reduces the health hazards associated with exposure to air borne particulate matter (fly soot and BAS). 
Figure 4.6. Summarized interactive benefits of sugarcane trash farming to the soil, farmer, society, and the environment.

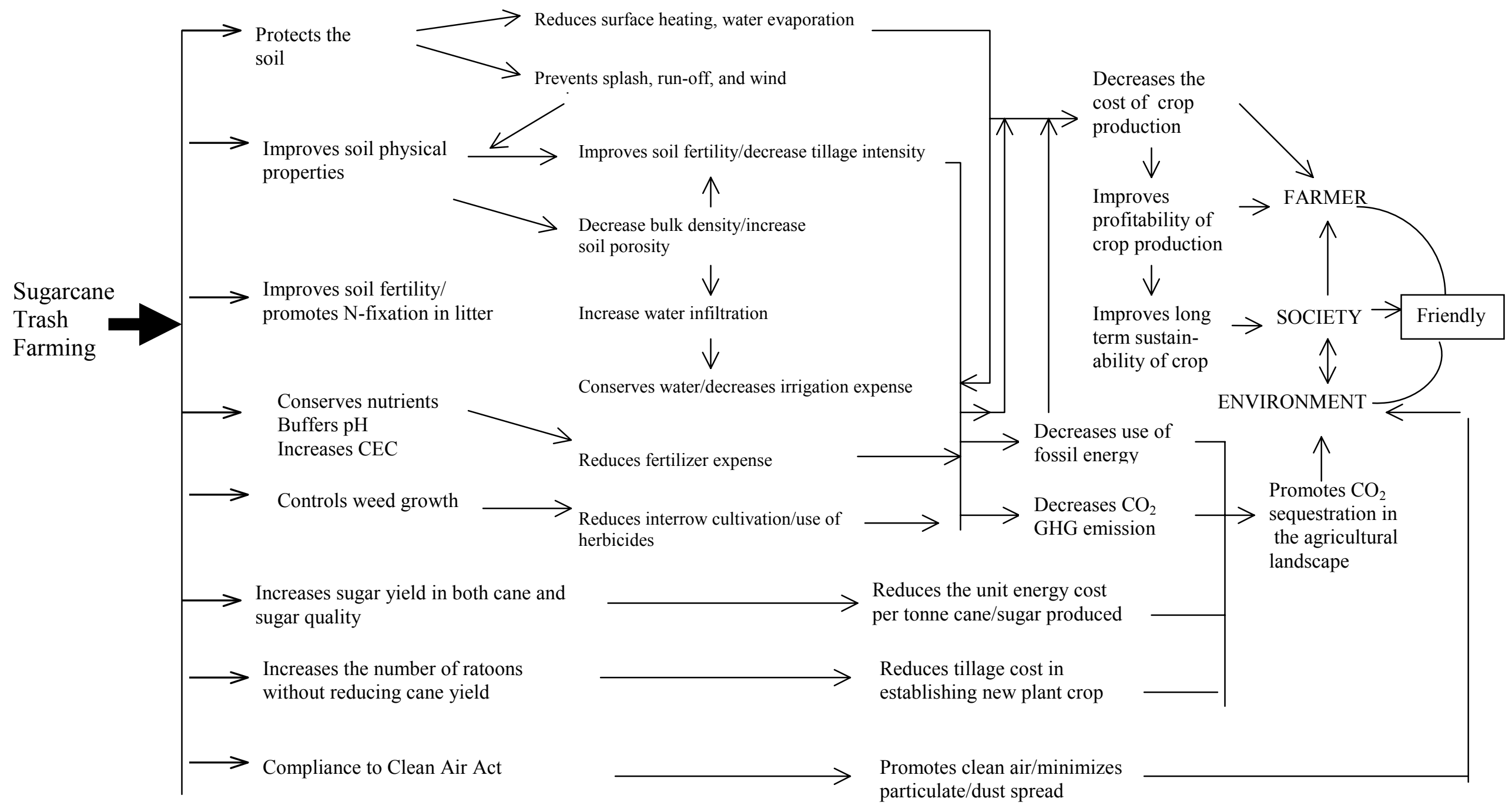




\subsection{Promotion of Trash Farming in Sugarcane}

\subsubsection{Reasons for Burning the Trash}

The positive impacts of trash-farming on sugarcane production are not well recognized. Pre- and/or post-harvest burning of trash is still the dominant practice in the Philippines. Minimum estimates of burned cane fields in the Philippines are placed at 64\% (Mendoza and Samson, 2000). This value would be larger, but burning is frequently prevented by wet weather during early and late harvest schedules. Factors influencing the pre- and post-harvest burning of sugarcane fields are presented in Table 4.7. In contrast to the Philippines, the tropical zone of Northern Australia has undergone a recent rapid transition from burned to green cane harvesting and retention of crop residues as a surface trash blanket (Wood, 1991).

Table 4.7. Reasons for pre-and post-harvest burning of sugarcane fields in the Philippines

A. Pre-harvest burning facilitates cutting and piling of sugarcane stalks.

- Unburnt canes slow the harvest. Of the 25-40 leaves produced by a sugarcane plant, only 7-8 are green at harvest. It is laborious to remove the dead leaves during the busy harvest period and burning accelerates harvesting by about $40 \%$.

- Sugar mills impose stiff penalties for delivery of trashy canes, since the mill extraction efficiency declines by $0.47 \%$ for every $1 \%$ of cane trash processed. While a trash loss factor table is available, farmers can be over-penalized for trashy canes, as it is somewhat a subjective measurement.

B. Post-harvest burning of remaining trash and tops (or even those unburned canes before harvest) is done for the following reasons:

- Unburned fields are perceived as "Dirty" fields. Farm workers are accused of being lazy by the landowner ("haciendero") if the fields are "dirty."

- Remaining trash and tops obstruct the operations involved in ratoon crop establishment or in land preparation for new cane establishment.

- There are cases or experiences where properly piled trashes between cane rows are accidentally or deliberately burned together with the established cane crop.

- It is laborious to pile the trash between cane rows to provide space for cultivation and fertilizer application. Harvest is also the time to establish new cane crops or ratoons. Competition for "labor" is severe.

- Piled trash is perceived as a hiding and/or breeding place for rats. 


\subsubsection{The Economics of Trash Farming Sugarcane}

Section 4.4.3 and Appendix 4.10 demonstrate that the plant crop does not generally yield a highly profitable economic return. Increasing both the productivity and number of ratoon crops is essential to increasing the economic return of sugar cane production.

The following analysis compares the profitability of conventional ratoon cropping with that of trash farming. It has been assumed that trash farming leads to a $20 \%$ yield increase in the ratoon crop. Additionally, a $110 \mathrm{~kg} \mathrm{~N} / \mathrm{ha}$ reduction in fertilizer is projected for trash farming. However, increased harvest and transport costs are associated with higher yielding trash farming systems (Appendix 4.10).

Trash farming is financially beneficial (Figure 4.7). It is projected that where trash farming is implemented, net returns drop by $4 \%$ in the plant crop but increase by $28 \%$ in the first ratoon crop, with a net improvement in return over the two years of P7740 (Figure 4.7 vs. Figure 4.3). The trash farmed ratoon crop (Figure 4.7) achieved the lowest cost per tonne (P377/tonne). It was 31\% below the cost per tonne of the conventional plant crop and $8 \%$ below the ratooned conventional crop. In the final year of the ratoon crop, additional returns may be generated from the harvest of the sugarcane trash. Eight to ten tonnes of trash (Chapter 3, Table 3.5) are available in the field after harvesting the cane, of which $60 \%$ to $70 \%$ could be harvested as a biofuel. For example, at Hacienda Luisita, 8.6 tonnes/ha of trash per year (representing 68.8\% recovery) are harvested on average. The peso value of this trash based on its nutrient content was estimated to be $110 \mathrm{P} /$ tonne. Its peso value based on its equivalent oil energy value was estimated to be $2000 \mathrm{P} /$ tonne (Ch.3). In the future, farmers will likely be able to sell the material to mills for $200 \mathrm{P} /$ tonne in the field. This would enable farmers to generate an additional $1600 \mathrm{p} / \mathrm{ha}$ in the final ratoon year, assuming an 8 tonne trash harvest. 
Figure 4.7 Costs associated with sugarcane trash farming

\section{Plant Crop}

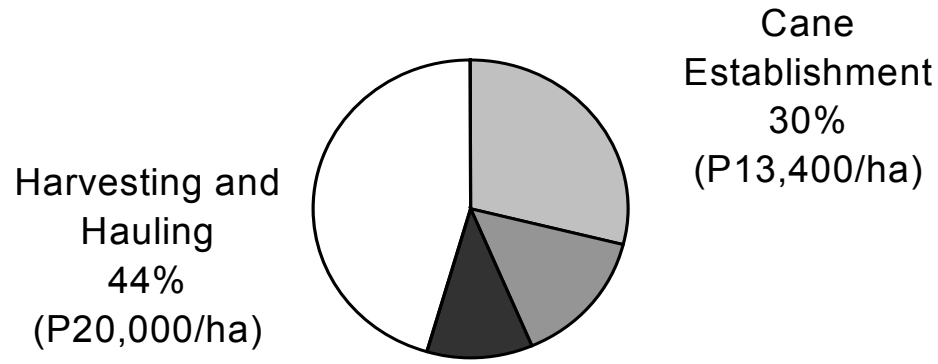

$$
\begin{gathered}
\text { Maintenance } \\
11 \% \\
(\mathrm{P} 5,050 / \mathrm{ha})
\end{gathered}
$$

Fertilizer

$15 \%$

(P6,916/ha)

Total Variable Cost $=\mathrm{P} 45,366$ based on a yield of 80 tonnes/ha Net Return to Variable Cost $=$ P26,690/ha

\section{Ratoon Crop}

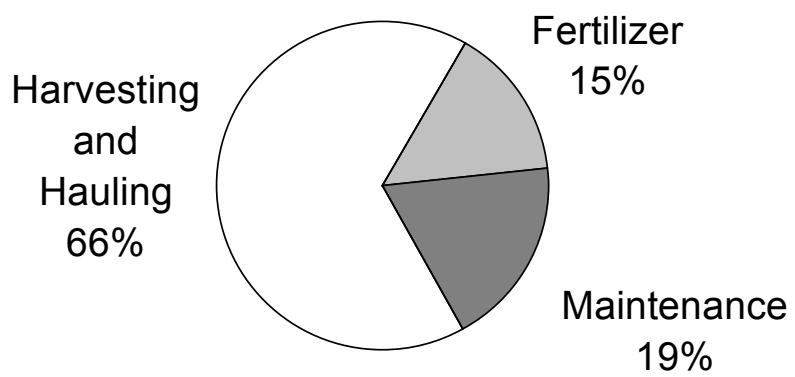

Total Variable Cost $=P 29,462$ based on a yield of 78 tonnes/ha Net Return to Variable Cost $=$ P40,618/ha (For Conventional sugarcane production, see Figure. 4.3 and Appendix 4.10) 


\subsubsection{Optimizing the Trash Farming System}

One disadvantage of trash farming is that unburned green cane harvesting is laborious and $40 \%$ slower. Furthermore, the additional work associated with managing trash residues coincides with new cane establishment. This leads to some difficulties in prioritizing activities.

It must be recognized that the adoption of trash farming is not simply the nonburning of cane. Some remedial measures have been tested to optimize the farming method:

1. Wider row spacing to ease trash deposition (Figure 4.4). This spatial arrangement minimizes labor needed to pile the trash in the interrows, which facilitates the emergence of tillers in the ratoon. In this spatial arrangement, trash-mulches also do not impair cultivation and fertilizer application. This spacing is also suitable for inter-cropping, which benefits small scale sugarcane farmers, including Agrarian Reform Beneficiaries (ARB's) in the sugarlands.

2. The use of self-detrashing varieties. A few locally adapted and high yielding cane cultivars exist that are self-detrashing. Identifying and selecting cane cultivars that are self-detrashing in addition to their desirable agronomic traits is a novel-breeding objective. Self-detrashing varieties are becoming a more popular trait associated with new cane introductions.

3. Pre-harvest detrashing of canes. The dried and non-functional leaves of the cane are manually removed 8-9 months after planting or 3-4 months before harvesting, using a $1.5 \mathrm{~m}$ round bar. During the growth stage of the sugarcane plant, 20 to 27 leaves are formed, of which 7-8 functional leaves are retained. From 12 to $19 \mathrm{dry} /$ non-functional leaves can be removed per plant, resulting in 3-4 tonnes/ha of trash. If detrashing is done in the rainy season, the mulch will be largely decomposed by harvest.

The advantages of pre-harvest cane detrashing are listed below:

- Minimization of the bulky trash to be managed at harvest time. Detrashed leaves $8-9$ months after planting represent about $25-33 \%$ of the total trash (12 tonnes/ha) at harvest time.

- Creation of an active microbial inoculum that will initiate rapid decomposition of the remaining trash at harvest time (if moisture is available)

- Reduction of crop lodging caused by typhoons

- Suppression of weed growth and conservation of soil moisture

- Elimination of the difficulties/delay in cane stalk cutting at maturity

- Improved air $\left(\mathrm{CO}_{2}\right)$ circulation. Sugarcane can be sweeter at harvest (more sugar per tonne cane). In one study detrashed canes had $21.7 \%$ higher piculs of sugar per tonne than trashy canes (Dosayla, 1994). 
- The base of the stalk is exposed, facilitating the use of the mechanical cane cutter which could speed harvesting and reduce costs.

- Cleaner (less trashy and muddy) canes can be delivered to the mill, improving sugar recovery and mill efficiency.

- Detrashing provides essential employment during the off-milling season. The added benefits readily offset the added costs.

- Cane detrashing facilitates the introduction of short maturing inter-crops, especially in association with the double row planting patterns described in Figure 4.4 .

On the other hand, both small and large planters with tight budgets may find detrashing to be an added cost, especially in the plant year. Pre-harvest detrashing along with modified (double) row spacing are suggested (tested) remedial measures to offset the difficulties associated with trash farming. More on-farm trials should be conducted to explore and promote the benefits of this system. Since some Filipino farmers are already practicing trash farming on their farms, their efforts can serve as on-site examples for demonstrations to others.

\subsection{The Implications of Altering Agronomic Practices on Fossil Fuel and Residue Usage}

\subsubsection{Energy Assessment}

The effect of trash farming practices on fossil fuel usage from agricultural operations was examined between conventional cane (Figure 4.2) and trash farming (Figure 4.8). The trash farmed crop had a higher ratoon yield (78 tonnes/ha) compared to conventional cane (65 tonne/ha). This increased the harvest/hauling energy for the trash farmed cane, but reduced the overall energy input per tonne (mainly due to lower nitrogen fertilizer inputs and the impact of the increased yield). With trash farming the inter-row tillage is assumed to be only $1 / 2$ that of the plant crop (due to every other row being mulched). Fertilizer reduction is estimated to be $110 \mathrm{~kg} \mathrm{~N} / \mathrm{ha}$ (to $99 \mathrm{~kg} \mathrm{~N} / \mathrm{ha}$ ). The total fossil energy requirement for the fertilizer in the ratoon crop is thereby reduced to $9.1 \mathrm{GJ} / \mathrm{ha}$ (Appendix 4.5.3). 
Figure 4.8. Energy Use (\%) in trash farming cane production (plant and ratoon crops, GJ/ha)

\section{Plant Crop}

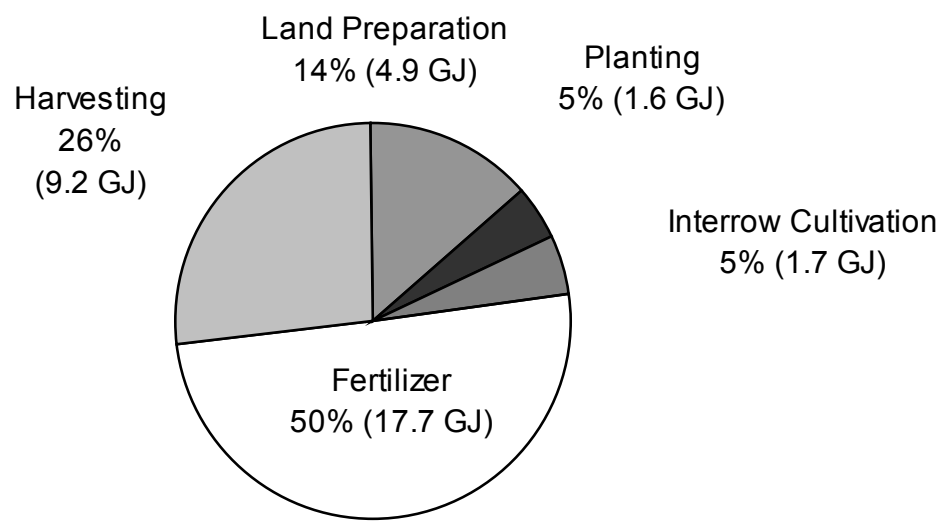

Total Energy Expenditure $=35.1 \mathrm{GJ} / \mathrm{ha}$ based on a yield of 80 tonnes/ha (or $0.439 \mathrm{GJ} /$ tonne)

\section{Ratoon Crop}

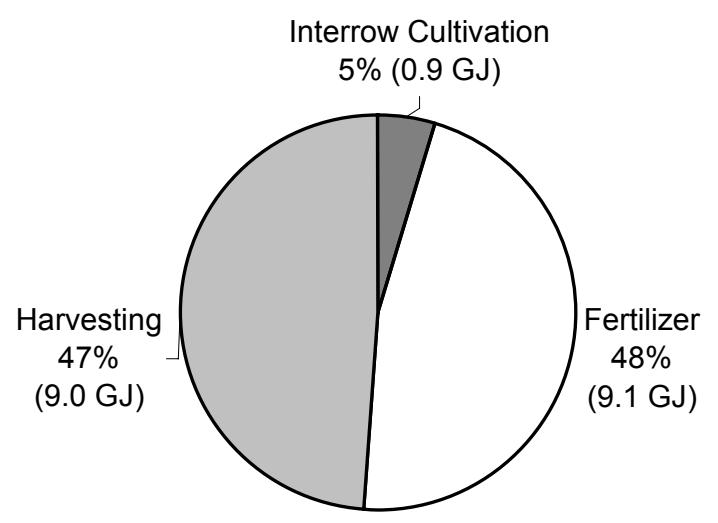

Total Energy Expenditure $=19.0 \mathrm{GJ}$ based on a yield of 78 tonnes/ha (or $0.24 \mathrm{GJ} /$ tonne) 


\subsubsection{Reducing Fossil Fuel Energy Input in Sugarcane Production}

The practices/operations that consume the most fossil fuel energy in sugarcane production in the Philippines were described in sections 4.4.2 and 4.7.1. Fertilizer consumes the greatest quantity of fossil fuel, and the reducing fertilizer inputs would have the greatest overall impact on fossil fuel energy demand. Reducing fertilizer input (particularly nitrogen fertilizer) appears to be achievable. Trash farming readily exhibits positive effects on the financial, soil and environmental challenges of sugarcane production. Trash farming is used in ratoon crops and automatically reduces the energy cost of land preparation to re-establish the canes. By mulching the rows, inter-row cultivation is also reduced by approximately $1 / 2$.

Rail transport could greatly reduce the cost of hauling canes to the mill. Only $10 \%$ of canes in the Philippines are transported to the mills by rail. However, additional railway construction requires a huge investment and may not be a priority for the government. Planters, on the other hand, desire the improvement of present roads, including the construction of all-weather bridges in rivers or creeks that traverse their farms. Rising energy costs for transportation fuels may encourage cane transport by railway.

At the farm level, it is obvious that the best way to improve the energy balance of sugarcane production is to ecourage practices that extend ratooning to a minimum of 3 cycles (1P:3R) (Table 4.8). Since nitrogen fertilizers account for the greatest energy input, practices that reduce fertilizer use, and cane that requires less nitrogen need to be identified and developed. This analysis indicates that trash farming could substantially reduce energy input in cane cultivation. Trash farming could reduce energy use per tonne by $5 \%$ in the plant crop and $40 \%$ in the ratoon crop. Developing high yielding cane crops adapted to low input trash farming management and extended ratooning cycles is an important step. Assuming a $25 \%$ reduction in energy could be achieved per tonne (from 0.4 to $0.3 \mathrm{GJ} /$ tonne), it would result in a fossil energy input savings of 1.8 million GJ for the industry at current production levels. Reducing fossil energy use may be much easier to achieve than producing bioenergy to substitute for fossil energy. 
Table 4.8. 15 Steps for 1 plant crop: 3 ratoon cane cycles of sugarcane production cum-trash farming Plant Crop

1. Ensure adequate land preparation, including:

- Deep plowing (mold board plow)

- Thorough soil pulverization, $3-4 \times$ harrowing and deep furrowing $(30-40 \mathrm{~cm})$

2. Use only quality/selected cane points of locally adapted high yielding sugarcane varieties, including early, mid, and late maturing varieties to extend to harvest season

3. Ensure adequate interrow cultivation for weeding

4. Ensure balanced and timely application of chemical fertilizer

5. Provide adequate drainage canals

6. Detrash canes 7-8 months after planting

7. Conduct a timely harvest with no pre-harvest burning

8. Cut the canes close to the ground to eliminate the need for stubble shavings, enable a timely start of the next ratoon, and allow for extended ratoon cycles. The trash is then used for mulching.

\section{First to Second Ratoon}

9. Arrange the piles of trash in the furrows to allow interrow cultivation in the ratoon 10. Reduce nitrogen fertilizer application based on local $\mathrm{N}$ response trials

11. Detrash canes 7-8 months after planting

12. Conduct a timely harvest with no pre-harvest burning

13. Cut canes close to the ground

\section{Third ratoon}

14. Bale trash for power COGEN in the mill or trash briquettes/pellets

15. Repeat steps for plant crop establishment

\subsubsection{Implication of Trash Farming in the Utilization of Biofuels}

The best utilization option for sugarcane trash must take into account the following considerations: the aggregate financial benefits to the farmer (Figure 4.3, Table 4.3), and the long-term ecological impacts of in-situ trash utilization (Table 4.5).

\section{Considerations:}

If the sugarcane producer were to realize the benefits of in-situ trash utilization:

- The farmer must be flexible, tolerant, and ready to adjust to the labor/management requirements of trash farming.

- The farmer must be able to define a plan of action (POA) outlining the conversion from burned to green cane harvesting. It may also be necessary to re-design planting patterns (furrow spacings) to accommodate trash and minimize trash handling difficulties. 
The complete adoption of changes in agronomic practices and technologies may take 10-20 years, so it is imperative to begin promoting biomass utilization immediately. Crop residue biomass in sugarcane, as per our intensive analysis, can be best handled by:

(a) In-situ trash mulching from the plant crop to second ratoon;

(b) Prior to establishing a new plant crop after the third ratoon, bale the trash as a fuel for sugar boilers, a fuel for pelleting, or for charcoal production.

Optimal use of the sugarcane resources:

- Ensures the long term productive capacity of the land.

- Increases productivity and reduces production costs and fossil energy inputs/tonne of cane (resolving two major problems; the lack of cane and the high cost of production).

- Provides a sustainable biofuel resource for household cooking, replaces bunker oil in sugar mill boilers, and expands off-season power generation.

Finally an assessment of sugarcane trash mulch farming was completed (Table 4.9) to determine the impact of increasing yield and trash removal (one year in three) on increasing sugar cane bioenergy residues.

Table 4.9: Potential for trash farming to increase biomass residue supplies for bioenergy applications

\begin{tabular}{|l|c|c|}
\hline \multicolumn{1}{|c|}{ Average } & $\begin{array}{c}\text { Conventional } \\
\text { Cane }\end{array}$ & $\begin{array}{c}\text { Trash Farming and Trash } \\
\text { Retrieval (1 yr in 3) }\end{array}$ \\
\hline Assumed Cane Yield & $70 \mathrm{t} / \mathrm{ha}$ & $77 \mathrm{t} / \mathrm{ha}$ \\
\hline Bagasse Yield & $20.0 \mathrm{t}$ & $22.0 \mathrm{t}$ \\
\hline Bagasse energy & $180 \mathrm{G}$ & $198 \mathrm{GJ}$ \\
\hline Cane Trash Energy & & $48.5 \mathrm{GJ}$ \\
\hline Total Biomass Energy & & $246.5 \mathrm{GJ}$ \\
\hline
\end{tabular}

Assumptions:

- Bagasse energy is derived from a yield of $285 \mathrm{~kg}$ bagasse/tonne cane processed $X 9$ GJ/tonne (at $50 \%$ moisture basis).

- Cane Trash energy is derived from an oven dry trash yield of $15 \%$ of cane yield $\times 70 \%$ recovery rate $\times 18 \mathrm{Gj} /$ tonne, with harvest taken only one year in three (following final ratoon).

- Typically yields increase under trash farming by $20 \%$ in the first ratoon crop, thus an average yield increase of $10 \%$ is assumed over the cropping cycle ( 7 tonnes/ha).

The analysis indicates that an additional $66.5 \mathrm{GJ} / \mathrm{ha}$ of biomass energy could be made available for bioenergy applications. Assuming there is a total of 350,000 ha of available land, full implementation of this system would result in an additional 23.3 million GJ of bioenergy for processing. This is equivalent to the amount of energy available from the recoverable rice hulls in the Philippines. Increasing cane productivity and optimizing the use of cane trash can be important strategies to enhance bioenergy development in the Philippines. 


\subsection{References}

ABRIGO, C.C. Ed. 1981. Organic fertilizer from cane trash as soil ameliorant. PHILSUTECH. Proc., $28^{\text {th }}$ Ann. Conv. 448-462.

ALABAN, R., F.C. BARREDO, and A. L. AGUIRE. 1990. An assessment of some indicators and determinants of farm productivity and soil fertility in VMC district. Trends association, Interactions. Paper presented during PHILSUTECHS $37^{\text {th }}$ Annual Convention, August 8-10, 1990. PICC, Manila.

AMRE, D.K., C. Infante-Rivard, A. Dufresne, P.M. Durgawale, and P. Ernst. 1999. Casecontrol study of lung cancer among sugar cane farmers in India. Occupational and Environmental Medicine. 56(8):548-252.

AZEREDO, D. F., J. Bolsanello, M. Weber, and J. R. Viera. 1986. Nitrogenio em cana planta, doses e fracionamento. STAB (Sao Paulo), 4:26-32.

BALL-COELHO, B., I. H. Salcedo, H. Tressen, and J. B. Stewart. 1993. Short and long term phosphorus dynamics in a fertilized ultisol under sugar cane. Soil Sci. Soc. Am. J. 57:1027-1034.

BODDEY, R.M. 1995. Biological nitrogen fixation in sugar cane: A key to energetically viable biofuel production. Critical Reviews in Plant Science. 14(3):263-379.

BODDEY, R.M., O.C. de Olivera, S. Urquiaga, V.M. Reis, F.F.L. de Olivarea, V.L.D. Baldani, and J. Dobereiner. 1995. Biological nitrogen fixation associated with sugarcane and rice: contributions and prospects for improvement. Plant and soil 174:195-209.

CERBO, B.P., J. C. Palmaran, R. E. Tapay, and E. D. Buenafe. 1996. Yield Constraints and Profitability in Sugarcane Production. PHILSUTECH Proc. 43rd Annual Convention Cebu Plaza Hotel, Aug. 6-9, 1996. p. 220-231.

COOK, G. D. 1994. The fate of nutrients during fires in a tropical savanna. Australian Journal of Ecology. 19:359-365.

COVAR, R.R. 1989. Factors Affecting Cane Juice Quality. PHILSUTECH Proc. $36^{\text {th }}$ Annual Convention. p. 313-333.

DOSAYLA, R. D. 1994. The Influence of trash on the yield components of sugarcane varieties. PHILSUTECH Proc. $41^{\text {st }}$ Annual Convention. Aug. 17-20, 1994. Cebu Plaza Hotel, Cebu City. p. 198-203.

DURST, Patrick, 1986. Wood-fired power plants in the Philippines: financial and economic assessment of wood-supply strategies. Biomass, vol. 11, pp. 115-133.

FAO, 2001.http://apps.fao.org/page/collections?subset=agriculture. Website visited on June 28, 2001. 
HILL, N.M. and Patriquin, D.G. 1990. Evidence for the involvement of Azospirillum brasilense and Helicomyces roseus in the aerobic nitrogen-fixing/cellulolytic system from sugarcane litter. Soil Biology \& Biochemistry 22, 313-319.

HODGE, R. 1998. Soil Organic Matter : Its Central Position in Organic Farming. In Advances in Soil Organic Matter Research. p. 355-363.

LEDESMA, J. 1997. Productivity Constraints in the Philippine Sugar Industry. PHILSUTECH Proc. 44 ${ }^{\text {th }}$ Annual Convention, 19-22 Aug. 1997, PICC, Mla. Phil.

MENDOZA, T.C. and R. Samson. 2000. Estimates of $\mathrm{CO}_{2}$ production from the burning of crop residues. Environmental Science and Management 3(1): 25-33.

MENDOZA, T.C., and R. A. Samson. 1999. Strategies to avoid crop residue burning in the Philippine context. Conference on Canadian International Initiatives toward Mitigating Climate Change. April 24-May 2, 1999, San Salvador, El Salvador.

MENDOZA, T. C. 1995. From Sugar Exporting to Sugar Importing Country : What are the Reasons? Occasional Paper. Dept. of Agronomy, College of Agriculture, U. P. Los Baños, College, Laguna. Nov. 7, 1995. 9 p.

MENDOZA, T. C. 1993. Assessment of Sugar Yield Trends in the Philippines and their Implications. The Phil. Agric. 76(2) 133-145.

MENDOZA, T.C. 1989. Development of organic farming practices for sugarcane-based farms. IFOAM Proc. $7^{\text {th }}$ Int'l. Scientific Conference. Onagadougou. Jan. 2-5, 1989. Burkina Fasso. p. 189.202.

MENDOZA, T. C., E. R. Celestino, and C. J. Andam. 1987. Developing Trash Farming Practices in Sugarcane Production : A Preliminary Report. PHILSUTECH Proc. $34^{\text {th }}$ Ann. Conv. Amigo Terrace Hotel, lloilo City, Phil. p. 249-252.

MENDOZA, T.C. 1985. Bioproductivity and economic evaluation of some sugar cane production alternatives. PHD Thesis UPLB College, Laguna, Philippines.

MENDOZA, T.C. 1979. Optimum spatial arrangement in sugar cane-legume intercropping. MS Thesis UPLB College, Laguna, Philippines.

MUI THI NGUYEN, N. T. Dung, D. Van Binh, and T. R. Preston. 1997a. On-farm evaluation of planting distance and mulching of sugarcane. Livestock Research for Rural Devt. 9(3) 1-6.

MUI THI NGUYEN, T. R. Preston, I. Ohlsson. 1997b. Response of four varieties of sugarcane to planting distance and mulching. Livestock Research for Rural Development. 9(3)1-10.

MUI THI NGUYEN, T. R. Preston, Dinh van Binh, Le Vietly, and Ingvan Ohlsson. 1996. Effect of management practices on yield and quality of sugarcane and soil fertility. Livestock Research for Rural Development. 8(3) 1-11. 
MULVEY , J.J., and H. Rothschild. 1983. Sugarcane farming-Is there a link with cancer? Ecology of Disease. 2(4): 267-270.

PINDA, F.A.1956. Trash mulching improved the yield of sugarcane. PHILSUTECH Proc. 196-198.

PATRIQUIN, D. 2001. Personal Communication.

PATRIQUIN, D. 2000. Overview of $\mathrm{N}_{2}$ Fixation in sugar cane residues: Levels and effects on decomposition. Biology Department, Dalhousie University, Halifax Nova Scotia

PENNINGTON, M., I. Lacrose, and A.D.C. Gonzales. 1996, Economin, Technological and Financial Issues related to Energy Generation in the Philippine Sugar Industry. Proc. 43 ${ }^{\text {rd }}$ PHILSUTECH Annual Convention. August 6-8, Cebu city, Philipppines.

POOLCHUND H.N. 1991. Aspects of occupational health in the sugar cane industry. Journal of the Society of Occupational Medicine. 41(3): 133-136.

ROSARIO, E. L., E. P. Paningbatan, A. Gerwin, and P. Dionora. 1992. Study on the Causal Factors of Declining Sugarcane Quality in the La Carlota Mill District. PHILSUTECH Proc. $39^{\text {th }}$ Annual Conv. Bacolod Convention Plaza Hotel, Bacolod City. p. 168-184.

SANTO, L. T. 1991. Agronomic Issues in Sugarcane Residue Collection. Paper No. 778, Journal Series of the Expt. Stn., Hawaiian Sugar Planters Association, Aiea, H196701. p. 267-281.

SORIANO, A. 1982. Energy-based Analysis of Alternative Production Systems in Irrigated Lowland Rice. UPLB MS Thesis. $123 p$.

SRA. (Sugar Regulatory Authority) 1994. Annual Synopsis of Philippine Raw Sugar Factories. Production Performance Data for Crop Years 1983-94. SRA. Diliman, Quezon City.

TAN, P. G. 1995 December. Effect on production of sugar cane on soil fertility of leaving the dead leaves on the soil or removing them. Livestock research for Rural Development 7(2).

WOOD, A.W. 1991. Management of crop residues following green cane harvesting of sugar cane in north Queensland. Soil and Tillage Research 20:69-85.

ZABALETA, J. M. T. 1999. The Sweet Spot of Philippine Agriculture. The Food and Agriculture Centennial Book. 100 years of Philippine Agriculture. University of Asia and the Pacific, Manila, Philippines.

ZAMPERLINI, G.C.M., M.R.S. Silva, and W. Vilegas. 1997. Identification of polycyclic aromatic hydrocarbons in sugar cane soot by gas chromatography-mass spectroscopy. Chromatographia 46(11/12): 655-663. 


\section{Glossary of Terms}

Bagasse Milling by-product remaining after extracting sugar from the stalk

BAP

BFOE

Benzo-alpha-pyrene

Cane Trash

Barrel of fuel oil equivalent

COGEN

field residue remaining after harvesting the cane stalk

plant

Plant with bioenergy development and feedstock supply systems enabling year-round power generation

DM

Dry Matter (usually expressed in percent)

FGTS

Fast growing tree species for biofuel

GCY

GJ

HFCS

LPG

MDF

Gross cane yield in a given mill district

Giga Joule (unit of energy measurement)

High fructose corn syrup

Liquefied petroleum gas

MBFOE

Mill district factor

MLOE

NEM

ODT

OJT

Million barrels of fuel oil equivalent

Million liter oil equivalent

Nursery establishment and management

Oven dried tonne

On-the-job training

PAH

POA

Polycyclic aromatic hydrocarbon

Plan of action

RHY

Rice hull yield in the area

RPR

Residue to product ratio

RTI

Lower respiratory tract infections

RTY

Recoverable trash yield

SOM

Soil organic matter

SWOT Strength/ weaknesses/ opportunities/threats analysis

TRY

Total rice yield in the area

TY\%

Percentage trash yield 
Appendices 
Appendix 1.1. Agricultural Crop Data from the Philippines (FAO statistics, 1961-1999)

\begin{tabular}{|c|c|c|c|c|c|c|c|c|c|c|c|c|}
\hline Year & $\begin{array}{c}\text { Rice (Paddy) } \\
\text { Yield } \\
\text { (tonnes/ha) }\end{array}$ & $\begin{array}{c}\text { Rice } \\
\text { Production } \\
\left(\text { Mtonnes } \times 10^{6}\right)\end{array}$ & $\begin{array}{l}\text { Rice Area } \\
\text { Harvested } \\
\text { (ha) }\end{array}$ & $\begin{array}{c}\text { Maize } \\
\text { Yield } \\
\text { (tonnes/ha) }\end{array}$ & $\begin{array}{c}\text { Maize } \\
\text { Production } \\
\text { (Mtonnes) }\end{array}$ & $\begin{array}{c}\text { Maize Area } \\
\text { Harvested } \\
\text { (ha) }\end{array}$ & $\begin{array}{c}\begin{array}{c}\text { Coconut } \\
\text { Yield } \\
\text { (tonnes/ha) }\end{array} \\
\end{array}$ & $\begin{array}{l}\text { Coconut } \\
\text { Production } \\
\text { (Mtonnes) }\end{array}$ & $\begin{array}{l}\text { Coconut Area } \\
\text { Harvested } \\
\text { (ha) }\end{array}$ & $\begin{array}{c}\text { Sugarcane } \\
\text { Yield (kg/ha) }\end{array}$ & $\begin{array}{l}\text { Sugarcane } \\
\text { Production } \\
\text { (Mtonnes) }\end{array}$ & $\begin{array}{l}\text { Sugarcane } \\
\text { Area } \\
\text { Harvested } \\
\text { (ha) }\end{array}$ \\
\hline 1961 & 1.23 & 3.91 & $3,179,190$ & 0.63 & 1.27 & $2,016,270$ & 4.19 & 5.02 & $1,199,880$ & 75.19 & 17.46 & 232,200 \\
\hline 1962 & 1.25 & 3.97 & $3,161,320$ & 0.65 & 1.27 & $1,949,500$ & 5.01 & 6.43 & $1,283,740$ & 76.01 & 19.36 & 254,700 \\
\hline 1963 & 1.24 & 3.84 & $3,087,450$ & 0.68 & 1.29 & $1,897,570$ & 5.27 & 7.35 & $1,394,310$ & 79.65 & 20.61 & 258,770 \\
\hline 1964 & 1.25 & 3.99 & $3,199,670$ & 0.68 & 1.31 & $1,922,750$ & 4.63 & 6.87 & $1,482,890$ & 81.46 & 21.98 & 269,880 \\
\hline 1965 & 1.31 & 4.07 & $3,109,180$ & 0.66 & 1.38 & $2,106,080$ & 4.16 & 6.68 & $1,604,700$ & 60.35 & 21.15 & 350,480 \\
\hline 1966 & 1.32 & 4.09 & $3,096,120$ & 0.69 & 1.49 & $2,157,900$ & 4.67 & 7.53 & $1,610,920$ & 60.95 & 19.22 & 315,280 \\
\hline 1967 & 1.38 & 4.56 & $3,304,000$ & 0.72 & 1.62 & $2,247,900$ & 3.44 & 6.32 & $1,840,000$ & 68.94 & 21.28 & 308,690 \\
\hline 1968 & 1.33 & 4.44 & $3,332,150$ & 0.77 & 1.73 & $2,256,100$ & 3.41 & 6.13 & $1,800,410$ & 68.68 & 21.86 & 318,290 \\
\hline 1969 & 1.71 & 5.46 & $3,195,830$ & 0.83 & 2.01 & $2,419,600$ & 2.86 & 5.28 & $1,845,480$ & 64.09 & 21.98 & 342,960 \\
\hline 1970 & 1.75 & 5.58 & $3,195,000$ & 0.83 & 2.01 & $2,427,750$ & 3.02 & 5.69 & $1,883,920$ & 71.41 & 26.14 & 366,070 \\
\hline 1971 & 1.60 & 5.32 & $3,332,290$ & 0.82 & 2.02 & $2,454,270$ & 3.59 & 7.36 & $2,048,490$ & 62.59 & 27.64 & 441,620 \\
\hline 1972 & 1.44 & 4.61 & $3,194,150$ & 0.78 & 1.84 & $2,350,600$ & 4.29 & 9.11 & $2,125,530$ & 56.23 & 24.80 & 441,020 \\
\hline 1973 & 1.46 & 5.16 & $3,527,750$ & 0.83 & 2.26 & $2,726,390$ & 3.68 & 7.85 & $2,133,300$ & 61.44 & 27.97 & 455,160 \\
\hline 1974 & 1.55 & 5.62 & $3,632,490$ & 0.84 & 2.51 & $3,009,910$ & 2.71 & 5.98 & $2,206,010$ & 71.08 & 34.88 & 490,670 \\
\hline 1975 & 1.66 & 6.11 & $3,674,040$ & 0.85 & 2.72 & $3,193,160$ & 4.04 & 9.22 & $2,283,100$ & 66.91 & 35.87 & 536,059 \\
\hline 1976 & 1.80 & 6.54 & $3,641,380$ & 0.86 & 2.77 & $3,242,520$ & 4.56 & 11.50 & $2,521,190$ & 67.61 & 38.71 & 572,600 \\
\hline 1977 & 2.01 & 7.25 & $3,601,700$ & 0.89 & 2.80 & $3,158,070$ & 3.79 & 10.28 & $2,713,960$ & 60.75 & 34.82 & 573,150 \\
\hline 1978 & 2.03 & 7.21 & $3,560,700$ & 0.94 & 3.07 & $3,252,430$ & 3.56 & 10.29 & $2,889,800$ & 58.59 & 30.56 & 521,613 \\
\hline 1979 & 2.11 & 7.68 & $3,636,810$ & 0.98 & 3.12 & $3,201,070$ & 2.76 & 8.45 & $3,064,000$ & 70.67 & 31.89 & 451,200 \\
\hline 1980 & 2.21 & 7.65 & $3,459,130$ & 0.96 & 3.11 & $3,238,690$ & 2.82 & 9.14 & $3,236,000$ & 72.77 & 30.90 & 424,620 \\
\hline 1981 & 2.30 & 7.91 & $3,442,830$ & 0.98 & 3.29 & $3,360,700$ & 3.05 & 9.84 & $3,224,000$ & 79.01 & 31.60 & 399,949 \\
\hline 1982 & 2.63 & 8.53 & $3,239,630$ & 0.99 & 3.13 & $3,157,480$ & 2.84 & 9.11 & $3,203,000$ & 85.96 & 35.80 & 416,457 \\
\hline 1983 & 2.32 & 7.29 & $3,140,670$ & 1.02 & 3.35 & $3,270,210$ & 2.66 & 8.50 & $3,202,000$ & 69.76 & 28.70 & 411,396 \\
\hline 1984 & 2.43 & 7.83 & $3,221,770$ & 1.07 & 3.44 & $3,226,950$ & 1.87 & 6.04 & $3,223,000$ & 83.76 & 34.30 & 409,501 \\
\hline 1985 & 2.59 & 8.81 & $3,402,610$ & 1.12 & 3.92 & $3,510,910$ & 2.63 & 8.60 & $3,270,000$ & 61.98 & 22.84 & 368,547 \\
\hline 1986 & 2.72 & 9.25 & $3,402,910$ & 1.15 & 4.09 & $3,563,000$ & 3.43 & 11.28 & $3,284,000$ & 69.94 & 20.99 & 300,118 \\
\hline 1987 & 2.62 & 8.54 & $3,255,900$ & 1.16 & 4.28 & $3,682,650$ & 3.23 & 10.52 & $3,252,000$ & 63.92 & 17.21 & 269,270 \\
\hline 1988 & 2.64 & 8.97 & $3,392,670$ & 1.18 & 4.43 & $3,745,070$ & 2.47 & 7.94 & $3,221,819$ & 89.50 & 19.30 & 215,640 \\
\hline 1989 & 2.70 & 9.46 & $3,497,280$ & 1.23 & 4.52 & $3,689,240$ & 2.53 & 7.87 & $3,110,423$ & 96.52 & 25.26 & 261,736 \\
\hline 1990 & 2.98 & 9.89 & $3,318,720$ & 1.27 & 4.85 & $3,819,560$ & 3.54 & 11.02 & $3,111,978$ & 80.03 & 25.48 & 318,403 \\
\hline 1991 & 2.82 & 9.67 & $3,424,960$ & 1.30 & 4.66 & $3,589,460$ & 2.79 & 8.64 & $3,093,260$ & 68.91 & 24.84 & 360,395 \\
\hline
\end{tabular}




\begin{tabular}{|c|c|c|c|c|c|c|c|c|c|c|c|c|}
\hline $\mid \begin{array}{l}\text { Year } \\
\end{array}$ & $\begin{array}{c}\text { Rice (Paddy) } \\
\text { Yield } \\
\text { (tonnes/ha) }\end{array}$ & $\begin{array}{c}\text { Rice } \\
\text { Production } \\
\left(\text { Mtonnes } \times 10^{6}\right)\end{array}$ & $\begin{array}{c}\text { Rice Area } \\
\text { Harvested } \\
\text { (ha) }\end{array}$ & $\begin{array}{c}\text { Maize } \\
\text { Yield } \\
\text { (tonnes/ha) }\end{array}$ & $\begin{array}{c}\text { Maize } \\
\text { Production } \\
\text { (Mtonnes) }\end{array}$ & $\begin{array}{c}\text { Maize Area } \\
\text { Harvested } \\
\text { (ha) }\end{array}$ & $\begin{array}{c}\begin{array}{c}\text { Coconut } \\
\text { Yield } \\
\text { (tonnes/ha) }\end{array} \\
\end{array}$ & $\begin{array}{c}\text { Coconut } \\
\text { Production } \\
\text { (Mtonnes) }\end{array}$ & $\begin{array}{l}\text { Coconut Area } \\
\text { Harvested } \\
\text { (ha) }\end{array}$ & $\begin{array}{c}\text { Sugarcane } \\
\text { Yield (kg/ha) }\end{array}$ & $\begin{array}{l}\text { Sugarcane } \\
\text { Production } \\
\text { (Mtonnes) }\end{array}$ & \begin{tabular}{|c|} 
Sugarcane \\
Area \\
Harvested \\
(ha) \\
\end{tabular} \\
\hline 1992 & 2.94 & 9.51 & $3,237,000$ & 1.33 & 4.62 & $3,482,000$ & 3.05 & 9.38 & $3,076,720$ & 81.11 & 28.86 & 355,767 \\
\hline 1993 & 2.87 & 9.43 & |3,282,400 & 1.52 & 4.80 & $3,149,240$ & 3.68 & 11.33 & $3,075,249$ & 77.47 & 29.75 & 384,009 \\
\hline 1994 & 2.89 & 10.54 & $3,651,500$ & 1.53 & 4.13 & $2,692,330$ & 3.66 & 11.21 & $3,061,860$ & 66.46 & 26.69 & 401,635 \\
\hline 1995 & 2.80 & 10.54 & \begin{tabular}{|l|}
$3,758,700$ \\
\end{tabular} & 1.52 & 4.16 & $2,735,720$ & 3.98 & 12.18 & $3,064,457$ & 65.56 & 24.59 & 375,098 \\
\hline 1996 & 2.86 & 11.28 & |3,951,100 & 1.59 & 4.35 & $2,728,680$ & 3.61 & 11.37 & $3,148,970$ & 67.21 & 26.59 & 395,640 \\
\hline 1997 & 2.93 & 11.27 & $3,842,270$ & 1.59 & 4.33 & $2,725,820$ & 3.66 & 12.12 & $3,314,390$ & 76.18 & 26.81 & 351,985 \\
\hline 1998 & 3.23 & 10.24 & $3,170,042$ & 1.62 & 3.82 & $2,354,208$ & 3.50 & 10.91 & $3,115,800$ & 72.42 & 26.29 & 363,000 \\
\hline 1999 & 2.86 & 11.39 & $3,978,000$ & 1.72 & 4.64 & $2,701,000$ & 3.61 & 11.00 & $3,050,000$ & 73.43 & 26.29 & 358,000 \\
\hline MEAN & 2.15 & $7,370,276$ & $3,403,367$ & 1.05 & $3,087,502$ & $2,882,378$ & 3.49 & $8,751,979$ & $2,596,681$ & 71.40 & 26 & 375,425 \\
\hline
\end{tabular}




\section{Appendix 1.2. Sugarcane Yield Calculations}

Example : Central Azucarera de Tarlac, Philippines

No. of milling weeks $=22$

No. of "dry" weeks = 16 weeks

Ratio: $16 / 22$ = mill district recovery factor: $72 \%$

In the Visayas, where the rainy season commences at an earlier stage in the milling season, the recovery factor also includes the trash that could be recovered during weeks of intermittent rain. During these weeks, it is estimated that only $50 \%$ of trash could be recovered.

Example: Victorias Milling district, Philippines

Total No. of milling weeks

Milling weeks where there is intermittent rainfall

No. of "dry" weeks

Ratio: $(8 / 36) 0.5+13 / 36)=$ mill district recovery factor: $47 \%$
$=36$

$=8$

$=13$ 
Appendix 1.3 Estimates of Maize Cob Production and Recoverability in the Philippines

A. Estimate of total maize cob production and barrel of fuel oil equivalent values (BFOE) by region.

\begin{tabular}{|r|r|r|r||}
\hline & \multicolumn{1}{|c|}{ A } & \multicolumn{1}{c|}{ B } & \multicolumn{1}{c|}{ C } \\
\hline REGION & $\begin{array}{c}\text { Maize Grain } \\
\text { x 1000 } \\
\text { (tonnes) }\end{array}$ & $\begin{array}{c}\text { Maize Cobs } \\
\text { x 1000 } \\
\text { (tonnes) }\end{array}$ & $\begin{array}{c}\text { BFOE } \\
\text { Maize Cob } \\
\text { (x 1000) }\end{array}$ \\
\hline CAR & 97.28 & 22.08 & 8.63 \\
C. VALLEY & 185.93 & 42.21 & 16.49 \\
C. LUZON & 689.91 & 156.61 & 61.18 \\
S. TAGALOG & 82.42 & 18.71 & 7.31 \\
BICOL & 91.53 & 20.78 & 8.12 \\
W. VISAYAS & 86.68 & 19.68 & 7.69 \\
C. VISAYAS & 142.75 & 16.51 & 6.45 \\
E. VISAYAS & 40.78 & 33.21 & 12.97 \\
W. MINDANAO & 172.91 & 9.26 & 3.62 \\
N. MINDANAO & 576.3 & 139.25 & 15.33 \\
S. MINDANAO & 666.12 & 151.21 & 51.1 \\
C. MINDANAO & 686.21 & 155.77 & 59.07 \\
ARMM & 590.57 & 134.06 & 60.85 \\
CARAGA & 51.52 & 11.7 & 52.37 \\
PHILIPPINES & $\mathbf{4 1 8 6 . 4}$ & $\mathbf{9 6 1 . 8 4}$ & $\mathbf{3 7 5 . 7 2}$ \\
\hline \hline
\end{tabular}

Source of data: BAS Cereal Statistics Section

$A=$ Maize grain is the average for CY 1996, 1998 and 1999,

$B=A^{*} 0.227$

$\mathrm{C}=\mathrm{B} / 2.56$. 


\section{B. Estimates of recoverable maize cobs by region, barrel of fuel oil equivalent (BFOE) and monetary value (US dollar)}

\begin{tabular}{|c|c|c|c|c|c|c|c|c|}
\hline & "Jan.-June & RF & Recoverable & July-Dec. & $\overline{\mathrm{RD}}$ & Recoverable & Total & $\begin{array}{c}\text { BFOE } \\
\text { R-Maize Cob }\end{array}$ \\
\hline & Maize Grain & & $\begin{array}{l}\text { Maize Cob } \\
\text { (tonne) }\end{array}$ & $\begin{array}{l}\text { Maize } \\
\text { Grain }\end{array}$ & & $\begin{array}{l}\text { Maize Cob } \\
\text { (tonne) }\end{array}$ & \multicolumn{2}{|c|}{ Recoverable } \\
\hline REGION & $\begin{array}{c}(\mathrm{J}) \\
(\times 1000)\end{array}$ & & $\begin{array}{c}(\mathrm{Rj}) \\
(\times 1000)\end{array}$ & $\begin{array}{c}(\mathrm{D}) \\
(\times 1000)\end{array}$ & & $\begin{array}{c}(\mathrm{Rd}) \\
(\times 1000)\end{array}$ & \multicolumn{2}{|c|}{$\begin{array}{c}\text { Maize Cob (tonne) } \\
(\times 1000)\end{array}$} \\
\hline CAR & 17.49 & 0.80 & 3.18 & 29.78 & 0.60 & 4.06 & \begin{tabular}{ll|}
7.23 \\
\end{tabular} & 18.51 \\
\hline Ilocos & 170.89 & 0.80 & 31.03 & 20.31 & 0.60 & 2.77 & 33.80 & 86.53 \\
\hline Cagayan Valley & 340.94 & 0.80 & 61.91 & 348.16 & 0.60 & 47.42 & 109.33 & 279.90 \\
\hline Central Luzon & 77.86 & 0.80 & 14.14 & 5.26 & 0.60 & 0.72 & 14.86 & 38.03 \\
\hline Southern Tagalog & 34.30 & 0.60 & 4.67 & 57.24 & 0.40 & 5.20 & 9.87 & 25.26 \\
\hline BICOL & 40.02 & 0.50 & 4.54 & 46.69 & 0.40 & 4.24 & 8.78 & 22.48 \\
\hline West Visayas & 22.71 & 0.60 & 3.09 & 50.04 & 0.40 & 4.54 & 7.64 & 19.55 \\
\hline Central Visayas & 24.19 & 0.60 & 3.29 & 122.10 & 0.40 & 11.09 & 14.38 & 36.82 \\
\hline Eastern Visayas & 11.78 & 0.60 & 1.60 & 22.06 & 0.40 & 2.00 & 3.61 & 9.24 \\
\hline Western Mindanao & 35.15 & 0.60 & 4.79 & 137.75 & 0.40 & 12.51 & 17.30 & 44.28 \\
\hline Northern Mindanao & 161.95 & 0.60 & 22.06 & 414.35 & 0.40 & 37.62 & 59.68 & 152.78 \\
\hline Southern Mindanao & 214.23 & 0.50 & 24.32 & 451.88 & 0.40 & 41.03 & 65.35 & 167.29 \\
\hline Central Mindanao & 237.87 & 0.60 & 32.40 & 448.35 & 0.40 & 40.71 & 73.11 & 187.16 \\
\hline ARMM & 241.71 & 0.50 & 27.43 & 348.86 & 0.40 & 31.68 & 59.11 & 151.32 \\
\hline CARAGA & 9.74 & 0.50 & 1.11 & 41.74 & 0.40 & 3.79 & 4.90 & 12.53 \\
\hline PHILIPPINES & $1,640.83$ & & 239.57 & $2,544.57$ & & 249.37 & 488.93 & $1,251.67$ \\
\hline
\end{tabular}

$\mathrm{RF}=$ Recovery Factor $(\mathrm{JJ}) \mathrm{Rd}=\mathrm{D}{ }^{*} 0.227^{*} \mathrm{BFOE}=\mathrm{TRC} * 2.73$

$\mathrm{Rj}=\mathrm{J} * 0.227{ }^{*} \mathrm{Rfj} \mathrm{TRC}=\mathrm{Rj}+\mathrm{Rd}$ Value $=\mathrm{BFOE}{ }^{*} 28$

SOURCE OF BASIC DATA: BAS Cereal Statistic Section 
Appendix 1.4. Potential Trash Yield and Recoverable Trash Yield as a Percent of Gross Cane Yield (Low, Average and High Estimates)

Source of basic data: PHILIPPINES SUGAR STATISTICS (1993-1998)

\section{A. Low Estimate}

\begin{tabular}{|c|c|c|c|c|}
\hline Region & $\begin{array}{c}\text { Gross Cane } \\
\text { Yield }\end{array}$ & $\begin{array}{c}\text { Potential Trash } \\
\text { Yield }\end{array}$ & $\begin{array}{l}\text { Mill District } \\
\text { Factor }\end{array}$ & $\begin{array}{c}\text { Recoverable Trash } \\
\text { Yield }^{*}\end{array}$ \\
\hline Luzon & 3832781 & 383278.10 & 0.82 & 199961.75 \\
\hline Batangas & 571000 & 57100.00 & 0.76 & 28207.40 \\
\hline Bisudeco & 245537 & 24553.70 & 0.64 & 10214.34 \\
\hline Carsumco & 197169 & 19716.90 & 0.90 & 11534.39 \\
\hline Don Pedro & 1325305 & 132530.50 & 0.90 & 77530.34 \\
\hline Manaoag & 14608 & 1460.80 & 0.90 & 854.57 \\
\hline Paniqui & 66207 & 6620.70 & 0.90 & 3873.11 \\
\hline Pasudeco & 311790 & 31179.00 & 0.80 & 16213.08 \\
\hline Tarlac & 1101165 & 110116.50 & 0.72 & 51534.52 \\
\hline Negros & 12338308 & 1233830.80 & 0.57 & 442181.87 \\
\hline Aidsisa & 565443 & 56544.30 & 0.50 & 18376.90 \\
\hline Bais & 752377 & 75237.70 & 0.70 & 34233.15 \\
\hline Binalbagan & 1376968 & 137696.80 & 0.46 & 41171.34 \\
\hline Dacongcogon & 244299 & 24429.90 & 0.57 & 9051.28 \\
\hline Danao & 275750 & 27575.00 & 0.50 & 8961.88 \\
\hline First Farmers & 808620 & 80862.00 & 0.60 & 31536.18 \\
\hline Hawaiian-Phil. & 1113734 & 111373.40 & 0.60 & 43435.63 \\
\hline La Carlota & 1202411 & 120241.10 & 0.58 & 45330.89 \\
\hline Lopez & 1140443 & 114044.30 & 0.48 & 35581.82 \\
\hline Sagay & 663674 & 66367.40 & 0.50 & 21569.41 \\
\hline San Carlos & 401510 & 40151.00 & 0.70 & 18268.71 \\
\hline Sonedco & 639453 & 63945.30 & 0.46 & 19119.64 \\
\hline Tolong & 298686 & 29868.60 & 0.77 & 14949.23 \\
\hline Upsumco & 791562 & 79156.20 & 0.73 & 37559.62 \\
\hline Victorias & 2063378 & 206337.80 & 0.47 & 63036.20 \\
\hline Panay & 1543077 & 154307.70 & 0.61 & 61486.09 \\
\hline Asturias & 184572 & 18457.20 & 0.60 & 7198.31 \\
\hline New Frontier & 508933 & 50893.30 & 0.63 & 20840.81 \\
\hline Passi & 465000 & 46500.00 & 0.66 & 19948.50 \\
\hline Pilar & 384572 & 38457.20 & 0.54 & 13498.48 \\
\hline $\begin{array}{r}\text { East. } \\
\text { Vis./Minda. }\end{array}$ & 2058660 & 205866.00 & 0.62 & 79344.34 \\
\hline Bogo-Mendellin & 352937 & 35293.70 & 0.60 & 13764.54 \\
\hline Busco & 163483 & 16348.30 & 0.66 & 7013.42 \\
\hline Davao & 533363 & 53336.30 & 0.55 & 19067.73 \\
\hline Durano & 143144 & 14314.40 & 0.66 & 6140.88 \\
\hline $\begin{array}{r}\text { Hideco } \\
\text { (Kananga) }\end{array}$ & 503616 & 50361.60 & 0.55 & 18004.27 \\
\hline $\begin{array}{r}\text { Nocosii } \\
\text { (Seasumco) }\end{array}$ & 222638 & 22263.80 & 0.66 & 9551.17 \\
\hline Ormoc & 139479 & 13947.90 & 0.64 & 5802.33 \\
\hline TOTAL & 37486992 & 3748699.20 & & 1486603.76 \\
\hline
\end{tabular}

${ }^{*}$ Recoverable Trash Yield $=G{ }^{*} P$ * $M D$ * 0.65 
B. Average estimate

\begin{tabular}{|c|c|c|c|c|}
\hline Region & $\begin{array}{c}\text { Gross Cane } \\
\text { Yield }\end{array}$ & $\begin{array}{c}\text { Potential Trash } \\
\text { Yield }\end{array}$ & $\begin{array}{l}\text { Mill District } \\
\text { Factor }\end{array}$ & $\begin{array}{c}\text { Recoverable Trash } \\
\text { Yield }^{*}\end{array}$ \\
\hline Luzon & 3832781 & 574917.15 & 0.82 & 299942.62 \\
\hline Batangas & 571000 & 85650.00 & 0.76 & 42311.10 \\
\hline Bisudeco & 245537 & 36830.55 & 0.64 & 15321.51 \\
\hline Carsumco & 197169 & 29575.35 & 0.90 & 17301.58 \\
\hline Don Pedro & 1325305 & 198795.75 & 0.90 & 116295.51 \\
\hline Manaoag & 14608 & 2191.20 & 0.90 & 1281.85 \\
\hline Paniqui & 66207 & 9931.05 & 0.90 & 5809.66 \\
\hline Pasudeco & 311790 & 46768.50 & 0.80 & 24319.62 \\
\hline Tarlac & 1101165 & 165174.75 & 0.72 & 77301.78 \\
\hline Negros & 12338308 & 1850746.20 & 0.57 & 663272.81 \\
\hline Aidsisa & 565443 & 84816.45 & 0.50 & 27565.35 \\
\hline Bais & 752377 & 112856.55 & 0.70 & 51349.73 \\
\hline Binalbagan & 1376968 & 206545.20 & 0.46 & 61757.01 \\
\hline Dacongcogon & 244299 & 36644.85 & 0.57 & 13576.92 \\
\hline Danao & 275750 & 41362.50 & 0.50 & 13442.81 \\
\hline First Farmers & 808620 & 121293.00 & 0.60 & 47304.27 \\
\hline Hawaiian-Phil. & 1113734 & 167060.10 & 0.60 & 65153.44 \\
\hline La Carlota & 1202411 & 180361.65 & 0.58 & 67996.34 \\
\hline Lopez & 1140443 & 171066.45 & 0.48 & 53372.73 \\
\hline Sagay & 663674 & 99551.10 & 0.50 & 32354.11 \\
\hline San Carlos & 401510 & 60226.50 & 0.70 & 27403.06 \\
\hline Sonedco & 639453 & 95917.95 & 0.46 & 28679.47 \\
\hline Tolong & 298686 & 44802.90 & 0.77 & 22423.85 \\
\hline Upsumco & 791562 & 118734.30 & 0.73 & 56339.43 \\
\hline Victorias & 2063378 & 309506.70 & 0.47 & 94554.30 \\
\hline Panay & 1543077 & 231461.55 & 0.61 & 92229.14 \\
\hline Asturias & 184572 & 27685.80 & 0.60 & 10797.46 \\
\hline New Frontier & 508933 & 76339.95 & 0.63 & 31261.21 \\
\hline Passi & 465000 & 69750.00 & 0.66 & 29922.75 \\
\hline Pilar & 384572 & 57685.80 & 0.54 & 20247.72 \\
\hline East. Vis./Minda. & 2058660 & 308799.00 & 0.62 & 119016.51 \\
\hline Bogo-Mendellin & 352937 & 52940.55 & 0.60 & 20646.81 \\
\hline Busco & 163483 & 24522.45 & 0.66 & 10520.13 \\
\hline Davao & 533363 & 80004.45 & 0.55 & 28601.59 \\
\hline Durano & 143144 & 21471.60 & 0.66 & 9211.32 \\
\hline Hideco (Kananga) & 503616 & 75542.40 & 0.55 & 27006.41 \\
\hline Nocosii (Seasumco) & 222638 & 33395.70 & 0.66 & 14326.76 \\
\hline Ormoc & 139479 & 20921.85 & 0.64 & 8703.49 \\
\hline TOTAL & 39545652 & 37486992 & & 2229905.64 \\
\hline
\end{tabular}

* Recoverable Trash Yield $=G$ * $P$ * MD * 0.65 
C. High estimate

\begin{tabular}{|c|c|c|c|c|}
\hline Region & $\begin{array}{l}\text { Gross Cane } \\
\text { Yield }\end{array}$ & $\begin{array}{c}\text { Potential Trash } \\
\text { Yield }\end{array}$ & $\begin{array}{l}\text { Mill District } \\
\text { Factor }\end{array}$ & $\begin{array}{c}\text { Recoverable Trash } \\
\text { Yield }^{*}\end{array}$ \\
\hline Luzon & 3832781 & 766556.20 & 0.82 & 399923.50 \\
\hline Batangas & 571000 & 114200.00 & 0.76 & 56414.80 \\
\hline Bisudeco & 245537 & 49107.40 & 0.64 & 20428.68 \\
\hline Carsumco & 197169 & 39433.80 & 0.90 & 23068.77 \\
\hline Don Pedro & 1325305 & 265061.00 & 0.90 & 155060.69 \\
\hline Manaoag & 14608 & 2921.60 & 0.90 & 1709.14 \\
\hline Paniqui & 66207 & 13241.40 & 0.90 & 7746.22 \\
\hline Pasudeco & 311790 & 62358.00 & 0.80 & 32426.16 \\
\hline Tarlac & 1101165 & 220233.00 & 0.72 & 103069.04 \\
\hline Negros & 12338308 & 2467661.60 & 0.57 & 884363.75 \\
\hline Aidsisa & 565443 & 113088.60 & 0.50 & 36753.80 \\
\hline Bais & 752377 & 150475.40 & 0.70 & 68466.31 \\
\hline Binalbagan & 1376968 & 275393.60 & 0.46 & 82342.69 \\
\hline Dacongcogon & 244299 & 48859.80 & 0.57 & 18102.56 \\
\hline Danao & 275750 & 55150.00 & 0.50 & 17923.75 \\
\hline First Farmers & 808620 & 161724.00 & 0.60 & 63072.36 \\
\hline Hawaiian-Phil. & 1113734 & 222746.80 & 0.60 & 86871.25 \\
\hline La Carlota & 1202411 & 240482.20 & 0.58 & 90661.79 \\
\hline Lopez & 1140443 & 228088.60 & 0.48 & 71163.64 \\
\hline Sagay & 663674 & 132734.80 & 0.50 & 43138.81 \\
\hline San Carlos & 401510 & 80302.00 & 0.70 & 36537.41 \\
\hline Sonedco & 639453 & 127890.60 & 0.46 & 38239.29 \\
\hline Tolong & 298686 & 59737.20 & 0.77 & 29898.47 \\
\hline Upsumco & 791562 & 158312.40 & 0.73 & 75119.23 \\
\hline Victorias & 2063378 & 412675.60 & 0.47 & 126072.40 \\
\hline Panay & 1543077 & 308615.40 & 0.61 & 122972.18 \\
\hline New Frontier & 508933 & 101786.60 & 0.63 & 41681.61 \\
\hline Passi & 465000 & 93000.00 & 0.66 & 39897.00 \\
\hline Pilar & 384572 & 76914.40 & 0.54 & 26996.95 \\
\hline East. Vis./Minda. & 2058660 & 411732.00 & 0.62 & 158688.67 \\
\hline Bogo-Mendellin & 352937 & 70587.40 & 0.60 & 27529.09 \\
\hline Busco & 163483 & 32696.60 & 0.66 & 14026.84 \\
\hline Davao & 533363 & 106672.60 & 0.55 & 38135.45 \\
\hline Durano & 143144 & 28628.80 & 0.66 & 12281.76 \\
\hline Hideco (Kananga) & 503616 & 100723.20 & 0.55 & 36008.54 \\
\hline Nocosii (Seasumco) & 222638 & 44527.60 & 0.66 & 19102.34 \\
\hline Ormoc & 139479 & 27895.80 & 0.64 & 11604.65 \\
\hline TOTAL & 37486992 & 7497398.40 & & 2973207.52 \\
\hline
\end{tabular}

* Recoverable Trash Yield = G * $P$ * MD * 0.65 
Appendix 1.5. Estimates of Excess Bagasse by Sugarcane Producing Regions in the Philippines (1995-1998)

\begin{tabular}{|c|c|c|}
\hline \multirow{2}{*}{\multicolumn{3}{|c|}{ Excess Bagasse (0.3) }} \\
\hline & & \\
\hline BISUDECO (Pensumill) & 65,580 & 19,674 \\
\hline PASUDECO & 84,329 & 25,298 \\
\hline Subtotal & 149,909 & 49,972 \\
\hline \multicolumn{3}{|l|}{ 2. NEGROS } \\
\hline BINALBAGAN & 391,599 & 117,479 \\
\hline DACONGCOGON & 68,016 & 20,404 \\
\hline DANAO & 76,885 & 23,065 \\
\hline HAWAIIAN-PHIL & 293,154 & 87,946 \\
\hline SAGAY & 172,001 & 51,600 \\
\hline SONEDCO & 133,214 & 39,964 \\
\hline TOLONG & 87,247 & 26,174 \\
\hline Subtotal & $1,222,116$ & 366,632 \\
\hline \multicolumn{3}{|l|}{ 3. PANAY } \\
\hline NEW FRONTIER & 145,422 & 43,626 \\
\hline PASSI & 110,654 & 33,196 \\
\hline PILAR (Capiz) & 103,583 & 31,074 \\
\hline Subtotal & 359,659 & 107,896 \\
\hline $\begin{array}{l}\text { 4. EAST VISAYAS/ } \\
\text { MINDANAO }\end{array}$ & & \\
\hline BOGO-MENDELLIN & 68,275 & 20,482 \\
\hline DAVAO & 165,097 & 49,529 \\
\hline HIDECO & 144,174 & 43,252 \\
\hline ORMOC & 20,458 & 6,137 \\
\hline Subtotal & 398004 & 119,400 \\
\hline TOTAL & $2,129,688$ & 643,900 \\
\hline
\end{tabular}

Source of basic data: PHILIPPINE SUGAR STATISTICS (1993-1998) 


\section{Appendix 1.6. The Top 20 Rice Producing Provinces of the Philippines}

\begin{tabular}{||c|l|c||}
\hline Rank & \multicolumn{1}{|c|}{ Province } & Yield (tonne) \\
\hline 1 & Nueva Ecija & 900,545 \\
\hline 2 & Isabela & 859,267 \\
\hline 3 & Pangasinan & 625,643 \\
\hline 4 & Cagayan & 388,007 \\
\hline 5 & North Cotabato & 353,409 \\
\hline 6 & Tarlac & 336,081 \\
\hline 7 & Sultan Kudarat & 283,019 \\
\hline 8 & Zamboanga del Sur & 259,071 \\
\hline 9 & Bulacan & 252,474 \\
\hline 10 & South Cotabato & 236,898 \\
\hline 11 & Bukidnon & 235,908 \\
\hline 12 & Pampanga & 231,755 \\
\hline 13 & lloilo & 223,826 \\
\hline 14 & Leyte & 215,494 \\
\hline 15 & Maguindanao & 210,692 \\
\hline 16 & Davao del Norte & 185,371 \\
\hline 17 & Capiz & 170,083 \\
\hline 18 & Bohol & 157,696 \\
\hline 19 & Nueva Viscaya & 151,066 \\
\hline 20 & llocos Norte & 150,632 \\
\hline
\end{tabular}

Source: BAS Cereal Statistics Section

\section{Appendix 1.7. Rice Yields Between 1995-1997 in the 14 Regions of the Philippines}

\begin{tabular}{|l|c|c||}
\hline \multicolumn{1}{|c|}{ REGION } & YIELD (tonne) & \% of TOTAL \\
CAR & 207,075 & 2.29 \\
llocos & $1,032,046$ & 11.42 \\
Cagayan Valley & $1,610,107$ & 17.82 \\
Central Luzon & $1,948,944$ & 21.57 \\
Southern Tagalog & 303,955 & 3.36 \\
Bicol & 185,524 & 2.05 \\
Western Visayas & 522,341 & 5.78 \\
Central Visayas & 233,242 & 2.58 \\
Eastern Visayas & 396,834 & 4.39 \\
Western Mindanao & 414,924 & 4.59 \\
Northern Mindanao & 382,537 & 4.23 \\
Southern Mindanao & 574,349 & 6.36 \\
Central Mindanao & 781,516 & 8.65 \\
Metro Manila & - & - \\
ARRM & 319,166 & 3.53 \\
CARAGA & 121,349 & 1.34 \\
PHILIPPINES & $\mathbf{9 , 0 3 3 , 9 0 8}$ & $\mathbf{1 0 0}$ \\
\hline
\end{tabular}

Source: BAS Cereal Statistics Section 
Appendix 1.8. Available and recoverable Rice Hull Yield Estimates by Region Source: BAS Cereal Statistics Section

\section{A. Available rice hull yields}

\begin{tabular}{|c|c|c|c|c|}
\hline \multirow[t]{2}{*}{ Region } & \multirow{2}{*}{$\begin{array}{l}\text { Total } \\
\text { Rice } \\
\text { Yield }\end{array}$} & \multicolumn{3}{|c|}{ Available Rice Hull Estimates } \\
\hline & & $\begin{array}{c}\text { Low } \\
(0.18)\end{array}$ & $\begin{array}{c}\text { Average } \\
(0.20)\end{array}$ & $\begin{array}{l}\text { High } \\
(0.24)\end{array}$ \\
\hline CAR & 207,075 & 37,273 & 41,415 & 49,698 \\
\hline Region 1 - llocos & $1,032,046$ & 185,768 & 206,409 & 247,691 \\
\hline Abra & 33,143 & 5,966 & 6,629 & 7,954 \\
\hline Benguet & 9,025 & 1,624 & 1,805 & 2,166 \\
\hline Ilocos Norte & 150,632 & 27,114 & 30,126 & 36,152 \\
\hline Ilocos Sur & 120,015 & 21,603 & 24,003 & 28,804 \\
\hline La Union & 93,589 & 16,846 & 18,718 & 22,461 \\
\hline Pangasinan & 625,643 & 112,616 & 125,129 & 150,154 \\
\hline Region 2 - Cagayan Valley & $1,610,107$ & 289,819 & 322,021 & 386,426 \\
\hline Cagayan & 388,007 & 69,841 & 77,601 & 93,122 \\
\hline Ifugao & 39,088 & 7,036 & 7,818 & 9,381 \\
\hline Isabela & 859,267 & 154,668 & 171,853 & 206,224 \\
\hline Kalinga and Apayao & 109,738 & 19,753 & 21,948 & 26,337 \\
\hline Mountain Province & 16,171 & 2,911 & 3,234 & 3,881 \\
\hline Nueva Viscaya & 151,066 & 27,192 & 30,213 & 36,256 \\
\hline Quirino & 46,770 & 8,419 & 9,354 & 11,225 \\
\hline Region 3 - Central Luzon & $1,948,944$ & 350,810 & 389,789 & 467,747 \\
\hline Aurora & 64,149 & 11,547 & 12,830 & 15,396 \\
\hline Bataan & 97,900 & 17,622 & 19,580 & 23,496 \\
\hline Bulacan & 252,474 & 45,445 & 50,495 & 60,594 \\
\hline Pampanga & 231,755 & 41,716 & 46,351 & 55,621 \\
\hline Tarlac & 336,081 & 60,495 & 67,216 & 80,660 \\
\hline Zambales & 66,041 & 11,887 & 13,208 & 15,850 \\
\hline Region 4 - Southern Tagalog & 303,955 & 54,712 & 60,791 & 72,949 \\
\hline Batangas & 4,734 & 852 & 947 & 1,136 \\
\hline Cavite & 1,127 & 203 & 225 & 270 \\
\hline Laguna & 1,786 & 322 & 357 & 429 \\
\hline Marinduque & 12,548 & 2,259 & 2,510 & 3,011 \\
\hline Mindoro Occidental & 80,158 & 14,429 & 16,032 & 19,238 \\
\hline Mindoro Oriental & 62,746 & 11,294 & 12,549 & 15,059 \\
\hline Palawan & 70,040 & 12,607 & 14,008 & 16,810 \\
\hline Quezon & 56,635 & 10,194 & 11,327 & 13,592 \\
\hline Rizal & 1,876 & 338 & 375 & 450 \\
\hline Romblon & 12,304 & 2,215 & 2,461 & 2,953 \\
\hline Region 5 - Bicol & 185,524 & 33,394 & 37,105 & 44,526 \\
\hline Albay & 19,748 & 3,555 & 3,950 & 4,740 \\
\hline Camarines Norte & 7,794 & 1,403 & 1,559 & 1,871 \\
\hline Camarines Sur & 73,892 & 13,301 & 14,778 & 17,734 \\
\hline Catanduanes & 11,186 & 2,014 & 2,237 & 2,685 \\
\hline Masbate & 51,992 & 9,359 & 10,398 & 12,478 \\
\hline Sorsogon & 20,910 & 3,764 & 4,182 & 5,018 \\
\hline Region 6 - Western Visayas & 522,341 & 94,021 & 104,468 & 125,362 \\
\hline Aklan & 37,086 & 6,675 & 7,417 & 8,901 \\
\hline Antique & 35,937 & 6,469 & 7,187 & 8,625 \\
\hline
\end{tabular}




\begin{tabular}{|c|c|c|c|c|}
\hline \multirow[t]{2}{*}{ Region } & \multirow{2}{*}{$\begin{array}{l}\text { Total } \\
\text { Rice } \\
\text { Yield }\end{array}$} & \multicolumn{3}{|c|}{ Available Rice Hull Estimates } \\
\hline & & $\begin{array}{l}\text { Low } \\
(0.18)\end{array}$ & $\begin{array}{c}\text { Average } \\
(0.20)\end{array}$ & $\begin{array}{l}\text { High } \\
(0.24)\end{array}$ \\
\hline Capiz & 170,083 & 30,615 & 34,017 & 40,820 \\
\hline Iloilo & 223,826 & 40,289 & 44,765 & 53,718 \\
\hline Negros Occidental & 55,410 & 9,974 & 11,082 & 13,298 \\
\hline Region 7 - Central Visayas & 233,242 & 41,984 & 46,648 & 55,978 \\
\hline Bohol & 157,696 & 28,385 & 31,539 & 37,847 \\
\hline Cebu & 12,242 & 2,204 & 2,448 & 2,938 \\
\hline Negros Oriental & 61,816 & 11,127 & 12,363 & 14,836 \\
\hline Siquijor & 1,489 & 268 & 298 & 357 \\
\hline Region 8 - Eastern Visayas & 396,834 & 71,430 & 79,367 & 95,240 \\
\hline Eastern Samar & 24,918 & 4,485 & 4,984 & 5,980 \\
\hline Northern Samar & 49,002 & 8,820 & 9,800 & 11,760 \\
\hline Western Samar & 58,305 & 10,495 & 11,661 & 13,993 \\
\hline Leyte & 215,494 & 38,789 & 43,099 & 51,719 \\
\hline Southern Leyte & 49,115 & 8,841 & 9,823 & 11,788 \\
\hline Region 9 - Western Mindanao & 414,924 & 74,686 & 82,985 & 99,582 \\
\hline Basilan & 3,590 & 646 & 718 & 862 \\
\hline Misamis Occidental & 52,839 & 9,511 & 10,568 & 12,681 \\
\hline Zamboanga City & 29,137 & 5,245 & 5,827 & 6,993 \\
\hline Zamboanga del Norte & 70,286 & 12,651 & 14,057 & 16,869 \\
\hline Zamboanga del Sur & 259,071 & 46,633 & 51,814 & 62,177 \\
\hline Region 10 - Northern Mindanao & 382,537 & 68,857 & 76,507 & 91,809 \\
\hline Agusan del Norte & 40,071 & 7,213 & 8,014 & 9,617 \\
\hline Agusan del Sur & 49,686 & 8,943 & 9,937 & 11,925 \\
\hline Bukidnon & 235,908 & 42,463 & 47,182 & 56,618 \\
\hline Camiguin & 2,298 & 414 & 460 & 552 \\
\hline Misamis Oriental & 17,855 & 3,214 & 3,571 & 4,285 \\
\hline Surigao del Norte & 17,406 & 3,133 & 3,481 & 4,177 \\
\hline Surigao del Sur & 19,314 & 3,477 & 3,863 & 4,635 \\
\hline Region 11 - Southern Mindanao & 574,349 & 103,383 & 114,870 & 137,844 \\
\hline Davao City & 13,872 & 2,497 & 2,774 & 3,329 \\
\hline Davao del Norte & 185,371 & 33,367 & 37,074 & 44,489 \\
\hline Davao del Sur & 97,403 & 17,532 & 19,481 & 23,377 \\
\hline Davao Oriental & 40,805 & 7,345 & 8,161 & 9,793 \\
\hline South Cotabato & 236,898 & 42,642 & 47,380 & 56,856 \\
\hline Region 12 - Central Mindanao & 781,516 & 140,673 & 156,303 & 187,564 \\
\hline Lanao del Norte & 145,088 & 26,116 & 29,018 & 34,821 \\
\hline North Cotabato & 353,409 & 63,614 & 70,682 & 84,818 \\
\hline Sultan Kudarat & 283,019 & 50,943 & 56,604 & 67,924 \\
\hline Region 13 - Metro Manila & 0 & 0 & 0 & 0 \\
\hline Region 14 - ARMM & 319,166 & 57,450 & 63,833 & 76,600 \\
\hline Lanao del Sur & 96,896 & 17,441 & 19,379 & 23,255 \\
\hline Maguindanao & 210,692 & 37,925 & 42,138 & 50,566 \\
\hline Sulu & 9,097 & 1,637 & 1,819 & 2,183 \\
\hline Tawi-tawi & 2,480 & 446 & 496 & 595 \\
\hline CARAGA & 121,349 & 21,843 & 24,270 & 29,124 \\
\hline PHILIPPINES & $9,033,908$ & $1,626,103$ & $1,806,782$ & $2,168,138$ \\
\hline
\end{tabular}


B. Recoverable rice hull yields

\begin{tabular}{|c|c|c|c|c|}
\hline \multirow[b]{2}{*}{ Region } & \multirow[b]{2}{*}{ Total Rice Yield } & \multicolumn{3}{|c|}{ Recoverable Rice Hull Estimates } \\
\hline & & $\begin{array}{l}\text { Low } \\
(0.18)\end{array}$ & $\begin{array}{c}\text { Average } \\
(0.20)\end{array}$ & $\begin{array}{l}\text { High } \\
(0.24)\end{array}$ \\
\hline CAR & 207,075 & 30,527 & 33,919 & 40,703 \\
\hline Region 1 - llocos & $1,023,021$ & 150,814 & 167,571 & 201,085 \\
\hline Abra & 33,143 & 4,886 & 5,429 & 6,515 \\
\hline Ilocos Norte & 150,632 & 22,206 & 24,674 & 29,608 \\
\hline Ilocos Sur & 120,015 & 17,693 & 19,658 & 23,590 \\
\hline La Union & 93,589 & 13,797 & 15,330 & 18,396 \\
\hline Pangasinan & 625,643 & 92,232 & 102,480 & 122,976 \\
\hline $\begin{array}{l}\text { Region } 2 \text { - Cagayan } \\
\text { Valley }\end{array}$ & $1,593,936$ & 234,978 & 261,087 & 313,304 \\
\hline Cagayan & 388,007 & 57,200 & 63,555 & 76,267 \\
\hline Ifugao & 39,088 & 5,762 & 6,403 & 7,683 \\
\hline Isabela & 859,267 & 126,673 & 140,748 & 168,898 \\
\hline Kalinga and Apayao & 109,738 & 16,178 & 17,975 & 21,570 \\
\hline Nueva Viscaya & 151,066 & 22,270 & 24,745 & 29,694 \\
\hline Quirino & 46,770 & 6,895 & 7,661 & 9,193 \\
\hline Region 3 - Central Luzon & $1,948,944$ & 287,313 & 319,237 & 383,084 \\
\hline Aurora & 64,149 & 9,457 & 10,508 & 12,609 \\
\hline Bataan & 97,900 & 14,432 & 16,036 & 19,243 \\
\hline Bulacan & 252,474 & 37,220 & 41,355 & 49,626 \\
\hline Nueva Ecija & 900,545 & 132,758 & 147,509 & 177,011 \\
\hline Pampanga & 231,755 & 34,165 & 37,961 & 45,554 \\
\hline Tarlac & 336,081 & 49,545 & 55,050 & 66,060 \\
\hline Zambales & 66,041 & 9,736 & 10,818 & 12,981 \\
\hline $\begin{array}{l}\text { Region } 4 \text { - Southern } \\
\text { Tagalog }\end{array}$ & 269,579 & 39,741 & 44,157 & 52,989 \\
\hline Mindoro Occidental & 80,158 & 11,817 & 13,130 & 15,756 \\
\hline Mindoro Oriental & 62,746 & 9,250 & 10,278 & 12,333 \\
\hline Palawan & 70,040 & 10,325 & 11,473 & 13,767 \\
\hline Quezon & 56,635 & 8,349 & 9,277 & 11,132 \\
\hline Region 5 - Bicol & 166,543 & 24,552 & 27,280 & 32,736 \\
\hline Albay & 19,748 & 2,911 & 3,235 & 3,882 \\
\hline Camarines Sur & 73,892 & 10,893 & 12,104 & 14,524 \\
\hline Masbate & 51,992 & 7,665 & 8,516 & 10,220 \\
\hline Sorsogon & 20,910 & 3,083 & 3,425 & 4,110 \\
\hline $\begin{array}{l}\text { Region } 6 \text { - Western } \\
\text { Visayas }\end{array}$ & 522,341 & 77,003 & 85,559 & 102,671 \\
\hline Aklan & 37,086 & 5,467 & 6,075 & 7,290 \\
\hline Antique & 35,937 & 5,298 & 5,886 & 7,064 \\
\hline Capiz & 170,083 & 25,074 & 27,860 & 33,431 \\
\hline Iloilo & 223,826 & 32,996 & 36,663 & 43,995 \\
\hline Negros Occidental & 55,410 & 8,168 & 9,076 & 10,891 \\
\hline $\begin{array}{l}\text { Region } 7 \text { - Central } \\
\text { Visayas }\end{array}$ & 219,511 & 32,360 & 35,956 & 43,147 \\
\hline Bohol & 157,696 & 23,247 & 25,831 & 30,997 \\
\hline Negros Oriental & 61,816 & 9,113 & 10,125 & 12,150 \\
\hline $\begin{array}{l}\text { Region } 8 \text { - Eastern } \\
\text { Visayas }\end{array}$ & 396,834 & 58,501 & 65,001 & 78,002 \\
\hline
\end{tabular}




\begin{tabular}{|c|c|c|c|c|}
\hline \multirow[b]{2}{*}{ Region } & \multirow[b]{2}{*}{ Total Rice Yield } & \multicolumn{3}{|c|}{ Recoverable Rice Hull Estimates } \\
\hline & & $\begin{array}{l}\text { Low } \\
(0.18)\end{array}$ & $\begin{array}{l}\text { Average } \\
(0.20)\end{array}$ & $\begin{array}{l}\text { High } \\
(0.24)\end{array}$ \\
\hline Eastern Samar & 24,918 & 3,673 & 4,082 & 4,898 \\
\hline Northern Samar & 49,002 & 7,224 & 8,027 & 9,632 \\
\hline Western Samar & 58,305 & 8,595 & 9,550 & 11,460 \\
\hline Leyte & 215,494 & 31,768 & 35,298 & 42,358 \\
\hline Southern Leyte & 49,115 & 7,241 & 8,045 & 9,654 \\
\hline $\begin{array}{l}\text { Region } 9 \text { - Western } \\
\text { Mindanao }\end{array}$ & 411,334 & 60,639 & 67,376 & 80,852 \\
\hline Misamis Occidental & 52,839 & 7,790 & 8,655 & 10,386 \\
\hline Zamboanga City & 29,137 & 4,295 & 4,773 & 5,727 \\
\hline Zamboanga del Norte & 70,286 & 10,362 & 11,513 & 13,815 \\
\hline Zamboanga del Sur & 259,071 & 38,192 & 42,436 & 50,923 \\
\hline $\begin{array}{l}\text { Region } 10 \text { - Northern } \\
\text { Mindanao }\end{array}$ & 325,665 & 48,009 & 53,344 & 64,013 \\
\hline Agusan del Norte & 40,071 & 5,907 & 6,564 & 7,876 \\
\hline Agusan del Sur & 49,686 & 7,325 & 8,139 & 9,766 \\
\hline Bukidnon & 235,908 & 34,778 & 38,642 & 46,370 \\
\hline \begin{tabular}{|l|} 
Region 11 - Southern \\
Mindanao \\
\end{tabular} & 560,477 & 82,626 & 91,806 & 110,167 \\
\hline Davao del Norte & 185,371 & 27,327 & 30,364 & 36,437 \\
\hline Davao del Sur & 97,403 & 14,359 & 15,955 & 19,145 \\
\hline Davao Oriental & 40,805 & 6,015 & 6,684 & 8,021 \\
\hline South Cotabato & 236,898 & 34,924 & 38,804 & 46,565 \\
\hline $\begin{array}{l}\text { Region } 12 \text { - Central } \\
\text { Mindanao }\end{array}$ & 781,516 & 115,211 & 128,012 & 153,615 \\
\hline Lanao del Norte & 145,088 & 21,389 & 23,765 & 28,518 \\
\hline North Cotabato & 353,409 & 52,100 & 57,888 & 69,466 \\
\hline Sultan Kudarat & 283,019 & 41,723 & 46,358 & 55,630 \\
\hline Region 13 - Metro Mar & & & & \\
\hline Region 14 - ARMM & 307,588 & 45,345 & 50,383 & 60,460 \\
\hline Lanao del Sur & 96,896 & 14,284 & 15,872 & 19,046 \\
\hline Maguindanao & 210,692 & 31,060 & 34,511 & 41,414 \\
\hline CARAGA & 121,349 & 17,889 & 19,877 & 23,852 \\
\hline PHILIPPINES & $8,855,713$ & $1,305,509$ & $1,450,566$ & $1,740,679$ \\
\hline
\end{tabular}


Appendix 1.9. Byproducts of coconut production

\begin{tabular}{|c|c|c|}
\hline 1000 nuts yield: & $\begin{array}{l}472 \mathrm{~kg} \text { coconut meat } \\
\text { yields: }\end{array}$ & $\begin{array}{l}400 \text { kg coconut } \\
\text { husks yield: }\end{array}$ \\
\hline $\begin{array}{l}472 \mathrm{~kg} \text { coconut meat } \\
260 \mathrm{~kg} \text { coconut water } \\
400 \mathrm{~kg} \text { coconut husk } \\
180 \mathrm{~kg} \text { coconut shell } \\
50 \mathrm{~kg} \text { charcoal }\end{array}$ & $\begin{array}{l}250 \mathrm{~kg} \text { copra } \\
158 \mathrm{~kg} \text { coco oil } \\
78 \mathrm{~kg} \text { copra meal } \\
\text { h } 162 \mathrm{~kg} \text { Desiccated } \\
\text { coconut }\end{array}$ & $\begin{array}{l}80 \mathrm{~kg} \text { Coir fibre } \\
40 \mathrm{~kg} \text { Coir brittle } \\
280 \mathrm{~kg} \text { Coir dust + } \\
\text { short fiber }\end{array}$ \\
\hline
\end{tabular}

Source: Philippines Recommends for coconut 1989. 
Appendix 1.10. Estimates of total and recoverable coconut husks and coconut fronds for the top 28 coconut yielding provinces in the Philippines

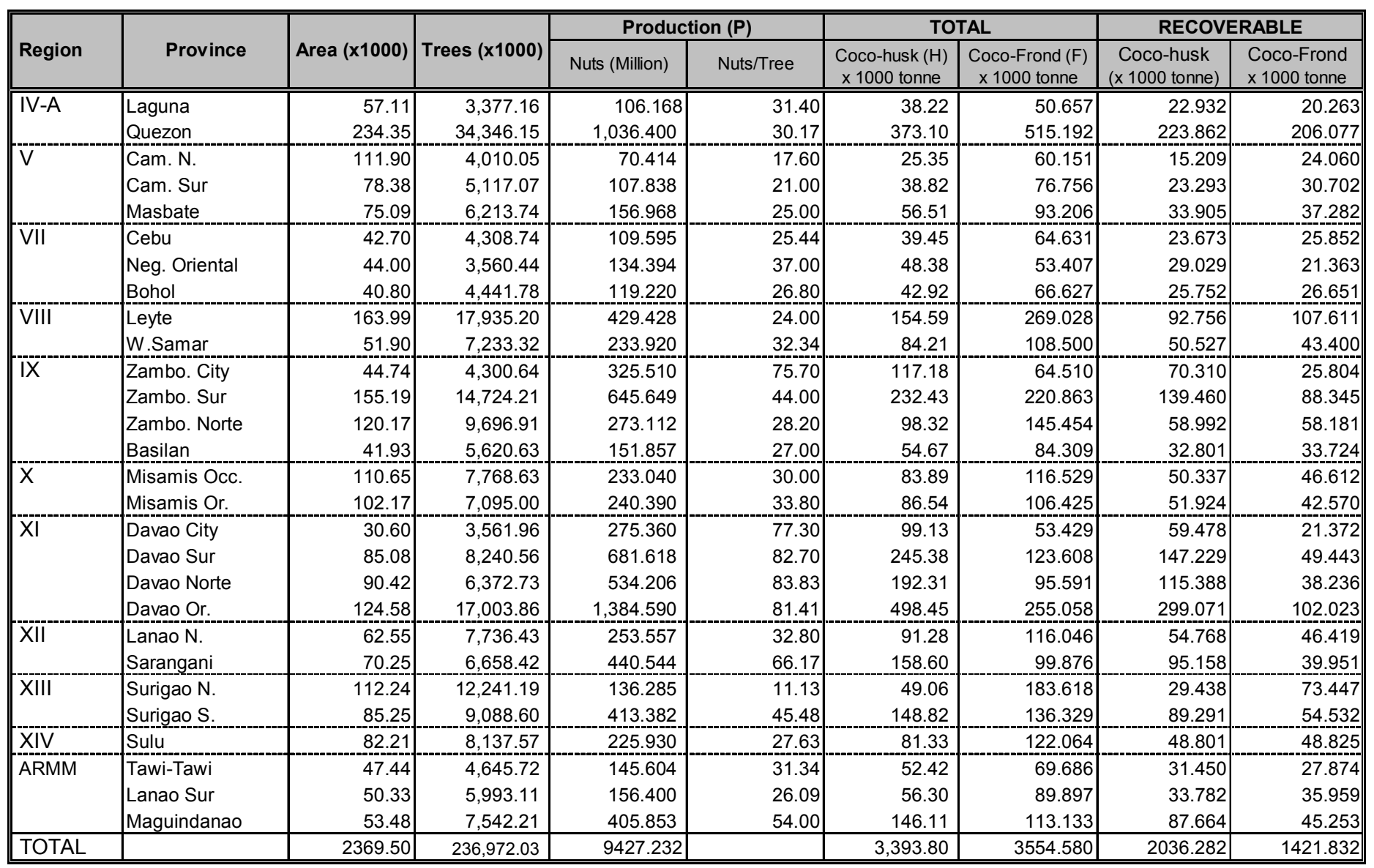

(H) Total Coco-husks $=\mathrm{P} * 1.2 * 0.3$

(F) Total Coco-Frond $=$ Trees * 0.015

Recoverable Coco-husks $=\mathrm{H}^{*} 0.5$

Recoverable Coco-frond $=F * 0.40$

Source of Basic Data : PCA and BAS Cereal Statistics Section

Yield parameters are average for 3 crop years (1996-1998) 


\section{Appendix 1.11 Estimates of Number and Weight of Coconut Frond (leaf fall) per Year, and Associated}

Energy Value (GJ)

\begin{tabular}{|c|c|c|c|c|c|c|c|c|c|c|}
\hline \multirow[t]{2}{*}{ REGION } & \multirow{2}{*}{$\begin{array}{c}\text { No. of } \\
\text { bearing } \\
\text { trees } \\
\left({ }^{\prime} 000\right)\end{array}$} & \multicolumn{3}{|c|}{ No. of coconut fronds } & \multicolumn{3}{|c|}{$\begin{array}{l}\text { Weight of coconut fronds } \\
\text { (tonne) }\end{array}$} & \multicolumn{3}{|c|}{$\begin{array}{c}\text { Energy value (GJ) of coconut } \\
\text { fronds }\end{array}$} \\
\hline & & $\begin{array}{l}\text { Low } \\
\text { (L1) }\end{array}$ & $\begin{array}{l}\text { Ave. } \\
\text { (A1) }\end{array}$ & $\begin{array}{l}\text { High } \\
\text { (H1) }\end{array}$ & $\begin{array}{l}\text { Low } \\
\text { (L2) }\end{array}$ & $\begin{array}{l}\text { Ave. } \\
\text { (A2) }\end{array}$ & $\begin{array}{l}\text { High } \\
(\mathrm{H} 2)\end{array}$ & $\begin{array}{l}\text { Low } \\
\text { (L3) }\end{array}$ & $\begin{array}{l}\text { Ave. } \\
\text { (A3) }\end{array}$ & $\begin{array}{l}\text { High } \\
(\mathrm{H} 3)\end{array}$ \\
\hline I (Ilocos) & 2175 & 17400 & 21750 & 26100 & 20880 & 32625 & 46980 & 19418 & 169909.6 & 244669.6 \\
\hline II (C. Valley) & 1338 & 10704 & 13380 & 16056 & 12845 & 20070 & 28900.8 & 11946 & 104524 & 150516.8 \\
\hline III (C. Luzon) & 129 & 1032 & 1290 & 1548 & 1238 & 1935 & 2786.4 & 1152 & 10080 & 14509.6 \\
\hline IV - A & 49906 & 399248 & 499060 & 598872 & 479098 & 748590 & 1077970 & 445561 & 3898658 & 5614067 \\
\hline IV - B & 8252 & 66016 & 82520 & 99024 & 79219 & 123780 & 178243.2 & 73674 & 644644 & 928289.6 \\
\hline V & 25540 & 204320 & 255400 & 306480 & 245184 & 383100 & 551664 & 228021 & 1995185 & 2873069 \\
\hline VI & 9098 & 72784 & 90980 & 109176 & 87341 & 136470 & 196516.8 & 81227 & 710735.2 & 1023462 \\
\hline VII & 12998 & 103984 & 129980 & 155976 & 124781 & 194970 & 280756.8 & 116046 & 1015403 & 1462182 \\
\hline VIII & 42881 & 343048 & 428810 & 514572 & 411658 & 643215 & 926229.6 & 382842 & 3349864 & 4823806 \\
\hline IX & 33617 & 268936 & 336170 & 403404 & 322723 & 504255 & 726127.2 & 300133 & 159 & 1669 \\
\hline$X$ & 15815 & 126520 & 158150 & 189780 & 151824 & 237225 & 341604 & 141196 & 1235466 & 1779075 \\
\hline$X I$ & 37546 & 300368 & 375460 & 450552 & 360442 & 563190 & 810993.6 & 335211 & 2933095 & 4223654 \\
\hline XII & 20774 & 166192 & 207740 & 249288 & 199430 & 311610 & 448718.4 & 185470 & 1622863 & 2336925 \\
\hline XIII (Caraga) & 14450 & 115600 & 144500 & 173400 & 138720 & 216750 & 312120 & 129010 & 1128837 & 1625523 \\
\hline XIX (ARMM) & 25907 & 207256 & 259070 & 310884 & 248707 & 388605 & 559591.2 & 231298 & 2023857 & 2914352 \\
\hline PHILIPPINES & 300426 & 2403408 & 2703834 & 3605112 & 2884090 & 4506390 & 6489202 & 2682203 & 23469281 & 33795759 \\
\hline
\end{tabular}

Number of coconut fronds: 8 (low), 10 (ave.), 12 (high)

Average weight of a coconut frond: $1.2 \mathrm{~kg}$ (low), 1.5 (ave.), 1.8 (high)

Source of basic data: PCA, BAS Cereal Statistics Section

1 tonne coconut frond $=5.2 \mathrm{GJ}$ 
Appendix 1.12 Oven Dry Yields of Various Perennial Grass Species

Appendix 1.4. Production and use of bagasse in the Philippines

\begin{tabular}{|c|c|c|}
\hline Species & Study & $\begin{array}{l}\text { Yield (oven } \\
\text { dry } \\
\text { tonnes/ha) }\end{array}$ \\
\hline $\begin{array}{l}\text { Guinea grass [Panicum Maximum } \\
\text { (Jacq.) L.] }\end{array}$ & $\begin{array}{l}\text { Singh et al. } 1995 \\
\text { Middleton \& McCosker, } \\
1975 \\
\text { Vicente-Chandler et al., } \\
1959 \\
\text { Hanna and Monson, } 1986 \\
\text { Omaliko, } 1980\end{array}$ & $\begin{array}{l}18.9-26.9 \\
60 \\
26.8 \\
14.4-22.6 \\
18.8\end{array}$ \\
\hline $\begin{array}{l}\text { Elephant grass [Pennisetum } \\
\text { purpureum Schum.] }\end{array}$ & $\begin{array}{l}\text { Prine and Woodard, } 1994 \\
\text { Woodard and Prine, } 1993 \\
\text { Ferraris and Stewart, } 1979 \\
\text { Williams, } 1980 \\
\text { Omaliko, } 1980 \\
\text { Vincete-Chandler et at, } \\
1959 \\
\text { Strickter et al, } 1993\end{array}$ & $\begin{array}{l}33.4 \\
46-47 \\
30.65-73.80 \\
10.7-60.3 \\
17.4 \\
84.8 \\
36.3-49\end{array}$ \\
\hline Sugarcane (Saccharum spp) & $\begin{array}{l}\text { Prine and Woodard, } 1994 \\
\text { Strickter et al, } 1993\end{array}$ & $\begin{array}{l}30.8 \\
49.7-56.2\end{array}$ \\
\hline Energy cane (Saccharum spp) & $\begin{array}{l}\text { Prine and Woodard, } 1994 \\
\text { Woodard and Prine, } 1993\end{array}$ & $\begin{array}{l}33.1 \\
49\end{array}$ \\
\hline $\begin{array}{l}\text { Signal grass (Brachiaria decumbens } \\
\text { Stapf) }\end{array}$ & $\begin{array}{l}\text { Barnard, } 1969 \\
\text { Romney, } 1961 \\
\text { Roberts, } 1970\end{array}$ & $\begin{array}{l}36.3 \\
23 \\
34.1\end{array}$ \\
\hline $\begin{array}{l}\text { Cogon grass (Imperata cylindrica (L.) } \\
\text { Beauv.) } \\
\text { Gamba grass (Andropogon gayanus } \\
\text { Kunth) }\end{array}$ & $\begin{array}{l}\text { Soerjani, } 1970 \\
\text { Adegbola, } 1964 \\
\text { Hendy, } 1975 \\
\text { Grof, } 1981\end{array}$ & $\begin{array}{l}11.5 \\
14.8 \\
40 \\
18.5\end{array}$ \\
\hline
\end{tabular}


Appendix 1.13. Trends of Fuelwood Acquisition and Wood Residue Generation in the Philippines

Source : Department of Energy, Republic of the Philippines. 1995.

Annual quantity of woodfuels in the Philippines by mode of acquisition (1995)

\begin{tabular}{|c|c|c|c|c|c|c|c|}
\hline \multirow[t]{2}{*}{ Area / Fuel type } & \multirow[t]{2}{*}{ Total } & \multicolumn{2}{|c|}{ Purchased } & \multicolumn{2}{|c|}{$\begin{array}{l}\text { Self Collected / } \\
\text { Self Produced }\end{array}$} & \multicolumn{2}{|c|}{$\begin{array}{l}\text { Both purchased and } \\
\text { self- } \\
\text { collected/produced }\end{array}$} \\
\hline & & Quantity & $\%$ & Quantity & $\%$ & Quantity & $\%$ \\
\hline \multicolumn{8}{|l|}{ Fuelwood } \\
\hline - Urban & $4,335,959$ & 902,330 & $21 \%$ & $3,226,769$ & $74 \%$ & 206,860 & $5 \%$ \\
\hline - Rural & $12,098,968$ & 841,721 & $7 \%$ & $9,785,667$ & $81 \%$ & $1,471,579$ & $12 \%$ \\
\hline - Philippines & $16,434,927$ & $1,744,051$ & $11 \%$ & $13,012,436$ & $79 \%$ & $1,678,440$ & $10 \%$ \\
\hline \multicolumn{8}{|l|}{ Charcoal } \\
\hline - Urban & 412,430 & 332,913 & $81 \%$ & 53,310 & $13 \%$ & 26,207 & $6 \%$ \\
\hline - Rural & 398,355 & 177,329 & $45 \%$ & 208,166 & $52 \%$ & 12,860 & $3 \%$ \\
\hline - Philippines & 810,785 & 510,242 & $63 \%$ & 261,476 & $32 \%$ & 39,067 & $5 \%$ \\
\hline
\end{tabular}


B. Estimated amount of wood residues generated in the Philippines (FAO, 1997)

\begin{tabular}{|c|c|c|c|}
\hline Process & Residue & Rate (\%) & $\begin{array}{c}\text { Philippine Estimate (1000 } \\
\text { tonnes) }\end{array}$ \\
\hline Logging & Solid & 40 & 1426 \\
\hline Saw-milling & Solid & 38 & 149 \\
\hline & Sawdust & 12 & 47 \\
\hline Plywood & Solid & 45 & 297 \\
\hline & Dust & 5 & 33 \\
\hline Particleboard & Dust & 10 & \\
\hline Chemical pulp & Black liquor & & $\begin{array}{r}0.6 \\
1426\end{array}$ \\
\hline Processing Based - Solid Wood & & & 446 \\
\hline $\begin{array}{l}\text { Processing Based - Fines Dust } \\
\text { Processing Based - Liquids }\end{array}$ & & & $\begin{array}{r}81 \\
0.6\end{array}$ \\
\hline Total Wood Residue & & & 1953 \\
\hline
\end{tabular}

Estimates based on area of production and rate of residue generation (see section 2.2). Data for area of production available from FAO Statistics. For rubber, palm oil and cocoa, waste is available from replanting.

Figures in brackets indicate rotation period. For calculations, it is assumed that replanting occurs on an average annual basis.

\begin{tabular}{|l|l|l|}
\hline Agro- Based Wood Residues (1000 tonne) \\
\hline Process & Residue & Annual Yield (tonne/ha) \\
\hline Cocoa tree & Prunings & 38 \\
Coconut tree & Fronds & 29379 \\
Rubber Tree (25 year) & Solid & 797 \\
Palm Oil (30 year) & Solid & 144 \\
Palm Oil (30 year) & Fronds & 32 \\
Cocoa Tree (25 year) & Solid & 38 \\
\hline
\end{tabular}

Estimates based on wood production and rate of residue generation (see section 2.1). Data for wood production available from FAO Statistics. For black liquor, it was assumed that 1 tonne of chemical pulp produced, produces $1 \mathrm{~m} 3$ of black liquor in wood equivalent. 
Appendix 1.14. Philippine Rice Mill Data Source: Vergara 1998

\section{A. Rice mill capacity in the Philippines}

\begin{tabular}{|c|c|c|c|c|c|c|}
\hline Region/Province & $\begin{array}{l}\text { NFA } \\
\text { Units }\end{array}$ & $\begin{array}{l}\text { Capacity } \\
\text { bag/hour }\end{array}$ & $\begin{array}{c}\text { Private } \\
\text { Units }\end{array}$ & $\begin{array}{l}\text { Capacity } \\
\text { bag/hour }\end{array}$ & $\begin{array}{l}\text { TOTAL } \\
\text { Units }\end{array}$ & $\begin{array}{l}\text { Capacity } \\
\text { bag/hour }\end{array}$ \\
\hline Region 1:llocos & 4 & 9.00 & $2,598.00$ & \begin{tabular}{|c|}
$1,111.03$ \\
\end{tabular} & $2,602.00$ & $1,120.03$ \\
\hline Abra & 1 & 0.75 & 203.00 & 56.04 & 204.00 & 56.79 \\
\hline Benguet & 0 & 0.00 & 105.00 & 61.55 & 105.00 & 61.55 \\
\hline Ilocos Norte & 2 & 3.25 & $1,001.00$ & 362.34 & $1,003.00$ & 365.59 \\
\hline Ilocus Sur & 0 & 0.00 & 383.00 & 201.85 & 383.00 & 201.85 \\
\hline La Union & 0 & 0.00 & 320.00 & 122.40 & 320.00 & 122.40 \\
\hline Pangasinan & 1 & 5.00 & 586.00 & 306.85 & 587.00 & 311.85 \\
\hline Region 2: Cagayan Valley & 9 & 48.50 & $1,512.00$ & $1,080.75$ & $1,521.00$ & $1,129.25$ \\
\hline Cagayan & 2 & 20.00 & 540.40 & 245.45 & 542.40 & 265.45 \\
\hline Ifugao & 1 & 0.75 & 21.00 & 12.70 & 22.00 & 13.45 \\
\hline Isabela & 4 & 26.00 & 399.00 & 492.15 & 403.00 & 518.15 \\
\hline Kalinga-Apayao & 0 & 0.00 & 247.60 & 137.35 & 247.60 & 137.35 \\
\hline Mt. Province & 0 & 0.00 & 105.00 & 61.55 & 105.00 & 61.55 \\
\hline Nueva Vizcaya & 1 & 1.00 & 114.00 & 80.30 & 115.00 & 81.30 \\
\hline Quirino & 1 & 0.75 & 85.00 & 51.25 & 86.00 & 52.00 \\
\hline Region 3: Central Luzon & 10 & 41.50 & $1,102.00$ & 798.86 & $1,112.00$ & 840.36 \\
\hline Aurora & 2 & 1.75 & 60.00 & 37.40 & 62.00 & 39.15 \\
\hline Bataan & 1 & 0.75 & 118.00 & 73.32 & 119.00 & 74.07 \\
\hline Bulacan & 1 & 10.00 & 208.00 & 196.41 & 209.00 & 206.41 \\
\hline Nueva Ecija & 4 & 18.50 & 274.00 & 229.35 & 278.00 & 247.85 \\
\hline Pampanga & 0 & 0.00 & 105.00 & 61.55 & 105.00 & 61.55 \\
\hline Tarlac & 2 & 10.50 & 213.00 & 148.85 & 215.00 & 159.35 \\
\hline Zambales & 0 & 0.00 & 124.00 & 51.98 & 124.00 & 51.98 \\
\hline Region 4: Southern Tagalog & 9 & 11.25 & $1,602.00$ & $1,040.59$ & $1,611.00$ & $1,051.84$ \\
\hline Batangas & 1 & 0.75 & 94.00 & 39.61 & 95.00 & 40.36 \\
\hline Laguna & 0 & 0.00 & 94.00 & 64.50 & 94.00 & 64.50 \\
\hline Marinduque & 1 & 1.00 & 99.00 & 30.40 & 100.00 & 31.40 \\
\hline Mindoro Occidental & 0 & 0.00 & 105.00 & 61.55 & 105.00 & 61.55 \\
\hline Mindoro Occidental & 1 & 0.75 & 116.00 & 123.23 & 117.00 & 123.98 \\
\hline Mindoro Oriental & 1 & 2.50 & 411.00 & 348.15 & 412.00 & 350.65 \\
\hline Palawan & 2 & 3.25 & 277.00 & 156.35 & 279.00 & 159.60 \\
\hline Quezon & 1 & 1.00 & 196.00 & 93.70 & 197.00 & 94.70 \\
\hline Quezon & 1 & 1.00 & 105.00 & 61.55 & 106.00 & 62.55 \\
\hline Romblon & 1 & 1.00 & 105.00 & 61.55 & 106.00 & 62.55 \\
\hline Region 5: Bicol & 4 & 7.64 & 696.00 & 427.96 & 700.00 & 435.60 \\
\hline Albay & 2 & 5.64 & 118.00 & 83.70 & 120.00 & 89.34 \\
\hline Camarines Norte & 0 & 0.00 & 86.00 & 37.35 & 86.00 & 37.35 \\
\hline Camarines Sur & 0 & 0.00 & 230.00 & 168.14 & 230.00 & 168.14 \\
\hline Catanduanes & 1 & 1.00 & 34.00 & 13.75 & 35.00 & 14.75 \\
\hline Masbate & 1 & 1.00 & 99.00 & 40.74 & 100.00 & 41.74 \\
\hline Sorsogon & 0 & 0.00 & 129.00 & 84.28 & 129.00 & 84.28 \\
\hline Region 6: Western Visayas & 5 & 35.00 & $1,107.00$ & 805.35 & $1,112.00$ & 840.35 \\
\hline Aklan & 0 & 0.00 & 134.00 & 75.55 & 134.00 & 75.55 \\
\hline Antique & 2 & 10.00 & 136.00 & 90.45 & 138.00 & 100.45 \\
\hline Capiz & 1 & 10.00 & 155.00 & 129.40 & 156.00 & 139.40 \\
\hline
\end{tabular}




\begin{tabular}{|c|c|c|c|c|c|c|}
\hline Guimaras & 0 & 0.00 & 105.00 & 61.55 & 105.00 & 61.55 \\
\hline Iloilo & 2 & 15.00 & 403.00 & 316.95 & 405.00 & 331.95 \\
\hline Negros Occidental & 0 & 0.00 & 174.00 & 131.45 & 174.00 & 131.45 \\
\hline Region 7: Central Visayas & 6 & 5.75 & 464.00 & 246.37 & 470.00 & 252.12 \\
\hline Bohol & 2 & 2.00 & 345.00 & 196.99 & 347.00 & 198.99 \\
\hline Cebu & 1 & 1.00 & 23.00 & 7.50 & 24.00 & 8.50 \\
\hline Negros Oriental & 2 & 1.75 & 87.00 & 39.65 & 89.00 & 41.40 \\
\hline Siquijor & 1 & 1.00 & 9.00 & 2.23 & 10.00 & 3.23 \\
\hline Region 8: Eastern Visayas & 7 & 9.50 & 599.00 & 372.05 & 606.00 & 381.55 \\
\hline Biliran & 1 & 0.75 & 94.00 & 47.35 & 95.00 & 48.10 \\
\hline Eastern Samar & 2 & 1.50 & 18.00 & 4.90 & 20.00 & 6.40 \\
\hline Leyte & 1 & 5.00 & 217.00 & 182.50 & 218.00 & 187.50 \\
\hline Northern Samar & 0 & 0.00 & 39.00 & 18.80 & 39.00 & 18.80 \\
\hline Southern Samar & 2 & 1.50 & 169.00 & 87.45 & 171.00 & 88.95 \\
\hline Western Samar & 1 & 0.75 & 62.00 & 31.05 & 63.00 & 31.80 \\
\hline Region 9: Western Mindanao & 8 & 11.20 & 730.00 & 386.31 & 738.00 & 397.51 \\
\hline Basilan & 0 & 0.00 & 105.00 & 61.55 & 105.00 & 61.55 \\
\hline Misamis Occidental & 1 & 1.00 & 115.00 & 64.70 & 116.00 & 65.70 \\
\hline Zamboanga City & 2 & 1.75 & 68.00 & 35.05 & 70.00 & 36.80 \\
\hline Zamboanga Norte & 1 & 0.75 & 106.00 & 60.18 & 107.00 & 60.93 \\
\hline Zamboanga Sur & 4 & 7.70 & 336.00 & 164.83 & 340.00 & 172.53 \\
\hline Region 10: Northern Mindanao & 8 & 9.50 & 961.00 & 625.29 & 969.00 & 634.79 \\
\hline Agusan del Norte & 0 & 0.00 & 119.00 & 78.40 & 119.00 & 78.40 \\
\hline Agusan del Sur & 1 & 1.00 & 137.00 & 88.95 & 138.00 & 89.95 \\
\hline Bukidnon & 1 & 3.50 & 289.00 & 239.06 & 290.00 & 242.56 \\
\hline Camiguin & 0 & 0.00 & 105.00 & 61.55 & 105.00 & 61.55 \\
\hline Misamis Oriental & 3 & 2.75 & 47.00 & 18.93 & 50.00 & 21.68 \\
\hline Surigao del Sur & 2 & 1.50 & 148.00 & 64.50 & 150.00 & 66.00 \\
\hline Surigao del Norte & 1 & 0.75 & 116.00 & 73.90 & 117.00 & 74.65 \\
\hline Region 11: Southern Mindanao & 4 & 21.35 & 487.00 & 402.60 & 491.00 & 423.95 \\
\hline Davao City & 1 & 1.00 & 42.00 & 34.88 & 43.00 & 35.88 \\
\hline Davao del Norte & 1 & 0.35 & 170.00 & 150.20 & 171.00 & 150.55 \\
\hline Davao del Sur & 1 & 10.00 & 57.00 & 49.40 & 58.00 & 59.40 \\
\hline Davao Oriental & 0 & 0.00 & 48.00 & 34.00 & 48.00 & 34.00 \\
\hline Saranggani & 1 & 10.00 & 36.00 & 39.47 & 37.00 & 49.47 \\
\hline South Cotabato & 0 & 0.00 & 134.00 & 94.65 & 134.00 & 94.65 \\
\hline Region 12: Central Mindanao & 4 & 37.00 & 371.00 & 397.40 & 375.00 & 434.40 \\
\hline Lanao del Norte & 0 & 0.00 & 69.00 & 61.10 & 69.00 & 61.10 \\
\hline North Cotabato & 1 & 10.00 & 153.00 & 95.05 & 154.00 & 105.05 \\
\hline Sultan Kudarat & 3 & 27.00 & 149.00 & 241.25 & 152.00 & 268.25 \\
\hline Region 13: Metro Manila & 2 & 1.75 & 273.00 & 149.10 & 275.00 & 150.85 \\
\hline Batanes & 1 & 0.75 & 0.00 & 0.00 & 1.00 & 0.75 \\
\hline Cavite & 1 & 1.00 & 63.00 & 26.00 & 64.00 & 27.00 \\
\hline Metro Manila & 0 & 0.00 & 105.00 & 61.55 & 105.00 & 61.55 \\
\hline Rizal & 0 & 0.00 & 105.00 & 61.55 & 105.00 & 61.55 \\
\hline Region 14: ARMM & 2 & 1.50 & 48.00 & 83.75 & 50.00 & 85.25 \\
\hline Lanao Sur/Maranao & 0 & 0.00 & 12.00 & 9.25 & 12.00 & 9.25 \\
\hline Maguindanao & 0 & 0.00 & 36.00 & 74.50 & 36.00 & 74.50 \\
\hline Sulu & 1 & 0.75 & 0.00 & 0.00 & 1.00 & 0.75 \\
\hline Tawi-Tawi & 1 & 0.75 & 0.00 & 0.00 & 1.00 & 0.75 \\
\hline Total: Philippines & 82 & 250.44 & $12,550.00$ & $7,927.41$ & $12,632.00$ & $8,177.85$ \\
\hline
\end{tabular}


B. Consolidated rice mill data by region (1997)

\begin{tabular}{|c|c|c|c|c|c|c|c|c|c|c|}
\hline \multirow[t]{2}{*}{ "Region/Province } & \multirow{2}{*}{$\begin{array}{l}\text { Cono } \\
\text { Unit }\end{array}$} & \multirow[b]{2}{*}{ Capacity } & \multicolumn{2}{|c|}{ Kiskisan } & \multirow{2}{*}{$\begin{array}{c}\text { Rubber } \\
\text { Roll } \\
\text { Unit }\end{array}$} & \multirow[b]{2}{*}{ Capacity } & \multicolumn{2}{|c|}{ Centrifugal } & \multirow{2}{*}{$\begin{array}{l}\text { Total } \\
\text { Unit }\end{array}$} & \multirow[b]{2}{*}{ Capacity } \\
\hline & & & Unit & Capacity & & & Unit & Capacity & & \\
\hline Philippines & 2,799 & $51,148.51$ & 2,867 & \begin{tabular}{|l|}
$16,219.03$ \\
\end{tabular} & 6,866 & $86,291.63$ & 14 & 274.00 & 12,546 & $153,933.17$ \\
\hline Ilocos Region & 312 & $3,763.80$ & 1,298 & $6,427.18$ & 991 & $11,208.86$ & 0 & 0.00 & 2,601 & $21,399.84$ \\
\hline Cagayan Valley & 291 & $7,700.00$ & 322 & $1,751.00$ & 984 & $13,626.00$ & 0 & 0.00 & 1,597 & $23,077.00$ \\
\hline Central Luzon & 620 & $10,092.44$ & 133 & $1,011.25$ & 411 & $5,670.25$ & 1 & 10.00 & 1,165 & $16,783.94$ \\
\hline Southern Tagalog & 229 & $5,014.28$ & 411 & $2,375.14$ & 886 & $11,627.67$ & 5 & 200.00 & 1,531 & $19,217.09$ \\
\hline Bicol Region & 135 & $2,807.00$ & 165 & $1,347.26$ & 496 & $5,882.50$ & 1 & 8.00 & 797 & $10,044.76$ \\
\hline Western Visayas & 176 & $5,062.50$ & 157 & $1,103.00$ & 759 & $10,006.50$ & 0 & 0.00 & 1,092 & $16,172.00$ \\
\hline Central Visayas & 87 & 828.86 & 47 & 172.32 & 334 & $4,082.46$ & 5 & 39.50 & 473 & $5,123.14$ \\
\hline Eastern Visayas & 265 & $3,400.00$ & 98 & 574.00 & 301 & $4,034.50$ & 0 & 0.00 & 664 & $8,008.50$ \\
\hline Western Mindanao & 76 & $1,172.18$ & 4 & 28.00 & 557 & $5,308.67$ & 0 & 0.00 & 637 & $6,508.85$ \\
\hline Northern Mindanao & 75 & $2,015.82$ & 62 & 284.98 & 586 & $8,023.00$ & 1 & 15.00 & 724 & $10,338.80$ \\
\hline Southern Mindanao & 236 & $4,682.51$ & 64 & 388.43 & 409 & $4,951.05$ & 0 & 0.00 & 709 & $10,021.99$ \\
\hline Central Mindanao & 231 & $3,816.66$ & 77 & 434.29 & 122 & $1,271.00$ & 0 & 0.00 & 430 & $5,521.95$ \\
\hline Metro Manila & 42 & 567.46 & 15 & 206.18 & 14 & 309.17 & 1 & 1.50 & 72 & $1,084.31$ \\
\hline ARMM & 24 & 225.00 & 14 & 116.00 & 16 & 290.00 & 0 & 0.00 & 54 & 631.00 \\
\hline \multicolumn{11}{|c|}{$\begin{array}{l}\text { Source: Vergara } 1998 . \\
\text { Ricemill data includes private ricemills only. } \\
\text { Capacities are in terms of input (bags of palay per hour). } \\
\text { Cono ricemills strictly refer to under-runner disk huller typ }\end{array}$} \\
\hline
\end{tabular}




\section{Appendix 2.1.}

\section{Improved Cooking Stove Review (Source: Vergara 1998)}

The use of improved cooking stoves (ICS) has become increasingly popular in developing nations. The efficiency of an ICS depends on a variety of factors, each particular to a given cooking scenario. In other words, a particular ICS and the means in which it is disseminated in Africa may not yield successful results in the Philippines. Once the particular needs of those to whom the technology is intended for are identified, then strategies to maximize the efficiency of the ICS and ensure its successful distribution can be addressed. Availability of materials, production costs, and distribution costs are but a few factors to consider.

In terms of the scientific efficiency of ICS technology, one must first examine the basic combustion process. All biomass contains some physical moisture. Upon combustion, the biomass fuel is 'dried' (the unbound water in the fuel is evaporated as water vapour). Once dry, the process of pyrolysis begins at temperatures ranging from $225^{\circ} \mathrm{C}$ to $325^{\circ} \mathrm{C}$. Hemicellulose begins to breakdown, and, as temperatures reach $500^{\circ} \mathrm{C}$, lignin and cellulose begin to degrade. It is during this process that volatiles and gases are released. The larger molecular constituents of these volatiles can be further broken down depending on the combustion efficiency of the ICS. Those ICS's which are able to maintain these volatiles at high enough temperatures and for long enough periods of time are favourable as they are able to breakdown tars and other molecules that would otherwise be released into the cooking area. (Hasan and Khan, online information).

An efficient stove is one that completely burns the biomass fuel being used, hence reducing the amount of fuel needed for cooking. However, an equally important consideration is that a stove must efficiently transfer the heat it produces to the cooking receptacle. Many believe that maximizing heat transfer can provide larger fuel savings than more efficient fuel combustion. These two factors, combined with the skill of the operator in effectively using the stove, lead to the overall efficiency of an ICS.

Biomass fuels range from wood products (fuel wood and charcoal), woodwastes, agricultural wastes (sugarcane bagasse, rice and maize husk, etc.), and dried dung. A given ICS can use one or a combination of these fuels. Fuel wood is by far the dominant fuel source in developing nations. Growing environmental concerns, health issues, and high fuel cost have increased the demand for ICS stoves. Many ICS's are modified versions of stoves that were originally used within the community, while others are new innovations.

\section{Some Stoves and their Performance}

ICS's can be constructed from a number of different materials that are chosen based on their physical qualities, availability, and cost effectiveness. Building an intricate and efficient stove is relatively easy; ensuring that it will work on a practical level and become widely distributed is much more difficult. The overall challenge is to build a stove that is affordable, effective, and reproducible by the local populace of the target area.

Several nations have been actively targeted in terms of the development and distribution of ICS technology. The various countries of Africa have always been highly dependent on charcoal and wood as fuel sources. Traditional cooking over open fire delivers some $10 \%$ of the heat released during combustion to the cooking pot. It is not that the combustion process itself is inefficient, as open fires can produce 60 to $70 \%$ combustion rates. However, due to air circulation and wind, this heat energy is dispersed into the atmosphere before ever reaching the pot (Still et al, 1996).

In the past, many Kenyan households cooked with metal bucket stoves using charcoal or firewood. With these stoves, $50 \%$ to $70 \%$ of the heat of combustion is conducted through the metallic walls of the 
cooking unit and into the atmosphere. Initial improvements to this metal bucket stove resulted in the Jiko (which means 'stove' in Swahili) cooking stove. Early models had inwardly sloping metal walls, and a ceramic and vermiculite insulating layer cemented to the inside walls. This model trapped the heat too effectively and caused cracks in the structure. The women of the Kenyan community proposed the hourglass shape that is now the ceramic Jiko cooking stove. By insulating only the top section of the hourglass structure, previous structural damage due to the intense heat does not occur, and provides a more stable cooking surface. The Jiko delivers $25 \%$ to $40 \%$ of the heat of combustion to the pot, while $20 \%$ to $40 \%$ is lost to the walls (10\% to $30 \%$ is lost to flue gases).

It has been estimated that fuel savings using the Jiko are on the order of $590 \mathrm{~kg}$ of fuel per household per year. This amount represents up to a fifth of the average urban household's annual income. The Jiko, at a cost of 2 - 5 \$US, is most popular in urban areas where the collection of fuelwood is difficult (Kammen, 1995). Rural households found it less expensive to collect firewood and utilize a traditional open cooking fire. As a result, a simplified version of the Jiko, called the Maendeleo stove, was developed. This model is much less expensive at 0.80 \$US. The stove consists of the ceramic liner that is set down in the middle of an open fire pit (Kammen, 1995). Although not as efficient as the Jiko, the Maendeleo does reduce fuel consumption and indoor smoke within the home.

China has long been a leader in ICS distribution programs. The most common version of the Chinese stove is built of brick and mortar and is equipped with a chimney. It is estimated that 7 out of 10 rural households own such units for a total of 120 million stoves (Kammen, 1995).

Research in the ICS field have led to stoves like the 'Winiarski Rocket Stove', and 'Estufa Justa' in Central America, the 'Lakech', 'Mirte', and 'Rondreza' stoves in Africa, the 'Sudha Chulha', 'Swosthee MS-4' and 'Astra ole three-pan' stoves in India and the 'Meechai' rice husk stove in Thailand, to name just a few. Each design conforms to the low-cost fuel saving criteria and is constructed of materials available in the particular target area.

- Winiarski Rocket Stove (Central America): has an efficiency between 12 and 38\% depending on what type of heat exchanger is used. It can cost between up to \$20 US depending on the type of construction materials used. The stove consists of a metal elbow in which a horizontal pipe enters a vertical combustion pipe. There is a shelf in the horizontal pipe onto which wood is lain lengthwise. Thus, it is only the tips of the sticks within the vertical combustion chamber that burn. Air enters under the shelf and is drawn up through the vertical pipe. The elbow functions more efficiently if it is placed in an insulated container, preventing heat loss through the outer walls. Also, a metal sleeve can be placed on top of the vertical pipe, embedding the pot. With a gap width of approximately 1 $2 \mathrm{~cm}$ between the sleeve and the pot, the thermal efficiency is improved (Aprovecho Research Center, online information).

- Estufa Justa (Central America): is a two pot stove with an approximate $20 \%$ efficiency. It is a more permanent long-lasting model then the Rocket stove costing between 25 and 35 \$US. Cooking takes place on the griddle that is also the stove's top surface. It is equipped with a chimney that removes smoke and volatiles from the cooking area (but decreases thermal efficiency). Some recommendations made by the designers include sinking the pots in the griddle and insulating those areas on the cooking surface which, on the present model, cause heat loss through conduction with the atmosphere (Aprovecho Research Center, online information).

- Lakech (Ethiopia, Africa): is an improved charcoal stove that was based on the Kenyan Ceramic Jiko stove (previously mentioned). It was designed by the private UK firm Energy for Sustainable Development (ESD) in 1991. The stove is said to reduce charcoal consumption by $25 \%$ and improve stove efficiency by $35 \%$ at a cost of 1 \$US per stove. According to ESD, the stove saves an average of $75 \mathrm{~kg}$ of charcoal per household per year. The 1996 figures placed the savings at an estimated 20,000 tonnes of charcoal, which represents approximately 8 million $\$$ US. The forest saving is the 
equivalent of over 2,000 hectares of dryland forest. Recent figures show that sales of the Lakech have exceeded 300,000 units in Ethiopia (ESD, online information).

- Mirte (Ethiopia, Africa): was developed in 1994 by the ESD. Studies showed that the largest consumption of fuel in Ethiopia came from the baking of "injera", a household bread. The cooking of injera accounts for $50 \%$ of all energy consumption in Ethiopia, and over $90 \%$ of all household energy use. With this in mind, the Mirte was developed at a production cost of $6 \$$ US per stove. In the lab, fuel consumption was reduced by $50 \%$, with noticeable reduction in the amount of smoke produced. In Ethiopia, many housewives earn virtually all of their income by baking injera bread and selling it to hotels and restaurants. The Mirte saves approximately $5 \mathrm{~kg}$ of wood per injera bread baking session during which 30 injera breads can be baked. Considering that those who produce the bread for commercial purposes are cooking 300-500 injeras per day, seven days a week, the fuel savings are quite substantial. Household fuel savings are nearly $260 \mathrm{~kg}$ of wood a year, worth over 32 \$US, while commercial bakers save over 3.5 tonnes of fuelwood a year, worth over 400 \$US. The stove itself reduces the risk of severe burns that are common with the traditional three stone fire cooking. Commonly, 'volatile' woods such as eucalyptus branches and leaves are used as fuel, often causing 'flashbacks' that endanger the cook. The Mirte stove effectively reduces the risk of using such fuels (ESD, online information).

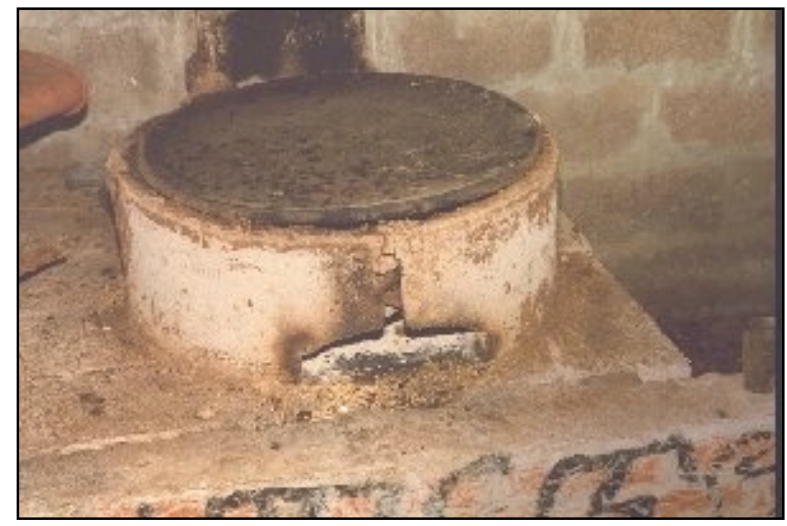

Photo 1 . The Mirte stove efficiently bakes household bread in Ethiopia (ESB, online information).

- Rondereza (Urban Rwanda, Africa): is an improved charcoal stove with a life span of approximately 18 months. The stove itself costs 6 \$US. A 1991 cost analysis compared the Rondereza to the traditional charcoal stove, the Imbabura that has a 9 month life span. The study showed that the increased efficiency and life span of the Rondereza can yield significant household savings (Table 1).

Table 1. Financial comparison of annual costs of traditional (Imbabura) and improved (Rondereza) stoves for an average urban family in Rwanda, 1991. (cost analysis based on a typical household owning 2 stoves)

\begin{tabular}{|l|c|c|c|}
\hline $\begin{array}{c}\text { Present value of costs } \\
\text { over 18-month lifetime } \\
\text { of 2 stoves }\end{array}$ & $\begin{array}{c}\text { Imbabura (traditional } \\
\text { stove) US\$ }\end{array}$ & $\begin{array}{c}\text { Rondereza (improved } \\
\text { stove) US\$ }\end{array}$ & $\begin{array}{c}\text { Cost savings of the } \\
\text { improved stoves US\$ }\end{array}$ \\
\hline Cost of two stoves & 10 & 12 & -2 \\
\hline Cost of fuel & 332 & 217 & 115 \\
\hline Total cost & 342 & 229 & 113 \\
\hline
\end{tabular}

The discount rate used in the analysis was $12 \%$

Such cost savings account for a significant portion of a household's annual income. Considering that payments for the stoves are usually made in 2 \$US per month increments, the monthly savings when using the Rondereza (approximately 3.10 \$US per month per stove) accounts for the stove's cost .

- Sudha Chulha (India): is a single pot pottery stove with double walls and a fired-clay grill. It was developed at the Technical Back-up Unit, Energy Research Centre, Punjab University, Chandigarh, India in 1992. It can accommodate $20-30 \mathrm{~cm}$ diameter flat or spherical pots that sit on top of the stove and can be used with fuelwood, fuelwood wastes, agricultural residues, dung and briquettes. 
It's thermal efficiency has been rated at $42.8 \%$, while the stove itself costs only 2 \$US. It is suitable for families of 8 to 12 people (Luo \& Hulscher, 1999).

- Swosthee MS-4 (India): is a single pan metal stove designed at the Indian Institute of Science in Bangalore. The cooking pot sits on top of the stove unit. Unlike the Sudha Chulha, there is no insulating material. Considering this, it is easy to see why the stove's efficiency is somewhat lower at $17.2 \%$. However, the unit has been found to reduce fuel consumption as well as the amount of smoke within the home (Dutt \& Ravindranath, 1993).

- ASTRA ole three-pan (India): is a version of the traditional three-pot stove constructed with mud and equipped with a chimney. The improved three-pot stove was conceptualized at the Center for the Application of Science and Technology to Rural Areas (ASTRA) in India. These modifications increased the stove's efficiency from 15 to $45 \%$. Water boiling field tests rated the stove at $33.5 \%$ efficiency. However, the construction of the modified version requires a trained builder (Dutt \& Ravindranath, 1993).

- Meechai rice husk stove: is usually constructed from scrap metal or galvanized sheet. It is basically an inverted cone into which the stove body is placed. The cone is held by a metal stand (usually steel rods) and underneath the cone is an ash receptacle. Rice husk is poured into the cone while the fire is ignited through the stove body. Extensive research was done on this stove by the Forest Products Research Division of Thailand (1984) along with several other improved stoves. A series of nine cooking trials showed that it took an average of only 12 minutes to boil 3.7 kilograms of water. Cooking efficiencies averaged $18 \%$ for the nine tests.

\section{The Ideal Stove}

Conceptually, an ideal ICS should yield complete combustion of the fuel being used, recapture the heat energy of the water vapour inherent in the combustion process through some type of heat exchanger, and emit only $\mathrm{CO}_{2}, \mathrm{H}_{2} \mathrm{O}_{(\mathrm{g})}$ and trace amounts of $\mathrm{CO}$, particulate matter and other products of incomplete combustion (PIC). According to studies carried out in India, traditional cookstoves emit more than 10\% of their carbon as PIC. They release 100 to $180 \mathrm{~g}$ of CO and $7.7 \mathrm{~g}$ of particulate matter per $\mathrm{kg}$ of fuel wood. Traditional metal charcoal stoves emit from $250-350 \mathrm{~g} \mathrm{CO}$ and $2.4 \mathrm{~g}$ particulate matter (Grover, 1999).

Researchers in India have conceptualized one such ideal cookstove, aptly named 'the Dream stove'. To obtain clean emissions (i.e. very little PIC's and a low $\mathrm{CO} / \mathrm{CO}_{2}$ ratio), the Dream stove involves a two chambered burning compartment. The first stage of the stove would be for the heating, drying, and pyrolysis of the fuel with a minimum of air, while the second would be for the thermal cracking and burning of the gaseous pyrolytic products. Additional air, as well as a heat source, would have to be introduced into the system for the burning of these gaseous products to occur. Hence, the stove would most effectively function if charcoal burning were started in the second stage. For maximum efficiency, leftover charcoal from the previous operation of the stove would be used to initiate the process.

Thermal efficiency models for such a stove were based on the following criteria:

- Wood fuel with $15 \%$ moisture and 3\% ash

- No losses other than heat losses from the flue gas

- Complete combustion of the wood with total recovery of heat to utility

- Heating value of wood is estimated at $20 \mathrm{MJ} / \mathrm{kg}$ on a dry basis, and $17 \mathrm{MJ} / \mathrm{kg}$ at $15 \%$ moisture content

The results of the model show that when no excess air allowed into the system during the first stage, with excess air being introduced into the second stage, the stove's efficiency is upwards of $85 \%$. 


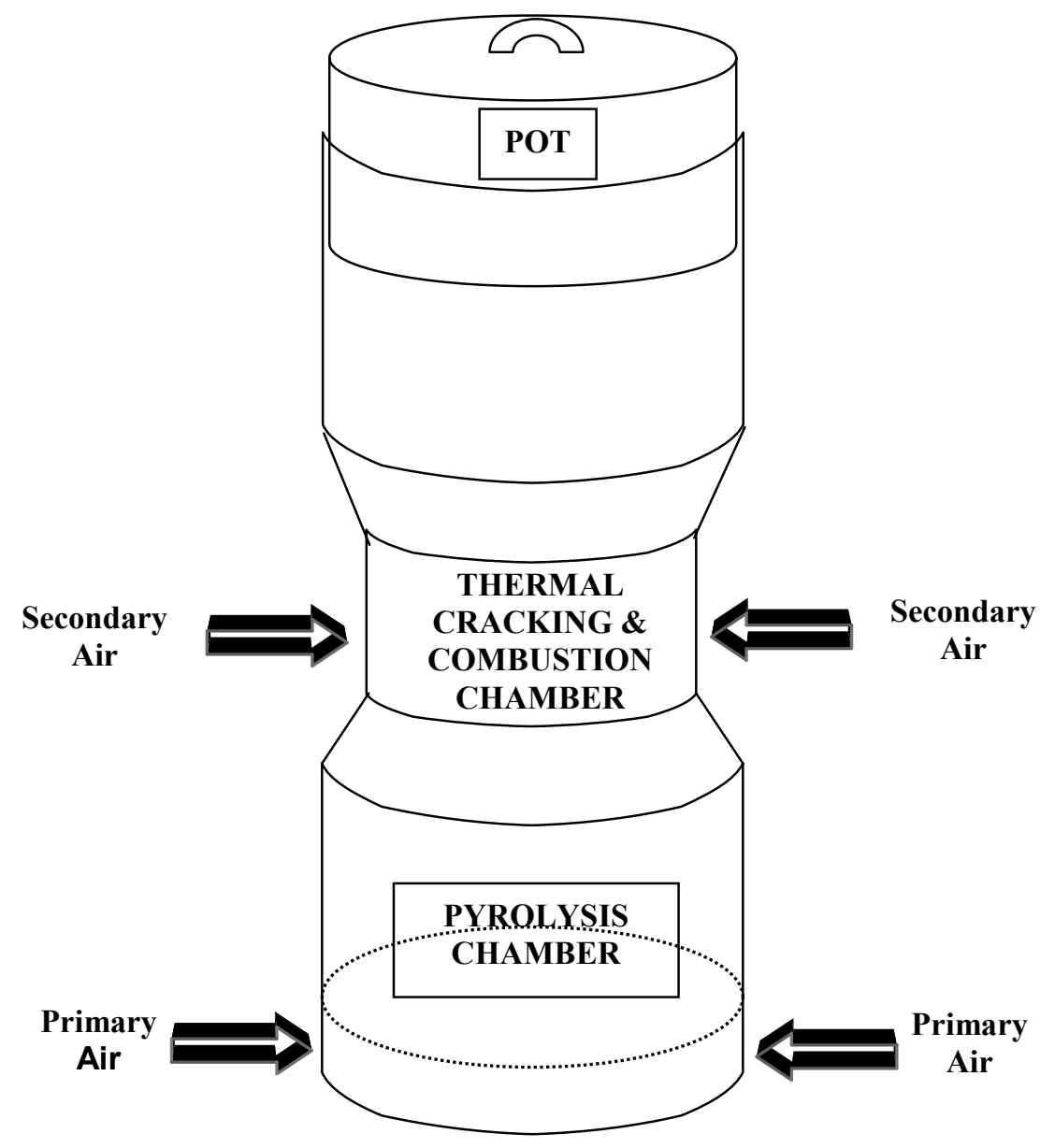

Figure 1. Conceptual design of the single pot 'dream' stove

To increase the efficiency of such a stove, a lightweight ceramic fibre blanket has been suggested as an effective insulation. Ceramic fibre blankets have very low thermal conductivities, are lightweight, and can withstand temperatures of up to $1300^{\circ} \mathrm{C}$. Designs include single pot (Figure 1) and multi-pot versions with estimated costs of 11 \$US and 30 \$US respectively (Grover, 1999).

\section{Improved Cooking Techniques}

It has been previously mentioned that the efficiency of a stove does not rely solely on the efficiency of the combustion process within the unit, but also on the heat transfer to the pot or cooking receptacle. With this in mind, simple improvements can be made to the stoves already in use (Figure 2). 


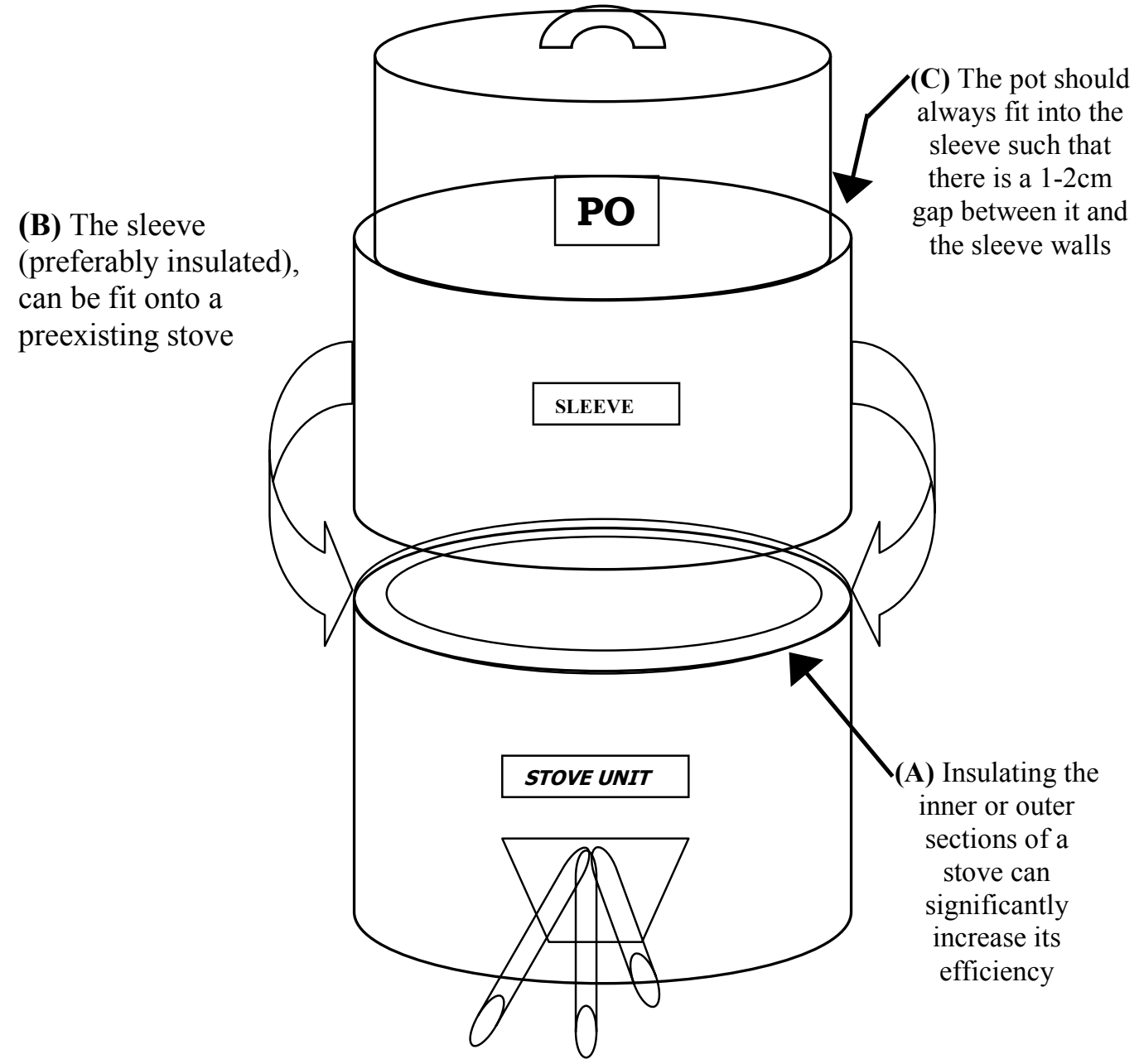

Figure 2. Schematic of a typical ICS showing some possible modifications to maximize stove efficiency.

For example, stoves where the pot rests directly over the combustion chamber can be equipped with a sleeve in which the pot would sit (B). Ideally, both the combustion chamber and the sleeve would be insulated (A). Also, the cooking pot should fit into the sleeve leaving a $1-2 \mathrm{~cm}$ gap between it and the sleeve wall (C). 
Table 2. Possible reasons for success or failure of stove programs

\begin{tabular}{|c|c|}
\hline Reasons for success & Reasons for failure \\
\hline $\begin{array}{l}\text { - Program targets region where traditional fuel and } \\
\text { stove are purchased or fuel is hard to collect }\end{array}$ & $\begin{array}{l}\text { - Program targets region where traditional fuel or } \\
\text { stoves are not purchased or fuel is easy to collect }\end{array}$ \\
\hline $\begin{array}{l}\text { - People cook in environments where smoke causes } \\
\text { health problems and is annoying }\end{array}$ & $\begin{array}{l}\text { - People cook in the open, and smoke is not really a } \\
\text { problem }\end{array}$ \\
\hline $\begin{array}{l}\text { - Market surveys are undertaken to assess potential } \\
\text { market for improved stoves }\end{array}$ & $\begin{array}{l}\text { - Outside "experts" determine that improved stoves } \\
\text { are required }\end{array}$ \\
\hline $\begin{array}{l}\text { - Stoves are designed according to consumer } \\
\text { preferences, including testing under actual use }\end{array}$ & $\begin{array}{l}\text { - Stove is designed as a technical package in the } \\
\text { laboratory, ignoring customers' preferences }\end{array}$ \\
\hline $\begin{array}{l}\text { - Stoves are designed with assistance from local } \\
\text { artisans }\end{array}$ & $\begin{array}{l}\text { - Local artisans are told or even contracted to build } \\
\text { stoves according to specifications }\end{array}$ \\
\hline $\begin{array}{l}\text { - Local or scrap materials are used in production of } \\
\text { the stove, making it relatively inexpensive }\end{array}$ & $\begin{array}{l}\text { - Imported materials are used in the production of the } \\
\text { stove, making it expensive }\end{array}$ \\
\hline $\begin{array}{l}\text { - The production of the stove by artisans or } \\
\text { manufacturers is not subsidized }\end{array}$ & $\begin{array}{l}\text { - The production of the stove by artisans or } \\
\text { manufacturers is subsidized }\end{array}$ \\
\hline - Stove or critical components are mass produced & - Critical stove components are custom built \\
\hline - Similar to traditional stoves & - Dissimilar to traditional stoves \\
\hline $\begin{array}{l}\text { - The stove is easy to light and accepts different sized } \\
\text { wood }\end{array}$ & $\begin{array}{l}\text { - The stove is difficult to light and requires the use of } \\
\text { small pieces of wood }\end{array}$ \\
\hline - $\quad$ Power output of stove can be adjusted & - $\quad$ Power output cannot be easily controlled \\
\hline $\begin{array}{l}\text { - The government assists only in dissemination, } \\
\text { technical advice, and quality control }\end{array}$ & - The government is involved in production \\
\hline - $\quad$ The stove saves fuel, time, and effort & $\begin{array}{l}\text { - The stove does not live up to promised economy or } \\
\text { convenience under real cooking conditions }\end{array}$ \\
\hline $\begin{array}{l}\text { Donor or government support extended over at least } \\
5 \text { years and designed to build local institutions and } \\
\text { develop local expertise }\end{array}$ & $\begin{array}{l}\text { - Major achievements are expected in less than } 3 \\
\text { years, all analysis, planning, and management done } \\
\text { by outsiders }\end{array}$ \\
\hline $\begin{array}{l}\text { - Monitoring and evaluation criteria } \\
\text { responsibilities chosen during planning } \\
\text { according to specific goals of project }\end{array}$ & $\begin{array}{l}\text { Monitoring and evaluation needs are not planned } \\
\text { and budgeted, or criteria are taken uncritically from } \\
\text { other projects or not explicitly addressed }\end{array}$ \\
\hline - Consumer payback of 1 to 3 months & - Consumer payback of more than 1 year \\
\hline
\end{tabular}

*from World Bank Technical Paper Number 242, Barnes, Openshaw, Smith, and van der Plas 1994. 


\section{$\underline{\text { References }}$}

Aprovecho Research Institute. http://www.etn.org/ apro/atitlepage.html

Barnes, D.G., Openshaw, K., Smith, K.R., and van der Plas, R. 1994. "What makes People Cook with Improved Biomass Stoves?: A Comparative International Review of Stove Programs." The World Bank, Technical Paper Number 242, Energy Series, 1994. 44pp.

Energy for Sustainable Development. http://www.ikweb.com/enuff/public html

Dutt, G. S. and Ravindranath, N.H. (1993). "Chapter 15 - Bioenergy: Direct Application in Solar Cooking". ed. Johansson, T.B. et al., Renewable Energy: Sources for Fuel and Electricity, Island Press, Washington.

Forest Products Research Division, Thailand. (1984). "Improved Biomass Cooking for Household Use." Submitted to the National Energy Administration.

Grover, P.D. (1999) “Cost Estimates for a 'Dream Stove' for Asia”. IRP Energy Consultants, New Delhi, http://solsticecrest.org/renewables/stoves-list-archive/msg01091.html

Hasan, A. M., and Khan, R. "Clean Combustion of Wood: Part II.” Institute of Fuel Research and Development, Bangladesh. http://www.ikweb.com/enuff/public html

Kammen, D. M. (1995). "Cookstoves for the Developing World". Scientific American. http://www.wws.princeton.edu/programs/stpp.articles/cookstoves.html.

Luo, Z. and Hulscher, W. (1999). "Woodfuel Emissions". Regional Wood Energy Development Program in Asia, Bangkok, May 1999.

Still, D. et al. (1996). "Fuel Efficient Wood Stoves: Efficiency of Combustion, Operator Expertise, and Heat Transfer Efficiency." http://www.efn.org/!apo/stove96.html

World Health Organization (WHO). "Air Quality Guidelines for Europe". WHO Regional Publication, European Series, Number 23, World Health Organization, Copenhagen, p. 426. 


\section{Appendix 2.2.}

\section{Review of Rice Hull Cookers}

Presently, some rice mills in the Philippines dispose of rice hull by dumping with trucks, or pay workers to bag or bulk handle rice hull for disposal. These 10-kilogram $(\mathrm{kg})$ sacs can be purchased by the public for approximately 5 Philippine pesos (approximately 13 cents US). Comparatively, in some communities families spend as much as 200 Philippine pesos per month on firewood. In other cases, women are expected to walk more than half a day three times a week to collect firewood. This is due to the fact that the majority of land surrounding rural communities is agricultural, making the collection of fuelwood near the home increasingly difficult.

The LO-TRAU rice hull cookers presently being utilized on a limited basis in the Philippines are relatively inexpensive (\$20 US), considering the low cost of the fuel. The device is lightweight $(2.5 \mathrm{~kg})$ and has been tested and demonstrated recently by REAP-Canada on the island of Negros in the Philippines. Figure 1 illustrates the basic design of the stove. To operate, the stove's main drum (1) is filled with rice husk. The user ignites the husk with a simple piece of paper and regulates the even burning of the fuel. The main drum is topped off with husk approximately every 10 minutes and about $1.2-1.5 \mathrm{~kg}$ of husk is consumed per hour. The combustion process can be quenched at any time by removing the inner drum (2), and the heat output will gradually diminish if the outer drum is not periodically tapped to move the fuel.

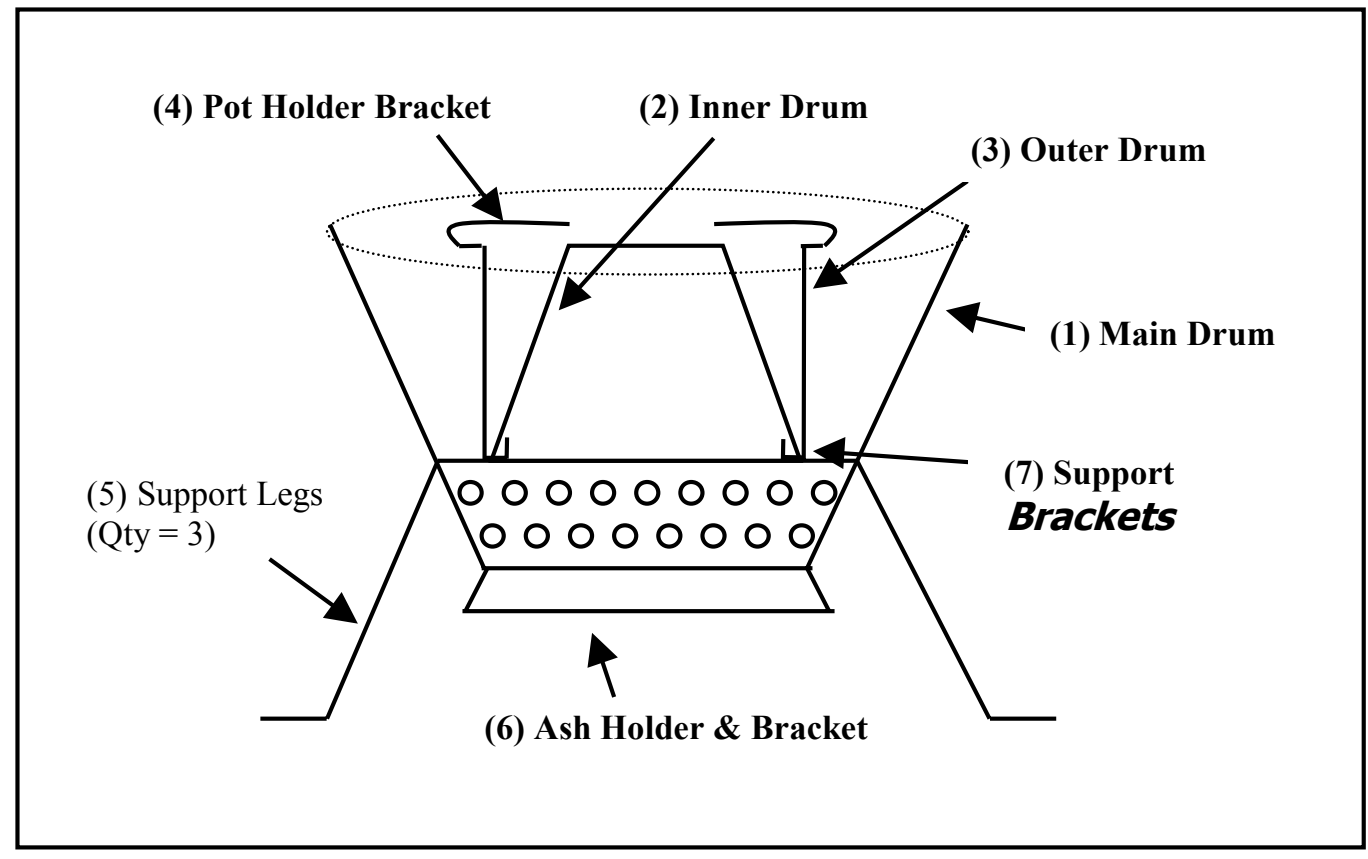

Figure 1. Basic design of the LO-TRAU rice hull cooker

Early demonstrations showed that there was a great deal of interest in the cookers due to the relatively easy ignition and rapid cooking times. In situ test findings showed that it took only 5 minutes to boil 1 liter of water using approximately $180 \mathrm{~g}$ of rice husk. This figure is impressive when compared to liquefied petroleum gas (LPG), fuelwood, and charcoal, which required 5, 15, 
and 20 minutes respectively to boil the same amount of water. It should also be noted that at the present time both wood and charcoal fires are commonly ignited using kerosene, a cost that would be eliminated with the rice husk stove.

The LO-TRAU stoves were found to burn cleanly, emitting very little smoke. The high quantity of ash associated with rice hull is easily managed by removing the ash from the holder (Figure 1, item (6)) following cooking. The ash can be used as a fertilizer for home gardens, vegetable seedlings or recycled to rice paddies. The disadvantage of the household stove arises in the possible health risks associated with the ash and particulate matter produced during combustion. The formation of the silica mineral cristobalite can cause respiratory problems if inhaled over long periods of time. Further investigation into the specific health risks is necessary.

The main inconvenience of using the stove besides the ash handling issue is the somewhat tedious requirement for period tapping during the cooking process. Dr. Teodoro Mendoza has been cooking with the stove for about a year now during the course of the biomass project overview. He realized improved user convenience by using coconut husk as a fuel in the central chamber. In this way, the rice hull is used to rapidly fire the stove and bring it to a boil, and the coconut husk is used to simmer the meal. Minimal intervention is required in the cooking process using this system. The same effect can also be achieved by using maize cobs, chopped coconuts fronds or firewood. Due to the humid weather and the corrosive susceptibility of thin G.I. sheets, Dr. Mendoza noted the short-lived usability of the inner drum which is destroyed at the base after 5-6 months of regular use. Using a thicker GI sheet should extend the life of the centre cone. The centre cone is detached so it can be replaced separately from the main cooker body which is expected to last 3 years. An inner drum made of stainless steel will last longer but appears too expensive. The stove is currently being modified to make a slightly larger central chamber to accompany these fuels more readily. As such, the stove can be utilized as a multifuel burner capable of utilizing almost all agricultural and wood residues in the farming regions of the Philippines. Solid fuels go in the centre chamber and less bulky fuels such as sawdust or rice hulls in the outer chamber. This saves the users from investing in other stoves and resolves concerns about seasonalilty of the rice hull supply.

\section{$\underline{\text { References: }}$}

Van Nguu, N. 1992. "The LO-TRAU: Using LO-TRAU Rice Husk Stoves.” 


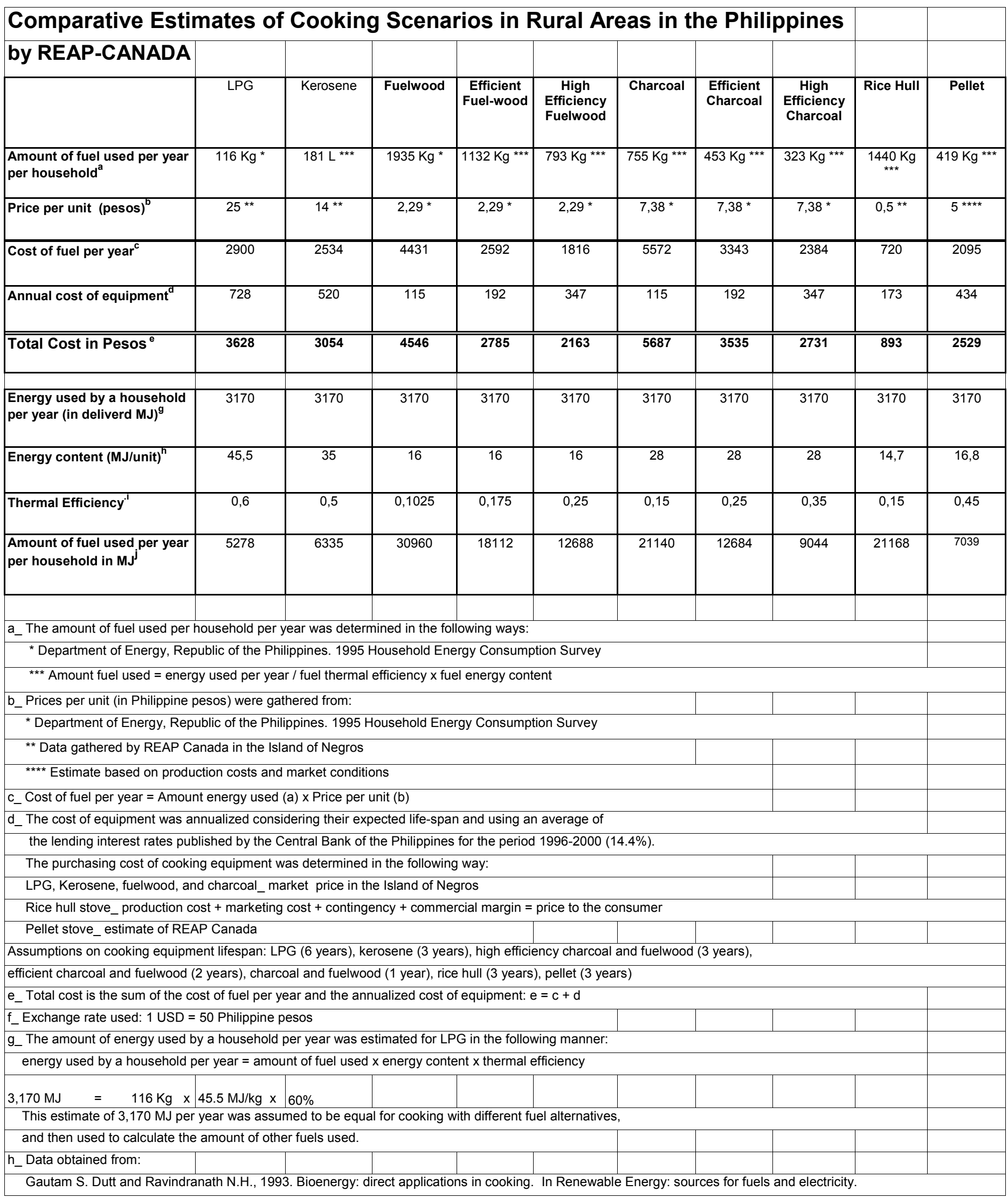




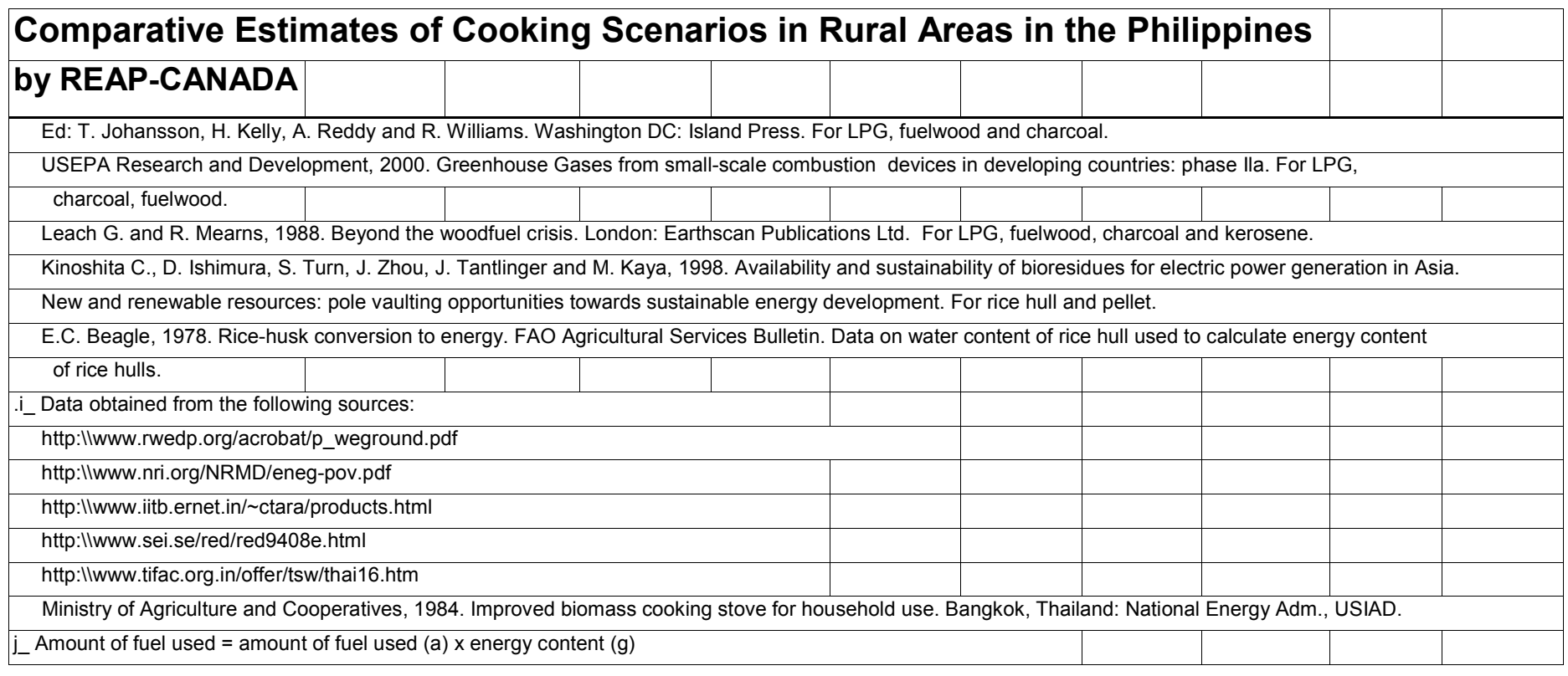

\section{Appendix 2.4 US Dollar Exchange Rates with Peso}

\begin{tabular}{||l||c|}
\hline \multicolumn{1}{|c||}{ Date } & Exchange rate \\
& \\
1995 (average) & 25.71 \\
2000 (November) & 49.75 \\
2000 (average) & 44.20 \\
2001 (average Jan-May) & 50.00 \\
\hline
\end{tabular}


Appendix 3.1: Philippine Sugar Mill Data

Table A. Sugar Mills with Excess Bagasse (CY 1989-1990)

\begin{tabular}{|l|c|}
\hline Sugar Mill & Amount (thousands of tonnes) \\
\hline 1. Hind & 0.38 \\
\hline 2. Paniqui & 23.89 \\
\hline 3. ARCAM $^{\mathrm{a}}$ & 15.36 \\
\hline $4 . \quad$ Canlubang & 23.52 \\
\hline 5. PASUDECO & 21.00 \\
\hline $6 . \quad$ Don Pedro & 1.00 \\
\hline 7. Bogo-Mundellin & 10.04 \\
\hline 8. Durano & 11.03 \\
\hline 9. HIDECO & 14.99 \\
\hline 10. Ormoc & 10.00 \\
\hline 11. Pilar & 0.29 \\
\hline 12. Passi & 23.09 \\
\hline 13. First Farmers & 5.46 \\
\hline 14. Lopez & 9.78 \\
\hline 15. San Carlos & 4.99 \\
\hline 16. La Carlota & 5.78 \\
\hline 17. SONEDCO & 22.24 \\
\hline 18. URSUMCO & 3.37 \\
\hline 19. Bais & 20.00 \\
\hline 20. Tolora & 18.38 \\
\hline 21. BUSCO & 12.00 \\
\hline
\end{tabular}

${ }^{a}$ no longer operating since 1991 (affected by Pinatubo eruption)

${ }^{\mathrm{b}}$ no longer operating since 1995 (sugarlands converted into industrial/commercial estate.

SOURCE : Corpuz and Aguilar (1992) 
Table B. Energy (by source) utilization in the Philippine Sugar Mills.

\begin{tabular}{|lc||}
\hline Energy Source & $\%$ \\
\hline Bagasse & 87.10 \\
Supplementary & \\
\hline source & \\
Fuel Oil & 5.90 \\
Wood & 3.15 \\
Others & 1.28 \\
Electricity & 2.57 \\
\hline
\end{tabular}

Table C. Breakdown (\%) of fuel mix utilization by region in the Philippine Sugar Mills

\begin{tabular}{|l|l|l|l|l|l|l||}
\hline & \multicolumn{2}{|c|}{ Bagasse } & \multicolumn{2}{c|}{ Supplementary } & \multicolumn{2}{c|}{ Electricity } \\
\hline Region & $88-89$ & $89-90$ & $88-89$ & $89-90$ & $88-89$ & $89-90$ \\
\hline Luzon & 90.06 & 83.05 & 5.5 & 11.91 & 1.11 & 5.01 \\
\hline $\begin{array}{l}\text { East } \\
\text { Visayas }\end{array}$ & 98.51 & 98.11 & 0.31 & 0.02 & 1.18 & 1.89 \\
\hline Panay & 99.14 & 95.61 & 0.38 & 3.39 & 0.18 & 1.00 \\
\hline Negros & 88.09 & 90.17 & 10.58 & 7.91 & 1.33 & 1.89 \\
\hline Mindanao & 90.50 & 90.22 & 7.36 & 7.10 & 2.11 & 2.38 \\
\hline
\end{tabular}

SOURCE: Corpuz and Aguilar (1992)

Table D. Comparative figures of the different energy source utilized in Philippine Sugar Mills (MLOE)

\begin{tabular}{|llrr|}
\hline \multicolumn{1}{|c}{ Source } & & $\mathbf{1 9 8 8 - 8 9}$ & $\mathbf{1 9 8 9 - 9 0}$ \\
\hline Bagasse & & 614.971 & 850.920 \\
Supplementary & & & \\
& bunker & 47.992 & 43.831 \\
& oil & & \\
& Wood & 19,634 & 10.397 \\
& Others & 9.191 & 19.875 \\
Electricity & & & \\
& Grid & 17.791 & 16.018 \\
& Diesel & 4.529 & 6.638 \\
\hline
\end{tabular}

${ }^{*}$ MLOE - Million Liter Oil Equivalent

SOURCE: Corpuz and Aguilar (1992) 
Table E. Energy consumption of Philippine sugar mills.

\begin{tabular}{|c|c|c|}
\hline Mill & $\begin{array}{l}\text { Energy Consumption } \\
\text { (LOE/TC)* }\end{array}$ & $\begin{array}{l}\text { Total consumption (LOE/TC) } \\
\text { per region }\end{array}$ \\
\hline \multicolumn{3}{|l|}{ Luzon } \\
\hline CASUCO & & 52.49 \\
\hline Hind & 77.34 & \\
\hline Paniqui & 51.72 & \\
\hline Tarlac & 65.44 & \\
\hline ARCAM & 52.78 & \\
\hline PASUDECO & 35.87 & \\
\hline Canlubang & 49.32 & \\
\hline Don Pedro & 51.46 & \\
\hline Batangas & 40.24 & \\
\hline BISUDECO & 47.90 & \\
\hline \multicolumn{2}{|c|}{ 2. Eastern Visayas } & 41.24 \\
\hline Bogo-Mendellin & 42.74 & \\
\hline Durano & 38.59 & \\
\hline HIDECO & 40.64 & \\
\hline Ormoc & 41.33 & \\
\hline \multicolumn{2}{|l|}{ 3. Panay } & 47.59 \\
\hline Pilar & 82.68 & \\
\hline Asturias & 50.86 & \\
\hline Cal-Lambunao & - & \\
\hline Passi & 35.07 & \\
\hline Golden Frontier & 67.30 & \\
\hline Santa Lopez & - & \\
\hline \multicolumn{2}{|l|}{ 4. Negros } & 51.46 \\
\hline Azucar & 20.35 & \\
\hline DAESUMICO & 57.90 & \\
\hline First Farmers & 45.54 & \\
\hline Hawaii-Phil. & 43.26 & \\
\hline AIDSISA & 43.13 & \\
\hline VICMICO & 65.45 & \\
\hline Lopez & 44.61 & \\
\hline Sagay & 38.60 & \\
\hline Danao & 59.27 & \\
\hline San Carlos & 45.37 & \\
\hline Ma-ao & 48.40 & \\
\hline La Carlota & 55.85 & \\
\hline BISCOM & - & \\
\hline Sonedco & 42.85 & \\
\hline Dacong-cogon & 43.84 & \\
\hline USUMCO & 49.98 & \\
\hline Bais & 42.92 & \\
\hline Tolong & 47.79 & \\
\hline \multicolumn{2}{|l|}{ 5. Mindanao } & 46.04 \\
\hline BUSCO & 44.72 & \\
\hline DASUCECO & 52.48 & \\
\hline NACOSII & - & \\
\hline \multicolumn{2}{|l|}{ Philippines } & 50.42 \\
\hline
\end{tabular}

* $\mathrm{LOE} / \mathrm{TC}=$ liter oil equivalent per tonne cane

SOURCE : Corpuz and Aguilar (1992) 
Table F. Energy utilization in the Philippine sugar mills

\begin{tabular}{|cc|}
\hline Section & $\%$ \\
\hline Factory & 82.82 \\
Auxilliary Plants & 15.28 \\
Admin/lighting & 0.94 \\
Housing/domestic & 0.80 \\
Others & 0.16 \\
TOTAL & 100.00 \\
\hline
\end{tabular}

Table G. Comparative energy utilization of some sugar producing countries

\begin{tabular}{||llccc||}
\hline \multirow{2}{*}{ Country } & \multicolumn{2}{c}{$\%$ Utilization } & LOE/TC & $\begin{array}{c}\text { No. of } \\
\text { Mills }\end{array}$ \\
\cline { 2 - 3 } & Bagasse & Others & & $16 / 16$ \\
\hline South Africa & 61.86 & 38.14 & 74.83 & 16 \\
\hline Swazeland & 98.04 & 1.96 & 52.96 & $3 / 3$ \\
\hline Malawi & 99.52 & 0.48 & 57.83 & $2 / 2$ \\
\hline Zimbabwe & 98.14 & 1.86 & 57.86 & $2 / 2$ \\
\hline Australia & 93.10 & 6.90 & 61.27 & $31 / 31$ \\
\hline Thailand & 99.77 & 0.23 & 52.26 & $16 / 41$ \\
\hline Philippines & 83.82 & 14.18 & 50.42 & $29 / 38$ \\
\hline
\end{tabular}

SOURCE : Corpuz and Aguilar (1992) 


\section{Appendix 3.2: Victorias Milling Data}

Victorias Milling Corporation (VMC)

\section{Background Information}

1. Capacity, tonnes cane per day: up to 15,000 ton cane per day (note that the boiling house is the bottleneck in operation)

2. Season duration: October to June (effectively 9 months)

3. Land area, hectares: District of Victoria has 30,000-34,000 hectares

4. Plant/machinery year of installation: two boilers were installed in 1992, one in 1991 and the rest from 1960's

5. Output

- Refined sugar, bags of 50-kg: target of 2.0 million bags per year

- Crude yeast, $\mathrm{kg} / \mathrm{day}$

- Alcohol distillery, li/day

- Liquid carbon dioxide, tonnes/day

- Biogas

6. Waste water treatment

\section{Co-Generation}

1. Steam plant

- No. of units: seven (7) units, Riley, John Thompson, Yoshimine

- Steam turbine: $120,000 \mathrm{lb}$ steam/h

- Pressure: 400 psi

- Temperature

2. Load

- Milling equipment

- Boiler auxilliary equipment

- Electricity generator

3. Input/output

4. Exhaust steam

\section{Bagasse}

1. Bagasse production, tonnes/season

2. Hessey formula:

$$
\begin{aligned}
& G C V= 8,345-22 S-83.45 \mathrm{~W} \\
& \mathrm{GCV}=\text { gross calorific value, Btu } \\
& \mathrm{S}=\text { sugar in bagasse, usually at } 3 \% \\
& \mathrm{~W}=\text { moisture in bagasse, usually at } 52 \%
\end{aligned}
$$

3. Typical boiler efficiency $=65 \%$

4. Flue gas exit temperature $=350^{\circ} \mathrm{F}$

\section{Others:}

1. The corporation has allotted 150 million pesos for about 19,000 tonnes of bunker to be purchase.

2. Cost of hauling bagasse from other mills: $\$ 1.25 U S$ (P50)/tonnes bagasse and $\$ 8.75-18.88$ US(P350-755)/tonnes trucking, depending on the distance.

3. Boiler efficiency with bagasse is about 65 to $70 \%$, slightly lower than with bunker.

4. Heating value of bunker is about 6 times that of the bagasse.

5. Bunker costs $\mathrm{P} 8,820$ per tonnes of bunker.

6. Coal in the Philippines has a high ash content. It results in clinkering even at $5 \%$ mixed with bagasse. 
7. Wood is not a sustainable source of energy. Dealers began cutting fruit trees just to supply woodfuel.

8. Bagasse shed at the moment can accommodate up to 40,000 tonnes. Boiler has capacity of 24 tonne/h/boiler.

9. Total plant has a rated capacity of about $913,000 \mathrm{lb}$ steam per hour. Utilization is only about $840,000 \mathrm{lb} / \mathrm{h}$.

10. Average sugarcane yield is about 40 to 100 tonne per hectare. Trash is approximated at 8 tonne/hectare at $30 \% \mathrm{mc}$.

11. Power cost is about $\$ 0.11$ US (P4.55)/kWh.

12. The Victoria district has a nearly $70 \mathrm{~km}$ radius.

13. VMC Raw Sugar Processing

- Milling

- Clarification and Filtration

- Evaporation

- Pan Boiling

14. VMC Refining Process

- Affination

- Carbonation and Filtration

- Decolorization

- Evaporation

- Pan Boiling

- Packaging

- Recovery House 
Table H: Victorias Milling Corporation: Monthly Data

\begin{tabular}{|l|l|l|l|l|l|l|l|l|l||}
\hline \hline & $\begin{array}{l}\text { Cane } \\
\text { tonne }\end{array}$ & $\begin{array}{l}\text { Refined } \\
\text { sugar } \\
50 \mathrm{~kg} \text { bag }\end{array}$ & $\begin{array}{l}\text { Diesel } \\
\text { liter }\end{array}$ & $\begin{array}{l}\text { VRESCO } \\
\text { kWh }\end{array}$ & $\begin{array}{l}\text { Bunker } \\
\text { metric } \\
\text { tonne }\end{array}$ & $\begin{array}{l}\text { Outside } \\
\text { Bagasse } \\
\text { tonne }\end{array}$ & $\begin{array}{l}\text { Bagasse } \\
\text { tonne }\end{array}$ & $\begin{array}{l}\text { Heating } \\
\text { Value } \\
\text { Btu }\end{array}$ & $\begin{array}{l}\text { Efficiency } \\
\%\end{array}$ \\
\hline Sep & & & & 672,918 & & & & & \\
\hline Oct & 212,714 & 242,350 & 61,485 & 380,950 & 304 & 1,946 & 63,814 & 3939.6 & 65 \\
\hline Nov & 229,673 & 342,800 & 26,577 & 856,928 & 88 & 5,739 & 68,902 & 3939.6 & 65 \\
\hline Dec & 265,607 & 682,650 & 36,116 & 426,052 & 1,835 & 2,020 & 79,682 & 3939.6 & 65 \\
\hline Jan & 263,197 & 527,525 & 30,680 & 678,240 & 708 & 3,622 & 78,959 & 3939.6 & 65 \\
\hline Feb & 246,758 & 503,321 & 43,720 & 687,824 & 1,214 & 1,630 & 74,027 & 3939.6 & 65 \\
\hline Mar & 226,996 & 216,801 & 53,205 & $2,105,466$ & 346 & 3,217 & 68,099 & 3939.6 & 65 \\
\hline
\end{tabular}

Assumptions:

Bagasse/Cane Ratio 29-32\%

Heating value, GCV (gross calorific value),

$\mathrm{Btu}=8,345-22$ (sugar in bagasse) - 83.45 (moisture) 


\section{APPENDIX 3.3: Pricing of biomass resources relative to their fossil fuel value}

A competitive pricing of biomass resources relative to their fossil fuel value is being proposed, as shown in table I.

Table I. Fuel value, cost of production and suggested purchase price of sugarcane bagasse, cane trash, napier grass and fuelwood.

\begin{tabular}{|c|c|c|c||}
\hline Biomass & $\begin{array}{c}\text { Fuel value* per tonne } \\
\text { (wet basis) relative to } \\
\text { bunker oil }(\mathrm{P})\end{array}$ & $\begin{array}{c}\text { Cost } \\
\text { of Production } \\
(\mathrm{P})\end{array}$ & $\begin{array}{c}\text { Suggested Purchase } \\
\text { price per wet tonne } \\
\text { (farmgate) }(\mathrm{P})\end{array}$ \\
\hline Sugarcane bagasse & 1,658 & 0 & $900^{1}$ \\
\hline Sugarcane trash & 2,489 & 1,048 & $1,650^{2}$ \\
\hline Napier & 2,489 & 1,339 & $1,650^{3}$ \\
\hline Fuelwood & 3,100 & Undetermined & $1,950^{4}$ \\
\hline
\end{tabular}

*bunker oil priced at $\$ 30$ US/barrel

Notes:

(1) The Victorias Milling Company is buying bagasse at $\$ 1.25 \mathrm{US} /$ tonne $+\$ 8.75$ hauling cost or $\$ 10 /$ tonne delivered price.

(2) The main compensation to the farmers should be the nutrient value of the trash, which is $\$ 3.58 \mathrm{US} /$ tonne (only $9.4 \%$ of the suggested purchase price of the sugarcane trash used as a biofuel, see Table 3.1).

(3) Assumed price of napier (30-35\% m.c.) delivered at mill yard.

(4) Assumed price of fuel wood delivered at mill yard. 


\section{Appendix 3.4}

\section{Data Sheet: Economic Analysis of Using Sugarcane Trash to Supplement the Use of Bagasse in Sugarcane Mills.}

Knowing the heating values, moisture content, and purchase price of the fuel, the cost of steam production per biomass was determined. A simplified method (but less accurate) to calculate the savings would be to compare heating values of the materials, and to calculate their bunker oil energy equivalent.

Currently bagasse accounts for $87 \%$ of the fuel requirements of Philippine sugarcane mills. A financial analysis was completed to examine the feasibility of using sugarcane trash to supplement bagasse use and maximize the replacement of bunker oil.

Current Price of oil: \$30USD/barrel

$\%$ of fuel requirements fulfilled by Bagasse: $87 \%$

Oil Equivalent of Bagasse used in sugar industry: $\quad 8.51 \times 10^{8}$ litres of oil $\sim 312,000$ tonnes bagasse

Total energy requirements: $8.51 \times 10^{8}$ litres of oil / $87 \%=9.78 \times 10^{8}$ litres of oil

Energy Deficit: $127,160,919.5$ litres of oil $(803,000$ barrels of oil or 4,739,415 GJ) Cost of Energy Deficit $=\$ 30$ US/barrel ${ }^{*} 803,000$ barrels of oil $=\$ 24,090,000$ US if the $13 \%$ deficit were covered only by oil. To replace this energy deficit of 803,000 barrels of oil equivalent represents $355,811.95$ tonnes of SC trash are required assuming $26 \%$ moisture and a HHV of $18 \mathrm{GJ} /$ dry tonne.

However, only $5.9 \%$ of the nationwide fuel use in sugar mills is by bunker oil (See Table B, Appendix 3.1).

To displace only the bunker oil $(5.9 \%=364,570$ barrels of oil) would require $161,483.89$ tonnes ( $26 \%$ moisture) of cane trash which would have an equivalent oilenergy value of $\$ 10,937,112$ US.

\section{Comparison of calorific properties of sugrcane trash, napier grass, wood,} bagasse and oil:

HHV of bagasse and trash 8345 Btu/lb (19.4 GJ/tonne)

Hessey formula:

5. Hessey formula:

$G C V=8,345-22 S-83.45 \mathrm{~W}$

$\mathrm{GCV}=$ gross calorific value, Btu

$\mathrm{S}=$ sugar in bagasse, usually at $3 \%$

$\mathrm{W}=$ moisture in bagasse, usually at $52 \%$

6. Average heating value was observed $6.5 \%$ lower than GCV

GCV of bagasse $\left(H H V_{b}\right)=3,683.53 \mathrm{Btu} / \mathrm{lb}$

$\mathrm{GCV}$ of cane trash $\left(\mathrm{HHV}_{\mathrm{CF}}\right)=5,774 \mathrm{Btu} / \mathrm{lb}$ 
GCV of napier $\left(H H V_{\text {napier }}\right)=5,774 \mathrm{Btu} / \mathrm{lb}$

$\mathrm{GCV}$ of wood $\left(\mathrm{HHV}_{\text {wood }}\right)=6837 \mathrm{Btu} / \mathrm{lb}$

Weight of steam generate per pound of fuel:

$\mathrm{WSNf}=\mathrm{HHV}_{\text {bagasse, cane trash }}{ }^{*}$ Boiler efficiency

$\mathrm{h}^{*}$

where $\mathrm{h}^{*}=\mathrm{h} 1$-h2 and h1 = enthalpy @ 250psi, 500 degrees $\mathrm{F}=1,262 \mathrm{Btu} / \mathrm{lb}$ and h2 $=$ enthalpy of feedwater $=32 \mathrm{Btu} / \mathrm{lb}$

WS/Wf for Oil $=12.5 \mathrm{lbs}$ of steam/lb of fuel

WS/Wf for bagasse $=2.25 \mathrm{lbs}$ of steam/lb of fuel

WS/Wf for Sugarcane trash and Napier grass $=3.5 \mathrm{lbs}$ of steam/lb of fuel

$\mathrm{WS} / \mathrm{Wf}$ for wood $=4.18 \mathrm{lbs}$ of steam/lb of fuel

Table J. Comparison of biofuel energy costs versus bunker oil costs for steam production

\begin{tabular}{|l|c|c|c|c|}
\hline \multicolumn{1}{|c|}{ Fuel } & $\begin{array}{c}\text { Delivered Fuel Cost } \\
\text { (pesos/tonne) } \\
(\$ 1 \cup S: P 40)\end{array}$ & $\begin{array}{c}\text { Lbs } \\
\text { steam/lbs } \\
\text { fuel }\end{array}$ & $\begin{array}{c}\text { Lbs/steam per } \\
\text { tonne fuel }\end{array}$ & Pesos Ib/steam \\
\hline Bunker oil & 8820 & 12.5 & 27563 & .32 \\
\hline Bagasse & 1050 & 2.25 & 4961 & .21 \\
\hline Napier grass & 1650 & 3.5 & 7717 & .21 \\
\hline Sugar cane trash & 1650 & 3.5 & 7717 & .21 \\
\hline Wood & 2000 & 4.18 & 9217 & .21 \\
\hline
\end{tabular}

- Bunker oil at $8820 \mathrm{P} /$ tonne $=\$ 30 /$ barrel

- On a per lb per delivered steam basis, all biofuels are priced at $2 / 3^{\text {rd }}$ cost of oil or $\$ 20$ per barrel equivalent

Savings attained by using biofuels to replace bunker oil (at $\$ 30$ per barrel) equals $\$ 10,937,112 * 1 / 3=\$ 3,642,058$ US or $P 145,000,000$. 


\section{Appendix 3.5}

Table K. Nutrient content (N, P, K) at various trash yield levels

\begin{tabular}{|l|c|l|c|c|}
\hline & $\mathrm{N}$ & $\mathrm{P}$ & $\mathrm{K}$ & $\begin{array}{l}\text { Total (pesos) } \\
(\$ 1 \text { (US:P40) }\end{array}$ \\
\hline $\begin{array}{l}\text { Kg per tonne } \\
\text { of trash }\end{array}$ & 2.87 & .02 & 4.6 & \\
\hline Price/kg $(\mathrm{P})$ & 17.7 & 26.6 & 10.6 & \\
\hline 8 tonne trash & 22.3 & 4.16 & 36.6 & \\
\hline Value $(\mathrm{P})$ & 406.9 & 110.7 & 388.34 & 906.0 \\
\hline 10 tonne trash & 28.7 & 5.2 & 45.8 & \\
\hline Value $(\mathrm{P})$ & 508.7 & 138.3 & 485.5 & $1,132.4$ \\
\hline 12 tonne trash & 34.4 & 6.2 & 55.0 & \\
\hline Value $(\mathrm{P})$ & 610.4 & 166.0 & 582.6 & $1,358.9$ \\
\hline
\end{tabular}




\section{Appendix 3.6: Fuelwood Data}

Table L1. Some fuelwood tree species, their adaptability, fuelwood quality and yields

\begin{tabular}{lll}
\hline \hline Species/Common Name & $\begin{array}{c}\text { Soil and Climate Requirements } \\
\text { (adaptability) }\end{array}$ & Fuelwood quality/Yields
\end{tabular}

\section{Albizia falcataria (L.)}

Fosberg (Falcata)

Eucalyptus

camaldulensis Dehn.

(Eucalyptus)

Gliricidia sepium

H.b.\& k.

(Madre cacao,

Kakawati)
Adapted to wide range of soil types,

it is widespread in the humid

tropics, $1000 \mathrm{~mm}$ minimum rainfall

Tolerates calcareous soil, acidity or salinity, periodic waterlogging, prefers moist alluvial valleys and riverbanks but can withstand shallow/dry soils; thrives with 400 to $1000 \mathrm{~mm} / \mathrm{yr}$ rainfall and can withstand 4 to 8 months dry season

Thrives in wide variety of soils - saline soils, heavy clays, acidic/alkaline soils; as legume, it can be established on infertile soils; thrives in areas with rainfall of 1,500-2,300 mm or more, tolerates regions with extended dry season.
Commonly grown as pulp/paper, wood has low timber quality (Low sp. gr. $=0.33$ ), fast grower; being a legume it has high yields even in low fertile soil

Fast grower, it is commonly planted in roadside, useful as windbreaks and shelterbelts or reforestation, good as fuelwood (sp. gr. $=0.60-0.87$; calorific value $=4,800 \mathrm{kCal} / \mathrm{kg}$ ). Yields can be as high as $30 \mathrm{cu}$. m./ha on wetter sites

Fast grower, as legume, it is valuable plant for erosion control and soil enrichment, commonly used as a living fence, windbreak shade for plantation crops, classified as hardwood,

Sp. gr. $=0.48-0.75$ and

Caloric value $=4,900 \mathrm{kcal} / \mathrm{kg}$. 
Table L1. cont. . . 2/

$\begin{array}{lll}\text { Species/Common Name } & \begin{array}{l}\text { Soil and Climate Requirements } \\ \text { (adaptability) }\end{array} & \text { Fuelwood quality/Yields }\end{array}$

Gmelina arborea Roxb. (gmelina, paper tree)

Leucaena leucocephala de Wit (Ipil-ipil)
Tolerates acidic, calcareous, and lateritic soils, grows poorly if the soil is thin, leached acidic, dry, sandy, or poorly drained; grows in all 4 climatic types in the Phil.; rainfall ranges $750 \mathrm{~mm}$ $4,500 \mathrm{~mm}$.

Grows well on a neutral or alkaline soils grows less vigorously on soils with $\mathrm{pH}$ below 5.5; growth is stunted above $500 \mathrm{~m}$; requires $1000-3000 \mathrm{~mm}$ of evenly distributed rainfall, psyllids severely reduced growth in 19861987 in the Phil.
Commonly planted in road sides, it does not fix nitrogen, its large root system and dense canopy make it inappropriate for soil erosion control, has high quality, quick burning wood. sp. gr. $=0.41-0.64$.

calorific value $=4,800 \mathrm{kcal} / \mathrm{kg}$

As fast growing tree legume, Leucaena is desirable for soil improvement and reforestation, its wood is good for firewood, charcoal, lumber, pulp, roundwood, construction material, fenceposts and as fuel for steam generators

sp. gr. $=0.54-0.7$

calorific value $=4,200-4,600 \mathrm{kcal} / \mathrm{kg}$

Table L1. cont. .. . 3/ 

(adaptability)

Fuelwood quality/Yields

Thrives on poor to fertile soils that are neutral to acid with light to heavy texture, grows from 0 to $700 \mathrm{~m}$, adapted to $600-2000 \mathrm{~mm} / \mathrm{yr}$ with less than 6 months dry

Grows in poor soils and barren environments, can grow up to 2000 m; prefers humid, moist climate with high rainfall but it is also found in areas having 6 months dry season, tree grows rapidly but is short-lived, host for population of defoliating insects
Excellent timber and good roundwood, fair for fuelwood.

Wood yield : $15 \mathrm{~m}^{3} / \mathrm{ha} / \mathrm{yr}$

sp. gr. $=0.42-0.6$

Its fast growth and coppicing ability makes it good as fuelwood though light,

sp. gr. $=0.28-0.40$

Calorific value $=4,500 \mathrm{kcal} / \mathrm{kg}$

In good sites, it yields about

$28-40 \mathrm{~m}^{3} / \mathrm{ha} / \mathrm{yr}$ in 6 year rotation

Source: Hens Leigh and Holaway (1988) 


\section{Appendix 4.1: Photo Diary of Sugarcane Trash Farming}

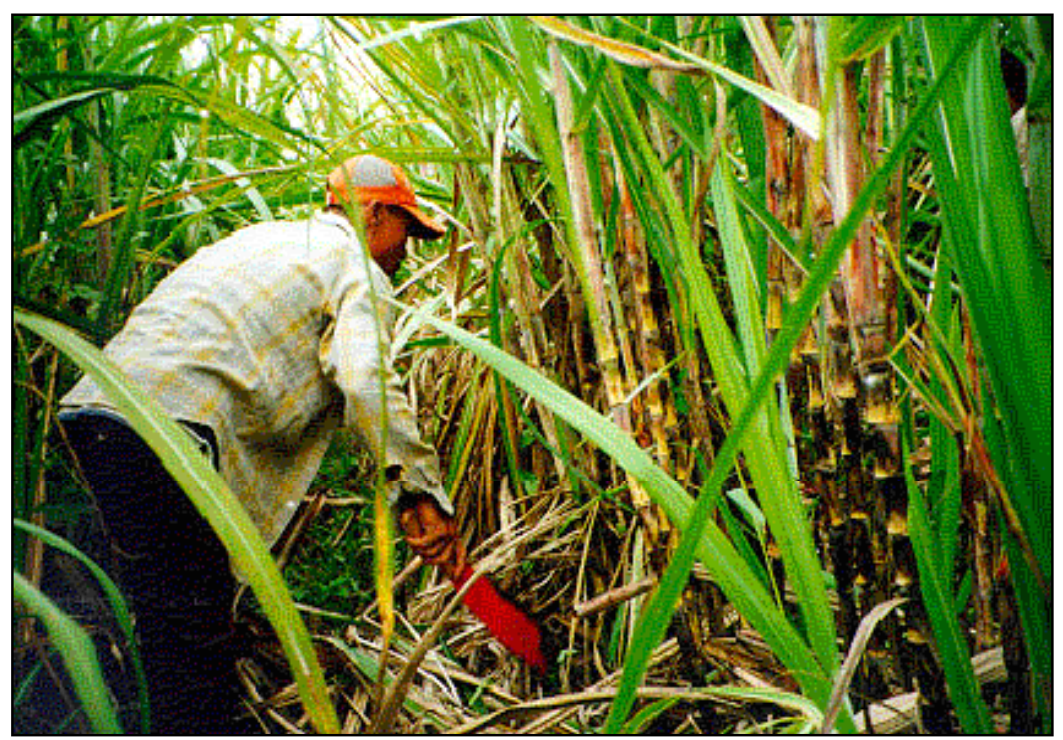

Photo A: By detrashing sugarcane 3-4 months before harvest, decomposition of trash is accelerated, weeds are controlled, and crop lodging from typhoons is reduced. The preharvest detrashing also makes more efficient use of on-farm labor and reduces the workload associated with harvesting.

Photo B: Just prior to harvest, the trash is largely decomposed. Harvesting will proceed quickly as the cleaning of leaves from the cane will be an easy task.

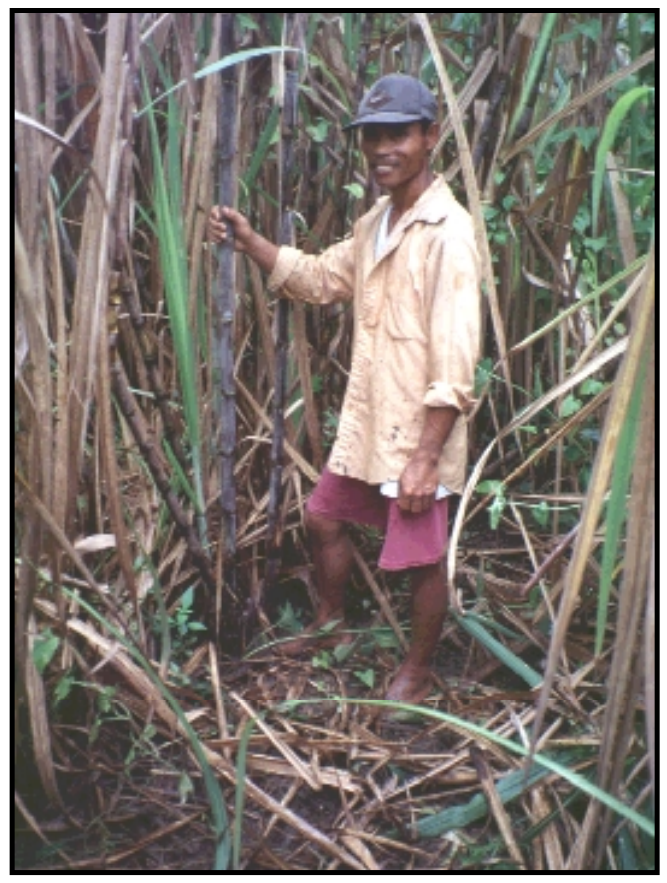




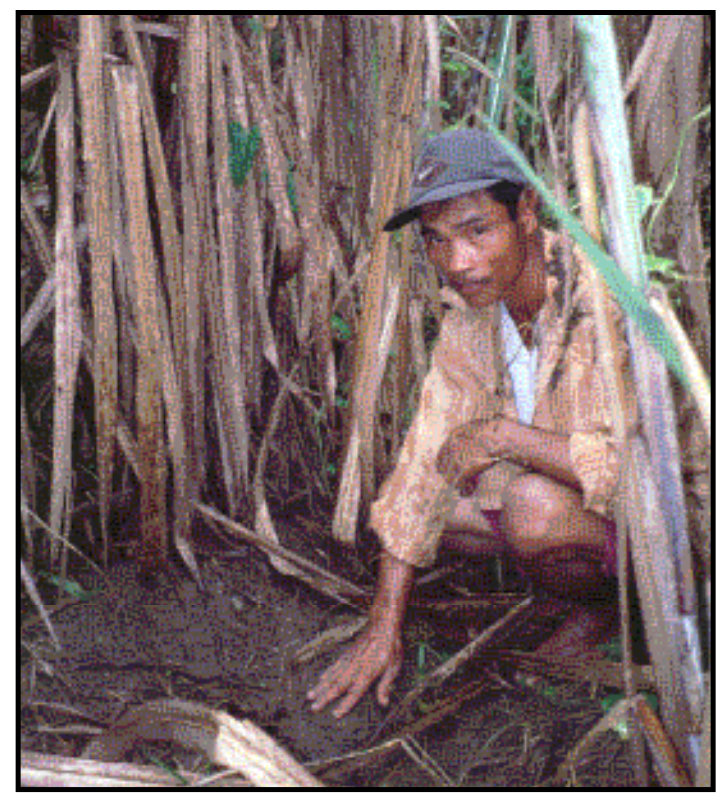

Photo C: Immediately preceding harvest in a non-detrashed plot the soil is bare and the cane stalks are covered in leaves, slowing harvest.

Photo D: Leaf litter turns black during decomposition, indicating the presence of nitrogen fixing fungi.

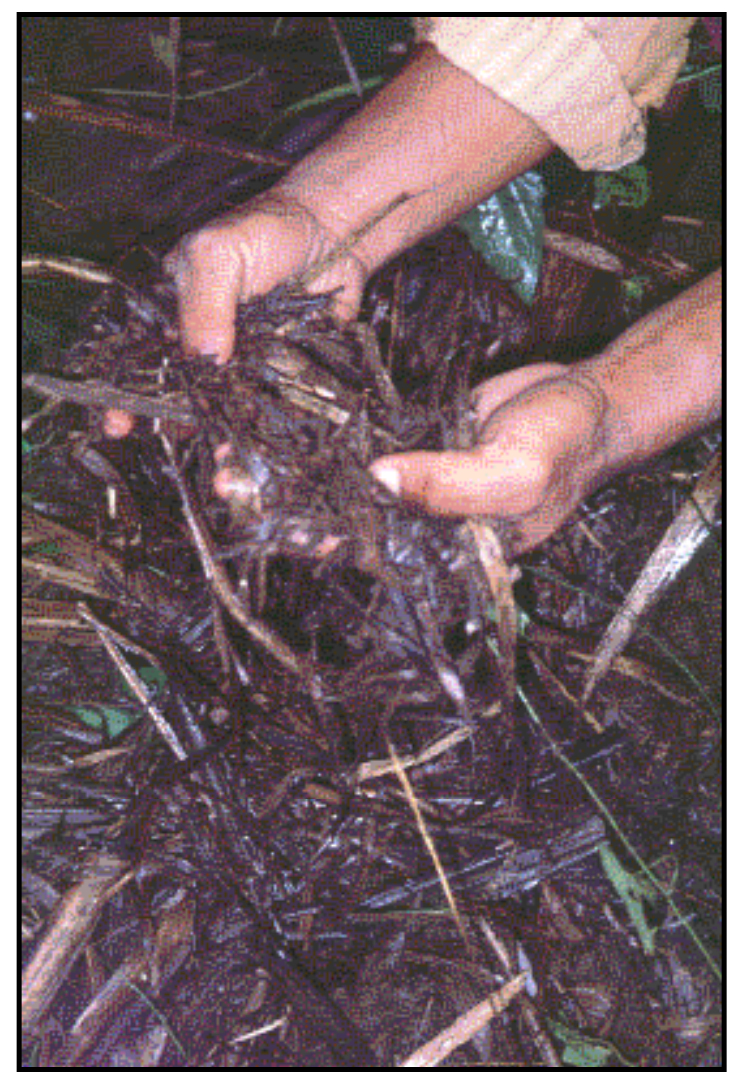




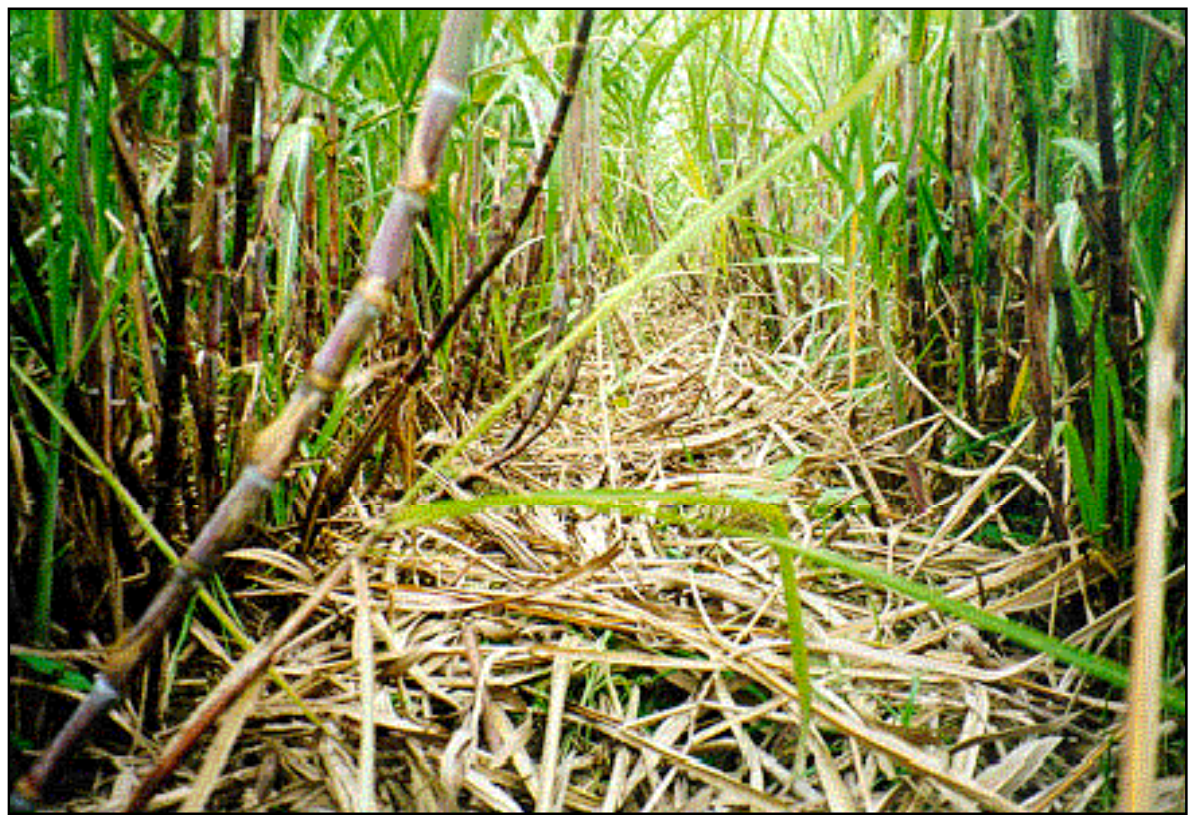

Photo E: Pre-Harvest detrashing, 3-4 months before harvest reduces crop lodging, promotes $\mathrm{N}_{2}$ fixation, reduces water stress, and facilitates residue management after harvest.

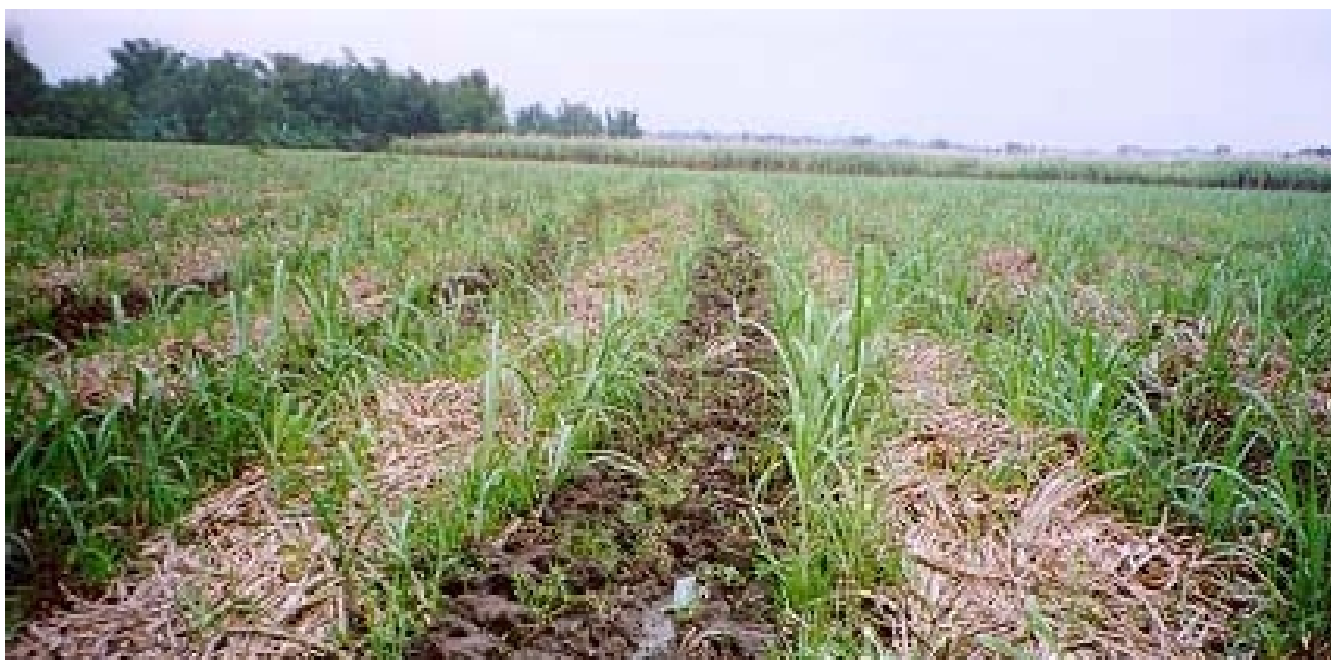

Photo F: Alternate row placement of cane trash is a best management practice for cane trash farming. The decomposing cane can fix an average of $125 \mathrm{~kg} \mathrm{~N} / \mathrm{ha}$ through asymbiotic $\mathrm{N}$ fixation, greatly reducing $\mathrm{N}$ fertilizer requirements for cane crops. 


\title{
Appendix 4.2
}

\section{OVERVIEW OF N $\mathrm{N}_{2}$ FIXATION IN SUGARCANE RESIDUES Levels and effects on decomposition}

\author{
D. Patriquin (patriqui@IS.Dal.ca) \\ Biology Department \\ Dalhousie University \\ Halifax, Nova Scotia
}

Sugarcane produces $15-20$ tonnes ha-1 of low $\mathrm{N}$ residues, most of it from old leaves or "trash"(Barnes, 1964; Wood, 1991). With movement of the sugarcane industry away from burning of residues before harvest and towards litter conservation/minimum tillage systems, there is a need to manage the decomposition process (Wood, 1991; Spain and Hodgen, 1994). On farms practicing "CIPAV technology", cane is grown as livestock feed using manure as the only fertilizer, and litter is conserved (Preston, 1991). In such systems, stimulating asymbiotic $\mathrm{N}_{2}$ fixation could be of benefit by alleviating $\mathrm{N}$ immobilization and by speeding decomposition, as well as by providing net inputs of $\mathrm{N}$. Following is a review of $\mathrm{N}_{2}$ fixation in cane trash and its effects on decomposition. The term "diazotroph" means $\mathrm{N}_{2}$-fixing; "asymbiotic" is often used to describe diazotrophs that are active in decomposing plants residues. "Nitrogenase" is the key enzyme involved in $\mathrm{N}_{2}$-fixation.

The possibility that asymbiotic $\mathrm{N}_{2}$ fixation could make significant $\mathrm{N}$ inputs to agricultural systems has been largely discounted (Loomis and Conner, 1992). Most of the naturally occurring asymbiotic $\mathrm{N}_{2}$ fixation, and $\mathrm{N}_{2}$ fixation by introduced assemblages of diazotrophs and cellulolytic organisms have proven to be active only at moisture contents well above those in upland litters and soils (Jensen, 1965; Roper, 1983; Harper and Lynch, 1984). Some assemblages of diazotrophs and cellulolytic fungi that looked promising in laboratory systems have not proven to increase $\mathrm{N}$ inputs in the presence of indigenous microflora (Magan et al., 1989).

Access of cellulolytic organisms to cellulose in low $\mathrm{N}$ residues is highly dependent on the breakdown of lignin by other organisms (Swift et al.,1969). Halsall (1993) reported that inclusion of Cyantus stercoreus, a lignocellulolytic fungus, in inoculants with aerobic diazotrophs and with or without cellulolytic fungi increased nitrogenase activity in straw amended soil, suggesting that ligninolytic fungi may be critical components of nitrogen fixing assemblages in nature.

The majority of studies on asymbiotic $\mathrm{N}_{2}$ fixation have been conducted with litters and soils from cooler climatic regions. More limited studies have suggested that $\mathrm{N}$-poor litters from tropical upland crops, including cane, can support significant levels of $\mathrm{N}_{2}$ fixation by naturally occurring microbial associations (Dobereiner and Alvaydo, 1959; Abd-el-Malek, 1971). Better protection of aerobic diazotrophs' nitrogenase from oxygen by increased community respiration at higher temperatures (Hill et al., 1990) may be a factor favoring evolution of such systems in the tropics. Another may be the lower $\mathrm{N}$ content of $\mathrm{C}_{4}$ compared to $\mathrm{C}_{3}$ type grasses (Brown, 1978); nitrogenase activity supported by residues of differing $\mathrm{N}$ content inoculated with a crude cane culture decreased by approximately 5 fold as $\mathrm{N}$ content of the residues increased from 0.2 to $1.4 \%$ (Hill, 1988).

A highly active aerobic $\mathrm{N}_{2}$-fixing system found in cane litter in Barbados (Patriquin, 1992) and transferred to wheat straw (Hill and Patriquin ,1988) proved to be very stable and fully active under air, and at moisture contents similar to those found in tropical upland litter (Hill and Patriquin, 1988, Hill et al., 1990). Attempts to reconstitute this "CCC" (crude cane culture) by combining as many as 64 microbes isolated from cane litter were not successful. However evidence indicates that 
the microaerophilic $\mathrm{N}_{2}$ fixer Azosprillium basilense and the dematiaceous (melanic) fungus Helicomyces roseus are essential components (Hill and Patriquin, 1990).

In both cane litter in the field (Patriquin, 1982) and in experimental straw based systems (Hill and Patriquin, 1988), peak $\mathrm{CO}_{2}$ production occurs coincident with or after peak nitrogenase activity, suggesting a priming effect of $\mathrm{N}_{2}$ fixation on decomposition. Both systems consistently darken with the onset of high nitrogenase activity, which is attributable to melanin production by $H$. roseus (Hill and Patriquin, 1990).

The darkening of residues appears to have potential as a visible presumptive indicator of the occurrence and onset of $\mathrm{N}_{2}$ fixation in the field. Darkening was always associated with high nitrogenase activity in field and lab systems (Patriquin, 1982; Hill, 1988). When mineral $\mathrm{N}$ was added to suppress $\mathrm{N}_{2}$ fixation, it stimulated growth of fast growing, non-melanic fungi, and darkening did not occur (Hill and Patriquin, 1990).

Melanin may function in protection of microbes from UV radiation, heat and dessication (Linhares and Martin, 1978). Interestingly, A brasilense forms brown, melanin-like pigments in the process of cyst formation (Sadaviasan and Neyra, 1991). Melanin production and formation of resistant structures by both organisms (sclerotia in $H$. roseus, cysts in $A$. brasilense) are likely factors permitting them to withstand stresses encountered in exposed litter in cane fields; they probably also account for dried, once active straw retaining its inoculum potential for 5 years or more (the longest period we have tested). It was estimated that production of melanin by $H$ roseus sequesters more than half of the recently fixed $\mathrm{N}$ (Hill and Patiquin, 1990). Thus melanin production may stimulate $\mathrm{N}_{2}$ fixation by sequestering $\mathrm{N}$ and by preventing the feedback inhibition of nitrogenase.

There are several potential benefits to this system in the field.

(i) Addition of $\mathrm{N}$. Total nitrogenase activity in simulated field systems was equivalent to $1.2 \mathrm{~kg}$ N/tonne litter based on a 3:1 molar ratio (Patriquin, 1982). Empirical ratios of acetylene reduced to $\mathrm{N}$ gained in experimental systems are lower (Hill and Patriquin, 1988) and suggest $\mathrm{N}_{2}$ fixation could have been twice that value. In straw systems, $\mathrm{N}$ gains up to $6.6 \mathrm{mg} \mathrm{g}^{-1}$ were observed (Hill and Patriquin, 1988). These values are in the same range suggested by other studies: Dobereiner and Alvayado (1959) reported gains of $2.3 \mathrm{mg} \mathrm{N} \mathrm{g}^{-1}$ in cane litter, and Abd-el-Malek gains of 3-10 mg N $\mathrm{g}^{-1}$ residue in Egyptian soils amended with residues. A range of 1.2 to $6.6 \mathrm{mg} \mathrm{N} \mathrm{g}^{-1}$ straw corresponds to $18-132 \mathrm{~kg} \mathrm{~N}$ ha-1 for 15 to $20 \mathrm{t} \mathrm{ha}^{-1}$ cane residues. While asymbiotic $\mathrm{N}_{2}$ fixers were once thought to contribute substantial $\mathrm{N}$ in Brazilian cane systems (Dobereiner and Alvaydo, 1959), more recent research has focussed on $\mathrm{N}_{2}$ fixation by rhizopheric and endophytic diazotrophs (Boddey et al., 1995). However, a long term $\mathrm{N}$ balance experiment by these same researchers shows a large difference in the $\mathrm{N}$ gains between burned and unburned cane. This suggests that free-living diazotrophs using the trash as an energy source are more important: over the period 1983-1992, unburned cane gained an average of $544 \mathrm{~kg} \mathrm{~N} / \mathrm{ha}$ in the soil-plant system, while burned cane lost the equivalent of $444 \mathrm{~kg} \mathrm{~N} / \mathrm{ha}$. The gain is equivalent to 544/8=68 kg N/ha per annum which is well within the range for asymbiotic N2 fixation suggested by the studies cited above. Additional nitrogen was also removed through cane removal each year and is estimated at $75 \mathrm{~kg}$ $\mathrm{N} / \mathrm{ha} /$ year. Thus, the total $\mathrm{N}$ contribution was $140 \mathrm{~kg} / \mathrm{year}$. As much of the $\mathrm{N}$ added by asymbiotic $\mathrm{N}_{2}$ fixation appears to go into melanin which decomposes slowly (Linhares and Martin, 1978), benefits due to $\mathrm{N}$ additions by asymbiotic $\mathrm{N}_{2}$ fixation will be longer term ones.

(ii) The large amounts of melanin (estimated as $63 \mathrm{mg} \mathrm{g}^{-1}$ straw; Hill and Patriquin, 1990) may contribute to improvement of soil quality (Mahmood et al., 1985). 
(iii) Acceleration of decomposition and turnover of nutrients: some cane growers, concerned about the slow rates of trash decomposition are trying to accelerate it by applications of lime and organic fertilizers (Wood, 1991). Use of the $\mathrm{N}_{2}$ fixing system might be more effective. CCC appears to be exceptionally efficient at decomposing lignocellulosic material under $\mathrm{N}_{2}$-fixing but not under nonfixing conditions. Under $\mathrm{N}_{2}$-fixing conditions, crude cane culture affected weight loss in straw that was 1.1 fold greater than that achieved by an IWM (indigenous wheat microflora) with added N, 2.5 fold greater than that effected by IWM alone, and 1.2 to 1.4 fold greater than that achieved by CCC with sufficient $\mathrm{N}$ added to repress nitrogenase synthesis (Hill and Patriquin, 1988).

It is possible that the $\mathrm{N}_{2}$-fixing $A$. brasilense/H.roseus system or related systems have been lost from intensively managed cane systems because of burning of residues, and use of $\mathrm{N}$ fertilizer (Patriquin, 1982). Studies with experimental systems (Patriquin, 1982, Hill, 1988, Hill (1988; Hill and Patriquin, 1988) suggest that it can be quite readily reestablished by the introduction of residues from sites where it is still active. Furthermore, it is thought that these residues retain their potential even after being ground and stored dry for several years.

The prime requirement for $\mathrm{N}_{2}$ fixation and enhanced decomposition by CCC once established is probably to manage $\mathrm{N}$ fertilizers to minimize suppression of nitrogenase synthesis. Small amounts of $\mathrm{N}\left(0.5 \mathrm{mg} \mathrm{g}^{-1}\right.$ litter) may stimulate nitrogenase activity by about 1.6 fold (Hill and Patriquin, 1988) or have no effect (Hill, 1988). $4 \mathrm{mg}$ of added $\mathrm{N} \mathrm{g}^{-1}$ straw is sufficient to suppress nitrogenase activity; this corresponds to $60 \mathrm{~kg} \mathrm{~N}^{-1}$ for a crop with $15 \mathrm{t} \mathrm{ha}^{-1}$ residues. Patriquin (1982) observed that banding of $100 \mathrm{~kg} \mathrm{~N} / \mathrm{ha}$ next to stooles of cane, which is the traditional procedure in Barbados and elsewhere but is giving way to broadcasting (Wood, 1991) had no effect on interrow nitrogenase activity; broadcasting $100 \mathrm{~kg} \mathrm{~N} / \mathrm{ha}$ caused immediate suppression of nitrogenase activity. The cane industry at the time was changing over from traditional hand banding to machine broadcasting; a simple device was constructed that allowed the same devices to band fertilizer (Annual Report for Carib Agro-Industries, 1992, 1993). In Australia, growers are experimenting with addition of lime and organic $\mathrm{N}$ sources to stimulate decomposition of cane residues (Wood, 1991) Although, it seems logical that $\mathrm{N}$ addition would stimulate decomposition in systems high ratios of $\mathrm{C}: \mathrm{N}$, there is evidence large additions of $\mathrm{N}$ may have no effect or a negative effect over longer periods (Lueken et al., 1962; Knapp et al. 1983) If a system of the type in the CCC is present, then managing residues to encourage $N_{2}$ fixation may be the best option for stimulating decomposition. 


\section{REFERENCES}

Abd-el-Malek, Y. (1971) Free-living nitrogen-fixing bacteria in Egyptian soils and their possible contribution to soil fertility. Plant and Soil Special Volume, 432-442.

Barnes, A.C. (1964) The Sugarcane. Interscience Publishers Inc., New York.

Boddey, R.M., de Olivera, O.C., Urquiaga, S., Reis, V.M., de Olivares, F.FL, Baldani, V.L.D. and Dobereiner, J. 1995. Biological nitrogen fixation associated with sugarcane and rice: contributions and prospects for improvement. Plant and Soil 174: 195-209.

Brown, R.M. (1978) A difference in nitrogen use efficiency in $\mathrm{C}_{3}$ and $\mathrm{C}_{4}$ plants and its implications in adaptation and evolution. Crop Science 18, 93-98.

Carib Agro-Industries Limited (1982). Research \& Development Section, Annual Report for 1982. Carib Agro-Industries, Barbados.

Carib Agro-Industries Limited (1983). Research \& Development Section, Annual Report for 1983. Carib Agro-Industries, Barbados.

Dobereiner, J. and Alvaydo, R. (1959) Sobre a influencia de cana de acucar na ocorrencia de Beijerinckia no solo II. Influencia das diversas partes do vegetal. Revista Brasiliensis Biologica 19, 401-412.

Halsall, D.M. (1993) Inoculation of wheat straw to enhance lignocellulose breakdown and associated nitrogenase activity. Soil Biology \& Biochemistry 25, 419-429,

Hill, N.M. and Patriquin, D.G. (1988) Induction of aerobic nitrogen fixation and enhancement of wheat straw decomposition by inoculation with a crude culture form sugarcane litter. Soil Biology \& Biochemistry 20, 613-618.

Hill, N.M. and Patriquin, D.G. (1990). Evidence for the involvement of Azospirillum brasilense and Helicomyces roseus in the aerobic nitrogen-fixing/cellulolytic system from sugarcane litter. Soil Biology \&Biochemistry 22, 313-319.

Hill, N.M. and Patriquin D.G. (1992) Interactions between fungi and nitrogen-fixing bacteria during decomposition. In The Fungal Community: its organization and role in the ecosystem (G.C. Carroll and D.T. Wicklow, Eds.), pp 783-795 Marcel Dekker,Inc. New York.

Hill, N.M. and Patriquin, D.G., and Sircom, K. (1990) Increased oxygen consumption at warmer temperatures favours aerobic nitrogen fixation in plant litters. Soil Biology \& Biochemistry 22, 321325.

Jensen, H.L. (1965) Non symbiotic nitrogen fixation. In Soil Nitrogen Vol 10 Agronomy (V.V. Bartholemew and F,E. Clark, Eds.), pp 440-445. American Society of Agronomy, Madison.

Knapp, E. B. Elliott and Campbell, G.S. (1983) Microbial respiration and growth during the decomposition of wheat straw. Soil Biology \& Biochemistry 3: 319-323. 
Leuken, H., Hutcheon, W.L. and Paul, E.A. (1962). The influence of nitrogen on the decomposition of crop residues in the soil. Canadian Journal of Soil Science 42. 276-288.

Linhares, L.F. and Martin, J.P. (1978) Decomposition in soil of the humic acid-type plolymers (melanins) of Eurotium echinulatum, Aspergilus glaucus and other fungi. Soil Science Society of America Journal 42,738-743

Loomis, R.S. and Conner. D.J. (1992) Crop Ecology: Productivity and management in Agricultural Systems. Cambridge University Press, Cambridge, U.K.

Magan N., Hand, P., Kirkwood, I.A. and Lynch, J.M. (1989). Establishment of microbial inocula on decomposing wheat straw on soil of different water contents. Soil Biology Biochemistry 21, 15-22.

Mahmood, T., Azam, F., and Malik, K.A. (1985). Decomposition and humification of plant residues by some soil fungi. Biotechnology Letters 7: 207-212.

Patriquin. D.G.(1992) Nitrogen fixation in sugarcane litter. Biological Agriculture and Horticulture 1,39-64.

Roper, M.M. (1983) Field measurements of nitrogenase activity in soils amended with wheat straw. Australian Journal of Agricultural Research 34, 725-739.

Sadasivan, L. and Neyra, C.A. (1987) Cyst production and brown pigment formation in aging cultures of Azospirillum brasilense ATCC 29145. Journal of Bacteriology 169,1670-1677.

Spain, A.V. and Hodgen, M.J. (1994) Changes in the composition of sugarcane harvest residues during decomposition as a surface mulch. Biology \& Fertility of Soils 17: 225-231.

Swift, M.J., Heal, O.W. and Anderson, J.M. (1969) Decomposition in Terrestrial Ecosystems. Blackwell Scientific Publications, Oxford.

Veiga, F.M., Dobereiner, J., Gondin, G.S. \& da Silva O Pinto, R. (1961) Influencia do tratamento do palhico de cana-de-acucar na producao e conservacao de materia organica do solo. Communcada Tecnico 13, Instituto de Ecologia e experimentacao agricolas; Rio de Janeiro, Brasil.

Wood, A.W. (1991) Management of crop residues following green cane harvesting of sugarcane in north Queensland. Soil \& Tillage Research 20, 69-85. 
Appendix 4.3. Sugarcane Mills, Areas, Yield Components, and Philippine Sugar Export to the U.S. (1933-34; 1945-1990).

\begin{tabular}{|c|c|c|c|c|c|c|c|}
\hline Crop year & $\begin{array}{l}\text { No. of } \\
\text { operating } \\
\text { mills }\end{array}$ & Area (ha) & $\begin{array}{l}\text { Tonnes of } \\
\text { sugarcane } \\
\text { produced }\end{array}$ & $\begin{array}{l}\text { Sugar } \\
\text { per } \\
\text { tonne } \\
\text { cane }\end{array}$ & $\begin{array}{l}\text { Piculs } \\
\text { tonnes } \\
\text { cane per } \\
\text { hectare }\end{array}$ & $\begin{array}{l}\text { Metric } \\
\text { piculs } \\
\text { sugar } \\
\text { per } \\
\text { hectare }\end{array}$ & $\begin{array}{l}\text { Philippine } \\
\text { sugar export } \\
\text { to U.S. } \\
\text { (thousands of } \\
\text { tonnes) }\end{array}$ \\
\hline $1933-34$ & 46 & 283,269 & $1,431,906$ & 1.76 & 45.41 & 79.92 & 1,088 \\
\hline $1945-46$ & 5 & 2,390 & 11,715 & 1.80 & 43.05 & 77.50 & 0 \\
\hline $1946-47$ & 16 & 15,236 & 76,727 & 1.82 & 43.75 & 79.62 & 0 \\
\hline $1947-48$ & 23 & 74,444 & 361,168 & 1.75 & 43.75 & 76.70 & 252 \\
\hline $1948-49$ & 27 & 117,504 & 660,968 & 1.87 & 47.47 & 88.93 & 525 \\
\hline $1949-50$ & 28 & 127,903 & 621,073 & 1.79 & 43.01 & 76.77 & 474 \\
\hline $1950-51$ & 27 & 154,607 & 848,559 & 1.81 & 47.98 & 86.77 & 706 \\
\hline $1951-52$ & 28 & 188,503 & 976,685 & 1.71 & 47.90 & 81.92 & 860 \\
\hline $1952-53$ & 25 & 209,265 & $1,028,637$ & 1.72 & 45.29 & 77.72 & 932 \\
\hline $1953-54$ & 25 & 220,596 & $1,301,356$ & 1.74 & 53.62 & 93.27 & 974 \\
\hline $1954-55$ & 25 & 218,443 & $1,244,464$ & 1.73 & 51.98 & 90.07 & 977 \\
\hline $1955-56$ & 25 & 188,015 & $1,105,449$ & 1.77 & 52.45 & 92.96 & 982 \\
\hline $1956-57$ & 25 & 178,006 & $1,037,116$ & 1.82 & 50.66 & 92.12 & 906 \\
\hline $1957-58$ & 25 & 183,700 & $1,250,392$ & 1.86 & 57.84 & 107.62 & 980 \\
\hline $1958-59$ & 24 & 193,822 & $1,372,132$ & 1.78 & 63.04 & 111.93 & 980 \\
\hline $1959-60$ & 24 & 206,762 & $1,387,362$ & 1.71 & 62.04 & 106.09 & 1,155 \\
\hline $1960-61$ & 24 & 210,075 & $1,316,757$ & 1.77 & 55.91 & 99.10 & 1,355 \\
\hline $1961-62$ & 25 & 216,484 & $1,467,507$ & 1.77 & 60.46 & 107.18 & 1,256 \\
\hline $1962-63$ & 25 & 246,336 & $1,554,947$ & 1.73 & 57.76 & 99.80 & 1,195 \\
\hline $1963-64$ & 25 & 282,410 & $1,683,628$ & 1.62 & 58.22 & 94.26 & 1,217 \\
\hline $1964-65$ & 27 & 327,610 & $1,557,765$ & 1.51 & 49.75 & 75.18 & 1,178 \\
\hline $1965-66$ & 26 & 297,516 & $1,401,981$ & 1.67 & 44.64 & 74.50 & 1,186 \\
\hline $1966-67$ & 26 & 287,949 & $1,560,077$ & 1.61 & 53.06 & 85.66 & 1,123 \\
\hline $1967-68$ & 26 & 305,810 & $1,596,557$ & 1.63 & 50.73 & 82.54 & 1,124 \\
\hline $1968-69$ & 27 & 319,447 & $1,597,369$ & 1.54 & 51.49 & 79.06 & 1,124 \\
\hline $1969-70$ & 33 & 346,393 & $1,927,172$ & 1.42 & 61.89 & 87.96 & 1,298 \\
\hline $1970-71$ & 35 & 422,528 & $2,059,600$ & 1.40 & 55.11 & 77.07 & 1,591 \\
\hline $1971-72$ & 36 & 424,435 & $1,817,216$ & 1.47 & 45.92 & 67.69 & 1,432 \\
\hline $1972-73$ & 37 & 433,228 & $2,246,413$ & 1.57 & 52.34 & 81.98 & 1,454 \\
\hline $1973-74$ & 37 & 466,091 & $2,445,805$ & 1.48 & 55.96 & 82.96 & 1,472 \\
\hline $1974-75$ & 38 & 481,382 & $2,396,577$ & 1.54 & 51.09 & 78.71 & 412 \\
\hline $1975-76$ & 38 & 544,579 & $2,879,983$ & 1.55 & 53.83 & 83.61 & 915 \\
\hline $1976-77$ & 40 & 523,784 & $2,685,876$ & 1.56 & 51.97 & 91.07 & 1,310 \\
\hline $1977-78$ & 41 & 503,425 & $2,334,571$ & 1.64 & 44.74 & 73.32 & 847 \\
\hline $1978-79$ & 42 & 429,394 & $2,289,370$ & 1.61 & 52.45 & 84.19 & 368 \\
\hline $1979-80$ & 42 & 402,176 & $2,266,963$ & 1.59 & 55.92 & 89.12 & 383 \\
\hline
\end{tabular}


Appendix 4.3 continued. Sugarcane Mills, Areas, Yield Components and Philippine Sugar Export to the U.S. (1933-34; 1945-1990).

\begin{tabular}{|c|c|c|c|c|c|c|c|}
\hline Crop year & $\begin{array}{l}\text { No. of } \\
\text { operating } \\
\text { mills }\end{array}$ & Area (ha) & $\begin{array}{l}\text { Tonnes of } \\
\text { sugarcane } \\
\text { produced }\end{array}$ & $\begin{array}{l}\text { Sugar } \\
\text { per } \\
\text { tonne } \\
\text { cane }\end{array}$ & $\begin{array}{l}\text { Piculs } \\
\text { tonnes } \\
\text { cane per } \\
\text { hectare }\end{array}$ & $\begin{array}{l}\text { Metric } \\
\text { piculs } \\
\text { sugar } \\
\text { per } \\
\text { hectare }\end{array}$ & $\begin{array}{l}\text { Philippine } \\
\text { sugar export } \\
\text { to U.S. } \\
\text { (thousands of } \\
\text { tonnes) }\end{array}$ \\
\hline $1980-81$ & 41 & 395,382 & $2,314,872$ & 1.59 & 58.30 & 92.57 & 255 \\
\hline $1981-82$ & 41 & 418,030 & $2,425,102$ & 1.53 & 59.87 & 91.72 & 246 \\
\hline $1982-83$ & 41 & 410,239 & $2,465,162$ & 1.62 & 58.66 & 95.01 & 320 \\
\hline $1983-84$ & 41 & 415,982 & $2,335,622$ & 1.42 & 62.43 & 88.77 & 437 \\
\hline $1984-85$ & 39 & 384,357 & $1,722,209$ & 1.45 & 48.70 & 70.84 & 225 \\
\hline $1985-86$ & 38 & 307,967 & $1,526,724$ & 1.50 & 52.36 & 78.38 & 248 \\
\hline $1986-87$ & 38 & 269,058 & $1,345,701$ & 1.55 & 51.11 & 79.08 & 156 \\
\hline $1987-88$ & 36 & 270,142 & $1,387,183$ & 1.40 & 57.98 & 81.19 & 146 \\
\hline $1988-89$ & 36 & 300,242 & $1,597,706$ & 1.30 & 64.53 & 84.13 & 180 \\
\hline $1989-90$ & 38 & 334,919 & $1,703,362$ & 1.39 & 57.78 & 80.41 & 275 \\
\hline $1990-91$ & & & & & & & \\
\hline $1991-92$ & & & & & & & \\
\hline $1993-94$ & & 381,605 & $1,809,311$ & 1.26 & 59.62 & 74.96 & 271 \\
\hline $1994-95$ & & 369,132 & $1,647,023$ & 1.41 & 50.13 & 70.54 & 149 \\
\hline $1995-96$ & & 372,399 & $1,790,788$ & 1.24 & 61.51 & 76.03 & 229 \\
\hline $1996-97$ & & 372,130 & $1,828,609$ & 1.32 & 58.70 & 77.48 & 248 \\
\hline $1997-98$ & & 368,168 & $1,802,744$ & 1.39 & 55.70 & 77.42 & 199 \\
\hline
\end{tabular}

Source: $\quad$ 1933-1990 from SRA planning office as cited by Mendoza, 1993. 1993-1998 from Sugar Statistics and Monitoring Division, Planning and International Sugar Affairs Office, SRA. 


\section{APPENDIX 4.4 Processed Sugar Data}

Sugar yield trend for the last 60 years in the Philippines*

\begin{tabular}{|l|l|l|l|}
\hline Year & Tonnes of cane & Sugar \%cane & Sugar/ha (tonne) \\
\hline $1933-34$ & 45.4 & 11.1 & 5.1 \\
\hline $1947-53$ & 45.8 & 11.3 & 5.2 \\
\hline $1954-74$ & 53.4 & 10.5 & 5.6 \\
\hline $1975-86$ & 50.7 & 9.7 & 4.9 \\
\hline $1986-94$ & 57.5 & 8.9 & 5.1 \\
\hline $1994-98$ & 57.1 & 8.4 & 4.8 \\
\hline \multicolumn{2}{|c|}{ "Sources: Ledesma (1997), Sugar Regulatory Authority (SRA) }
\end{tabular}




\section{Appendix 4.5: Philippine Fertilizer Data:}

Appendix 4.5.1: Trends in sugar cane fertilizer use $(\mathrm{kg} / \mathrm{ha})$ in three regions of the Philippines, 1982-83 to 1987-88

\begin{tabular}{||lrrrr||}
\hline Year & & Luzon & $\begin{array}{c}\text { Visayas \& } \\
\text { Mindanao }\end{array}$ & $\begin{array}{c}\text { Total } \\
\text { (R.P.) }\end{array}$ \\
\hline $1982-83$ & $\mathrm{~N}$ & 121.4 & 120.5 & 120.7 \\
& $\mathrm{P}$ & 14.3 & 61.6 & 47.6 \\
& $\mathrm{~K}$ & 21.9 & 73.1 & 57.9 \\
\hline $1983-84$ & $\mathrm{~N}$ & 119.1 & 105.1 & 109.2 \\
& $\mathrm{P}$ & 10.8 & 39.0 & 30.8 \\
& $\mathrm{~K}$ & 7.8 & 54.4 & 40.9 \\
\hline $1984-85$ & $\mathrm{~N}$ & 106.4 & 91.6 & 96.0 \\
& $\mathrm{P}$ & 6.1 & 30.0 & 23.1 \\
& $\mathrm{~K}$ & 11.6 & 39.7 & 31.5 \\
\hline $1985-86$ & $\mathrm{~N}$ & 97.8 & 92.2 & 93.9 \\
& $\mathrm{P}$ & 1.14 & 31.6 & 28.63 \\
& $\mathrm{~K}$ & 1.42 & 2.9 & 28.81 \\
\hline $1986-87$ & $\mathrm{~N}$ & 121.1 & 89.06 & 94.35 \\
& $\mathrm{P}$ & 9.71 & 39.37 & 26.11 \\
& $\mathrm{~K}$ & 3.74 & 37.94 & 52.27 \\
\hline $1987-88$ & $\mathrm{~N}$ & 130.57 & 117.45 & 122.70 \\
& $\mathrm{P}$ & 7.0 & 49.44 & 32.46 \\
& $\mathrm{~K}$ & 19.58 & 59.28 & 43.4 \\
\hline
\end{tabular}

Source: Covar (1989)

Appendix 4.5.2: NPK (\%) in terms of energy equivalent (GJ/ha) of the fertilizer applied to plant and ratoon cane, Negros Occidental

\begin{tabular}{|l|l|l|l|}
\hline Plant crop & $\begin{array}{l}\text { Application rate } \\
\text { (kg/ha) } \mathbf{X} \text { energy } \\
\text { value (GJ/kg) }\end{array}$ & Energy equivalent (GJ/ha) & $\%$ \\
\hline $\mathrm{N}$ & $225 \times 0.079$ & 17.9 & 84.2 \\
\hline $\mathrm{P}$ & $120 \times 0.012$ & 1.4 & 6.8 \\
\hline $\mathrm{K}$ & $240 \times 0.0079$ & 1.9 & 9.0 \\
\hline & & TOTAL $=21.2$ & \\
\hline Ratoon & & & 90.4 \\
\hline $\mathrm{N}$ & $225 \times 0.079$ & 17.9 & 9.6 \\
\hline $\mathrm{K}$ & $240 \times 0.0079$ & 1.9 & \\
\hline & & TOTAL $=19.8$ & \\
\hline
\end{tabular}

Data provided by Samson (2000), GJ values for NPK were adopted from Soriano (1982) 


\section{Appendix 4.5.3. Sugarcane Fertilizer Data}

\begin{tabular}{|l|c|c|c|}
\hline Year & $\begin{array}{c}\text { Area planted with } \\
\text { sugarcane (ha) }\end{array}$ & $\begin{array}{c}\text { Fertilizer sales* } \\
\text { (tonnes) }\end{array}$ & Fertilizer use (kg/ha) \\
\hline 1991 & 370,718 & 67,136 & 180 \\
\hline 1992 & 375,572 & 95,522 & 250 \\
\hline 1993 & 381,204 & 90,935 & 240 \\
\hline 1994 & 365,688 & 63,158 & 170 \\
\hline 1995 & 374,629 & 115,228 & 300 \\
\hline 1996 & 367,926 & 125,840 & 340 \\
\hline
\end{tabular}

Source : Phil. Phospate Co. and Sugar Regulatory Authority 1994

${ }^{*}$ Excludes imported DiAmmonium Phosphate (DAP) fertilizer

1.) Using the 1996 fertilizer sales at $340 \mathrm{~kg} / \mathrm{ha}$ and Covar (1989) data on NPK, the 1996 NPK use was estimated as follows:

$$
\begin{aligned}
& \mathrm{N}=61.4 \% \times 340 \mathrm{~kg}=208.8 \mathrm{~kg} / \mathrm{ha} \\
& \mathrm{P}=16.25 \% \times 340 \mathrm{~kg}=55.3 \mathrm{~kg} / \mathrm{ha} \\
& \mathrm{K}=21.73 \% \times 340 \mathrm{~kg}=73.9 \mathrm{~kg} / \mathrm{ha}
\end{aligned}
$$

2.) The fossil energy equivalent (li-oil, GJ) is computed at $17.7 \mathrm{GJ}$ (458 li diesel oil equivalent).

$$
\begin{aligned}
& \mathrm{N}=208.8 \mathrm{~kg} / \mathrm{ha} \times 0.079 \mathrm{GJ} / \mathrm{kg}=16.5 \mathrm{GJ} / \mathrm{ha} \\
& \mathrm{P}=55.3 \mathrm{~kg} / \mathrm{ha} \times 0.012 \mathrm{GJ} / \mathrm{kg}=0.67 \mathrm{GJ} / \mathrm{ha} \\
& \begin{aligned}
\mathrm{K}=73.9 \mathrm{~kg} / \mathrm{ha} \times 0.0079 \mathrm{GJ} / \mathrm{kg} & =0.58 \mathrm{GJ} / \mathrm{ha} \\
\text { TOTAL } & =17.7 \mathrm{GJ} / \mathrm{ha} \\
& =458 \mathrm{Li} \text {-diesel oil equivalent (LDFE) }
\end{aligned}
\end{aligned}
$$

3.) In Figure 4.8, fertilizer requirement is reduced to $99 \mathrm{~kg} \mathrm{~N} / \mathrm{ha}$ for trash farming in the ratooon crop as it is assumed $110 \mathrm{~kg} \mathrm{~N} / \mathrm{ha}$ are fixed through in field decomposition of trash. This reduces the Nitrogen fossil energy equivalent to $7.8 \mathrm{GJ} / \mathrm{ha}$. A total fertilizer energy equivalent (assuming no reduction in Phosphorus or Potassium requirements) under trash farming is $9.1 \mathrm{GJ} / \mathrm{ha}$. This represents an overall $49 \%$ reduction in fertilizer energy use. 
Appendix 4.6. Number of Typhoons and Typhoons Exceeding $100 \mathrm{kph}$ in the Philippines (1948-78, 1990).

\begin{tabular}{|c|c|c|}
\hline Year & Total Number of Typhoons & Typhoons exceeding 100 kph \\
\hline 1948 & 21 & 1 \\
\hline 1949 & 23 & 3 \\
\hline 1950 & 21 & 2 \\
\hline 1951 & 13 & 5 \\
\hline 1952 & 29 & 7 \\
\hline 1953 & 15 & 6 \\
\hline 1954 & 18 & 7 \\
\hline 1955 & 15 & 3 \\
\hline 1956 & 36 & 13 \\
\hline 1957 & 15 & 8 \\
\hline 1958 & 18 & 10 \\
\hline 1959 & 18 & 11 \\
\hline 1960 & 29 & 11 \\
\hline 1961 & 23 & 5 \\
\hline 1962 & 21 & 6 \\
\hline 1963 & 16 & 4 \\
\hline 1964 & 32 & 16 \\
\hline 1965 & 21 & 8 \\
\hline 1966 & 22 & 4 \\
\hline 1967 & 21 & 6 \\
\hline 1968 & 16 & 9 \\
\hline 1969 & 15 & 4 \\
\hline 1970 & 21 & 8 \\
\hline 1971 & 27 & 12 \\
\hline 1972 & 17 & 7 \\
\hline 1973 & 12 & 3 \\
\hline 1974 & 23 & 11 \\
\hline 1975 & 15 & 3 \\
\hline 1976 & 22 & 8 \\
\hline 1977 & 29 & 9 \\
\hline 1978 & 22 & 10 \\
\hline 1979 & - & - \\
\hline 1980 & 23 & 9 \\
\hline 1981 & 21 & 7 \\
\hline 1982 & 23 & 8 \\
\hline 1983 & 24 & 4 \\
\hline 1984 & 20 & 4 \\
\hline 1985 & 17 & 4 \\
\hline 1986 & 21 & 6 \\
\hline 1987 & 16 & 6 \\
\hline 1988 & 20 & 5 \\
\hline 1989 & 19 & 7 \\
\hline 1990 & 20 & 5 \\
\hline
\end{tabular}

Source: Mendoza 1993. 
Appendix 4.7. Sugarcane Factory Data from the Philippines*

\begin{tabular}{|c|c|c|c|c|c|c|c|}
\hline & 1993-94 & $1992-93$ & $1991-92$ & $1990-91$ & $1989-90$ & $1988-89$ & $\begin{array}{l}\text { Average } \\
\text { for } 6 \text { years }\end{array}$ \\
\hline $\begin{array}{l}\text { Number of } \\
\text { factories operating }\end{array}$ & 35 & 38 & 39 & 38 & 38 & 36 & \\
\hline $\begin{array}{l}\text { Total capacity } \\
\text { (tonnes/day) }\end{array}$ & 181,000 & 182,300 & 179,530 & 178,530 & 173,130 & 169,630 & \\
\hline *Milling Plant & & & & & & & \\
\hline - \%Pol extraction & 92.83 & 92.05 & 92.06 & 91.80 & 92.34 & 91.91 & 92.165 \\
\hline - $\%$ Milling loss & 6.32 & 6.75 & 6.89 & 6.46 & 7.04 & 6.74 & 6.695 \\
\hline $\begin{array}{l}\text { - } \% \text { Capacity } \\
\text { utilization }\end{array}$ & 57.75 & 65.24 & 66.19 & 60.38 & 64.79 & 59.83 & 62.365 \\
\hline 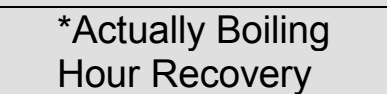 & 85.42 & 85.29 & 85.46 & 85.54 & 86.09 & 85.29 & 85.515 \\
\hline $\begin{array}{l}{ }^{*} \text { Actual Over-all } \\
\text { Recovery }\end{array}$ & 78.62 & 78.51 & 78.64 & 78.53 & 78.44 & 78.39 & 78.521 \\
\hline $\begin{array}{l}{ }^{*} \text { Total Losses in \% } \\
\text { Pol in Cane }\end{array}$ & 21.38 & 21.49 & 21.36 & 21.47 & 20.48 & 21.61 & 21.298 \\
\hline${ }^{*}$ Time Account & & & & & & & \\
\hline $\begin{array}{l}\text { - Total hours actual } \\
\text { grinding }\end{array}$ & $\begin{array}{l}106,009.7 \\
3\end{array}$ & $\begin{array}{l}117,492.5 \\
6\end{array}$ & $\begin{array}{l}114,590.4 \\
9\end{array}$ & $\begin{array}{l}197,418.8 \\
4\end{array}$ & $\begin{array}{l}101,037.0 \\
0\end{array}$ & $\begin{array}{l}100,169.0 \\
0\end{array}$ & \\
\hline $\begin{array}{l}\text { Total elapsed } \\
\text { time (hours) }\end{array}$ & $\begin{array}{l}173,541.8 \\
3\end{array}$ & $\begin{array}{l}169,168.6 \\
9\end{array}$ & $\begin{array}{l}165,486.1 \\
4\end{array}$ & $\begin{array}{l}163,617.3 \\
3\end{array}$ & $\begin{array}{l}153,192.0 \\
0\end{array}$ & $\begin{array}{l}104,974.0 \\
0\end{array}$ & $\begin{array}{l}154,996.6 \\
5\end{array}$ \\
\hline $\begin{array}{l}\text { - Mechanical time } \\
\text { efficiency }\end{array}$ & 86.82 & 85.37 & 86.57 & 88.03 & 86.89 & 86.57 & 86.708 \\
\hline - $\quad$ Total Hours Delay & $67,535.18$ & $51,676.13$ & $50,895.67$ & $56,198.49$ & $52,154.00$ & $64,805.00$ & \\
\hline
\end{tabular}

*Source : Annual Synopsis of Philippine Raw Sugar Factories. Production Performance Data for Crop Years 1983-94. SRA, Diliman, Quezon City 
Appendix 4.8: Fossil Fuel Energy (diesel oil eq., GJ) Consuming Operations and Prices of Sugarcane Production in Batangas, Philippines.*

\begin{tabular}{|c|c|c|}
\hline Activity & Diesel oil eq./ha & GJ/ha \\
\hline 1. Land Preparation & $128 \mathrm{li}$ & 5.0 \\
\hline - Mold board plowing: $6 \mathrm{hr}$ & & \\
\hline - $3 \times$ harrowing: $6 \mathrm{hr}$ & & \\
\hline - Furrowing: $3 \mathrm{hr}$ & & \\
\hline - $15 \mathrm{hr} 15 \mathrm{li} / \mathrm{hr}=125 \mathrm{li}$ & & \\
\hline - Oil: $15 \mathrm{hr} / 200 \mathrm{hr} \times 20 \mathrm{li}=1.5 \mathrm{li} \times 2=3 \mathrm{li}$ & & \\
\hline 2. Planting & $25 \mathrm{li}$ & 0.97 \\
\hline - Cane points: 50,000 & & \\
\hline - Hauling cane points: $5 \times 5 \mathrm{li}=25 \mathrm{li}$ & & \\
\hline - Planting: 22 days $\times \mathrm{P} 150 /$ day $=\mathrm{P} 3,300$ & & \\
\hline 3. Cultivation/Weeding & $45 \mathrm{li}$ & 1.7 \\
\hline - 3 passes $\times 1 \mathrm{hr} /$ pass $\times 15 \mathrm{li} /$ pass $=45 \mathrm{li}$ & & \\
\hline - 2 days $/$ ha $\times \mathrm{P} 350=\mathrm{P} 700$ & & \\
\hline - 3 days $/$ ha $\times \mathrm{P} 150=\mathrm{P} 450$ & & \\
\hline 4. Fertilizer & $1.077 .5 \mathrm{li}$ & 41.7 \\
\hline - $300 \mathrm{kgN} / \mathrm{ha}$ & & \\
\hline - 2 tonnes manure & & \\
\hline - Application: 3 days/ha x P150= P450 & & \\
\hline 5. Cane Detrashing & & \\
\hline - 8 days $/$ ha $\times \mathrm{P} 150 /$ day $=\mathrm{P} 1,200$ & & \\
\hline 6. Harvesting & $250 \mathrm{li}$ & 9.7 \\
\hline - Cutting and loading & & \\
\hline - P150/tonne x 79.5 tonnes/ha & & \\
\hline - Hauling: 50 li/trip x 5 trips $=250 \mathrm{li}$ & & \\
\hline
\end{tabular}

*Source: Samson 2000. 


\section{Appendix 4.9. Sugarcane Yield of Two Varieties as Affected by Trash Application.}

\begin{tabular}{|c|c|c|c|c|c|c|c|}
\hline & \multirow[t]{3}{*}{ Variety } & \multicolumn{2}{|l|}{ Trash } & \multicolumn{4}{|c|}{$\begin{array}{l}\text { Yield Components } \\
\text { eatment }\end{array}$} \\
\hline & & \multicolumn{2}{|c|}{$\mathrm{TC} / \mathrm{Ha}$} & \multicolumn{2}{|c|}{$\mathrm{PS} / \mathrm{TC}$} & \multicolumn{2}{|c|}{$\mathrm{Ps} / \mathrm{Ha}$} \\
\hline & & Plant & Ratoon & Plant & Ratoon & Plant & Ratoon \\
\hline \multirow[t]{3}{*}{$\begin{array}{l}\text { PHIL } \\
56-226\end{array}$} & $\begin{array}{l}\text { w/o } \\
\text { trash }\end{array}$ & $81.6 a$ & $55.4 a$ & 1.56 & 1.52 & 127.3 & $84.2 b$ \\
\hline & $\begin{array}{l}\text { with } \\
\text { trash }\end{array}$ & $82.5 a$ & $57.4 b$ & 1.56 & 1.75 & 128.7 & $100.4 b$ \\
\hline & MEAN & $82.1 a$ & $56.4 \mathrm{~b}$ & 1.56 & 1.63 & 128.0 & $92.3 b$ \\
\hline \multirow[t]{3}{*}{$\begin{array}{l}\text { PHIL } \\
67-23\end{array}$} & $\begin{array}{l}\text { w/o } \\
\text { trash }\end{array}$ & $68.2 b$ & $67.6 \mathrm{~b}$ & 1.35 & 1.61 & 92.0 & $108.8 b$ \\
\hline & $\begin{array}{l}\text { with } \\
\text { trash }\end{array}$ & $70.2 b$ & $90.1 a$ & 1.35 & 1.74 & 97.2 & $156.7 a$ \\
\hline & MEAN & $69.2 b$ & $78.8 a$ & 1.35 & 1.68 & 94.6 & $132.8 \mathrm{a}$ \\
\hline \multicolumn{8}{|l|}{ F-Test } \\
\hline $\begin{array}{l}\text { Variety } \\
\text { (V) }\end{array}$ & & ns & ** & * & ns & ns & * \\
\hline $\begin{array}{l}\text { Trash } \\
\text { Treatm } \\
\text { ent }(\mathrm{T})\end{array}$ & & ns & $* *$ & ns & * & ns & * \\
\hline$V \times T$ & & ns & ns & $\mathrm{ns}$ & $\mathrm{ns}$ & $\mathrm{ns}$ & $\mathrm{ns}$ \\
\hline
\end{tabular}

Source: Mendoza, et al., 1987.

ns- not significant

* significant at $0.05 \mathrm{p}$-level

** significant at $0.01 \mathrm{p}$-level

Means with the same letter are not significant different at 0.05 p-level (DMRT) 
Appendix 4.10 Cost and Return Projection for Sugarcane Trash Farming in Negros Occidental, Philippines. Comparison with conventional sugarcane systems

\begin{tabular}{|c|c|c|}
\hline Activity & \multicolumn{2}{|c|}{ Cost (pesos/ha) } \\
\hline I. PLANT CROP & Conventional & $\begin{array}{l}\text { Trash } \\
\text { farmed }\end{array}$ \\
\hline A. CANE ESTABLISHMENT AND CARE & & \\
\hline 1. Preharvest Detrashing & 0 & 1400 \\
\hline $\begin{array}{ll}\text { 2. } & \text { Land Preparation } \\
\text { - } & \text { Mold board (P2500) and secondary plowing (P1000) } \\
\text { - } & \text { Harrowing }(900 \times 2=\mathrm{P} 1800) \text { Furrowing }(900 \times 1=\mathrm{P} 900)\end{array}$ & 6,200 & 6,200 \\
\hline $\begin{array}{l}\text { 3. Cane points } \\
\text { - Preparation of points }(P 400 / \text { laksa } \times 6 \text { laksa }=P 2,400) \\
\text { - Hauling of cane points }(P 300 / l a k s a \times 6 \text { laksa }=P 1,800)\end{array}$ & 4,200 & 4,200 \\
\hline 4. Planting (P500/laksa $\times 6$ laksa $=P 3000)$ & 3,000 & 3,000 \\
\hline 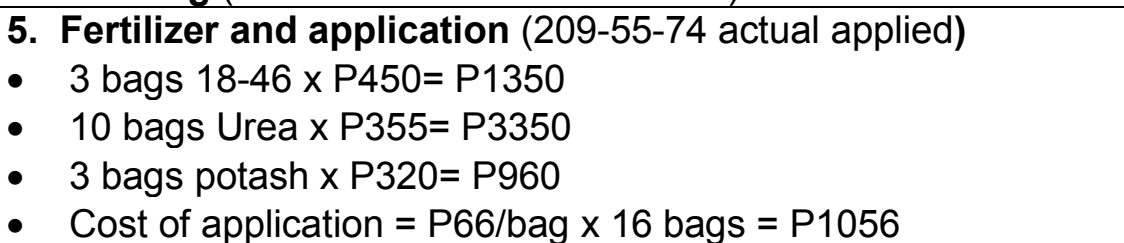 & 6,916 & 6,916 \\
\hline $\begin{array}{ll}\text { 6. } & \text { Weeding } \\
\text { - } & \text { Chisel plow/ripper }=(\mathrm{P} 900) \\
\text { - } & \text { Cultivator }(2 \times 600 / h a)=\mathrm{P} 1200 \\
\text { - } & \text { Handweeding }(\mathrm{P} 1000)\end{array}$ & 3,100 & 3,100 \\
\hline $\begin{array}{l}\text { 7. Drainage canal } \\
\text { Clearing (P330) + Dredging (P220) }\end{array}$ & 550 & 550 \\
\hline TOTAL: Plant Crop Establishment and Maintenance & 23,966 & 25,366 \\
\hline $\begin{array}{l}\text { B. HARVESTING } \\
\text { 1. Cutting and loading (Conventional P100/tonne } \times 80 \\
\text { tonnes/ha, trash farming: } 100 \mathrm{P} \times 80 \text { tonnes/ha) }\end{array}$ & 8,000 & 8,000 \\
\hline $\begin{array}{l}\text { Hauling/trucking (Conventional :P150/tonne } \times 80 \text {, trash farming: } \\
\mathrm{P} 150 \times 80 \text { tonnes/ha) }\end{array}$ & 12,000 & 12,000 \\
\hline TOTAL: Harvesting & 20,000 & 20,000 \\
\hline TOTAL COST: Plant crop & 43,966 & 45,366 \\
\hline $\begin{array}{l}\text { Revenues } \\
\text { Conventional = } 80 \text { tonne @ P850/tonne cane } \\
3.20 \text { tonne molasses @ P2000/tonne x 60\% planter share } \\
\text { Trash farming = } 80 \text { tonne @ P850/tonne } \\
3.38 \text { tonne molasses @ } 2000 \times 60 \% \text { planter share }\end{array}$ & $\begin{array}{r}68,000 \\
3,840\end{array}$ & $\begin{array}{r}68,000 \\
4,056\end{array}$ \\
\hline TOTAL REVENUES & 71,840 & 72,056 \\
\hline NET RETURN & 27,874 & 26,690 \\
\hline
\end{tabular}




\begin{tabular}{|c|c|c|}
\hline II. RATOON & $\begin{array}{l}\text { Conventional } \\
\text { ratoon }\end{array}$ & $\begin{array}{l}\text { Trash } \\
\text { farmed } \\
\text { ratoon }\end{array}$ \\
\hline A.CANE ESTABLISHMENT AND CARE & $\begin{array}{c}\text { Cost } \\
\text { (pesos/ha) }\end{array}$ & $\begin{array}{c}\text { Cost } \\
\text { (pesos/ha) }\end{array}$ \\
\hline 1.Preharvest Detrashing (14 days @ P 100/day) & - & 1,400 \\
\hline 2. Trash clearing after harvest & 440 & 1,000 \\
\hline 3. Stubble shaving & 464 & 464 \\
\hline $\begin{array}{l}\text { 4. Cultivation and Weeding } \\
\text { - } \quad 2-3 \text { off barring carabao x P321= P802.5 ( } 2.5 \text { passes }) \\
\text { - } 2-3 \text { hilling-up x P } 321=\mathrm{P} 802.5 \text { ( } 2.5 \text { passes }) \\
\text { - } \quad \text { Middle breaking } 1 \text { pass = P160 }\end{array}$ & 1,765 & 882.5 \\
\hline 5. Fire control (3 days @ P100/day) & & 300 \\
\hline 6. Rat baiting & & 600 \\
\hline $\begin{array}{r}\text { 7. Fertilizer (209-55-74 actual applied/ha-conventional) } \\
\text { (99-55-74 actual applied/ha-trash farmed) } \\
\text { - } 3 \text { bags } 18-46 \text { XP450=P 1,350 (both systems) } \\
\text { - } 10 \text { bags urea x P355/bag conventional P3,550 } \\
\text { - } 4.2 \text { bags urea x P355/bag trash farmed }=\text { P } 1,491 \\
\text { - } 3 \text { bags Potash } \times \text { P320/bag= P960 (both systems) } \\
\text { - } \quad \text { Application x P66/bag }=\text { P } 1,056 \text { conventional } \\
=P 673 \text { trash farmed }\end{array}$ & 6,916 & 4,474 \\
\hline $\begin{array}{l}\text { 8. Replanting } \\
\text { - Planting: P441 }\end{array}$ - Cane points: P400 & 841 & 841 \\
\hline TOTAL: Ratoon Maintenance & 10,426 & 9,962 \\
\hline B. HARVESTING & & \\
\hline $\begin{array}{l}\text { 1. Cutting/loading Conventional=P100/ tonne } \times 65 \text { tonne Trash } \\
\text { farming }=P 100 / \text { tonne } \times 78 \text { tonne }\end{array}$ & 6,500 & 7,800 \\
\hline 2. Hauling $\mathrm{P} 150 /$ tonne & 9,750 & 11,700 \\
\hline TOTAL: Harvesting & 16,250 & 19,500 \\
\hline TOTAL COST: Ratoon Crop & 26,676 & 29,462 \\
\hline $\begin{array}{l}\text { Revenues } \\
\text { Conventional= } 65 \text { tonne @ P850/tonne cane } \\
2.60 \text { tonne molasses @ P2000/tonne x 60\% planter share } \\
\text { Trash farming= } 78 \text { tonne @ P850/tonne cane } \\
3.15 \text { tonne molasses @P2000/tonne x 60\% planter share }\end{array}$ & $\begin{array}{c}55,250 \\
3120\end{array}$ & $\begin{array}{r}66,300 \\
3,780\end{array}$ \\
\hline TOTAL REVENUES & 58,370 & 70,080 \\
\hline NET RETURN & 31,694 & 40,618 \\
\hline
\end{tabular}


Notes for Appendix 4.10

\section{Costs}

The cost and operations of sugar cane farming was estimated by Teodoro Mendoza and based on the study by Samson (2000) (Appendix 4.8 and 4.11). It involved an examination of the labor, material supplies, and capital requirements, and an analysis of the price of those inputs.

The cost of conventional farming was modified to calculate the cost of trash farming in the following ways:

The increased cost of harvesting and hauling was determined using the increase in yield in tonnes per hectare obtained by trash farming relative to conventional farming, multiplied by the price of hiring harvesting and hauling services paid by farmers per tonne of sugar cane.

The reduction in fertilizer cost was determined multiplying the estimate of decreased fertilizer use, which was based on $\mathrm{N}$ fertilizer substitution achieved by decomposing cane trash in the field without burning.

The cost of pre-harvest detrashing and post-harvest trash clearing was estimated by multiplying the amount of labour needed by the labour rate in Batangas (150 pesos/tonne). Lower labour rates (150 pesos-day) would be experienced in Negros, the primary area of cane cultivation in the Philippines, however these daily rates leave farmers in an impoverished state.

Cultivation and weeding were estimated to require half the labour when trash farming relative to conventional farming, because half of the interrows are trash-mulched and do not need cultivation; thus, the cost was estimated to decrease also $50 \%$.

\section{Revenues}

The revenues were calculated as the total yield in tonnes per hectare multiplied by the market price of one tonne of sugar cane. For the conventional system, the average yield (80 tonnes /ha in the plant crop) was estimated by Teodoro Mendoza based on interviews with farmers using these input levels. The higher yields obtained through the application of trash farming were estimated using the results produced by the studies summarized in Table 4.3. The price used was the prevailing market price in the Island of Negros at the time of the study. It should be noticed that sugar cane prices are highly volatile, and large variations may significantly affect the present analysis. 


\section{Appendix 4.11: Energy (GJ) Consumed per Fossil Energy Consuming Operation in Sugarcane Production (2 sites) (Samson, 2000)}

\begin{tabular}{|l|l|l|l|}
\hline Operation & $\begin{array}{l}\text { Energy use in } \\
\text { Batangas (GJ) }\end{array}$ & $\begin{array}{l}\text { Energy use in Negros } \\
\text { Occidental (GJ) }\end{array}$ & $\begin{array}{l}\text { Average energy use } \\
\text { (GJ) }\end{array}$ \\
\hline A. Plant Crop & & & \\
\hline 1. Land Preparation & 4.9 & 4.9 & 4.9 \\
\hline 2. Planting & 0.96 & 2.3 & 1.6 \\
\hline 3. Cultivation & 1.7 & 1.7 & 1.7 \\
\hline 4. Fertilizer & 23.9 & 21.3 & 22.6 \\
\hline 5. Harvesting/hauling & 11.5 & 11.5 & 11.5 \\
\hline TOTAL ENERGY (GJ) & 43 & 41.7 & 42.4 \\
\hline TOTAL YIELD (tonne/ha) & 120 & 80 & 100 \\
\hline $\begin{array}{l}\text { ENERGY USE } \\
\text { (GJ/tonne) }\end{array}$ & 0.36 & 0.52 & 0.43 \\
\hline B. Ratoon & & & \\
\hline 1. Cultivation & 1.72 & 0.57 & 1.1 \\
\hline 2. Fertilizer & 23.9 & 19.8 & 21.8 \\
\hline 3. Harvesting/Hauling & 11.4 & 9.6 & 10.5 \\
\hline TOTAL ENERGY (GJ) & 37.7 & 30 & 33.4 \\
\hline TOTAL YIELD (tonne/ha) & 120 & 65 & 92.5 \\
\hline $\begin{array}{l}\text { ENERGY USE } \\
\text { (GJ/tonne) }\end{array}$ & 0.31 & 0.46 & 0.36 \\
\hline
\end{tabular}

*Note 1. Fertilizer represents $53.3 \%$ and $65.3 \%$ of the energy in the plant and ratoon crops respectively.

*Note 2. The average energy use for harvesting and hauling is .115 GJ/tonne harvested cane, which is used as the default value for the yields projected in Figures 4.2 and 4.8.

*Note 3. The energy use estimate in figure 4.2 and 4.8 are based on the fixed energy costs from Appendix 4.11. The yield estimates for trash farming are based on data from Table 4.3. To derive these values the conventional cane yield in figure 4.2 is multiplied by the yield increase from trash farming (5.8\% in the plant crop and $21.1 \%$ in the first ratoon) to derive a projected yield of 84 and $78 \mathrm{t} / \mathrm{ha}$. 


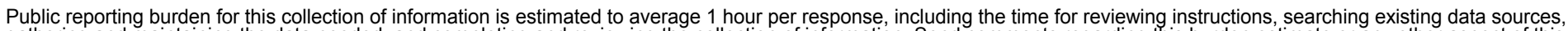

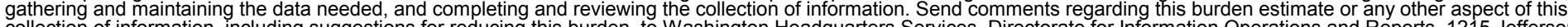

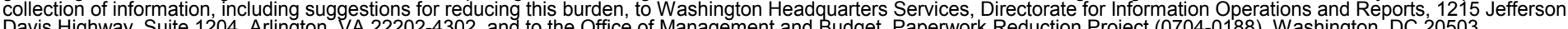

Davis Highway, Suite 1204, Arlington, VA 22202-4302, and to the Office of Management and Budget, Paperwork Reduction Project (0704-0188), Washington, DC 20503.
1. AGENCY USE ONLY (Leave blank)
2. REPORT DATE
October 2001
3. REPORT TYPE AND DATES COVERED Subcontractor Report

4. TITLE AND SUBTITLE

Strategies for Enhancing Biomass Energy Utilization in the Philippines

6. AUTHOR(S)

R. Samson, T. Helwig, D. Stohl, A. De Maio, P. Duxbury, T. Mendoza, and A. Elepano

7. PERFORMING ORGANIZATION NAME(S) AND ADDRESS(ES)

Resource Efficient Agricultural Production-Canada, Box 125, Ste Anne de Bellevue, Quebec, H9X3V9

8. PERFORMING ORGANIZATION REPORT NUMBER

5. FUNDING NUMBERS

AXE-0-30001-01
9. SPONSORING/MONITORING AGENCY NAME(S) AND ADDRESS(ES)
National Renewable Energy Laboratory
1617 Cole Blvd.
Golden, CO 80401-3393

10. SPONSORING/MONITORING AGENCY REPORT NUMBER

NREL/SR-510-30813

11. SUPPLEMENTARY NOTES

NREL Technical Monitor: Ralph P. Overend

12a. DISTRIBUTION/AVAILABILITY STATEMENT

National Technical Information Service

12b. DISTRIBUTION CODE

U.S. Department of Commerce

5285 Port Royal Road

Springfield, VA 22161

13. ABSTRACT (Maximum 200 words)

Technical report on Biofuel energy development in the Philippines and the role it can play in eradicating rural poverty and creating self-reliant communities.

Philippines; biomass; biofuel; sugar cane; rice hulls

15. NUMBER OF PAGES

14. SUBJECT TERMS

17. SECURITY CLASSIFICATION OF REPORT

Unclassified

18. SECURITY CLASSIFICATION OF THIS PAGE Unclassified
19. SECURITY CLASSIFICATION OF ABSTRACT

Unclassified
16. PRICE CODE

20. LIMITATION OF ABSTRACT

UL 